Portland State University

PDXScholar

Fall 9-30-2016

\title{
Configuring the Urban Smart Grid: Transitions, Experimentation, and Governance
}

Anthony Michael Levenda

Portland State University

Follow this and additional works at: https://pdxscholar.library.pdx.edu/open_access_etds

Part of the Power and Energy Commons, and the Urban Studies and Planning Commons Let us know how access to this document benefits you.

\section{Recommended Citation}

Levenda, Anthony Michael, "Configuring the Urban Smart Grid: Transitions, Experimentation, and Governance" (2016). Dissertations and Theses. Paper 3290.

https://doi.org/10.15760/etd.3281

This Dissertation is brought to you for free and open access. It has been accepted for inclusion in Dissertations and Theses by an authorized administrator of PDXScholar. Please contact us if we can make this document more accessible: pdxscholar@pdx.edu. 
Configuring the Urban Smart Grid:

Transitions, Experimentation, and Governance

\author{
by \\ Anthony Michael Levenda \\ requirements for the degree of \\ Doctor of Philosophy \\ in \\ Urban Studies \\ Dissertation Committee: \\ Loren Lutzenhiser, Chair \\ Thaddeus R. Miller \\ Nathan McClintock \\ Sy Adler \\ Amy Lubitow
}

A dissertation submitted in partial fulfillment of the

Portland State University

2016 
(C) 2016 Anthony Michael Levenda 


\begin{abstract}
In the face of challenges of energy security, decarbonization, resilience, and the replacement of aging infrastructure systems, federal, state, and local actors are facilitating the development of smart electricity networks to transition towards a more sustainable electricity system. In the United States, development of "smart grids" is being pursued as a national policy mandate and goal, promising that the deployment of smart grid technologies - referring in general to digital information and communication technologies that sense, monitor, control and manage the electric grid - will make electricity systems more environmentally sustainable and reliable, and at the same time, provide opportunities for growth and innovation.

This dissertation examines and analyzes three interconnected issues relating to these sociotechnical changes in electricity infrastructure: the material and discursive construction of the smart grid, urban smart grid experimentation, and the mobility of smart grid models and knowledge. A conceptual framework is proposed for investigating sociotechnical transitions that accounts for dimensions of power and politics that are commonly overlooked in conventional analysis, and highlights how governance regimes shape and are shaped by sociotechnical change. Utilizing Foucauldian discourse analysis and relational comparative case study methodology, this dissertation analyzes the development of the smart grid as a governmental program highlighting its rationalities, techniques, and imagined subjects.
\end{abstract}

The findings of these analyses suggest that the transition to a smarter grid involves much more than top-down policy mandates; significant urban experimentation is 
involved, as well as inter-city learning that is shaped by local political economy and broader political rationalities. This dissertation also argues for a synthesis between policy mobilities and sociotechnical transitions theory, highlighting through case studies how urban smart grid experiments are influenced by experiences and knowledge generated from "vanguard" cities. The conclusion of this dissertation is that the creation of the smart grid is far from a purely technical infrastructural intervention, and instead, requires significant changes in the everyday social practices and conduct of energy consumers, while also reconfiguring the city, engaging in a material politics in order to govern energy transitions. 
For Kelly 


\section{Acknowledgements}

This dissertation would not have been possible without the generous support of numerous individuals. I first want to thank my dissertation committee, Loren Lutzenhiser, Thad Miller, Nathan McClintock, Sy Adler, and Amy Lubitow, for working with me through this project. Each committee member provided me with valuable advisement and continued support that was central to the completion of this work.

My family and friends provided motivation and existential support. I would like to thank my parents, my siblings, and my non-human companions for their love and support throughout this process. My dear friends, members of the "DZ," receive an especially important thank you for their absolutely essential support, motivation, intellectual stimulation, editing, reviewing, and nourishing. Dillon Mahmoudi, Erin Goodling, and Ellie Harmon, thank you so much. This dissertation would not have been possible without you. RJ Koscielniak, Jamaal Green, Austin Cummings, and numerous other colleagues have provided intellectual inspiration and support over the years at Portland State University. Scott Jasinski, Heather Cermak, TJ Tumasse, and Sarah Hanneken, thanks for always being there to offer support and distraction.

My advisors over the years, Brian Deal at the University of Illinois, David Sailor at Portland State University, offered encouragement and support. Henrik Ernstson, Jonathan Silver, and Mary Lawhon supported me and inspired me with their work bringing attention to the complexity of power relations in cities. Erik Fisher, Jennifer Richter, and Abraham Tidwell at Arizona State University have helped me integrate into the STS community. David J. Hess and attendants of his summer school provided inspiration for working towards a more political understanding of energy transitions. Harriet Bulkeley 
and others at Durham University supported my work and offered tremendous insights. Vanesa Castan Broto and Laurent Dissard at University College London were kind, welcoming, and provided tremendous feedback at a time when I needed it dearly. Numerous other colleagues have been supportive of my work and inspired me. Thanks to David Sadoway, Sarah Knuth, Patrick Bigger, Alan Wiig, Conor Harrison, Heather Rosenfeld, Ingrid Behrsin, Laura Tozer, Sangeetha Chandrashekeran, Elliot Trettor, Anthony McClean, Heather Lovell, Ozzie Zehner, Anne Rademacher, and Lisa Bjorkman. In Fort Collins and Boulder, thanks to Adam Mayer for his hospitality and kindness. In Austin, thanks to Jay Reddy for his hospitality, generosity, and conversation.

Finally, the biggest thank you goes to Kelly Levenda for her patience and enduring support. 


\section{Table of Contents}

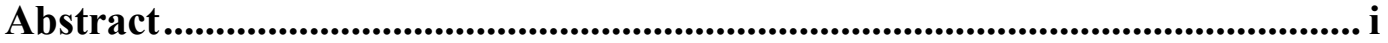

Dedication .......................................................................................................... iii

Acknowledgements.......................................................................................................... iv

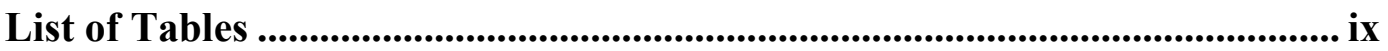

List of Figures ...................................................................................

1 Chapter 1: Introduction ...................................................................... 1

1.1 Background and Problem Statement ............................................... 2

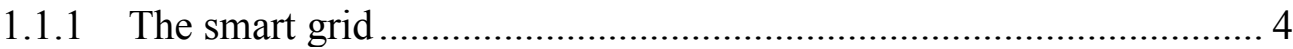

1.1.2 Existing social science literature on smart grids ............................ 7

1.1.3 Understanding the smart grid through sociotechnical transitions

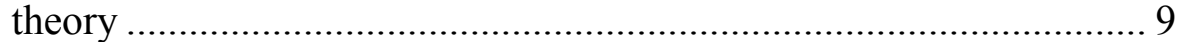

1.1.4 The limitations of sociotechnical transitions theory ...................... 13

1.1.5 Summary: Addressing the empirical gaps and contributing to theory..

1.2 Purpose and Significance

1.3 Conceptual Framework................................................................... 19

1.3.1 Constructing a smart grid............................................................. 20

1.3.2 Smart grid experimentation......................................................... 22

1.3.3 Understanding mobility of smart grid policies, models, and knowledge ............................................................................... 24

1.3.4 Governance regimes and sociotechnical transitions ..................... 26

1.4 Research Questions................................................................... 27

1.5 Overview of Methodology ........................................................... 28

1.6 Organization of Dissertation ................................................................. 30

2 Chapter 2: Methodology, Research Design, and Methods....................... 35

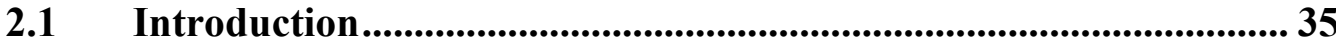

2.2 Research Design and Orientation ................................................... 39

2.3 Data Collection ..................................................................................5 50

$2.4 \quad$ Validity and Reliability ....................................................................5 56

2.5 Data Analysis...................................................................................... 56

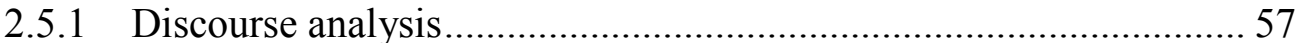

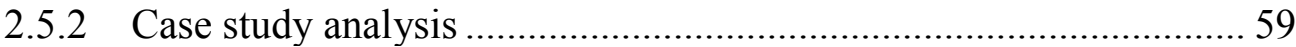

2.6 Role of the Researcher ......................................................................6 61

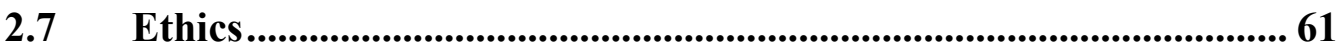

3 Chapter 3: Making Grids Smart, Making Smart Consumers................ 62

3.1 Introduction: Smart Grids and Electricity System Change ........... 62

3.1.1 Demand, smart markets, and smart end-users ................................ 64

3.2 The Politics and Governance of Sociotechnical Systems................ 70

3.2.1 Regimes of government ......................................................... 72

3.2.2 Analyzing governance regimes: rationalities, techniques, subjectivities 
3.2.3 Problematizing consumption: Ways of understanding domestic energy use ................................................................................ 83

3.3 Making a Smart Grid Regime ...................................................... 87

3.4 Efficiency, Security, Economy ..................................................... 95

3.4.1 Overview of governmental rationalities: efficiency, security,

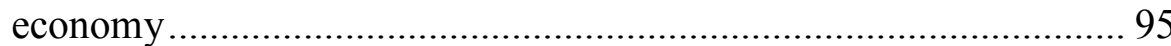

3.4.2 Efficiency: Smart grid as technical progression for electricity markets

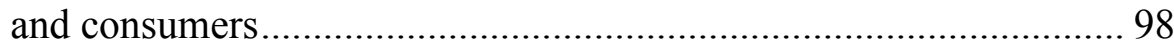

3.4.3 Security: Smart grid as a mechanism to secure critical infrastructure for human well-being ............................................................. 108

3.4.4 Economy: Helping customers save money …............................. 111

3.4.5 Summary of discourse analysis.............................................. 124

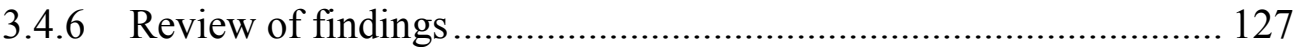

3.5 Conclusion: The Smart Grid and Smart Consumer....................... 128

4 Chapter 4: "A Living Lab for the Smart Grid": Experimentation,

Governmentality, and Urban Energy Transitions.................................. 131

4.1 Urban Living Labs and Smart Grids ........................................... 131

4.2 Laboratorizing the City: A Smart Grid Experiment in Austin,

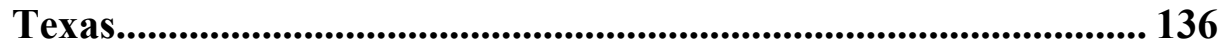

4.2.1 Labs in, of, or for the city? ...................................................... 136

4.2.2 Urban living labs and governance............................................... 138

4.2.3 A living lab for the smart grid in Austin, Texas .......................... 140

4.3 Governing through Experimentation: Demonstration and Test-

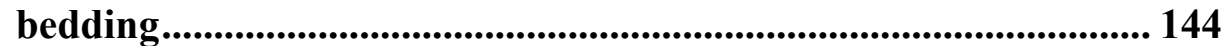

4.3.1 Urban living labs as demonstrations .......................................... 150

4.3.2 Urban living labs as test-beds and protected niches .................... 154

4.4 Making Smart Consumers, Governing Demand............................ 160

4.5 Rationalities of Governance Experimentation .............................. 162

4.5.1 Making smart subjects or a smart techno-fix? .............................. 164

4.6 Conclusion: Urban Smart Grids for Whom? ................................... 167

5 Chapter 5: Mobile Experiments: Models, Visions, and Politics ........... 170

5.1 Introduction................................................................................ 170

5.2 Urban Energy Transitions and Policy Mobilities ......................... 174

5.3 Mobile Experiments, Failed Experiments, Spectacular

Experiments? ................................................................................ 184

5.3.1 Seductive visions: Oak Park's SmartCityUSA project ................... 186

5.3.2 Take the power back? Boulder's SmartGridCity and municipalization 195

5.3.3 A platform for sociotechnical experimentation: Fort Collins'

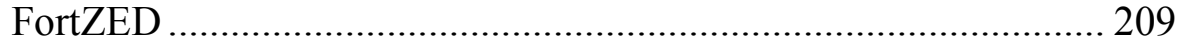

5.3.4 Austin as exemplar? Traveling logics, rationalities, techniques.... 218

5.3.5 Experiments, Mobilities, Transitions........................................... 220

5.4 Conclusion: Mobile Experiments and the Politics of Urban Energy

Transitions 228 
6 Chapter 6: Discussion and Conclusions.................................................... 229

6.1 Review of findings ............................................................................. 229

6.1.1 Synthesis and connections to conceptual framework ................... 233

6.1.2 Contributions to scholarship ................................................. 235

6.2 Implications for policy and practice................................................ 237

6.3 Limitations and areas for future research ........................................ 240

References .......................................................................................................... 242

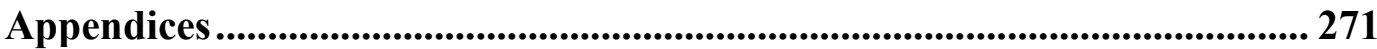

Appendix A: Sample Recruitment Letter ................................................ 271

Appendix B: Sample Interview Protocol...................................................... 272 


\section{List of Tables}

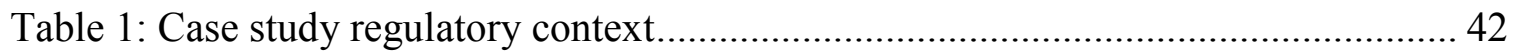

Table 2: Discourse actors, by sector, and document types analyzed in Chapter 3 .......... 55

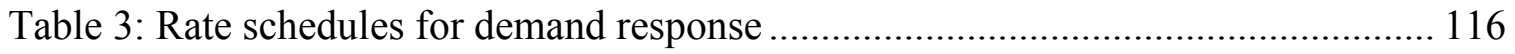

Table 4: General types of user participation in industry discourse ............................. 123

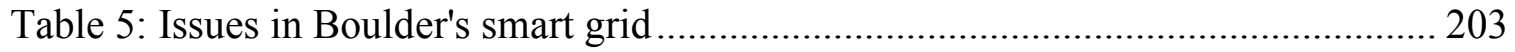




\section{List of Figures}



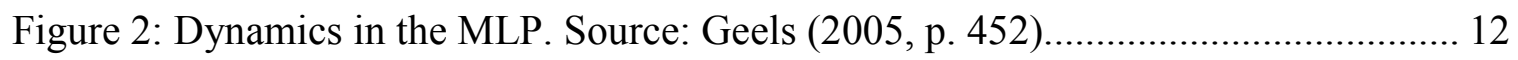

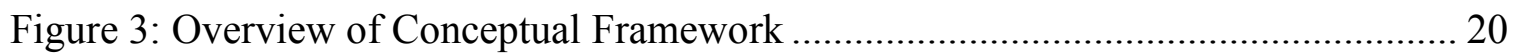

Figure 4: Policy mobilities approach. Source: Cook and Ward (2012)........................ 25

Figure 5: Overview of Conceptual Framework …................................................ 47

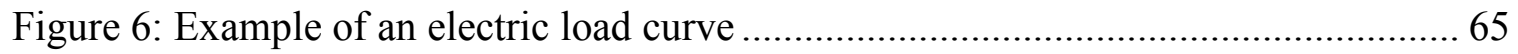

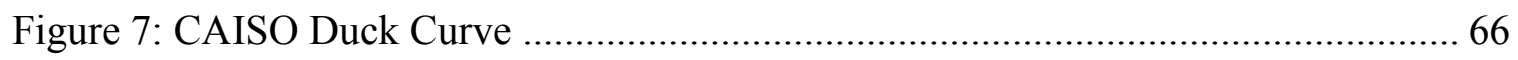

Figure 8: Aerial view of solar installations in Mueller neighborhood .......................... 140

Figure 9: Three dimensional model of Mueller PUD in the development offices on site

Figure 10: Balancing Authority, RTO, and ISO Regions. Source: eia.gov ................... 171

Figure 11: Geels (2007) Diagram of Niche-Regime-Landscape Interactions ................ 176 


\section{Chapter 1: Introduction}

This dissertation investigates how the smart grid has emerged as a solution to a number of energy related problems. In this historical process, the technological transition to a smart grid has disrupted an industry characterized by lock-in and path dependency, not only in technology, but also organizational structure. This process of sociotechnical change, however, is piecemeal and experimental. The context of smart grid development and experimentation shapes and is shaped by exisiting sociotechnical systems and sociotechnical regimes. In addition, these forms of experimentation suggest new opportunities for testing and learning, providing lessons and best practices that influence broader implementation. Furthermore, with the transition towards a smart grid, assumptions about how to best govern electricity generation and consumption privilege particular forms of knowledge about technology, energy consumption, and policy.

In this dissertation, I critically analyze the material and discursive construction of the smart grid, the implementation of urban smart grid experiments, and the mobility of knowledge, models, and best practices pertaining to the smart grid. To do this, I build on

and synthesize existing literature on sociotechnical systems, the social construction of technological systems, urban experimentation, and policy mobilities in a conceptual framework that helps addresses many limitations through an analysis of governmentality. This addresses important limitations in our understanding of crucial questions relating to how regimes of power and governance shape and are shaped by sociotechnical systems and sociotechnical change. 


\subsection{Background and Problem Statement}

The United States' electrical grid is characterized as the "largest machine on earth." The grid enables electricity generated in distant (or near) places to be delivered to our homes, businesses and industries for various uses. Electricity is of vital importance to nearly every aspect of modern life. In the face of significant environmental, technical, and political challenges, however, the electricity system needs upgrading, maintenance, and retrofitting. The grid is failing and fragile. It's an aging infrastructure that relies on century-old technology limiting the ability for interconnecting renewable energy, controlling electricity flows, and managing the system. Each of these challenges have been met with an optimism of how the smart grid will address them, transforming our electricity system resulting in multiple economic and environmental benefits.

The grid is an incredibly complex system of interlinked generation facilities, transmission and distribution networks, transformers and substations, and a variety of end-uses. Generation facilities convert chemical or potential energy into mechanical energy to create electrical energy through in an electrical generator. The resulting electricity (usually in alternating current, but also in direct current from solar panels and wind turbines) is carried at high voltage through the transmission system to load centers where a distribution system then delivers the electricity at a lower voltage to homes and businesses where electricity is ultimately consumed in a variety of applications. The grid is all of these things. When one part of the system changes, the rest of the system has to adapt and change as well, and quickly, as grid operators have to balance supply and demand at every instant to ensure voltage, frequency, and current are at optimal and safe levels. 
The electrical grid began not as one (or three as in the US today) interconnected regional systems, but multiple, local grids in urban areas. Nye (1992) explains that the early grid systems were local, utilizing direct current dynamos or alternating current alternators for generation, and often had multiple utilities with their own sets of wires and customers in one given territory or city. For example, in Muncie, Indiana, during the early 1900s, what Nye $(1992,17)$ calls a "microcosm of the US" at that time, three utilities served the city: one public for street lighting, one private for the streetcar system, and one private for other uses.

Electricity transformed Muncie's industries, effectively deskilling labor or reducing need for it altogether, and at the same time created new electricity dependent industries. While commercial uses of electricity were large in the 1900s, few residential homes were electrified. However, by 1930 , national home electrification grew to 70 percent, mostly in urban areas as electricity networks had not been built into rural areas (Nye 1992). Trends of increasing demand due to growth in industry and electrification of the home, incorporating new appliances and lighting, coupled with the centralization of ownership of generation facilities and distribution networks fueled by economies of scale and scope, transformed the system of small scale, local generation, into large scale, interconnected systems under vertically integrated companies, and eventually regulated monopolies.

All of these developments were thoroughly social and technical. As Nye (1992, 27) explains, "technological developments are too often understood as irresistible, when in fact people shape the form of the electrical system as they incorporate it into everyday life." The sociotechnical nature of electricity networks is essential to understanding how 
and why and if these sociotechnical systems change. As Nye notes, the electricity grid shaped and was shaped by the cultural, economic, and political context in which it was developed. Its technical changes were outcomes of cultural changes, and vice-versa.

Similarly, with the development of the "smart grid" today, electricity systems are being reimagined, reshaped, and reconfigured to respond to pressures to act on climate change, resource constraints, and overconsumption, signaling a renewed importance and attention to the ways in which the electricity systems are integrated into everyday urban life.

\subsubsection{The smart grid}

The smart grid means numerous things to different audiences. It's a blanket term that envelops a whole host of technologies, business models, and visions. The US Department of Energy (DOE) (2016) describes the smart grid as a necessary technological progression in electricity generation, transmission, and distribution:

"The grid," refers to the electric grid, a network of transmission lines, substations, transformers and more that deliver electricity from the power plant to your home or business. It's what you plug into when you flip on your light switch or power up your computer. Our current electric grid was built in the 1890s and improved upon as technology advanced through each decade. Today, it consists of more than 9,200 electric generating units with more than 1 million megawatts of generating capacity connected to more than 300,000 miles of transmission lines. Although the electric grid is considered an engineering marvel, we are stretching its patchwork nature to its capacity. To move forward, we need a new kind of electric grid, one that is built from the bottom up to handle the groundswell of digital and computerized equipment and technology dependent on it — and one that can automate and manage the increasing complexity and needs of electricity in the 21 st Century. In short, the digital technology that allows for two-way communication between the utility and its customers, and the sensing along the transmission lines is what makes the grid smart. Like the Internet, the Smart Grid will consist of controls, computers, automation, 
and new technologies and equipment working together, but in this case, these technologies will work with the electrical grid to respond digitally to our quickly changing electric demand.

The smart grid, for the DOE, is a "new kind of electric grid" that enables an "energy internet" (The Economist 2004) to handle the growing demands placed on the grid utilizing digital technologies.

Smart grid technologies include generation, transmission, distribution, and enduse applications. In the current system, generation is centralized in large-scale power plants that produce alternating current (AC) electricity, transmission transports high voltage electricity from power plants to substations closer to consumers, distribution transports low voltage electricity from substations to households and other buildings; and enduses are as varied as appliances and consumer devices to pumps and lights for industrial uses. In this "legacy" systems model, electricity moves in a single direction, flowing down to areas of lower voltage like water down a hill, from generation to consumption (Figure 1).

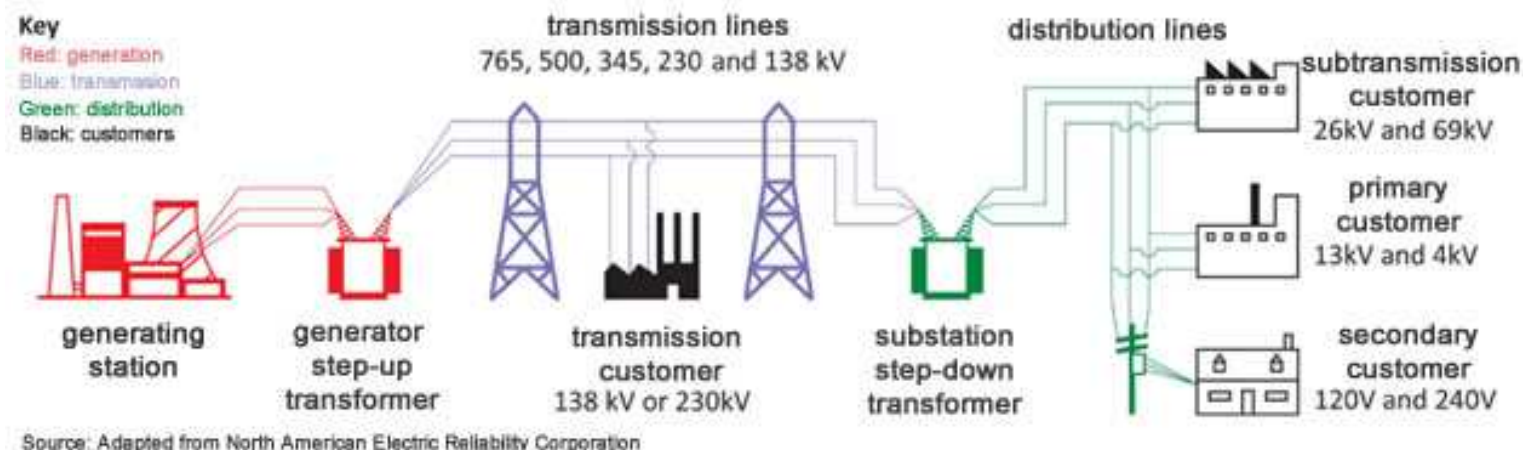

Figure 1: Legacy electric grid. Source: http://www.eia.gov/energy_in_brief/power_grid.cfm

In the smart grid, all elements of this legacy system are changed or transformed in some way. As the US Department of Energy's definition above details, the smart grid entails 
the use of digital technologies, sensors, actuators, and other ICTs that are integrated into the existing electric grid, "modernizing" it to enable a variety of new capacities (see Stephens, Wilson, and Peterson 2015; Carvallo and Cooper 2015; Farhangi 2010; FoxPenner 2014).

On the generation side, grid tie-inverters allow integration of renewable energy sources such as PV, which generate direct current (DC) electricity. Transmission system technologies include synchrophasors used to collect data on grid functions, power transmission analysis software to study, model, or control transmission systems, and smart inverters and rectifiers for conversion between alternating and direct current. On the distribution side, substation automation technologies, application of new relays and breakers to direct electricity flows, fault locator systems, advanced metering infrastructures and software, and distribution automation and software that enable identification of outages or system inefficiencies more quickly. On the end-use side, consumer applications include smart meters and information management software (both utility and consumer), load control systems such as programmable thermostats, and all manner of energy management systems and smart appliances. Smart grids technologies also include a variety of energy storage technologies including pumped hydro, compressed air storage, batteries and flywheels. Electrified transport is also included in smart grid technologies because of the possibility of using, for example, electric vehicle batteries for storing energy.

These technologies are associated with a range of promises, visions, and imaginaries of the smart grid. These include: climate change mitigation and adaptation through integrating clean renewable energy and creating microgrids that operate independently in case of extreme events; the creation of new jobs in renewable and smart energy industries 
boosting a so-called "clean energy economy"; energy security and independence at the national level through increases in efficiency and renewables and electrification of transport; and "empowering" consumers to save money through better energy consumption choices.

\subsubsection{Existing social science literature on smart grids (Empirical Gap)}

While changes in sociotechnical systems associated with the US smart grid have been studied by social scientists, the work has produced more descriptive treatments to identify key issues for development and policy, and as such, has received less consideration of power dynamics and politics (Stephens, Wilson, and Peterson 2015; Langheim et al. 2014; Stephens et al. 2013; Slayton 2013). The framework of sociotechnical systems analysis, and in particular attention to sociotechnical regimes, provides a starting point for analyzing the politics and governance of the smart grid. However, its limitations in terms of analyzing power, discussed above, point to a need for further theoretical development. This is all the more important considering the co-constitution of energy systems, culture, and everyday life (Nye 1992; Shove and Walker 2014; Hughes 1983; M. T. Huber 2013).

With all of the technological changes and promises of the smart grid, however, the majority of attention in public discourse is on consumer, or end-use technologies, especially the smart meter (Langheim et al. 2014). This is for good reason: most installations of smart grid technologies have included smart metering infrastructure, and meters or electric bills are the traditional points of contact for consumers' interaction with utilities. Attention to the consumer, to economic concerns, and to environmental benefits all focus 
attention on the notion that the smart grid is far from purely technological, but also social and cultural.

Numerous recent social science approaches have addressed many social changes and concerns arising with the smart grid. Many studies have considered the visions, promises, and imaginaries around the smart grid (Tricoire 2015; Stephens, Wilson, and Peterson 2015; Ballo 2015; Engels and Münch 2015; Vesnic-Alujevic, Breitegger, and Pereira 2016; Groves et al. 2016), although primarily in a European context. These studies aim to uncover the visions of technological progress that undergird the transition to a smart grid while also thinking through the implications for policy and technical implementation.

Some critical studies explicitly engage with the notion of users of the smart grid (Goulden et al. 2014; Nyborg 2015; Verbong, Beemsterboer, and Sengers 2013), whereas studies on technology acceptance and behavior changes to time of use pricing schemes enabled by smart meters tends to focus on "consumers" more narrowly defined (e.g. Abi Ghanem and Mander 2014; Gangale, Mengolini, and Onyeji 2013; Casey and Jones 2013; Torriti 2012). Industry related discussions also involve considerable work on "demand-side management" and “demand response" (Gellings 1985; López et al. 2015; Loughran and Kulick 2004) which has received considerable attention as smart grid technologies enable new programs to be devised for controlling demand. And as the US Department of Energy definition above explains, a huge part of the smart grid requires a rethinking of the relationships between supply and demand.

Electric demand has always fluctuated with the rhythms and practices of industry, commerce, and everyday life, but the smart grid promises a way to handle and manage 
this dynamism. Managing demand, making it flexible and responsive, is a key driver for smart grid implementation (see for example Rahimi and Ipakchi 2010; Abi Ghanem and Mander 2014; Biegel et al. 2014). Yet, demand is highly variable and difficult to manage. As social practice scholars have been keen to point out, energy is consumed through habitual social practices unlikely to be heavily influenced by pricing schemes (Shove and Walker 2014; Strengers 2013; Gram-Hanssen 2008; Hargreaves 2011). The impacts of this scholarship suggest that radical re-thinking of smart grid technologies and policies are necessary to realize sustainability promises.

While there has been considerable recent attention to "social" issues in the smart grid, including attention to policy, economic incentives, and technological visions, less attention has been paid to understanding the smart grid as a governmental program, a way of governing energy systems change, energy consumption, and everyday life (see Bulkeley, Powells, and Bell 2016; Powells et al. 2014; Bulkeley, McGuirk, and Dowling 2016). In addition, urban studies literature has not attended to the context of smart grid implementation in cities across the US (see McLean, Bulkeley, and Crang 2015; Luque 2014), nor the way that smart grid experiments foster learning between cities attempting to implement the smart grid to realize its numerous promises.

\subsubsection{Understanding the smart grid through sociotechnical transitions theory}

The smart grid promises sweeping social and technical change in a large technological system (LTS). Hughes (1983) coined the term "large technological systems" in his study of the development of electricity networks, the seminal work, Networks of Pow$e r$, to understand the process of innovation, focusing on "system builders" and "socially 
useful technical systems" (Hughes and Coutard 1996). Hughes was interested in the "heterogeneous engineering" that "system builders" performed in order to develop electricity systems, often partaking in raising funds, circulating publicity, dealing with legal issues and constraints and founding organizations (Hughes 1983). This work was essential not so much for understanding how technical systems work, but how they were made to be socially useful.

Hughes' sociotechnical approach to studying the evolution of large technological lays a foundation for this dissertation, and for scholars in science and technology studies (STS) and urban studies. In essence his work demonstrated how technological change both shapes and is shaped by social, political, cultural, and economic change; and how LTS have an endurance, or "momentum," that "stems from their embeddedness in social values and from their materiality" (Hecht and Allen 2001, 2). Hughes' work lays a foundation for understanding the connections and mutual shaping of technology, power, and authority.

Building on the LTS approach, scholars in STS and innovation studies have tried to understand how sociotechnical systems change over time, or how they "transition" (Geels 2004; Geels 2002; Geels 2005). The general principle is that if there is a better understanding of processes of technological change and innovation, it may help direct change towards more sustainable outcomes. The dominant perspective and analytical framework on sociotechnical transitions is the multi-level perspective, or MLP. This was developed at the intersection of evolutionary economics and technology studies, building largely on Hughes' work and his understanding of sociotechnical systems, and Rip and 
Kemp's (1998) understanding of the multi-level framework of technological change (see Rip and Kemp 1998; Kemp 1994; Kemp, Schot, and Hoogma 1998).

The MLP provides a 'heuristic' framework for thinking through sociotechnical transitions, providing a basis for understanding how transitions come about and through what processes (A. Smith, Voß, and Grin 2010; Elzen, Geels, and Green 2004). Technological change does not come easily, though; different social, cultural, economic, and political forces create resistance to change. Geels $(2002,1259-60)$ explains that this "stability of established sociotechnical configurations" is a result of "the linkages between heterogeneous elements" which are coordinated and configured by "sociotechnical regimes." Geels sociotechnical regime concept builds on Rip and Kemp's (1998, 340, emphasis added) definition: "A technological regime is the rule-set or grammar embedded in a complex of engineering practices, production process technologies, product characteristics, skills and procedures, ways of handling relevant artifacts and persons, ways of defining problems; all of them embedded in institutions and infrastructures." Important here is the complex interactions not only of engineers working on technical systems, but a variety of social groups that influence technological trajectories (policy makers, civil society groups, corporations and suppliers, scientists, financial institutions, etc.). 




Figure 2: Dynamics in the MLP. Source: Geels (2005, p. 452)

The MLP includes consideration of both macro-scale or "landscape" factors that create strong forms of structuration and are very resistant to change, and "niches" which are micro-scale processes that produce radical innovations (Geels 2004). Whereas regimes may produce incremental innovations, niches develop radical innovations that may challenge existing regimes (see Figure 2). Niches are typically "protected" from market processes and serve as spaces for innovations to be cultured, spaces of learning by doing, using, and interacting, and spaces to build the social networks and capacities required to reconfigure regimes (Geels 2002; Kemp, Schot, and Hoogma 1998; Geels and Raven 2006; Hommels, Peters, and Bijker 2007). Regimes may be challenged by niches, but they always exist within a largely "exogenous" landscape of political, economic, and en- 
vironmental factors slow to change, such as "cultural changes, demographic trends, and broad political changes" (Geels 2002, 1262).

In summary, the MLP provides an understanding of technological change as an evolutionary process through which sociotechnical regimes are reconfigured as radical innovations break through from technological niches. The promises of the smart grid include a variety of sociotechnical changes that would seemingly result in sweeping technological transitions in electricity systems (for example, from fossil-fuel based, centralized generation to distributed, renewable-based generation) and reconfigurations of sociotechnical regimes (for example, consumers becoming producers). However, there are many limitations to the sociotechnical systems approach that need to be addressed before it can be applied to study the smart grid.

\subsubsection{The limitations of sociotechnical transitions theory (Theory Gap)}

While the MLP provides a valuable framework for understanding sustainability, lowcarbon, and energy transitions (see Markard, Raven, and Truffer 2012; Bulkeley, Broto, and Maassen 2014; Araújo 2014), it has faced several criticisms relevant to this study of the US smart grid and its urban implementation.

First, while Geels (2002) suggests that regimes fulfill socially valued functions, he also argues that they constitute them, wherein new technologies and innovation co-evolve with their social functions. As Smith et al $(2005,1493)$ explain, "regimes therefore embody strongly held convictions and interests concerning technological practices and the best ways in which these might be improved." This suggests the MLP would consider how these socially desirable functions come to be, how they are reproduced by regimes, 
and how certain technologies are made to serve these functions. The lack of attention to these considerations suggests a need for a better understanding of the ways in which sociotechnical regimes interact with and shape user practices, and develop rationales for the development of certain forms of technology and governance.

Second, and relatedly, the theories of sociotechnical transitions has been criticized for its lack of attention to power and politics (Meadowcroft 2009; Meadowcroft 2011; Lawhon and Murphy 2012; Shove and Walker 2007; Shove and Walker 2008; Walker and Shove 2007; Lovell 2007). Of special concern to many critical scholars is the approach of "transition management" that applies the MLP to advocate for shaping and governing long-term sociotechnical change (Kemp, Loorbach, and Rotmans 2007; Loorbach 2010). Meadowcroft (2009), for example, has highlighted the complexity of doing any sort of "management" stemming from the multiple visions, goals, values, and directives guiding such management, the decentralized nature of innovations, the tendency for systems to 'lock-in', and the centrality of politics in all of these issues. Similarly, Shove and Walker $(2007,764)$ caution against approaches to "manage" system change, citing the political issues of authority, legitimacy, and democratic choice, before questioning if it is even possible to manage transitions at all given the context of a "world dominated by hegemonic ideologies of neoliberal capitalism, global finance and commodity flows."

This attention to issues of power and politics in sociotechnical transitions complicates the applicability of the MLP framework (Genus and Coles 2008). Lawhon and Murphy $(2012,366)$ suggest that too much focus on technological artifacts and transition management has created a void in attention to power, and therefore, "reconsidering how 
a problem is defined by looking at the broader context expands the type and level of intervention, inducing a movement away from material factors and artifacts and towards social explanations of and responses to the rules governing a particular regime." These considerations would help to address how and why particular regimes are reconfigured and how and why sociotechnical transitions occur.

Moreover, while sociotechnical regimes have been described as "relatively stable configurations of institutions, techniques and artifacts, as well as rules, practices and networks that determine the 'normal' development and use of technologies" (Smith, Stirling, and Berkhout 2005, 1493, emphasis added), there is surprisingly little analysis of what and how technologies comes to be "normal." This is of particular importance to questions of power and politics because regimes not only include technologies, but "user practices and application domains (markets), symbolic meaning of technology, infrastructure, industry structure, policy and techno-scientific knowledge" (Geels, 2002, 1262). As Geels (ibid.) suggests, "users also have to integrate new technologies in their practices, organisations and routines, something which involves learning, adjustments and domestication." The process by which this occurs, however, is not straightforward, and instead arises from social and cultural processes of which power, knowledge, and discourse are key.

One promising approach to address these limitations suggests that a Foucauldianinspired analysis of governmentality provides theoretical resources to address the interaction between specific socio-technical systems and broader power regimes (Tyfield 2014). Furthermore, Tyfield $(2014,593)$ explains, "the focus on power relations mediated via knowledge and measurement technologies also alerts us to the possibility that the key 
technological issue for a [sociotechnical] transition may well not be in the technologies (i.e. machines) per se, but rather in how these interact and coordinate amongst themselves and the power-knowledge technologies they must integrate for this to be possible." I take these criticisms into account in my analysis of "governance regimes" in the conceptual framework for this dissertation (see Figure 3), utilizing Foucault's "analytics of governmentality" to focus on governmental rationales, techniques, and subjectivities.

A third criticism of the MLP approach to sociotechnical transitions relates to the lack of consideration of important factors of space, place and scale (Lawhon and Murphy 2012; Coenen and Truffer 2012; Murphy 2015; Coenen, Benneworth, and Truffer 2012; Hansen and Coenen 2015; Truffer, Murphy, and Raven 2015). Three elements of this critique are relevant to this dissertation. First, the under-theorized role of the city in processes of transitions has caused concern for urban studies scholars interested in infrastructure and change (Hodson and Marvin 2009d; Hodson and Marvin 2010a; Hodson and Marvin 2012; Monstadt 2007; Moss 2014). Their work highlights the need to consider the city itself as a sociotechnical process (Graham and Marvin 2001) through which transition processes are mediated. They place specific attention on the urban as an important scale and place for the energy and sustainability transitions because of the increasing devolution of responsibilities for key aspects of technology, innovation, and competitiveness have been moved from the nation-state to the city/region.

Second, cities are characterized as sites of experimentation, where transition processes may be ignited. As more responsibilities for acting on climate change and sustainability transitions are place on cities, they have responded with experimental projects and programs (Harriet Bulkeley, Castán Broto, and Edwards 2014; Harriet Bulkeley and 
Castán Broto 2013a; Harriet Bulkeley and Castán Broto 2013b). These projects are often explicitly set up in "urban laboratories" (Karvonen and van Heur 2014) to foster learning and broader innovation. This relates to the third criticism in regards to the socio-spatial concerns: the geographies of learning and experimentation. This concern has only recently been raised, suggesting a need for synthesis between policy learning and sustainability transitions (Affolderbach and Schulz 2016; Voytenko et al. 2016; Sheldrick, Evans, and Schliwa 2016). This dissertation addresses these criticisms as well, by specifically engaging with a critical perspective on urban living labs, experimentation, and policy mobilities theory (see Conceptual Framework section below).

\subsubsection{Summary: Addressing the empirical gaps and contributing to theory}

This section has introduced the smart grid and existing social science scholarship on the topic. I proposed a way of studying sociotechnical systems utilizing existing sociotechnical systems theory, highlighted its limitations, and proposed some ways forward. This dissertation addresses both an empirical gap in social science literature on smart grids, and adds to existing sociotechnical systems and transitions theory. Below, I propose a conceptual framework (see Figure 3) that addresses the theoretical limitations of the sociotechnical approach described above.

\subsection{Purpose and Significance}

The purpose of this dissertation is to analyze the development of the US smart grid from

a critical, sociotechnical perspective. I focus on three central issues: the construction of the smart grid in public discourse, the urban context of smart grid experimentation, and the mobility of smart grid policy, models, and knowledge. 
This dissertation research began as a way to study what I call "urban smart grid experiments" that were being developed in response to a variety of electricity system challenges, and to consider their impacts on broader energy transition processes. The goal was not only to build an understanding of how smart grids were discussed in public discourse, largely as a national project to spur development and innovation, but also to trace how smart grid experiments actually were implemented in different utility territories and cities.

Cities were a key concern because the smart grid offered an opportunity to transform their electricity systems and reduce carbon emissions associated with electricity consumption. Urban smart grid experiments thus served as demonstrations of a national project for grid modernization, and an opportunity for cities to shrink their carbon footprints. However, I saw these developments as part of one project, a program of government through which smart grid technology and policies would enact a regime of energy governance, with possible significant implications for urban infrastructure and the urban energy transitions.

While experimentation, itself, has been considered a form of governance, I characterize this as just one part of a regime of government in which energy practices and energy infrastructure is governed in and through cities. Central to urban smart grid experiments is their significant political attention and contributions to policy models and knowledge for broader smart grid development. Capturing this process of inter-city learning, not just between federal agencies and one-off projects, and comparing across different smart grid experiments is a key goal of this dissertation. 
As cities attempt to rework energy infrastructures and policies for the smart grid, a change to an extremely large sociotechnical system, understanding how urban smart grid experiments are created, what programs and technologies they "test-out", and what potential implications they have on both cities and low-carbon energy transitions are of ut-

most concern. With the debates and concern on climate change, resource scarcity, and technological change, the smart grid offers a number of potential pathways for change. Yet, at the same time, these smart grid experiments occur within and through the urban fabric and existing sociotechnical regimes, limiting wholesale sweeping changes and transitions, and instead developing in a piecemeal, contested, and contingent ways.

Thus, this dissertation brings an understanding of how "governance regimes" are established and constructed, how they get enacted through sociotechnical systems of urban infrastructures, and how elements of those regimes in the form of policy models, best practices, or knowledge are mobilized and mutated en route to different places. I attend to the needs of addressing power through theories of governmentality. This adds a more nuanced understanding of power to studies of sociotechnical regimes and their role in governing sociotechnical systems.

\subsection{Conceptual Framework}

As outlined above, this dissertation examines the construction of the smart grid in public discourse, the urban context of smart grid experimentation, and the mobility of smart grid policy, models, and knowledge. Each of these elements are discussed further below, highlighting how these fit with the overall conceptual framework (Figure 3) for this dissertation. 


\section{Governance Regime}

- Sociotechnical regimes are the heterogeneous set of actors, institutions, and technologies that structure sociotechnical systems

- Governmentality brings understanding of power through analysis of rationalities, techniques and subjectivities operating in and through regimes

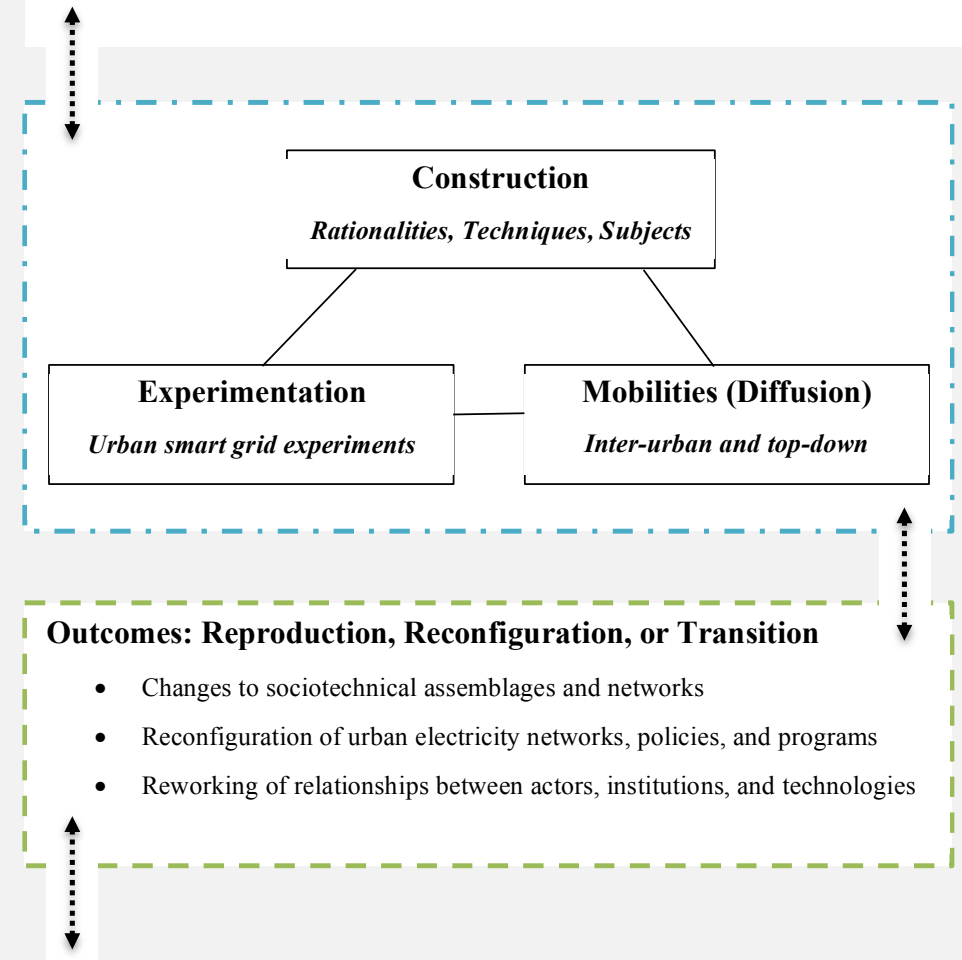

Figure 3: Overview of Conceptual Framework

\subsubsection{Constructing a smart grid}

The smart grid is an object of considerable attention from a variety of disciplines and sectors. In the US, much of the work on smart grids was initiated by national policies, including the Bush-era Energy Independence and Security Act of 2007 that created the "smart grid" as a national priority. The Act authorized DOE to establish the Federal 
Smart Grid Task Force to coordinate national smart grid policies, and the National Institute of Standards and Technology (NIST) to develop a smart grid interoperability framework. In 2009, President Obama led the American Recovery and Reinvestment Act (ARRA) of 2009, which focused on accelerating the development of smart grid technologies providing $\$ 8$ billion in funding through the Smart Grid Investment Grant Program. The SGIG program enabled a variety of smart grid projects to be funded (cost-shared) across the country. The DOE played a key role in the SGIG including: selecting and monitoring the 99 projects, analyzing the project impacts, and identifying innovative ways to catalyze follow-on smart grid investments. The national smart grid project spurred broad interest from the utility industry and associated technology companies.

These important policies at the national level spurred a tremendous amount of "public talk" (S. A. Moore 2007) about smart grids and their potential. Experts in electricity industry (engineers, economists, and regulators) discussed the costs and benefits of the smart grid, with some trying to tame public excitement and expectations while others promoted techno-utopian visions of a smart grid supplied by renewable energies (Slayton 2013). This discourse, although emerging from a variety of sources, portrayed and privileged certain types of knowledge and expertise about the smart grid, what its capabilities and capacities were, and how it would address a number of energy related challenges. This "social construction" of the smart grid created through discourse structured and defined how a sociotechnical transition to the smart grid would take place, what it would entail, and who would use it and how, and in this way helped to shaped the smart grid as a particular socio-technical assemblage of technologies, infrastructures, practices, and norms. 
My dissertation unpacks this discursive construction of the smart grid to identify forms of what Foucault calls "power/knowledge," or the way knowledge is "put to work through discursive practices in specific institutional settings to regulate the conduct of others" (Hall 1997, 75). In this way, the "construction" element of my conceptual framework aims to uncover specific governmentalities that, through discourse, defines rationalities of governance, establishes its techniques, and creates its subjects.

\subsubsection{Smart grid experimentation}

As smart grid projects were implemented by various utilities across the country, spurred by national and state-level policy, and ARRA funds in many cases, different urban actors and institutions sought to participate and benefit from investments in energy infrastructure. Policy at the national level certainly influenced the development of smart grids, but the context of their implementation has also played a significant role in their development. For example, in Austin, Texas, the city implemented automated meter reading (AMR) systems early on, fitting with their reputation as a "pioneer" in sustainable development, but this system was quickly outdated as new two-way systems of advancing metering infrastructure (AMI) became the standard for smart grid development (Carvallo and Cooper 2015). But the urban context matters more than simply technical choice by early-adopters, the drive for urban innovation has created conditions in which local implementation of smart grids take place in particular neighborhoods or districts as one-off projects, or what I call "urban smart grid experiments."

This concept builds on three ideas of experimentation in the literature. First, from the field of sociotechnical transitions, the idea of "niche experiments" - small-scale, ap- 
plication domains, where risk-takers pioneering new technologies stimulate innovations for changes in sociotechnical regimes. Niches are projects at the fringes of regimes that can produce radical innovations, yet at the same time are often limited and shaped by incumbent regimes (Elzen, Geels, and Green 2004; Geels and Raven 2006; Kemp, Schot, and Hoogma 1998). The context of niche development suggests a need to analyze power relations and politics in as discussed above (Meadowcroft 2009; Lawhon and Murphy 2012; Hess 2015).

Second, I draw on the growing literature on "urban experiments" which has addressed the ways cities are involved in creating new configurations of urban infrastructures, policies, and programs which are "interventions to try out new ideas and methods in the context of future uncertainties serving to understand how interventions work in practice, in new contexts where they are thought of as innovative" (Castán Broto and Bulkeley 2013b; Harriet Bulkeley and Castán Broto 2013a). Urban experiments are the "means through which discourses and visions concerning the future of cities are rendered practical, and governable" (Bulkeley and Castan Broto, 2013b: 367). In this sense, urban smart grid experiments contribute to regimes of governance by reconfiguring urban infrastructures.

Lastly, this concept builds on the notion of "urban laboratories," closely related to urban experiments. Urban laboratories research focus on specific urban settings created to test sociotechnical interventions in "the real world" that produce knowledge about a specific issue and, in the process, materially change the city (Evans and Karvonen 2014; Karvonen and van Heur 2014). Urban laboratories are specific places to experiment with 
sociotechnical interventions in urban spaces, and although they offer opportunities for radical innovation and change, they are often limited and shaped by existing regimes.

This characterization of urban smart grid experiments places importance on the socio-spatial and political economic context of smart grid implementation. While simply naming and describing this concept is valuable in terms of understanding the piecemeal implementation of the smart grid, and its possible splintering effects (Graham and Marvin 2001; Coutard 2008), it also is useful for understanding the politics of urban experimentation in relation to energy governance and transition.

\subsubsection{Understanding mobility of smart grid policies, models, and knowledge}

The notion of urban smart grid experiments discussed above also promises opportunities for testing and learning. For example, the DOE conducted evaluations and developed overviews of ARRA-funded smart grid projects to facilitate learning and broader innovation, but the approaches they used did not consider extralocal effects or the intercity movement of policy models and knowledge. Instead, they assumed a more top-down model of smart grid policy and program diffusion and transfer. This dissertation critically assesses this idea of policy transfer and adoption. Instead, I build on the concept of "policy mobilities" to understand how policy models, practices, and expertise are mobilized, allowing different urban actors and institutions to focus on specific energy-related problems, propose specific solutions, and gather the political support and legitimacy needed to carry out particular interventions (i.e. smart grid experiments) (Temenos and McCann 2012; Temenos and McCann 2013; McCann 2011b). 


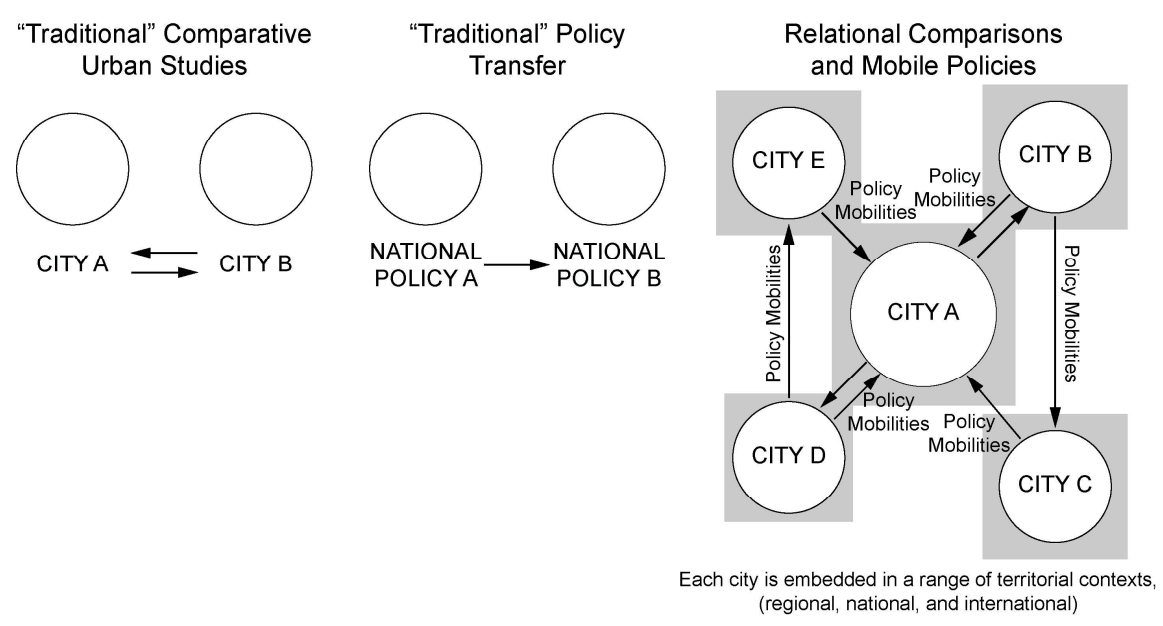

Figure 4: Policy mobilities approach. Source: Cook and Ward (2012).

The "policy assemblages, mobilities, and mutations" approach (Figure 4) "is characterized by a concern for the actors, practices, and representations that affect the (re)production, adoption and travel of policies and best practice models across space and time" (Temenos and McCann 2013, 345). This approach enriches the study of the geography of sociotechnical transitions addressing some of the limitations identified above. First, as Temenos and McCann $(2013,346)$ explain, it focuses attention on "more ephemeral spaces of knowledge production and circulation [such as conferences, meetings, or technology demonstrations] ... sites of encounter, persuasion, and motivation." This is important because urban smart grid experiments themselves may be temporally and spatially limited; while the infrastructures may endure, the activities that define the place as experimental are only present for a short period of time. Capturing attention of innovative experimentation places importance on practices of "boosterism" and demonstration around urban smart grid projects, often facilitated by actors other than city officials. Second, the policy mobilities approach helps enhance understandings of the role of the state (across scales) in the production and circulation of knowledge (J. Allen and Cochrane 
2010; J. Allen 2011; Temenos and McCann 2013). This suggests that consideration of national level policy and programs, like DOE's SGIG, is still of considerable importance.

\subsubsection{Governance regimes and sociotechnical transitions}

Urban infrastructure networks, such as electricity, communication, or water systems, are key sociotechnical systems in a city's functioning as an economic and cultural center of human activity. Innovations in these systems, such as smart grid technologies, promise opportunities to make cities more sustainable. As such a plethora of policy, planning, and associated research has emerged on sociotechnical transitions and the possibilities for contributing to more sustainable development (Markard, Raven, and Truffer 2012).

Urban infrastructures structure patterns of consumption and distribution of resources, enabling and disabling particular practices (Bulkeley, Broto, and Maassen 2014; Vliet, Shove, and Chappells 2012), and as such are key objects of governance (Graham and Marvin 2001; Bolton and Foxon 2015). At the same time, infrastructures are a means of governance, guiding processes of socioenvironmental transformation and sociotechnical transition (Swyngedouw 2006; Coutard and Rutherford 2015; Bulkeley, LuqueAyala, and Silver 2014). An understanding of how and why these infrastructures change, then, is a necessary part of understanding how sociotechnical transitions are governed.

I understand the processes of infrastructure change through my conceptual framework that builds on sociotechnical transitions theory (Figure 3). I expand on the concept of the sociotechnical regime with theories of governmentality to include a more robust conception of power in a "governance regime." The governance regime influences 
the processes and practices of the construction, experimentation, and diffusion, while these, also in turn, shape the governance regime. While this may result in reproducing the same relations of power in the governance regime, there may also be disturbances resulting from interconnections between experimentation, construction, and diffusion. As a result, sociotechnical systems may be reconfigured, or may transition, resulting in broader regime changes. In summary, this approach brings together elements of discursive construction, sociotechnical experimentation, and geographies of policy and knowledge to understand how regimes of governance and the sociotechnical systems they govern may be reproduced, reconfigured, or transitioned.

\subsection{Research Questions}

Each of these elements interplay with regimes of governance that I analyze through the lens of governmentality to answer three research questions:

First, How are smart grids constructed in national discourse? What is the political vision for smart grids in the US? Given the growing public discourse on the smart grid, I wondered how different concepts of the social impacts of smart grid implementation were being discussed. I noticed first that the general discussions circled around how energy consumers would adopt new smart grid technologies, such as smart meters, and how they might respond to smart grid enabled programs, such as demand response, both voluntary and automated.

Second, How are smart grid experiments implemented in different urban contexts and with what results? How do smart grid experiments impact broader implementation locally and "extralocally"? I wondered how the different policy directives and funding 
schemes would actually facilitate the implementation of the smart grid in different settings. After primary analysis, I thought that these might be considered as "experiments" or demonstrations wherein smart grid technologies would be tested. But I thought that these infrastructure changes could present cities with a variety of opportunities and challenges, considering infrastructures, cities, and urban life are co-constituted.

Third, How do different cities learn about smart grid experiments? How do associated policy models and knowledge move from one place another, and with what implications and limitations? The promises of smart grid demonstrations were that they would inspire further innovation and promote broader economic and environmental benefits. I wondered how processes of learning would take place, what sorts of lessons, best practices, or models would be adopted, and how different cities would change smart grid project to fit their needs, values, and political goals.

\subsection{Overview of Methodology}

This dissertation uses Foucauldian-inspired critical discourse analysis (Hajer 1995; Jager 2001; Waitt 2005) and case study methodology (Burawoy 2009; Peck and Theodore 2012; Yin 2003) to answer the above research questions. These methods are rooted in constructionist and critical theory paradigms, which together strengthen the overall mode of inquiry (Alford 1998). The project began by unpacking the public discourse on smart grids. I followed Hajer's $(1995,60)$ definition of discourse as “a specific ensemble of ideas, concepts, and categorizations that is produced, reproduced, and transformed in a particular set of practices and through which meaning is given to physical and social realities." As such, I wanted to understand how the smart grid was being con- 
structed socially and materially through discourse, and what sets of understandings and practices it privileged over others. In so doing, I used discourse analysis, instead of only content analysis, because I was specifically interested in power and governance. Whereas content analysis provides a useful entry point into understanding and categorizing what particular texts say, it does not help provide meaning through a broader understanding of social context (Hall 1997, 25; Hajer 1995). Changes in meaning imply the need for interpretation, which Foucault's theory of discourse links directly to the co-production of knowledge and power (Foucault 1980; Jasanoff 2004b).

I utilized case study methods to explore urban smart grid experiments with a specific focus on their urban context, bringing together multiple forms of evidence (documents, interviews, observation) to understand the phenomena of experimentation and mobility. I chose the Pecan Street project in Austin, Texas, because it was a key case of an urban smart grid experiment, presenting the possibility for exemplary knowledge (Flyvbjerg 2006; Thomas 2010). This key case was important to develop for this dissertation because it provided a way to understand the dynamics of experimentation in relationship to regimes of governance and the stability or rigidity of sociotechnical transitions. I build on existing theory and extend it to consider what different considerations need to be included. For example, as noted above, the notion of sociotechnical transitions suggests that niche experiments harness radical innovations and a weakness in a regime allows for that innovation to break through, but in the case of the smart grid, there is considerable resistance in regimes. Therefore, my analysis of governmentality adds to the regime of governance an understanding of power that is central to regime reproduction or reconfiguration, and a lack of transition. 
In addition, I utilized a relational comparative case study methodology (Ward 2010; Cook and Ward 2012) to examine and explore the processes of learning and policy mobility. For this method, the case includes multiple urban smart grid experiments and the networks that link them together (Peck and Theodore 2010a; Peck and Theodore 2012). Guided by methodological prescriptions of policy mobility scholars, I followed their approach to understand the ways in which "various "local" and "extra-local" urban actors — consultants, planners, politicians, and practitioners - have used comparison as a strategy to underscore the importance" of developing the smart grid in a particular way (Cook and Ward 2012, 778). These scholars suggest that policy should be more broadly understood as "sets of bundles of expertise, learning, and knowledge codified in one way or another" (Cook and Ward 2012, 779), which is produced and circulated with impacts not only for policy and policy making, but for knowledge and place. This mobilities ap-

proach allowed me to not just "compare," but to address how different urban smart grid experiments learn from each other, including ideas about which technologies to use, how to engage consumers, what studies are relevant, etc.

\subsection{Organization of Dissertation}

The dissertation is structured in six chapters, including this introduction. I structured the dissertation around the three key areas of investigation and related research questions discussed above: the construction of the smart grid in public discourse, the urban context of smart grid experimentation, and the mobility of smart grid policy, models, and knowledge. This introductory chapter has introduced the primary research problems, questions, and associated literature while also providing an introduction to the overall 
conceptual framework and methodology. I explained the several limitations in our understandings of the smart grid, the urban context and implications of smart grid implementation, the way policy models and knowledge move and mutate, and the relationships of these processes to the reproduction, reconfiguration, or transitions of sociotechnical systems. I suggested that there is a need to better understand the role of power in sociotechnical transitions and I proposed that theories of governmentality strengthen the regime concept. This was elaborated through the conceptual framework outline above.

In Chapter 2, I describe the research design and methodology utilized in this dissertation. I describe how this dissertation fits within the overall constructionist and critical theory research paradigms. Then I provide a justification for the methodologies used, focusing on the way both critical discourse analysis and case study methodologies help to answer my research questions. The conceptual framework for the dissertation is presented to highlight how the three areas of inquiry are linked together to examine and analyze governance regimes. I then describe the processes for data collection and analysis, the role of the researcher, and ethics.

As introduced above, in Chapter 3, I analyze the discursive construction of the US smart grid. This empirical analysis starts by introducing the history of national energy policy and the creation of the smart grid as a national policy program. I describe the conditions and context under which a governmental rationality enables the sociotechnical system of the smart grid to emerge as a solution to the problems of energy supply and demand. The discourse analysis provides three key rationalities: efficiency, security, and economy. I unpack these rationalities to address how discourse shapes our understanding of the smart grid, and ultimately shapes the techniques through which the smart grid is 
implemented, for what purposes, and embodying what values. The discourse analysis highlights the imagined and created subjects of the smart grid, and in particular, the construction of a "smart consumer." All three of these elements, rationalities, techniques, and subjectivities, are central to the ways in which regimes of governance are established and reproduced. This chapter also highlights a contradiction that arises in the dominant techno-economic discourse of the smart grid, that of the rational and smart consumer. The persistent failure of many price-dependent programs for consumer behavior change have resulted in continued studies and experiments on how to use existing (dominant technoeconomic) knowledge and making the smart grid "fit" with this approach. Instead, I suggest that a social practices approach may be a more appropriate way of thinking for future policy endeavors, wherein smart grid technology is made to fit with the existing consumers and their values.

Following this discourse analysis, I present a case study of the Pecan Street urban smart grid experiment in Austin, Texas in Chapter 4. This case is used to analyze the context of urban experimentation and its impacts on the city, infrastructure, and urban energy governance. I then explicate how urban smart grid experiments, discussed as urban living labs (ULLs) in literature on sociotechnical transitions, attempt to reconfigure the relationship that consumers have with energy systems. Using insights from governmentality studies, I argue that smart grid experiments rely on governing through "smart" subjects who reshape their energy consumption patterns in line with individual economic or environmental concerns. This chapter builds on Chapter 3 by focusing on how the public discourse on the smart grid impacts and shapes actual implementation in urban smart grid experiments. It also analyzes what neoliberal forms of urban experimentation imply for 
sociotechnical transitions and urban energy governance. Specifically, it highlights the "test-bed" approach to infrastructure development.

In Chapter 5, as introduced above, I present the analysis and findings of the relational comparative case studies of smart grid experiments. I suggest synergies between the literature on sociotechnical transitions and urban policy mobilities through the use of the conceptual framework advanced in this dissertation. The exploratory cases raise several issues for further work, but the analysis also highlights the interconnected and extralocal influence that project models, such as Austin's Pecan Street project, carries in diverse settings. In Oak Park, for example, Austin's urban smart grid experiment presents a model for replication. After consultations and in-person meetings with the non-profit leading Austin's project, Oak Park city officials gathered the model for an urban smart grid experiment in a 300-page "how-to manual" with the label of SmartCityUSA. Of course this project was modified for Oak Park's own experience and incorporated years of "best practice" lessons from Austin's project, but the Austin model itself, through reference, created the conditions for Oak Park's own project to emerge. Similarly, I examine issues related to the travelling of lessons and knowledge from Austin's smart grid experiment in Boulder and Fort Collins where the existing "landscape" factors shaped the possibilities of implementing similar projects in different ways. This is discussed in more detail while also considering the implications of policy mobility for understanding urban energy transitions and governance.

Lastly, Chapter 6 concludes the dissertation synthesizing the research contributions in each of the chapters and elaborates on how these fit with the overall conceptual framework. I then describe the practical, policy, and intellectual contributions that this 
dissertation makes. I end with a discussion of future research agendas that expand upon this dissertation. 


\section{Chapter 2: Methodology, Research Design, and Methods}

\subsection{Introduction}

This chapter presents the research design, conceptual framework, and methods utilized in this dissertation. The overall approach of the dissertation fits within the qualitative research foundations of the disciplines of urban studies, human geography, and science and technology studies. I employed critical discourse analysis methodologies and case study research design. These overall approaches were best suited to answer the critical questions this dissertation seeks to answer with a focus on the particularities of different urban contexts and the practices of various elite actors in urban electricity infrastructure networks.

Studying smart grids is difficult for numerous reasons, not least of which is the massive nature of the infrastructure networks spanning across the entire country (continental US), intersecting large and small cities, towns, and rural landscapes, different climates and economies, and different political and regulatory contexts. Electricity infrastructure spans across multiple levels of governance and interconnects (political and socially constructed) scales from the nation-state to the individual body. While this poses substantial problems for understanding the entirety of the system in a detailed way, discourse and case study methods examine particularly significant pieces of the whole to elucidate understandings about how this system, and changes to this system, are governed. In addition, the multiple case studies constructed and analyzed in this dissertation allow for comparison, which is done in a relational perspective, to highlight not only dif- 
ferences and similarities but networks of relationships of actors who carry and move policy models, knowledge, and rationalities from place to place.

This chapter presents the overall structure of inquiry into smart grids around three key issues - construction, experimentation, and mobilities/diffusion - and three associated research questions:

1. How are smart grids constructed in national discourse? What is the political vision for smart grids in the US? What policy problems do smart grids attempt to solve? What do smart grids do socially and technically, and who do they benefit?

2. How are smart grid experiments implemented in different urban contexts and with what results? How do smart grid experiments impact broader implementation?

3. How do different cities learn about smart grid experiments? How do associated policy models and knowledge from one place move to another place, and with what implications and limitations?

The outcomes of these questions provided me with the necessary information to support theoretical arguments outlined in the three following chapters, each of which corresponds the questions above in respective chronological order. Chapter 3 presents a critical discourse analysis of various national level actors in the smart grid sector to categorize how elites describe the smart grid and its various applications, benefits, costs, risks, and technologies, all of which are enrolled in a political vision of the smart grid which impacts both national and local policy and implementation. Critically, the dominant discourse reveals a technopolitics of the smart grid with particular aims to spur in- 
novation and economic growth while also reinforcing particular liberal governmental logics of individual action as social change and technological "fixes" to socioenvironmental and systemic concerns. Chapter 4 presents a deep case study, an exemplary case, of how the smart grid is actually implemented in Austin, Texas. The case study focuses on the concept of the "living laboratory" and highlights how the dominant discourse at the national level filters into local implementation and policy, but at the same time, shows how experimentation mutates and mobilizes urban smart grid policies. Chapter 5 presents a relational comparative case study of three smart grid experiments in Oak Park, Boulder, and Fort Collins. I analyze these cases with respect to urban energy transitions, experimentation, and policy mobilities. Each chapter corresponds to the empirical needs of the research questions, utilizing different methods of data collection and analysis. In general, however, each of these questions analyzes an element of governance and politics at different scales and through different networks of actors, institutions, and technologies. And more, there are theoretical connections between each of the chapters, between construction, experimentation, and diffusion, and their role in governing urban energy transitions which is discussed in more detail in Chapter 6.

While I did not have particular hypotheses to test, I formulated propositions based on literature review and theoretical guidance. That is to say, while I chose an inductive approach to research, my thoughts about the research were shaped and guided by established research. These propositions included:

1. Smart grids are constructed as particular technological fixes for social, economic, environmental, and political issues. The discourse is thus dominated 
by techno-economic episteme, discourse strands, and social representations representative as a dominant sociotechnical regime.

2. Smart grids are implemented as experimental projects for testing different types of sociotechnical interventions guided by dominant techno-economic epistemologies and values. While they promise to contribute to urban energy transitions, there is friction between economic, technical, political, and social outcomes and expectations. The lessons generated from these experiments, although dominantly techno-economic, influence other smart grid experiments.

3. Diffusion of learning from smart grid experiments carries with it particular episteme, visions, and ideas, carried in discourse and embodied in technologies and policies, that shape forms of urban energy governance and the materiality of the city.

These general ideas shaped my selection of research methodologies and methods, which I found appropriate for testing these propositions. Data availability was ensured through preliminary data collection of secondary sources including policy documents, political speeches, whitepapers, newspaper articles, and preliminary interviews with local smart grid experts. This ensured that the study was not only worthwhile, but possible. Through this preliminary phase and problem definition, I found several exemplary urban smart grid experiments, of which Austin was cited most frequently in industry journals and national policy discourse which signaled its importance for broader smart grid implementation. I then selected three different case study sites - Oak Park, Boulder, Fort Collins - based on their own implementation of smart grid projects and their connections 
to various actors involved in Austin's smart grid experiment. This allowed me to investigate relationships between different cities and the movement of policy knowledge and models. Of course, however, these cases are each situated in different institutional, organ-

izational, and political contexts (Table 1). These "regime" and "landscape" factors shape the context and efficacy of experimentation and policy mobility, and the ability of sociotechnical innovations to influence urban energy transitions.

The rest of this chapter provides detailed explanation of the research design, data collection process, validity and reliability, data analysis, and a reflection on my role as a researcher. I explain my research approach, why I chose the discourse analysis and case study methodologies, and explain how this methodology and methods addresses the research problem and questions.

\subsection{Research Design and Orientation}

The overall approach is situated in the constructivist and critical theory research paradigms (Guba and Lincoln 1994; Guba and Lincoln 1994). The constructivist approach makes an assumption that reality is brought about through the processes of describing it, in language, science, and other cultural practices. Discourse is of central concern and may be understood as situated symbolic action and practice. Constructivist and critical theory paradigms are mutually reinforcing and related. The critical theory paradigm focuses inquiry on critique and transformation while constructivism is focused on understanding and reconstruction (Guba and Lincoln 1994). While these are my general approaches, I follow a Foucauldian understanding of power, knowledge, and truth. This informs data collection, analysis, and interpretation. 
Central to the methodology of critical discourse analysis is the notion of discourse. Discourse, generally understood, is a way of talking about and understanding the world (Fairclough 2013; Hajer 1995; Jørgensen and Phillips 2002; Wodak and Meyer 2001). Discourse is a socially and culturally constructed representation of reality, and is thus removed from reality, but vitally shapes it. For Foucault $(1972,116-7)$, discourse is made up of 'statements' that belong to 'discursive formations,' which govern the meaning and regularity of statements, all of which are expressed through 'discursive practice' defined as the "body of anonymous, historical rules, always determined in the time and space that have defined a given period, and for a given social, economic, geographical, or linguistic area, the conditions of operation of the enunciative function." Discourse for Foucault then is not only about representations of reality, but knowledge of the world and the way we act in it.

Discourse, then, is intimately tied to power. Foucault (1981, p. 52) explained in his introductory lecture at the College de France in 1970 that, "in every society the production of discourse is at once controlled, selected, organized and redistributed by a certain number of procedures whose role is to ward off its powers and dangers, to gain mastery over its chance events, to evade its ponderous, formidable materiality." Discourse is controlled, constructs knowledge, and thus governs through the production, reproduction, and maintenance of categories and subjects of knowledge and sets of texts that limit what is conceived of as possible or not. The notion of power/knowledge thus refers to the mutual relationship between power and knowledge. For Foucault, power is diffuse and circulating, not only centralized, and produces both subjects and objects to be governed. 
Discourse analysis discussed here is not only a method or a tool for data analysis, but also a methodology, a way of orienting the research in line with a certain way of understanding the world. This notion of discourse is appropriate for RQ1, especially, but also in RQ2 and RQ3 in terms of analyzing governance in each of the case studies. Case study methodology is utilized to investigate the issues discussed in RQ2 and RQ3 offering arguments and contingently generalizable results. I used a relational comparative case study approach (Ward 2008, 2010). Case study methods in general are particularistic, descriptive and heuristic. They focus on the "how" and "why" of a particular phenomenon by using interviews, observations and other forms of data (Yin 2003).

This case study design entails five components (Yin 2003): (1) research questions, (2) propositions or hypotheses, (3) units of analysis, (4) determination of the relationship between the propositions and questions or linking the data collected to the research questions, and (5) interpretation of the findings. Components (1) and (2) were discussed above. Particular urban smart grid experiments - assemblages of actors, institutions, and technologies (see Castán Broto \& Bulkeley, 2013; Evans \& Karvonen, 2014; Fuchs \& Hinderer, 2016) - and policy assemblages - the heterogeneous set of models, knowledge, technology, actors, places, and policies that are processually being put together (J. Allen and Cochrane 2010; McCann 2011a; McCann, Roy, and Ward 2013; McCann and Ward 2011; McCann and Ward 2012b; McCann and Ward 2013) - are taken as the unit of analysis (3). Methods of data collection and analysis (4+5) are also discussed below

Case studies are an established methodology that has, however, received criticism for inadequately addressing theory and for having little relevance to broader contexts (Denzin and Lincoln 2011; Flyvbjerg 2006). To accommodate for this, (Payne 2005) ar- 
gue for an intermediate type of limited generalization, or 'moderate generalization' that acknowledges the scope and position in which the generalization is held, which is open to change. This research follows scholars in STS both in theory and methods to suggest that all knowledge claims are situated, contingent, and context-dependent (Haraway 1999). Thus, the accounts produced of smart grid experiments in this research that speak to and are guided by theory can develop new ideas that answer pressing research questions from my particular (researcher-activist-human) positionality.

Table 1: Case study regulatory context

\begin{tabular}{|c|c|c|}
\hline Case Loca- & $\begin{array}{r}\text { State } \\
\text { Structure }\end{array}$ & Utility Structure \\
\hline $\begin{array}{l}\text { Pecan Street Project } \\
\text { Austin, Texas }\end{array}$ & $\begin{array}{l}\text { Partially deregulated, in- } \\
\text { terconnected to ERCOT }\end{array}$ & $\begin{array}{l}\text { Austin Energy: Municipal Utility } \\
\text { with City Council as regulator }\end{array}$ \\
\hline $\begin{array}{l}\text { FortZED } \\
\text { Fort Collins, Colo- } \\
\text { rado }\end{array}$ & $\begin{array}{l}\text { Regulated, municipal utili- } \\
\text { ty with bulk power suppli- } \\
\text { ers }\end{array}$ & $\begin{array}{l}\text { Fort Collins: Municipal Utility with } \\
\text { City Council as regulator }\end{array}$ \\
\hline $\begin{array}{l}\text { SmartGridCity } \\
\text { Boulder, Colorado }\end{array}$ & $\begin{array}{l}\text { Regulated, vertically inte- } \\
\text { grated utility }\end{array}$ & $\begin{array}{l}\text { Served by investor owned utility, } \\
\text { Xcel Energy, but in process of mu- } \\
\text { nicipalization }\end{array}$ \\
\hline $\begin{array}{l}\text { SmartCityUSA } \\
\text { Oak Park, Illinois }\end{array}$ & $\begin{array}{l}\text { Deregulated, PJM Inter- } \\
\text { connection }\end{array}$ & $\begin{array}{l}\text { Investor owned utility, ComEd, } \\
\text { regulated by state PUC }\end{array}$ \\
\hline
\end{tabular}

Careful selection of case studies in the context of the particular research questions can improve their generalizability and intelligibility for theoretical arguments (Yin 2003; Stake 1995; Gerring 2007). Flyvbjerg (2006) proposes information-oriented selection as a method to improve generalization. This research uses information-oriented selection to build both key and exploratory cases. The cases included particular urban smart grid experiments and the networks between these cases. For example, the involvement of the 
research and development organization, Pecan Street, who coordinated one of Austin's smart grid experiments, served as a consultant and project organizer for the Village of Oak Park's SmartCityUSA project. The implications of this relationship can simply be seen as a consultancy, or it can be seen as a political channel through which policy models and knowledge move from place to place. This is one of central characteristics of the policy mobilities literature (McCann 2011b; McCann and Ward 2011; Peck and Theodore 2010a; Peck and Theodore 2015). The cases provided here explore how policy mobilities frameworks inform relational policy making and urbanism instead of focusing on more traditional notions of policy transfer from political science literature (cf Benson \& Jordan, 2011; Dolowitz \& Marsh, 2000).

In addition, the regulatory variables in Table 1 provide critical axes for comparison and case justification, yet simple comparison is not the aim of the approach taken here. While this context is important, providing a better understanding of sociotechnical regimes, it is only part of the networks and processes through which the governance of electricity networks is accomplished. By selecting case studies in different regulatory contexts, I am able to consider how regulatory environments may shape urban energy transitions at the regime level, but equally as important, I examine how smart grid experiments and policy assemblages contribute to the reconfiguration of urban electricity networks.

These methodologies are well suited to my dissertation research questions for several reasons. First, the dominant understanding of smart grids in public policy and understanding is primarily captured by technical and economic concerns. Therefore, uncovering and highlighting how these discourses have become dominant, what themes 
they reinforce, and what political configurations for governance they enable, and crucially which discourses, themes, concerns, values, and configurations they do not support or even repress, calls for a critical discourse analysis. Questions of concern here are related to what is being constructed, what is being problematized? Are these problems constructed as technical or social? What is being ignored or repressed? How has this come to be? What sorts of actions, practices, identities or subject positions are made possible, desirable, and/or required by the discourse and its way of understanding and representing the world? These questions bring to fore the relationships between power and knowledge in the smart grid, issues that carry across levels of governance and analysis. To analyze governance regimes at the national level, I draw on Hecht's $(2000,16)$ notion of technopolitics and the technopolitical regime - "linked sets of people, engineering and industrial practices, technological artifacts, political programs, and institutional ideologies, which act together to govern technological development and pursue technopolitics." Together with the analytics of governmentality (utilizing methods of Foucauldian discourse analysis), I not only tackle the sociotechnical nature of governance (i.e. technopolitics) but also the governmental logics and rationales created in these systems (i.e. governmentality).

Second, case study methodology is useful for drawing out intricacies of particular phenomena, such as experimentation with smart grid technologies. Relational comparative approaches (Ward 2008, 2010; McFarlane 2011; Robinson 2011) in case study methodology provides opportunities for greater external validity (generalization) and clearer illustration of differences and similarities, and importantly, contingencies in local processes. Explanatory models used to draw these relationships between cases reflect theorizations about space, place, and scale, and about the process of knowledge produc- 
tion and its relationships with urban development and governance (see each of the following chapters for further explanation and engagement with respective theoretical frameworks).

The relational comparative approach for case study methodology advocated by Ward (2010) has three key components relevant to this study. The first suggests that the city should be theorized as "open, embedded and relational," and as important elements of global systems, processes and flows that serve as, for example, "the 'laboratories' for policy formation and as arenas for the practising of state power" (Ward 2010: 482). The second concerns the dynamic and socially constructed nature of the 'city' scale. The third relates to the political aspect that the relational comparative approach takes in "speaking back" to established theories, and in asserting the context-specificity of theories to question their universalizing tendencies.

This leads to the third justification for this methodological entry. The comparative relational approach allows me to use comparison not to measure the cases developed in this dissertation against a universal 'yardstick' that shows difference and similarity. Instead, it allows me to trace how smart grid experiments are formed, how they are conceived, and how these are formed in relation to one another, through policy, knowledge, or broader urban processes. This allows particularities and specificities to come through "interrelations between objects, events, places and identities; and it is through clarifying how these relations are produced and changed in practice that close study of a particular part can illuminate the whole" (Hart 2002:14-15, quoted in Ward 2010:480). In this sense, examination of smart grid experiments in different contexts can help explicate the 
relationships between knowledge production, urban governance, and sociotechnical change.

Finally, each of my "axes" of inquiry - construction, experimentation, and diffusion - all require considerable attention in the literature, which in general lacks empirical examples related to the urban energy transitions, an area of increasing concern for urban infrastructure governance. Therefore, the case study methodology brings to fore examples and a better picture of the contingencies of processes of urban experimentation and policy mobility, and their implications for cities and urban governance.

The overall conceptual and analytical framework is guided by a "more political" sociotechnical transitions approach with attention to the national and local construction of smart grid discourse, the urban context of experimentation, and the geographies of policy (diffusion) related to "innovative" urban smart grid projects. This is represented in Figure 5 below. 


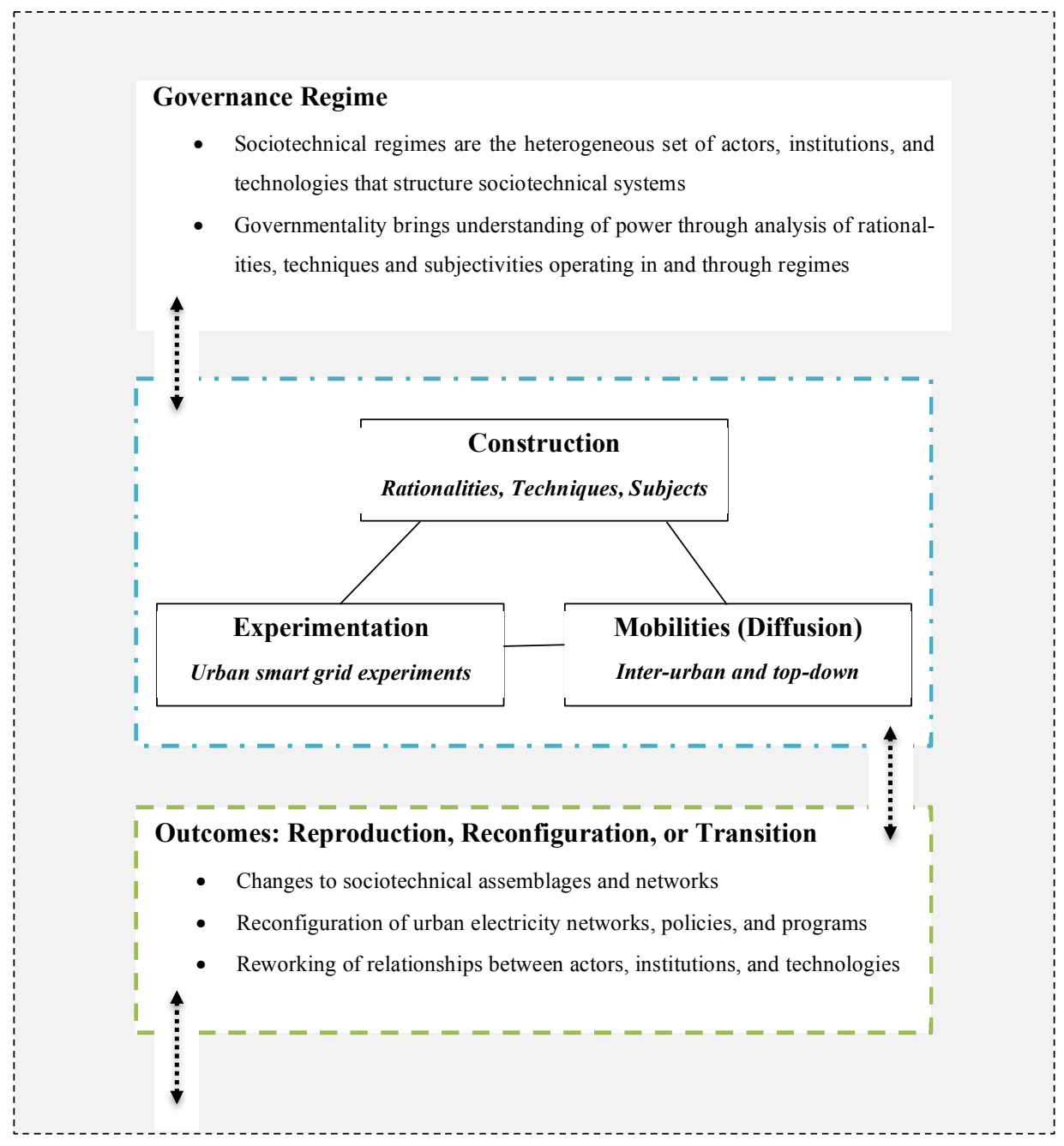

Figure 5: Overview of Conceptual Framework

I use the terminology governance regime referring to both a technopolitical regime (Geels 2014; Hecht 2000; Lawhon and Murphy 2012), and in relation to governmentality, wherein "regimes of truth and rationality" create the discursive field in which exercising governmental power is deemed rational (Lemke 2002). The technopolitical regime is similar to the concept of the sociotechnical regime from the literature on sociotechnical transitions in that it includes the laws, norms, regulations, discourses, and knowledge that 
give stability, power, authority, and legitimacy to particular configurations of actors, institutions, and technologies (e.g. Avelino \& Wittmayer, 2015; Geels, 2002; Moss, 2009). However, technopolitics entails a direct connection to politics and the materiality of technologies, or their material effectiveness, and is therefore a preferable concept for exploring the smart grid.

Different rationalities, techniques, and subjectivities are all important elements of governing the smart grid. In general, governing here means the "conduct of conduct," or "a form of activity aiming to shape, guide or affect the conduct of some person or persons" (Gordon 1991, 2). By rationalities, I mean the ways of or systems of thinking about the practice of government (who can govern, what governing itself is, and what or who is governed) as a way of making that activity itself thinkable and practicable (Gordon 1991; Lemke 2001; Lemke 2002). The concept of problematization in Foucault's work helps locate socio-political goals, or objects and reasons for governance, and positions them in relation to techniques and subjectivities. Foucault was specifically concerned with the problematization of population, for example, and this created political necessity and possibility for governmental thought: how to manage and govern populations within a certain territory (Foucault 2009). Techniques refer to the how of governing. For Foucault, this included disciplinary techniques, "techniques of power," or power/knowledge "designed to observe, monitor, shape and control the behavior of individuals" in a variety of institutions (Foucault 1977; Gordon 1991, 3). However, Foucault was concerned with multiple forms of power, and disciplinary power was only one element. Biopower, for Foucault, referred not to power over individuals, as in the penitentiary system, but power over populations, an essential element of his work on governmentality. In 
his later lectures on neoliberalism, Foucault argued that power also operated through forms of "freedom" in a neoliberal governmentality, that shaped the conduct of individuals through entrepreneurial and competitive mandates (Barry and Osborne 1996; Foucault 2010; N. S. Rose 1999). In other words, freedom was conscribed to "self-management" and introduced a new form of "self-regulation" always in relation to a broader set of norms that one either tried to distance themselves from or collapse onto (i.e. selfimprovement or responsibility). Central to each of these modes of power are particular subjectivities. That is, Foucault's interest in power was related to the ways in which it shaped subjects and proper conduct.

All of these elements - rationality, technique, subjectivity - add to the existing notion of the technopolitical regime an analysis of how governing actually happens and the forms of power on which it relies. This is particularly important in the smart grid because the smart grid not only entails a series of sociotechnical interventions, but itself is a governmental program to reshape relations of supply and demand in the electric power grid.

The governance regime influences and is influenced by the construction, experimentation, and diffusion of smart grid projects, policies, and knowledge. However, there is also an internal relation between construction, experimentation, and diffusion that influences the outcomes of smart grid development in different places. Outcomes may be either reproduction of existing regimes, reconfiguration of that regime where some dimension changes (for example the techniques or technologies), or transition of regimes. 


\subsection{Data Collection}

The data for this dissertation was collected over the course of the last two years. Data collection included semi-structured, in-person interviews, participant observation, and document review. Document (and other source media sources) review was used for discourse analysis and content analysis in the case studies. Interviews and participant observation were used for the case studies as well.

The primary source of data was collected during fieldwork in Austin, Texas, Boulder and Fort Collins, Colorado, and Oak Park, Illinois. I made three trips to Austin, one in October 2015, one in November 2015, and one in May of 2016, each for a period of approximately two weeks. In October of 2015, I travelled to Oak Park, Illinois for one week, and in November of 2015, I also travelled to Boulder and Fort Collins for approximately two weeks. During the course of this fieldwork I attended regulatory meetings, city council meetings, community meetings, technology demonstrations, and industry conferences. I participated in web-based meetings and reviewed and watched city council meetings and regulatory meetings where accessible. While in-person, I undertook participant observation, taking notes on the actors and discussions. I collected field notes according to the methods detailed in the Handbook of Ethnography. That is, written accounts and descriptions "that brings versions of these [new social] worlds to others" (2001, 352). Through transcription or inscription (Emerson, Fretz, and Shaw 2001) in this ethnographic context, reference back to meeting events and discourse was made possible. This proved insightful for numerous reasons. While participant observation was not a key source of data for my dissertation, it provided significant for orientation and direction and for conducting successful interviews and gaining insight into local issues. Dur- 
ing these meetings I had numerous informal discussions and even recruited interview participants, some of which I was able to record, and some not.

The key source of data for the case studies was developed from key informant interviews. Interviewees were (mostly) contacted beforehand to schedule meeting times during the travel period (example email letter in Appendix A). Anonymity was maintained to protect the identity of interviewees, however, many interviewees hold public positions with the cities. I conducted over 30 semi-structured interviews across all the cases. Austin was the central case study, where I spent most of my research time and conducted the most interviews. Interviews ranged from about 30 minutes to 90 minutes depending on the participant. Although I had a general interview guide, I customized questions based on the role of the participant. Interviewing an engineer with a municipal utility, for example, required different questions than interviewing a representative of an environmental group. Once I completed an interview, I transcribed it as soon as possible, taking notes on the content and themes. This was helpful in data analysis and coding. While I conducted over 30 interviews, only 24 were recorded due to the wishes of participants or the circumstances of phone conversations. In Austin, I interviewed 6 city officials with Austin Energy, the Austin Chamber of Commerce, the Office of Sustainability, 2 former Austin Energy officials, 2 former planning commissioners, 2 representatives of the Environmental Defense Fund, 2 representatives of the Austin Technology Incubator, 7 researchers at the University of Texas, 4 representatives of Pecan Street, 2 representatives of local development groups, 2 representatives of local media outlets, and 1 representative of the developer of the Mueller Development. In Boulder I conducted 2 interviews with city officials working in the Climate and Sustainability Division, 1 interview 
with a representative of a local technology company, and 3 interviews with local activists who worked on municipalization efforts. In Fort Collins, I interviewed 3 city officials with the City of Fort Collins Utilities and the Planning Department. In Oak Park, I conducted 1 interview with the Village Manager.

In-depth interviews allowed me to learn about the inner workings of each case study. I aimed to gather interview data that captured the experiences of key actors in each of the cities projects. I identified key actors by their roles in the projects, usually located in websites or in related documents. I further gained access to actors through snowball sampling and recommendations and connections through previous interviewees. While I was not able to interview some key informants due to geographical distance and participants' unavailability, I used document analysis as a supplement. Interviews were conducted in-person at the convenience of the interviewee.

I also collected secondary sources of data for both discourse analysis and the case studies. To start, I reviewed social science academic literature on the topic of smart grids, urban experimentation, smart cities, governance, and technology studies. This provided some insight into the ways that social scientists have studied, in a limited way, electricity networks at the national and urban and regional scales. While some studies have assessed the development of the smart grid at the national scale (Slayton 2013; Stephens, Wilson, and Peterson 2015), there has been little concern with a critical understanding of governance and experimentation. This presented an opportunity to develop a critical analysis of smart grid discourse and examination of case studies of smart grid experiments in cities. To collect data for the discourse analysis I followed the methodology laid out by Hajer (1995), Fairclough (2013), and Waitt (2005). Data collection for discourse analysis is 
informed by my research goals, which are to answer the research questions above. In particular, I wanted to understand how "dumb" grids were becoming "smart," and what sorts of problematizations of the electric grid required smartening. This accompanies both the techniques for making the grid smart and the subjects involved this construction. In other words, I was attempting to answer the "what, how, and who" questions (which are interconnected in the framework of governmentality) while illuminating the "why" questions for further analysis in the case studies.

Collecting data for discourse analysis includes identifying genres, audiences, and the places, texts, and authors. I collected over 400 documents of different genres and aimed at different audiences in different places. Document sizes ranged from 1 page, with for example a key website, to over 300 pages in the case of the Energy Independence and Security Act. The document coverage ranges from the late 1970s to 2016. Most documents were created within the last 10 years. For example, I not only collected documents produced by the Department of Energy for its smart grid program, but I also analyzed political speeches by President Obama, transcripts of congress hearings on smart grid cybersecurity, the feedback of industry to the government in requests for information, utility smart grid program websites, industry journals, and whitepapers of smart energy technology companies. In general, in keeping with the constructivist tradition, I chose "rich" texts from primary actors in smart grid development and testing. Richness, as Waitt $(2005,222)$ describes, refers to the depth of texts detail allowing the researcher to interpret the "effects of discourse in normalizing understandings." This means that while I was interested in the messaging on websites, I found industry whitepapers, journal articles, and other "insider" talk useful for understanding how the smart grid was being de- 
veloped and implemented by technology, research, and government leaders. While I identified key actors in smart grid development, I remained reflexive to ongoing discourse analysis and inter-community referencing, such as the Department of Energy reports citing particular economics and engineering literature. This allowed me trace links in epistemic communities and highlight dominant discourse.

I collected documents with internet and database searches. I utilized search terms that related to each of the key components of the analytical framework: what (rationalities), how (techniques), and who (subjectivities). Based on prior knowledge, experience, and interest in the topic of the smart grid, I found that many smart grid programs were being discussed in relation to making the grid more reliable, secure, efficient, and "green," all of which is performed through managing demand and supply (see Chapter 3). Demand management, involving various end-uses across sectors, and distributed generation positioned the study of smart grids to include customers of utilities. This made helped me narrow many of my searches related to smart grid activities by including terms such as: customer, consumer, end-use, demand, demand management, demand response, renewable generation, distributed generation, and distributed solar. I also, as mentioned before, looked through citations to find further connections between discourse actors. 
Table 2: Discourse actors, by sector, and document types analyzed in Chapter 3

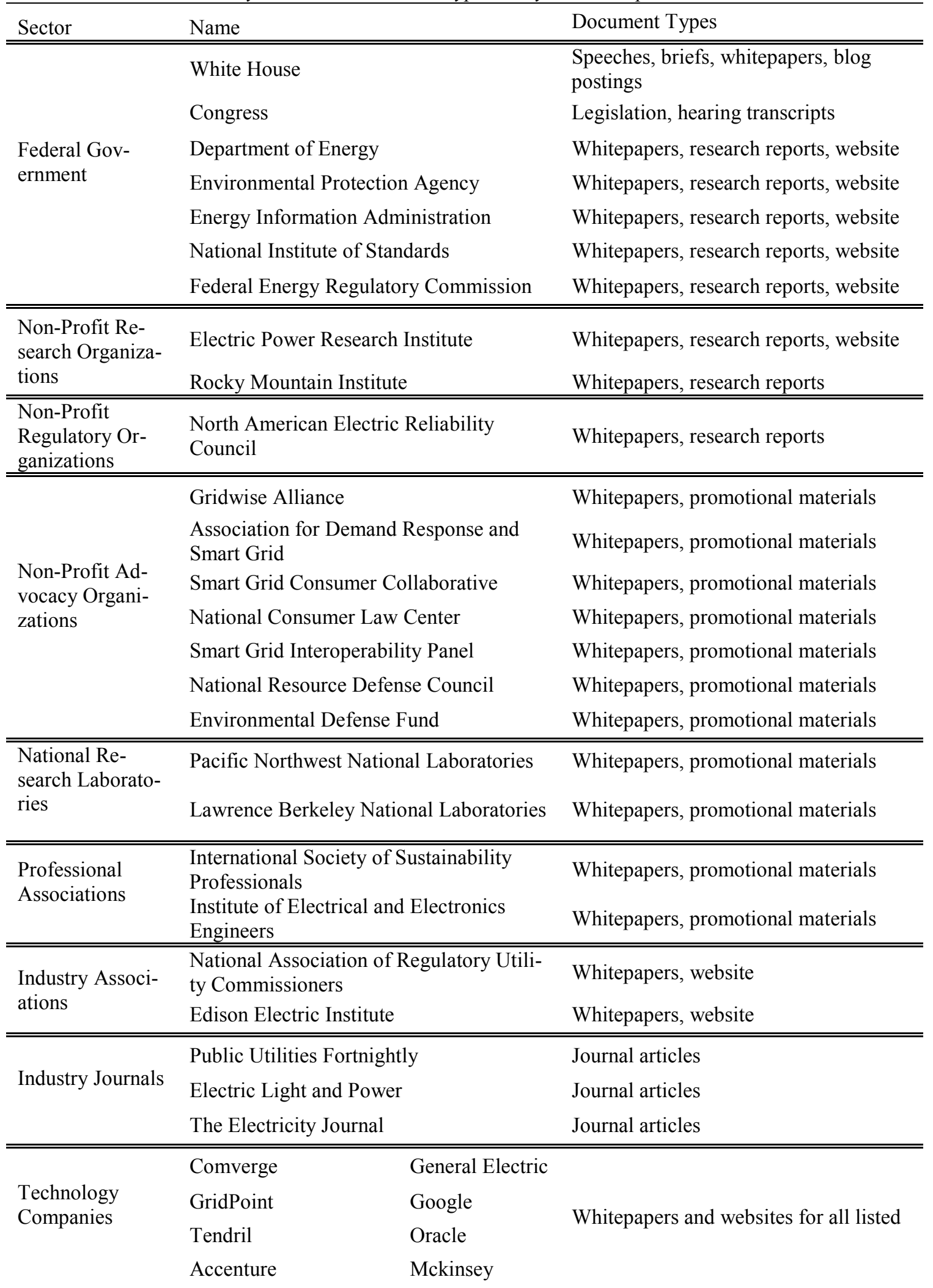




$\begin{array}{ll} & \text { Silver Spring } \\ & \text { Networks } \\ \text { Deloitte } & \text { Texas Instru- } \\ & \text { ments }\end{array}$

\subsection{Validity and Reliability}

I addressed and ensured validity and reliability of the data through several strategies. The first was the inclusion of multiple sources of data. I also used "chains of evidence" and asked follow-up questions to key informants to ensure construct validity. Secondly, during data analysis, the method of constant comparison helped address alternative explanations, which helped me ensure internal validity. Third, I addressed external validity through the use of existing theory and multiple cases. Reliability was ensured through the creation of a database for each case study (Yin 2003).

\subsection{Data Analysis}

I began to analyze data nearly one year ago. This primary data analysis included developing a database of documents in MaxQDA12 software organized by genre, date, and source author. I also began to develop an initial coding scheme at this time, which changed as I worked through further documentation and learned more about the smart grid discourse. My coding scheme was influenced by the analytical framework focusing on problematization, technical devices, and subjects of discourse. I also used thematic analysis in an ongoing process of coding, reflection, and revision. I continued to collect data for both cases and discourse analysis while I was coding and analyzing. This iterative, "constant comparison" (Merriam, 2009, p. 30) involves the comparing of one segment of data with another as its collected to determine similarities and differences. 


\subsubsection{Discourse analysis}

In Chapter 3, I utilize Foucauldian-inspired critical discourse analysis to bring about the understandings of each text analyzed, about its production, authors involved, and intended audiences. There are, in general, two types of discourse analysis: critical and descriptive. Critical discourse analysis is the more applied version for use in understanding issues related to cities, planning, environment, policy, technology, and power (Bacchi 2000; Caprotti 2012; Cotton and Devine-Wright 2011; Hajer and Versteeg 2005; Hastings 1999; Jacobs 2006). Discourse analysis has an explicit focus on power and social networks that create discourses that are taken as knowledge and truth. This insight directed me to look for dominant discourses to focus on how they constructed arguments and social facts about smart grids, their abilities, and their benefits. Basic questions that guide this approach included: Who made the text, with what technology, and with what intended audience? Who commissioned the text, who owns it, and who disseminated it? Why was the text made and where was it made? These questions about the production of texts led to questions about the circulation of texts: Was this text recirculated or reproduced elsewhere? How does the audience change in circulation and with what effects?

These questions guided my collection and analysis of texts. I coded the texts to structure and interpret the data. I coded in two main steps. First, I open coded the text to quickly analyze the data getting the descriptive elements while also taking notes and memos to generate questions and reflections for more analytical coding. I followed Cresswell's $(2009,186)$ notion of coding, which “involves taking text data or pictures gathered during data collection, segmenting sentences (or paragraphs) or images into categories, and labeling those categories with a term." Essentially the first step of coding 
was a content analysis aided by MaxQDA12's lexical search function. This looked for the instances of main themes of concern, such as consumer engagement and customer segmentation for demand response. I also coded for what Waitt $(2005,231)$ describes as four key categories for Foucauldian discourse analysis: context, practices (events, interconnections, and actions), attitudes, and experiences. This led to a second stage of coding, or analytical coding. This involves abstraction and reduction in the generation of interpretive themes in relation to the analytical framework described above.

The outcome of the analytical coding I performed was the development of key themes related to the discursive structures that underline the mutual relationship between power and knowledge. For Foucault (1980, p. 131), power and knowledge are mutually reinforced in "regimes of truth" that induce the effects of power:

Truth isn't outside power, or lacking in power ... Truth is a thing of this world: it is produced only by virtue of multiple forms of constraint. And it induces regular effects of power. Each society has its regime of truth, its 'general politics' of truth: that is, the types of discourse which it accepts and makes function as true; the mechanisms and instances which enable one to distinguish true and false statements, the mean by which each is sanctioned; the techniques and procedures accorded value in the acquisition of truth; the status of those who are charged with saying what counts as true.

This is important in shaping how I coded the texts and my focus. The important analytical element here are discursive structures, or discursive order, or rules by which discursive practices are regulated and through which object and subjects are constituted as communicable and thus governable in society (Hajer 1995). Discursive structures are both historically and spatially contingent, operating in ways that shape the realm of possible ways of being and becoming in the world through the establishment of norms, attitudes, and practices. Here, then, social power is subtler than violent or juridical power, but still 
operates as a mechanism of social control through the application of knowledge by institutions and the normalization of particular understandings of the world.

I followed Hajer's (1995) definition of discourse coalitions and storylines to analyze the, in part, the governance regimes discussed above. Hajer $(1995,62)$ defines storylines as "narratives on social reality through which element from many different domains are combined and that provide actors with a set of symbolic references that suggest a common understanding." Storylines here link discourse to particular regimes. They are "political devices" that enable users to reduce discursive complexity into simple problematizations that enable solutions, such as technological fixes. They are also ways to stabilize meaning and reinforce knowledge/power relations. Storylines, thus, are important political resources for technopolitical regimes in maintaining and reinforcing power.

\subsubsection{Case study analysis}

Case study methodology involves design, data collection, and data analysis. In Chapter 4, I utilized an abduction approach that results not in theory but phronesis (Flyvbjerg, Landman, and Schram 2012; Thomas 2010; Thomas 2011). This means, that for a case study approach, the focus is on narrative and interpretation. Thomas (2010) offers several guides for this sort of modest approach to case study analysis: questioning and noticing reveals insight for interpretation; heuristic and incremental "chunking" that, similar to Yin's (2003) chains of evidence, building a story through multiple sources of information; narrative diachronicity which brings history as an essential element (even brief history); particularity which brings focus not to existing theory but the case itself; 
intentional state entailment that brings focus to beliefs, desires, and values; counterfactuality to assess where a case may diverge from expectations; context sensitivity; and analogy, which is particularly relevant to the policy mobilities approach to case studies.

Analysis of case study data involves content analysis and discourse analysis, as described above, but can also be viewed itself as a form of analysis of deep particularity and description of a narrative about a particular object of inquiry. Theory here is not a means to an end, but rather a way of reaching explanation. Certainly, however, the case study approach may help to build theory or test it. In Chapter 4, I utilize what Thomas $(2011,514)$ calls a key case, which is important because of its "capacity to exemplify the analytical object of inquiry" (urban smart grid experiments). It is also related to the analytical frame from which the case is viewed, and in this case is both of intrinsic interest and illustrative purpose.

In Chapter 5, I followed the distended case approach advocated by Peck \& Theodore (2012), coupled with methodological insights from policy mobilities literature more broadly (Cochrane and Ward 2012; McCann 2011b; McCann and Ward 2011; McCann and Ward 2012b). To do this, I "followed" the experts from Austin's smart grid experiment to other locations, tracking their roles in mobilizing different models for urban smart grid experiments. This involves relational analysis of multiple research sites. Genealogical and discourse analyses, as described above, play an "indispensable role in the deconstruction of traveling policy technologies and texts, and the lineages and networks with which they are associated" (Peck and Theodore 2012, 23-4). To do this analysis, I interviewed key informant actors involved in mobilizing policies (on both sides of the equation, supply and demand), and mapped the multi-sited processes by which the 
rationales and rationalities for smart grid experiments were constructed and reconstructed (through analysis of interview and document data). The distended case approach builds on Burawoy's extended case method (Burawoy 2009) and multi-sited ethnography, but is exploratory and suggests that focus needs to be on the how of projects' success (Peck and Theodore 2012). Important here is the selection of cases, which in Chapter 5 are intrinsic and exploratory, calling for the possibility of extending and reworking existing theories as the policy mobilities approach entails. I utilize a form of process tracing and theoretical reflection within a dominant mode of understanding sociotechnical transitions in urban energy systems, for example.

\subsection{Role of the Researcher}

My role in this research may have undoubtedly impacted the study. Factors such as why I chose to conduct this study and my preconceived notions certainly impacted what sorts of issues I noticed and didn't. I tried to maintain an open mind, however, and remained reflexive in my processes of evaluation and interpretation. My interests in the project and my passion played a role in my topic selection. This being said, I also situated my work within an existing corpus of intellectual and scholarly work on the topic or similar topics. The approaches and methods I used are proven methods for qualitative research. Although some scholars may disagree with certain elements of my interpretation of the data, I followed methodological consistencies to ensure reliability.

\subsection{Ethics}

This research was carried out with the approval of the Human Subjects Research Review Committee at Portland State University (HSRRC Proposal \#153371). 


\section{Chapter 3: Making Grids Smart, Making Smart Consumers}

\subsection{Introduction: Smart Grids and Electricity System Change}

In the face of challenges of low-carbon transitions, energy security, and aging infrastructures, new programs for the development of smart electricity networks are being proposed by utilities and public authorities alike. The "smart grid," as it has come to be called, refers to the implementation and integration of digital information and communication technologies, sensors, controls, and software that control the electric grid and monitor it in real time. The smart grid allows greater integration of renewables, distributed generation, and energy storage while increasing the flows of information to utilities and their customers. These new technologies enable new models and logics for organizing electricity production, transmission, distribution, and consumption, often with a "more active" role for consumers. As such, the smart grid is often portrayed as a necessary step for sustainability, resilience, reliability, and growth. It responds to a series of problematics that cities have been increasingly responsible for quick response: climate change, economic decline, resource constraints. But in the changing landscape of electricity production, transmission, distribution, and use, the smart grid has come to mean a variety of things to a whole array of different actors at different levels. With sociotechnical change, there is the possibility for new norms, conventions, and forms of governance to arise. As such, with new technological interventions such as the smart grid, different visions and goals come to fore, igniting policy action but also barriers to change.

The term smart grid itself, has come to mean everything related to electricity system improvements and change, a "catch-all phrase" that represents the potential benefits 
of a revamped and "modernized" electricity system that fills several societal expectations related to efficiency, reliability, and sustainability. Smart grids are more than singular technologies, but represents a networked electrical system enhanced with a variety of technologies and visions. Smart grids are complex, involving a diversity of social actors, multiple guiding visions, and multiple possible sociotechnical configurations. This presents a need to understand the social and political context of smart grid development and the ways in which the smart grid technology is positioned to fulfill changing social expectations of electricity systems. The variety and diversity of actors and organizations who control and influence smart grid development, and who benefit from smart grid changes is of utmost concern.

Electricity systems are composed of interlinked technologies, social practices, people, organizations, and thus electricity system change is sociotechnical and political. The discourses of the smart grid highlight the visions and social expectations for electricity system change. Discourse expresses the interrelations between language, knowledge, and power. Analyzing discourse elucidates these interrelationships, and highlights how electricity system change enables or disables particular visions for smart grid development. At the same time, discourse also enacts particular kinds of governmental rationales and shapes subjective positions of various actors in the smart grid. This has tremendous implications for governing electricity system change. This chapter uses theories of governmentality to understand the ways in which smart grids are shaping new forms and relations of energy practice and conduct that are central to the actual implementation and realization of smart grids. 


\subsubsection{Demand, smart markets, and smart end-users}

President Obama believes in the need to transition to a cleaner, more reliable, and affordable 21 st century power grid. Under his leadership, transformations in how we produce and consume electricity are decreasing carbon pollution, scaling up renewable energy, and generating savings on consumers' energy bills. Since 2009, renewable energy generation has increased at a record pace, while costs have decreased dramatically. Building on this progress, smart electricity market reforms, enhanced transparency, and flexible energy resources such as storage and demand response have the potential to further accelerate the development of a cleaner and smarter grid. (The White House Office of the Press Secretary 2016)

As I was writing this chapter, a "fact sheet" emerged from the White House detailing the agenda and goals of the "Summit on Scaling Renewable Energy and Storage with Smart Markets."1 The fact sheet details the commitments of the federal government, utilities, municipalities, energy developers, and regulators to achieving an additional 1.3 GW of energy storage over the next five years. This (relatively) massive technological change promises a reinvention of the way we produce and consume electricity to decrease carbon pollution and save consumers money. Energy storage is just one element of a "smarter grid," but has been heralded as the saving grace for making (centralized and distributed) renewable energy integration possible (Nasiri 2008; Harris, Meyers, and Webber 2012; Dunn, Kamath, and Tarascon 2011). Energy storage is one way to address the challenges of matching supply and demand at any given point of the day, especially as there are increasing amounts of intermittent or variable sources of renewable energy.

\footnotetext{
1 White House Press Release," FACT SHEET: Obama Administration Announces Federal and Private Sector Actions on Scaling Renewable Energy and Storage with Smart Markets," June 16, 2016: https:/www.whitehouse.gov/the-press-office/2016/06/16/fact-sheet-obama-administration-announcesfederal-and-private-sector
} 
Storage technologies also offer an opportunity to smooth out the ever dynamic and pesky demand curves that plague energy planners and dispatchers. They offer a way out of the problematic "duck curve"- a demand curve shaped like a duck because of overgeneration during off-peak periods due to the growing adoption of solar energy technologies (Denholm et al. 2015). The mismatch of supply with peak periods of demand offers an opportunity for smart energy storage technologies to re-align "supply" with the peak period of demand.

Electric load curve: New England, 10/22/2010

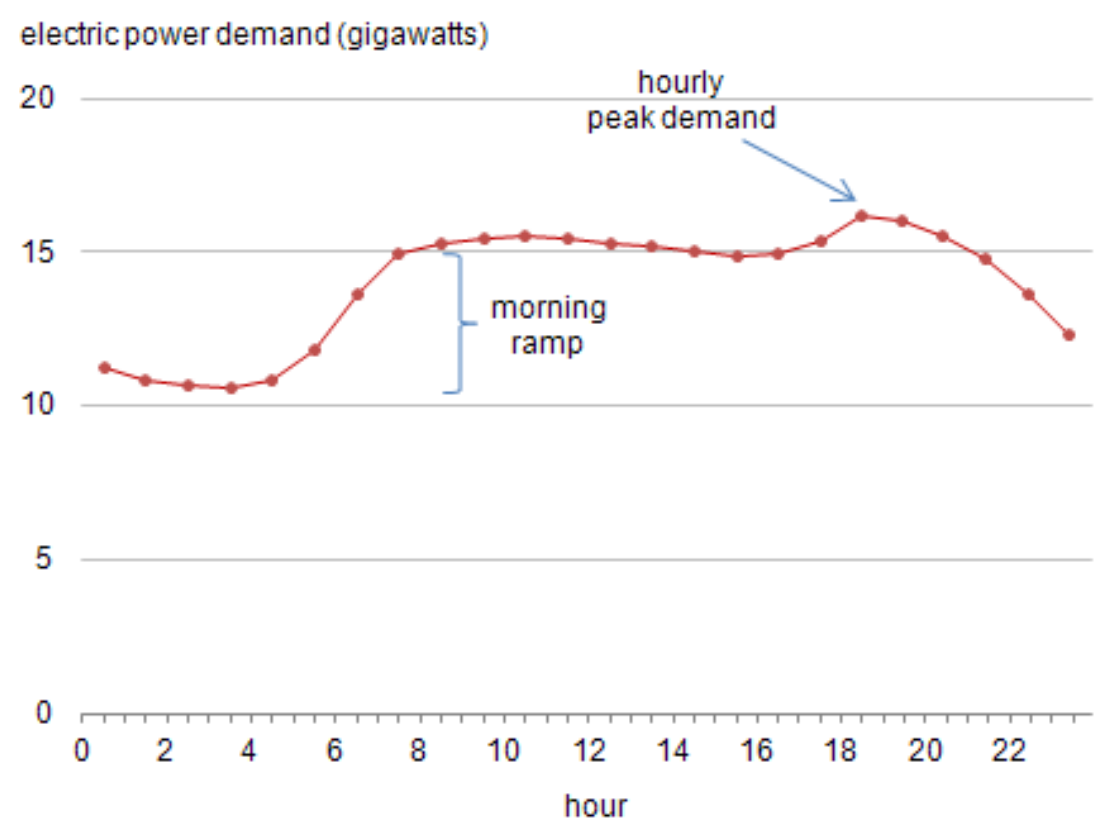

Figure 6: Example of an electric load curve (Source: US EIA http://www.eia.gov/todayinenergy/detail.cfm?id=830) 




Figure 7: CAISO Duck Curve (Source:

https://www.caiso.com/Documents/FlexibleResourcesHelpRenewables_FastFacts.pdf)

The White House Executive Council of Economic Advisers released a report accompanying the fact sheet, which explains the role of "smart markets" in developing integrated solutions for managing the electrical grid and matching supply and demand. ${ }^{2}$ The authors stress the uses of energy storage technologies to allow electricity to be released "during times of high value" (p. 2). The duck curve is discussed not as a problem, but as an opportunity for "grid management services" made possible by many new smart technologies - demand for grid management services to offer to grid operators and utilities in a smart market with the "correct" market structure and design. But in the section of the report detailing "new expanding opportunities for emerging technologies" the authors

\footnotetext{
2 "Incorporating Renewables into the Electric Grid: Expanding Opportunities for Smart Markets and Energy Storage," June 2016, https://www.whitehouse.gov/sites/default/files/page/files/20160616_cea_renewables_electricgrid.pdf
} 
suggest that smart markets and technologies also help to enable or even construct the "smart end-user."

Advances in smart markets and, in particular, the smart end-user, hold promise to help flatten the net load curve, allowing for demand to respond to spikes in wholesale prices due to the intermittency of VERs [variable energy resources] or the higher costs of ramping to meet demand increases. $[\ldots][\mathrm{N}]$ ew enabling technologies, including communications technologies, smart meters, smart inverters, and other smart grid technologies [...] have the potential to greatly facilitate the response of electricity demand to changes in price (i.e. demand response). (p. 26-27, italics added)

The enabling technologies described here refer to industrial, commercial, and residential applications. Certainly, demand response programs have been successful in many industrial settings where industrial processes can be altered or carried out at another time to shift demand to times that work better for grid operators and offer much cheaper rates for industrial users during these off-peak times (e.g. EnerNoc provides a business model for this approach).

In residential settings, the Council of Economic Advisers discuss the role of smart meters and information in shaping electricity consumption behavior, suggesting that these technologies will help consumers respond to demand response pricing events (i.e. lower energy consumption at high prices during peak demand periods). As the report explains further,

Smart meters, as well as other devices to provide information to customers (e.g., "energy orbs" that light up during times of peak prices), have been shown in randomized controlled trials to further help focus consumer attention on reducing energy use at times when prices are high, increasing the elasticity of demand for electricity. [...] Developments in smart appliances may eventually lead to a "smart home" that allows consumers to shape energy consumption patterns - and adjust them during times of higher prices. ( $\mathrm{p} 29$, italics added) 
Although the report was focused on issues related to markets to allow integration of renewable generation and smart technologies into the grid, the focus on economic aspects of consumption behaviors of residential users points towards a deficiency in the approach to understanding electricity demand. If the goal is for "demand to respond," then shouldn't we better understand demand? Is demand completely about price elasticity and economic motivation, or something else such as collective understandings, norms, culture, routines, habits, lifestyle preferences, devices, and infrastructures? And if it's the latter, then why does the economic logic still dominate?

Economic perspectives on changing demand is not unique to the White House, DOE, NREL, or other governmental organizations, but it is present in a variety of public discourses about the smart grid. From environmental NGOs to technology companies to the media, the overwhelming focus of public discourse is on the ways both smart technologies and economic rationalities will "help" or "empower" consumers to reduce their energy consumption. This chapter documents and analyzes this recent discourse and asks why it pervades and with what implications for governing energy use. I highlight the dominant mode of describing, analyzing, and theorizing energy consumption and behavior in policy and related public smart grid discourses. I also detail the broader discourses that suggest the smart grid will offer a range of solutions to a variety of economic, social, and environmental problems. It is this set of discourses which make up a "hegemonic" or dominant discourse that solidifies and reifies relations of power. I take a Foucauldian approach to discourse analysis, which highlights how particular discourses are privileged in support of certain knowledges. I use this analysis and theories relating to technopolitics 
and governmentality to interpret and understand how "smart" energy governance operates in a thoroughly "neoliberalized" world.

To situate and understand the development of the smart grid, the next section provides a brief history. I highlight how national energy policy and technological change influenced the electricity industry. Restructuring policies aimed at deregulating the industry brought forth a need for adapting electricity infrastructure and technologies to meet the demands of free-market ideologies. At the same time, these technologies were already being developed and deployed to help maintain reliability and efficiency. The early efforts for reliability and efficiency were central to the implementation of microcomputers in electricity infrastructure. As microcomputers were used more to manage the generation, transmission, and distribution systems, more data collection and communication networks were developed on top of the existing physical electrical infrastructure (Slayton 2013). The development of these networks were carried out regionally by utilities and by regional transmission operators (RTOs) or independent service operators (ISOs). Local solutions to meter data collection, for example, were developed to allow automatic meter reading systems to increase the speed at which meter data could be collected for billing purposes - these were the antecedents of the "smart meter." Energy efficiency, demandside management, and other consumer-oriented solutions developed in a parallel and intertwined history. These interactions are considered as the foundations for many smart grid programs now underway, such as demand response and behavioral energy efficiency programs. 


\subsection{The Politics and Governance of Sociotechnical Systems}

Electric power networks (and energy systems more generally) are the study of considerable historical, geographical, and STS scholarship. Historical perspectives on electrification, the diffusion of electrical technologies and innovations or the management of electricity infrastructures help highlight how these networks are much more than technical achievements. Thomas Hughes groundbreaking study, Networks of Power, details a 50-year history of electrification from 1880-1930 in the US, UK, and Germany. In this work, he elucidates the sociotechnical nature of large technical systems (Hughes 1983). He advances the idea that in addition to technological artifacts - generating stations, lamps, relays, etc. - local, regional, and national political structures, societal needs (both constructed and construed), geographical and environmental factors, and so on, are actually just as much constitutive of the electric power systems he analyzes. The form of the system, it's "technological style" (Hughes 2012: 62) is shaped by all of these factors. It explains the variation in electric power system development across the US, UK, and Germany, for example. At the same time, these technological systems shape and contort these social, political, cultural, and geo-environmental factors.

Perhaps more than any other scholar of electricity networks, Hughes has inspired a variety of intellectual trajectories and put the analysis of sociotechnical systems at the heart of urban infrastructure studies. His influential work here is important as it documented how the electricity grid was understood as it was initially developed and gained "momentum" as a fundamental technology of modern (urban and rural) life (Hughes 1983). Whereas David Nye (1992) focuses on the social and cultural aspects of electrification from 1880-1940, he channels Hughes notion of technological momentum as a bal- 
ance to the dualism of constructivism and determinism in understanding the development of electrical technologies. Telling vivid stories on the impacts of electrification on nearly every element of American life, Nye provides another useful framework for analyzing how electricity and electric power networks generated social meaning across a variety of contexts and was sold as a symbol and harbinger of modernity and progress. But as Nye (1992: 390) notes, people didn't merely use electricity, “[r]ather, the self and the electrified world have intertwined." Electricity consumption became constitutive of new forms of subjectivity and life itself.

Technology studies, in general, examines, in its best instances, the mutual construction of technology, politics, and culture. While these are broad categories necessitating further specification for any particular study, it is useful to think broadly about the interconnections between technology, culture, and politics. As Gabrielle Hecht (2000: 10, emphasis in original) explains, this enriches our explanations of technology: "Opening the black boxes of culture and technology simultaneously can (for example) give us insight into how technologies constitute a terrain for transforming, enacting, or protesting power relations within the social fabric." It is this possibility of enhancing technology studies that informed Hecht's version of technopolitics.

Hecht (2000: 15) study of sociotechnical systems focused on technopolitics as a methodological and conceptual tool that refers to the "strategic practice of designing or using technology to constitute, embody, or enact political goals." But technopolitics are more than just politics. They entail a material reality of the technologies themselves and the effects technology produces in the material world. This of course limits the possible technopolitical configurations available to those engaging in technopolitics. It suggests 
that the "material effectiveness of technologies can affect their political effectiveness" (Hecht 2000: 15-16). And further, technologies are important specifically because they enable and are enabled by the practices, knowledges, and expertise of technologists that give these actors particular kinds of authority and legitimacy.

This framing of technopolitics offers a way to understand technologies in social and political context, not only as co-produced, but also as tools and means through which forms of power and agency are realized, usually to achieve some political ends or goals. A key component of technopolitics are technopolitical regimes grounded in institutions and "consist of linked sets of people, engineering and industrial practices, technological artifacts, political programs, and institutional ideologies, which act together to govern technological development and pursue technopolitics" (Hecht 2000, p. 16). Technopolitical regimes work towards shaping technological systems - in Hecht's case nuclear power - from different institutional contexts with distinct ideas of the Hughesian technological styles they desire. The metaphor of regime is useful in the way it expresses an idea of who governs, their ideologies, and the ways they exert power (Hecht 2000, see also Blanco 2013; Geels 2014).

\subsubsection{Regimes of government}

Sociotechnical regimes are understood mainly as "rules" (Geels and Kemp 2007; Geels 2007) that guide and orient activities of social groups who maintain and refine sociotechnical systems. Rip and Kemp (1998: 340) explain that these technological regimes are "the rule-set or grammar embedded in a complex of engineering practices, production process technologies, product characteristics, skills and procedures, ways of handling 
relevant artifacts and persons, ways of defining problems; all of them embedded in institutions and infrastructures." As such, regimes make and shape and influence, and are hard to change. In the MLP, socio-technical regimes include scientists, users, policy makers and societal groups outside technical fields. These social groups interact and form networks with mutual dependencies (Geels 2007).

These regimes are the meso level of the MLP, niches are the micro level, and the sociotechnical landscape is the macro level. The sociotechnical landscape is exogenous, outside the direct influence of actors (Geels 2007). It is heterogeneous and includes issues such as economic growth, cultural and normative values, environmental problems such as climate change, and resource scarcities. It is also the large scale "material context of society, e.g. the material and spatial arrangement of cities, pervasive technologies, etc." (Geels 2007: 443). Niches may be thought of as the loci of innovation. They are the micro-level phenomenon, and often are "protected" spaces, or "incubators" for new technologies that protect them from market or societal pressures. In Chapter 4, I focus on the applicability of this framework and offer a critical approach to the MLP framework for sociotechnical transitions (Geels, 2000, 2002, 2007) by considering the political implications of these "niches" as they infiltrate the urban fabric as urban experiments.

The regime concept is foundational in the studies of sociotechnical systems and technological change (Rip and Kemp 1998). However, both Hecht's technopolitical regime and Geels sociotechnical regime do not fully account for the complex and diffuse forms of power that create the rationalities, techniques, and subjectivities needed to govern sociotechnical systems. While the sociotechnical regimes concept includes a variety of social, cultural, and technical factors, it stops short of explaining how different gov- 
ernance regimes come into being and how they configure "roles" for different actors in the system. Rather its assumes agency dictated by structured and hierarchical forms of power. Similarly, Hecht's conception of technopolitical regimes focuses heavily on the political role of shaping a national identity around different sociotechnical system, i.e. political power, and spends less concern on the way governance of these systems is enacted in and through regimes of technologies, people, institutions, and political programs, i.e. governmental power. Governmentality helps establish and explain the how of governing, and marks an essential task for understanding power and governance in sociotechnical systems.

The regime concepts outlined above takes rather broad categories - technology, politics, culture - and suggests they're co-produced and intertwined. It also suggests that technologies have an important agential role in shaping social organizations, institutions, and practices. The benefits and costs realized through the construction and implementation of sociotechnical systems are not equally distributed, which suggests a potential for politics. Decades of scholarship in STS has also clearly elucidated the political nature of science and technology, from visioning and imagination to application and use (Winner 2010; D. A. MacKenzie 1993; Bijker, Hughes, and Pinch 1987; Jasanoff 2004a). Questions of politics are interested in who wins and who loses from the outcomes of sociotechnical change. Yet, this is decided through the access to and control over various forms of knowledge, expertise, and authority that sway persuasion, cooptation, or coercion necessary for political power. However, the question of power in regimes, their ability to shape socio-technical systems and their relation to broader "landscape" issues are less well studied. 
Geels (2014) more recently has attempted to address power in regimes to explain resistance. He suggests that studies of instrumental, discursive, material, and institutional power and their relation to political economy can help provide a better understanding of how regimes reinforce particular sociotechnical configurations and resist change. Geels $(2014,29)$ discussion of discursive power begins to address "what is being discussed (setting agendas) but also how issues are discussed." Geels $(2014,29)$ suggests that an analysis of framing can show how the manipulation of discourse enhances the legitimacy of regimes: "a) diagnostic framing, which identifies and defines problems; b) prognostic framing, which advances solutions to problems; and c) motivational framing, which provides a rationale for action and serves as a 'call to arms'."

Geels (2014) conception of power here is concerned with a "center" of power, solidified in incumbent sociotechnical regimes, wielded to create resistance to challenges, creating lock-in and technological momentum. While there certainly is this form of power operating in sociotechnical systems, more diffuse forms of power must also be considered.

One promising approach to address these limitations suggests that a "Foucauldian-inspired analysis of governmentality and liberalism, as political regime, provides theoretical resources with which we can begin to think about the crucial question of the interaction between specific socio-technical systems and broader power regimes" (Tyfield 2014, 592). Furthermore, Tyfield $(2014,593)$ explains, "the focus on power relations mediated via knowledge and measurement technologies also alerts us to the possibility that the key technological issue for a [sociotechnical] transition may well not be in the technologies (i.e. machines) [] per se, but rather in how these interact and coordinate 
amongst themselves and the power-knowledge technologies they must integrate for this to be possible." I take these criticisms into account in my analysis of "governance regimes" in the conceptual framework for this dissertation, utilizing theories of governmentality to focus on governmental rationales, techniques, and subjectivities.

In a governance regime, the dynamics of sociotechnical systems change entails broader consideration of what are typically considered "landscape" factors: cultural norms, everyday practices, and political economy. This allows for a better account of forms of disciplinary power and biopower, what Foucault broadly termed the "power over life" (Foucault 1990). This form of power focuses on the norm and normalization as the central "technology of power" and the enabling effects of power through optimization of the body (disciplinary) or the population (biopolitical). This form of power acts to manage the "average" to promote consistency in a population, eliminating outliers or what Foucault (1990) calls "aleatory events." Biopower is enabled by the statistical surveillance of populations, and reinforces trends or what is "normal" and acceptable conduct. Managing this conduct, or more generally the "conduct of conduct" is the simplest definition of Foucault's notion of governmentality (Li 2007a).

The central point is that governing sociotechnical systems and transitions is also about governing people and practices. Governmentality, then, fills a necessary role in understanding how governing populations is central to enabling the smart grid, which has the central goal of changing the rhythms and temporalities of energy demand. 


\subsubsection{Analyzing governance regimes: rationalities, techniques, subjectivities}

In his lectures at the Collège de France, Foucault developed the concepts of governmentality, biopolitics, and neoliberal subjectivity as ways to understand power and the “art of government" (Foucault et al. 2003; Foucault 2009; Foucault 2010). Although these works were actual lectures, not intended for eventual publication, they have inspired a plethora of disciplines and a field of Foucauldian scholarship. Governmentality studies has arguably itself grown as a "field" within academic scholarship (Foucault et al. 1991; Bricking, Karman, and Lemke 2010; Brady 2014).

Governmentality has been defined in numerous ways, but Foucault (2009:144) describes it generally as three things:

First, by "governmentality" I understand the ensemble formed by institutions, procedures, analyses and reflections, calculations, and tactics that allow the exercise of this very specific, albeit very complex, power that has the population as its target, political economy as its major form of knowledge, and apparatuses of security as its essential technical instrument. Second, by "governmentality" I understand the tendency, the line of force, that for a long time, and throughout the West, has constantly led towards the pre-eminence over all other types of power - sovereignty, discipline, and so on - of the type of power that we can call "government" and which has led to the development of a series of specific governmental apparatuses (appareils) on the one hand, [and, on the other] $\dagger$ to the development of a series of knowledges (savoirs). Finally, by "governmentality" I think we should understand the process, or rather, the result of the process by which the state of justice of the Middle Ages became the administrative state in the fifteenth and sixteenth centuries and was gradually "governmentalized."

In this definition, Foucault stresses the complex assemblage of actors and technologies involved in the management of populations. Political economy is the governing knowledge, providing the dictates of the state and the market according to principles of liberalism. Security "apparatuses" are the technologies of power that shape the field of 
possible action for the population for the sake of wellbeing or liberal values. The infamous definition of governmentality as the "conduct of conduct" here refers not to the disciplinary focus of early Foucault (1977) that pitted freedom and power in opposition, but extends the notion of power in a "positive" way such that liberal freedom is seen as a mode of power (Rose 1999). In this way, the agency of individuals contributes to the overall impact of governance.

The concept of normalization also differs between discipline and security; whereas discipline used normalization to separate normal from abnormal in individuals, security establishes an overall statistical norm for a population and then produces a norm based on rational, calculative techniques to regulate normal and rational conduct of the population (Elden 2007). Foucault here also refers to a historical process of "governmentalization" which refers to the many "problems of government" and the specific practices of government within the institutions of the state that respond to these problems (Jessop 2007). The "art of government" is concerned with the population - not a single body but still tends to focus on the minute and seemingly mundane techniques of producing subjectivities that control the behavior of the collective(Foucault 2010; Lemke 2001). Governmentality is not only the practices of government, but a way of thinking about government, a rationality, and a description of the subjects being governed.

Governmentality studies has taken on a range of issues ranging from development and the "will to improve" and development (Li 2007a; Li 2007b), to healthcare and psychology (N. Rose 1998; N. Rose 2001), environmental protection, resilience, and sustainability (S. Rutherford 2007; Gabrys 2014; Goldman 2001; Joseph 2013). More recent scholarship has focused on climate change (Dowling 2010; Rutland and Aylett 2008; 
Stripple and Bulkeley 2013), energy transitions and solar photovoltaic electricity (Bues and Gailing 2016; Harriet Bulkeley, Powells, and Bell 2016), and smart technologies and smart cities (Vanolo 2013; F. Klauser, Paasche, and Söderström 2014). While these approaches provide insights into the study of the smart grid, I argue for an analytics of governmentality following Dean (2010) that highlights rationalities, techniques, and subjectivities. By integrating sociotechnical systems theory with governmentality, I am able to investigate how discourses, knowledge, practices, and technologies contribute to a particular mode of power and governance that utilizes various techniques and rationalities to manage energy consumption in the electric grid, and in this way enact and enable the smart grid.

In short, theories of governmentality bring an analytics of governmental rationalities, techniques, and subjectivities to bear on how governing occurs, enabling "regimes of government" or "regimes of practices" (Foucault et al. 1991; Bröckling, Krasmann, and Lemke 2010; Nadesan 2010; Dean 2010). Each of these concepts - rationalities, techniques, subjectivities - needs further elaboration to understand how they are deployed in the rest of this dissertation and its analyses of smart grid discourse and urban smart grid experiments.

First of all, it is important to note that governmentality implies that governmental rationalities are interconnected with techniques and subjectivities. As Gordon (1991, 3) explains, a "rationality of government will thus mean a way or system of thinking about the nature of the practice of government (who can govern; what governing is; what or who is governed), capable of making some form of that activity thinkable and practicable both to its practitioners and to those upon whom it it was practiced." For example, Fou- 
cault worked through the political rationality of liberalism and neoliberalism in his lectures, The Birth of Biopolitics, explicating the ways in which neoliberal rationality was entwined with market activities and the proliferation of enterprise into the social body, working on and through a particular subject, homo oeconomicus. Gordon (1991) argues that these later lectures were outcomes of Foucault's interest in "techniques of power" or "power/knowledge technologies" which were used to observe, monitor, shape, and control the behavior of individuals in societal contexts, but now applied to populations of subjects.

Governmental rationalities are specifically tied to "regimes of truth", or historically specific mechanisms which produce discourses that are perceived and accepted as true in particular places (Foucault 1977). They drawn on regimes of truth as bodies of knowledge and expertise to create the calculative means of addressing, reasoning, and responding to a set of particular problematics (N. S. Rose 1999, 19). Rationalities are thus tied to the Foucault's notions of episteme and power/knowledge, as well as "fields of visibility" (Dean 2010). Episteme refers to the specific set of ways of thinking and questioning, the general conditions for knowledge at a specific historical moment. As Rose $(1999,29)$ notes,

An analytics of government are not primarily concerned with language as a field of meaning, or with texts embodying authorial intentions which may be recovered and made intelligible in the appropriate historical context. They are concerned with knowledges, or regimes of truth. [...] It is not so much a question of what a word or a text 'means' - of the meanings of terms such as 'community', 'culture', 'risk', 'social', 'civility', 'citizen' and the like - but of analysing the way a word or a book functions in connection with other things, what it makes possible, the surfaces, networks and circuits around which it flows, the affects and passions that it mobilizes and through which it mobilizes. It is thus a matter of analysing what counts as truth, who has the power to define truth, the role of different au- 
thorities of truth, and the epistemological, institutional and technical conditions for the production and circulation of truths.

It is the forms of knowledge that shape and are shaped by, enact and empower particular forms of governing. The basic questions concerning episteme are: What are the essential bits of knowledge, expertise, means of calculation, and rationality utilized in practices of governing? How do practices of governing elicit particular forms of common sense knowledge? How do different ideas and knowledges seek to transform these practices? How do regimes of governance seek to render particular issues, domains, and problems governable? (Dean 2010, 42).

Fields of visibility make legible "who and what is to be governed, how relations of authority and obedience are constituted in space, how different locales and agents are to be connected with one another, what problems are to be solved and what objectives are to be sought" (Dean 2010, 41). They are, for example, architectural drawings, management flow charts, maps, panopticons, or, related more closely to the smart grid, demand curves, consumption profiles, and energy monitoring. Closely related are governmental techniques, or the technical means of government. Questions relating to governmental techniques include: What are the means, mechanisms, procedures, instruments, tactics, technologies and vocabularies by which authority is constituted and rule accomplished (Dean 2010, 42)? Sometimes referred to as "technologies of government," governmental techniques not only are the technical means, but also make possible certain forms of governing.

Lastly, analyzing governmentality entails attention to the formation of identities (individual and collective) and subjectivities. Questions related to this axis of analysis 
include: "What forms of person, self, and identity are presupposed by different practices of government and what sorts of transformation do these practices seek? What statuses, capacities, attributes, and orientations are assumed of those who exercise authority (from politicians and bureaucrats to professionals and therapists) and those are to be governed (workers, consumers, pupils and social welfare recipients)? What forms of conduct are expected of them? [...] How are certain aspects of conduct problematized? How are they then to be reformed? How are certain individuals and populations made to identify with certain groups, to become virtuous and active citizens, and so on?" (Dean 2010, 43). It is important to note here, however, that regimes of government do not determine forms of subjectivity, rather, they "elicit, promote, facilitate, foster, and attribute various capacities, qualities, and statuses to particular agents" (Dean 2010, 44).

These concepts of episteme, fields of visibility, technique, and identity/subjectivity are intertwined in the transformation of regimes. However there is one more element that Dean (2010) suggests is essential, the "utopian element." This means that governmentality has a utopian understanding of efficacy of government, of not only logic, but in action and possibility of reaching desired outcomes and goals. "It is to assume that we can draw upon and apply forms of knowledge to that task, that we can gain a secure knowledge of the world and of human beings in that world, that we can 'make things better', improve how we do things" (Dean 2010, 44). Unraveling and extracting this utopian element, or telos of government (Dean 2010, 44), is also a central part of analyzing governmentality.

Together, these elements of rationalities, techniques, and subjectivities (and the concepts within them - episteme, telos, visibility, technique, identity) provides a way to 
understand how different governance regimes are enacted through reconfigurations of particular socio-technical systems including technologies, policies, norms, and rules of conduct. We may think of this as adding an analysis of the "programmes of conduct" to the sociotechnical regimes approach: by this I mean adding an analysis of "all the attempts to regulate, reform, organize, and improve what occurs within regimes of practices in the name of a specific set of ends articulated with different degrees of explicitness and cogency" (Dean 2010, 43).

Because the smart grid has a central goal of making energy demand less dynamic and more controlled, it is essential to unpack different ways of understand energy demand. In the next section, I provide a brief overview of understanding domestic energy use as a basis for understanding how electricity consumption is problematized.

\subsubsection{Problematizing consumption: Ways of understanding domestic energy use}

Existing work on understanding domestic energy use has three primary approaches. The first is the engineering and technical approach. Under this approach, engineers identify a problem with domestic energy consumption and develop technological solutions. Technological solutions range from smartness, automation, design, information and feedback, or efficiency (Higginson, Thomson, and Bhamra 2014). For example, engineers can help reduce energy consumption by increasing energy efficiency of buildings, appliances, or other technologies often utilized in the home. This captures the simple engineering notion that the same amount of work can be accomplished with fewer energy inputs. Policy approaches over the last three decades have taken this approach, with some success (Geller et al. 2006). Many of these policy approaches include the development of 
new standards for appliances, starting as early as the development of the US DOE in 1979. The National Appliance Energy Conservation Act of 1987 helped established minimum efficiencies for appliances, and the EPAct of 1992 and 2005 and the EISA 2007 set new standards for a variety of appliances. These standards aim to increase energy efficiency through market transformation (Geller and Nadel 1994). Yet there are numerous problems with an engineering only approach. The most common cited issue is the "rebound effect" which suggests that energy costs will decrease with greater efficiency yielding consumption increases (Greening, Greene, and Difiglio 2000; Berkhout, Muskens, and W. Velthuijsen 2000; Saunders 2013). Limitations of technological approaches often are characterized as market failures (M. A. Brown 2001; M D Levine et al. 1995) that limit the effectiveness of energy efficiency programs and policies.

This brings us to the second general approach to understanding domestic energy consumption: the economists' approach. The economists' approach typically works in concert with the engineering approach to develop market directed policies. These approaches typically consider economic agents as rational individuals looking to maximize utility, or make the best economic decision for whatever set of circumstances they inhabit (Slovic et al. 2002; Mirowski 1991). This approach takes on a psychological bent, often utilizing theories from psychology to understand how people make decisions relating to a variety of economic and social factors (Simon 1986; V. L. Smith 1991). Still, these approaches take an individual approach and are often critiqued for their limitations including complete access to information and lack of broader social considerations (Goode 1997; Kahneman 2003). This has informed different varieties of economic approaches 
that try to provide better information to rational actors to enables better decision-making, and the development of new theoretical models in the field of behavioral economics.

The third approach to understanding domestic energy use critiques both the engineering and economics approaches, and takes culture and social practices as the primary explanations for energy consumption patterns. These approaches suggest that a number of alternative factors, both structural and cultural, are important to consider in addition to the techno-economic (Wilhite et al. 2000; Wilhite and Lutzenhiser 1999; Lutzenhiser 1992; Shove 2004). Lutzenhiser (1992) had explained the limitations of approaches from engineering, economics, psychology, and sociology approaches and the growing presence of cultural models of household energy consumption almost 20 years ago. In the same article, Lutzenhiser explains how a cultural model of energy that considers materiality that is, technologies, resources, objects - and the political economy of energy would provide not only a better theoretical understanding, but a better policy approach.

Cultural analysis involves the empirical investigation of what technologies mean to actors, and how they actually are used in everyday life in the US (where the fact that greater energy flows are involved in some end-uses than others may be of little significance to persons who are not consuming energy, per se, but rather are pursuing cultural forms of life). [...] The social sciences tell us that cultures are organized in social structures, by means of which political and economic interests find expression. It follows, then, that an approach which inquires only at the site of consumption will overlook political and economic dynamics that contribute directly to the creation and maintenance of that consumption. (Lutzenhiser 1992: $55,58)$

This cultural approach considers technology, political economy, and consumption as intertwined. The model developed by Lutzenhiser provided inspiration for much of the work following in social practices, energy anthropology, and social science research on energy, more generally. The social practices approach is complementary, but different. 
Building off the work of numerous theorists (Shove 2014; Shove, Pantzar, and Watson 2012; Schatzki, Knorr-Cetina, and Savigny 2001; Gram-Hanssen 2010; Hargreaves 2011), the practices approach challenges economic and psychological behavior change models arguing that norms, conventions, institutions, and habits - social forces and structures - play more important roles in determining consumption patterns. The focus on demand side management and now demand response and flexible demand within the electricity industry itself represents a semantic and discursive shift away from energy conservation, a behavioral approach, to a science and policy approach focusing on efficiency at the least cost (Wilhite et al. 2000). This trend still holds true despite the tremendous recent social science research on energy (Stirling 2014; Sovacool 2014; Lutzenhiser 2014; M. Huber 2015; Calvert 2015; Boyer 2011) and the growing trend towards understanding social practices impact on energy demand (Shove and Walker 2014; Shove, Watson, and Spurling 2015; Strengers 2012).

The majority of smart grid related approaches to demand side management and demand response utilize engineering and economic epistemologies and tools. This limits the potential of these programs and their effectiveness. Governing electricity demand seems to escape the purely economic form of decision-making that market approaches would enable. Yet, there is a continued reliance on price mechanisms and economic approaches. Smart technologies are intended to develop new producer-consumer relationships, enabling two way flows of information that can improve management of the grid for better social, economic, and environmental outcomes (Clastres 2011). These technologies rely on the same epistemological underpinnings that early DSM strategies utilized pricing fluctuations and information provision - to influence actions and behaviors 
(Rahimi and Ipakchi 2010; Siano 2014). But these technologies have multiple applications and also enable extended opportunities for automated energy management through interlinked networks of sensors, devices, appliances, communications, and controls. As such, the smart grid "paradigm" has elicited a tremendous response from the electricity industry, ICT companies, and government, much in speculation of what the technological future will hold. "Smartness" itself demands a new interpretation to understand how political technologies are used to govern energy conduct.

The next section discusses the sociotechnical and political history of the smart grid. Section 4 reports on the discourse analysis highlighting key rationalities, techniques and imagined subjectivities for the governance regime.

\subsection{Making a Smart Grid Regime}

The energy consultant and professor of practice at Boston University Peter FoxPenner argues that the smart grid has its roots in deregulation policy. In his text Smart Power (Fox-Penner 2014), one of the most widely-read and acclaimed texts on the smart grid, Fox-Penner explains how deregulation and smart technologies enable the transition away from the traditional kilowatt-hour commodity business model to new business models of utilities: either network operators (he calls "the smart integrator") or energy service utilities. In the old business model, the regulated electricity market guaranteed and set rates of profit for utilities based on the rate base - the value of property on which a public utility is permitted to earn a specified rate of return. This incentivized utilities to build more, sinking investments in new generation and transmission systems to enable further profits. This guided the early development of regional power networks, especially 
after the trust-busting Public Utility Holding Company Act of 1935 (PUHCA) and the period of unregulated monopolies. ${ }^{3}$ Along with this, there was a general incentive to sell more electricity. More electricity consumption coincided with economic growth generally in the US economy, especially in the post-WWI period. New business models require utilities to change and adapt to a new electricity landscape characterized by distributed generation facilities, two ways flows of information and electrons, and a more liberalized electricity market.

The evolution of the utility industry was heavily shaped by the technologies available, corporate organizational structures, and regulatory systems (Hirsh 2003). It also responded to the material realities of energy scarcity and the economics of energy production. Historian Richard Hirsh (2003) explains how the electric utility industry declined during the 1970 s as it reached a period of "technological stasis" - what he describes as the decline in technological progress and system efficiency of the electric industry that arose alongside a specific managerial culture, a specific set of manufacturing techniques and utility practices that only heightened stagnation and created barriers to addressing it. Hirsh shows how the industry began to lose the moniker of "high tech" to electronics and aerospace industries, failing to attract talented and skilled individuals who

\footnotetext{
${ }^{3}$ President Roosevelt established the National Power Policy Committee (NPCC) in 1934 to create "yardstick" rates for public and private utilities. This fueled public power enthusiasts and conservationists to lobby for the dissolution of monopolistic holding companies (Funigiello 1973). These large holding companies were broken up with the 1935 Public Utility Holding Company Act (PUHCA), one of the "trustbusting" initiatives enacted in response to the Great Depression. The PUHCA of 1935 established in the wake of the Great Depression to enable securities regulation and prevent abuse of holding company power and control over electricity markets. The Securities and Exchange Commission (SEC) was required to approve holding companies control of only a single integrated electric system.
} 
might have challenged the industry's stasis. The old, staid utility managers only allowed inefficiencies to become more deeply entrenched, contributing to the idea that utilities are slow-moving bureaucracies ill-equipped to innovate or change. Hirsh's idea of stasis alongside Hughes (1987) concept of technological momentum helps explain how the utility industry garnered the reputation it still holds (in many ways) today - rigid, inflexible, resistant.

Hirsh's (2002) more recent text Power Loss deals with the issues of deregulation and restructuring in the electric utility industry following this period of stasis. Hirsh describes the development and decline of the "utility consensus" - an agreement that utilities were "natural monopolies" that should be regulated by rate-setting as they achieved greater economies of scale and scope to increase their bottom line. Yet as Hirsh describes in the book this model was problematized as uncertainties in demand, price, and capacity complicated the traditional model. Coupled with the growing concerns over environmental pollution, accompanying new regulations, and technological stasis, the utility consensus began to be challenged and free market ideologies gained traction against traditional regulatory frameworks.

In 1978, the Public Utility Regulatory Policies Act (PURPA 1978) was enacted to help promote energy conservation and promote the development of domestic and renewable energy. As a part of President Carter's National Energy Act, PURPA was developed in response to the energy crisis of 1973 (Hirsh 1999). Fueled by anxieties of oil scarcity and extremes in oil prices, the US sought to boost its "energy independence." PURPA encouraged non-utility power production especially renewable sources, cogeneration, hydroelectric power, and conservation while limiting promotional rate structures - the 
decreased cost per kWh with increased usage. The development of a market for nonutility power production began the restructuring of the electric industry, providing competition in generation (Hirsh 1999). Vertically integrated companies no longer were the sole generators of electricity in their territory, challenging the half century long consensus that the electricity market encouraged a "natural monopoly." Although the intention of the Act was to provide momentum to the environmental movement, it served to introduce and stimulate competition into the generation sector of the electricity market. In addition, President Carter's energy focus also brought forth the Department of Energy Organization Act in 1977, which established the US DOE and replaced the Federal Power Commission of the President Roosevelt era (1935) with the Federal Energy Regulatory Commission (FERC). FERC was established to create and enforce wholesale electricity prices.

By 1992, there was a strong impetus to further restructure the electric industry. This was fueled by the characteristic neoliberal, free-market ideology of the 1980s and 1990s. Regulation was challenged on the grounds that it would only continue to interfere with the maximum efficiency allowed for by the free-market (Rudolph and Ridley 1986). Telecommunications, transportation, and natural gas industries were deregulated providing precedent for the electricity industry (Graham and Marvin 2001). The loss of the utility consensus, environmental groups movement to change energy policy, the growing realization that energy systems were contributing to a changing climate (e.g. Limits to Growth 1972, Brundtland Report 1987), strong movements towards energy efficiency, and a declining rate of electricity consumption all signaled a new era for energy policy. The Energy Policy Act of 1992 (EPAct 1992) partially repealed PUHCA 1935 even as 
concerned citizen and environmental groups grew anxious about the potential for corruption. President Bush's EPAct 1992 opened the transmission networks to non-utility generators or independent power producers (IPPs) and facilitated the creation of a competitive market for electricity by creating another category of qualifying facilities in addition to the cogeneration and IPPs President Carter's policy established 14 years earlier: exempt wholesale generators (EWGs). EWGs were exempt from regulations of traditional utilities and were aided to participate with the FERC Orders 888 and 889 which provided guidelines for opening electricity transmission networks for interstate commerce (Hirsh 2004). State level action also followed with California and Rhode Island passing deregulation legislation that allowed consumers to choose their electricity supplier. The "power to choose" has thus resonated as a popular discourse for consumer sovereignty and engagement with the electricity industry.

As the old utility business model was challenged, new structures needed to be implemented. Natural monopoly and state or federal regulation began to be replaced with a restructured system of electricity generators competing in a market designed to be efficient and profitable (Breslau 2013). Utilities provided maintenance of the transmission and distribution systems, while generators provided wholesale electricity to markets where power marketers and brokers would facilitate sales and transactions. Proponents suggested that the cost of electricity decreased due to competition, ultimately benefiting the end-use consumer. Environmental benefits of energy efficiency were also considered as competitive advantages. A new market for renewable focused IPPs was enabled to help meet mandates from renewable energy portfolio standards, such as the one implemented in 2002 in California or in Texas in 1999. The impacts of deregulation, however, 
are contested. Many argue that the opening of markets and market restructuring caused the electricity crisis in 2000-2001 in California (T. Slocum 2001). The failure and shortage of electrical supply was contributed to market manipulation, Enron's role in natural gas cut-offs, and capped retail electricity prices (Sweeney 2002). Many policymakers and think tanks suggest that deregulation in itself is not a bad goal, rather that the implementation of policy was flawed (Isser 2015).

A 2002 report from the Pacific Northwest National Labs (PNNL) provided a primer to understanding deregulation and restructuring, and it described the new business model for utilities results in "giving retail customers the opportunity to choose their power supplier" which "is expected to stimulate markets to reduce power costs and increase power products and services" (Warwick 2002: vi). In the deregulated market, the report notes, competition will take place in every part of the electricity system, from generation and transmission to wholesale markets (with many new third-party operators), and even in retail power sales as a variety of new power suppliers (often subsidiaries of existing utilities across state boundaries) enter the market. As competition reduced the incentive for utilities to implement energy management programs, new companies offer customers services of energy audits and other energy management services, often with a fee (paid by utility billing in many states with independent groups managing these funds, not utilities). In Oregon, for example, the Energy Trust of Oregon is one such provider of energy efficiency funded by utility billing fees, or a "public purchase charge," from customers of Portland General Electric, Pacific Power, NW Natural, and Cascade Natural Gas (Oregon Senate Bill 1149 1999). 
Deregulation policy slowed after the 2000-2001 California crisis, causing many states to reconsider their own restructuring laws. Numerous analyses emerged for the failure of electricity deregulation (Ardoin and Grady 2006; Blumsack, Apt, and Lave 2006; Woo, Lloyd, and Tishler 2003; Borenstein 2002; Joskow 2001), but the thought and drive for a competitive, thoroughly deregulated market for electricity did not dissipate. In 2005, President Bush signed the Energy Policy Act of 2005 (EPAct 2005) at Sandia National Laboratory in a symbolic nod to the support for ramping up nuclear power production. The Act fully repealed the PUHCA of 1935, eliminating corporate structure and governance restrictions enabling holding companies to tap a broader array of sources of capital for investment. This provided a victory to free-market enthusiast, and it fit with the logic of neoliberal capitalism towards deregulation and privatization (Harvey 2007). It also resonated with the strong desire of national security in a post-9/11 world. President Bush hammered home the idea that domestic energy resources including coal and renewables were key to "reducing our reliance on energy from foreign countries," and helping the US "economy grow so people can work" (Office of the Press Secretary 2005). But the Act also contained a hefty section on energy conservation and efficiency. President Bush (Office of the Press Secretary 2005, emphasis added) remarked:

The bill recognizes that America is the world's leader in technology, and that we've got to use technology to be the world's leader in energy conservation. The bill includes incentives for consumers to be better conservers of energy. If you own a home, you can receive new tax credits to install energy-efficient windows and appliances. If you're in the market for a car, this bill will help you save up to $\$ 3,500$ on a fuel-efficient hybrid or cleandiesel vehicle. And the way the tax credit works is that the more efficient the vehicle is, the more money you will save. Energy conservation is more than a private virtue; it's a public virtue. And with this bill I sign today, America is taking the side of consumers who make the choice to conserve. 
President Bush attempted to align a culture of American patriotism with a moral requirement for energy efficiency and conservation. As an individual consumer, it seemed, you could participate in the nation's goals for energy independence and security in a time of war by doing your part: purchasing a fuel efficient car and energy-efficient windows and appliances. And you could do so knowing you would uphold a public virtue while benefitting privately. But conservation for President Bush was not about changing behaviors or habits, but merely adopting new technologies. This quote illustrates the limited and technologically deterministic approach to energy efficiency and conservation that equates consumer-citizenship with environmentalism and patriotism (see: R. Slocum 2004a; R. Slocum 2004b).

While much of the EPAct of 2005 focused on oil and gas, the provisions for electricity solidified an era of deregulation and competition. Just two years later, the Energy Independence and Security Act of 2007 (EISA 2007) brought forth the "smart grid" as a national goal for modernization of the electricity grid. The act explained that the smart grid would utilize "digital information and controls technology to improve reliability, security, and efficiency of the electric grid." It also held provisions for renewable energy integration, demand response programs, information provision, and deployment of smart technologies.

In 2009, the American Recovery and Reinvestment Act (ARRA) provided the funds to research, implement, and demonstrate smart grid technologies throughout the country. The smart grid was positioned as a way to modernize aging electricity infrastructure improving security, efficiency, reliability, and environmental sustainability. Modernization, however, means many things. I argue that modernization, and much of the ac- 
companying discourse about technological change and consumer empowerment, are aimed at transforming infrastructure to enable a free-market inspired electric power network and at making demand price responsive. Simply put, smart grid technologies were, and are being, implemented as a governance regime that places market-driven efficiency, securitization of supply, and consumer empowerment as key rationalities, with accompanying techniques, and imagined "smart consumer" identities.

\subsection{Efficiency, Security, Economy}

\subsubsection{Overview of governmental rationalities: efficiency, security, economy}

Preliminary analysis of smart grid discourse resulting from content and thematic analysis (see Chapter 2 for more discussion of methods) identified key textual phrases that I grouped with codes and themes. The background above explains the historical conditions that allowed for this discourse to emerge. This discourse analysis helps to unravel the episteme, field of visibility, telos of government, the techniques and identities/subjectivities thus contributing to the analysis of governmentality and governance regimes in the smart grid. The analysis and coding identified efficiency, security, and economy as governmental rationalities. These enable and enact the smart grid through various techniques and a "smart consumer" identity. As such, the attention to the "consumer-side" of the smart grid discourse receives significant attention. It is through the creation of the "smart consumer" and associated practices that make the smart grid possible as a governmental program and as a sociotechnical infrastructure.

This discourse analysis reveals problematizations of the electricity system as the basis for three governmental rationalities: efficiency, security, and economy. By efficien- 
cy, I mean both technical and economic efficiency. Technical efficiency discourses come from the technical literature: electrical, power, computer, mechanical and other engineering disciplines; utilities and research organizations; government offices and research laboratories; nonprofit environmental groups; and more. Technical efficiency discourse focuses on improvements, benefits, and limitations resulting from smart grid technologies.

Technical efficiency is closely linked to the notion of economic efficiency, wherein both engineering and economics discursive practices interact. Economic efficiency discussion is based on the claims of technical efficiency with the basic conception that less energy is wasted. Economic efficiency often refers to the dollars saved in operation and maintenance costs across the entire grid. Efficiency is central to the dominant technoeconomic, even techno-utopian discourse of the smart grid. Various social visions are incorporated into this broad theme, making the smart grid an empty signifier capable of recruiting multiple meanings and expectations under the same moniker.

A second prevailing theme is security and securitization. Security refers to several concerns. As the grid becomes "digitized," that is controlled and managed with a digital information and communication infrastructure network, increasing concerns about the ability of hackers to break into the secured network and cause havoc on the electric grid is being battled with cyber-security and physical security programs. Security also refers to the role of the smart grid in reducing pollution and enabling renewable generation, a form of "ecological security" (Hodson and Marvin 2009a). Carbon and climate issues are enraveled in both security and efficiency discourses. 
Of course, however, climate change is also discussed in an opportunistic way, presenting the opportunity for "re-inventing" the power sector and creating an economy that runs on clean energy. Economy, thus, is a third major theme and refers to the traditional and more modern usage of the term. The modern usage of economy fits with the idea of a managed realm of social actions in which consumption and production, supply and demand are conducted in a regulated or unregulated market. Rooted in its etymology, economy also refers to "household management," "thrift," and "administration." Foucault's (2010) lectures on neoliberalism start from this meaning, as does Agamben's (2009) tracing of oikonomia and the theological roots of economic thinking, and Mitchell's (2008; 1998) discussion of Hughes (1983) work on electricity networks, for example, discusses how the economy was created in the production of a sociotechnical system. This latter meaning of economy is closely affiliated with domestic electricity consumption, energy management, and the variety of practices associated with household consumption.

While this is by no means exhaustive, these three groupings capture a majority of the social meanings and expectations assigned to the smart grid captured in major discourses. These three rationalities are sometimes at odd with each other. Sometimes, security concern is negotiated to enable new actors to participate in electricity management, such as is the case with distributed generation and home energy management systems (HEMS). Other times, environmental concerns over securitization of the climate (preventing further climate change) confronts an argument for economic or even technical efficiency, as is the case of the higher costs and intermittency of renewable energy sources such as wind and solar. There is considerable debate between actors in the smart 
grid. It is here where political visions collide and contestation ensues. Yet, there is a dominant way of thinking about government, the role of technology, and the imagined subjects of the smart grid.

This analysis brings to surface these three rationalities, how they are discussed, by whom, and with what effect. Discourse is used to aid in the stabilization of sociotechnical regimes, but act in a broader governance regime, analyzed through different governmental rationales, techniques, and subjectivities that are captured in sociotechnical changes and visions of the smart grid. In short, this analysis helps elucidate forms of governance enacted through the discourse and materiality of the smart grid.

\subsubsection{Efficiency: Smart grid as technical progression for electricity markets and consumers}

Technical efficiency discourse originates in engineering research and development. Specific discourses relating to technical and economic efficiency of the smart grid are produced in many different institutional contexts with a variety of practices, most notably here by engineers and economists. The professional organization, IEEE, has published journals, magazines, and conference proceedings that contain the minutiae of technical efficiency benefits of the smart grid, rationales for these benefits, and techniques of realizing these benefits. Practices and institutions matter a great deal to the "discursive order" of social transformations and to the production of subjects and objects of knowledge (Hajer 1995; Foucault 2002).

As early as 1988, with the inaugural issue of IEEE's Computer Applications in Power, engineers discussed the ability of the nascent "smart grid" to step away from 
nameplate data references and to harness the power of actual, real-time data to better simulate and manage generation, transmission and distribution (Undrill 1988); they discussed future applications of computers in power system operations, construction management, design engineering, maintenance, and new business opportunities for utilities (Denny 1988); and they highlighted the applications for data collection on energy-usage in end-use experiments where "the proliferation of inexpensive, high-quality computing" had enabled utilities to "have the necessary knowledge to design demand-side management programs and to demonstrate their value to customers and regulators"(Shirilau 1988, 20). Already in 1988, the capabilities of a smarter grid were being discussed with application to different sectors of electricity system operations.

Technical efficiency refers to the many things in the engineering and industry discourses: increases in reliability, decreased losses in the transmission and distribution systems, and greater utilization of generation assets are just some (Gellings 2009; Carvallo and Cooper 2015). As the widely acknowledged "father of the smart grid," University of Minnesota Professor Massoud Amin, has explained: "Smart grid is the enhancement to the sensors, communication, controls and devices and systems that operate as an overlay in parallel on top of [the] hardwired system to enhance reliability, minimize cost, reduce cost, improve security and resilience, robustness of the system" (Flatow 2011; see also Amin 2008). During his career working on smart grids, Amin worked with the Electric Power Research Institute, a nearly fifty-year-old non-profit research and development organization. EPRI's members represent approximately 90 percent of US power produc- 
tion, and thus, EPRI is largely responsive to their needs. ${ }^{4}$ EPRI's reports, documentation, and journal represent a key window into the issues that electricity industry finds important and pressing.

EPRI's decades of research on smart and intelligent grid technologies (IntelliGrid is EPRI's own methodology for integrating smart grid technologies) and collaborations with utilities and energy companies has highlighted technical efficiency gains. In the introduction to the June 1989 issue of the EPRI Journal, a featured article highlight how silicon thyristor technology "promises to transform the nations transmission system with fast, 'smart' solid-state switching devices that eliminate bottlenecks encountered with conventional, electromechanical equipment" (p. 5).

By 1997, the term "smart grid", or "SMART (Self-Managing and Reliable Transmission) Grid" was already catching on with promises to "use information technology to improve grid reliability and capability"(Vu, Begouic, and Novosel 1997, 42). The notion of a smart grid was tied to the idea of "self-healing" energy infrastructure systems that would improve grid reliability, and at the same time utilize the "infrastructures for a digital world" to "develop distributed management and control systems to keep infrastructures robust and operational" (Amin 2001, 27). In early 2000s, sociotechnical changes presented an opportunity for smart grid discourses to emerge, as Amin (2001, 27) notes: "Economic restructuring and increasingly powerful sensing, computation, and control options are changing the context in which power systems are operated and stud-

\footnotetext{
${ }^{4}$ See http://www.epri.com/About-Us/Pages/Our-Story.aspx.
} 
ied." With the introduction of enterprise energy management systems (EEMS), new configurations were being considered for the way producers and consumers interacted, and presented opportunities for "market-based pricing." Rising demand and the power and reliability (six nines or 99.9999\%) requirements of the "new digital economy" presented challenges for the existing industry, who was characterized as needing more information and more choice (Forth and Tobin 2002). Smart grid technologies, such as EEMS, provided a solution to the "technological barrier preventing true market economics from prevailing, regardless of what the regulators had intended" (Forth and Tobin 2002, 24). The need for appropriate technologies to enabled market-responsive (dynamic) pricing and responsive demand (price elastic) was also expressed by economists in the pages of IEEE's Transactions on Power Systems (e.g. Kirschen 2003). The idea of information technology aiding increases in the price elasticity of electricity demand, or in general making demand more responsive across sectors (industrial, commercial, and residential), is a common thread among the technical discourses of the smart grid.

Technical discourse related to efficiency is almost always bolstered by arguments or visions for economic efficiency. In the history of the smart grid, since the 1970s when microcomputers became popular, the structure of the utility industry shaped and was shaped the role of information infrastructure where economic efficiency, technical efficiency, reliability, and security were points of negotiation in sociotechnical changes that took place. Slayton (2013) argues, firstly, that information infrastructure helped vertically integrated utilities gain economies of scale and scope because it allowed utilities to plan for the most economic dispatch from various generating sources now, in ever more distant locations in a growing electricity network. This meant that the technical benefits of 
information infrastructure could be used to increase economic efficiencies of utility organization. Computers were used not only for planning, but also for controls. SCADA systems were developed to manage industrial systems in a more centralized and coordinated way. Information infrastructure aided both economic efficiency and physical efficiency simultaneously. The improvements in information technology allowed more costeffective production, expansion of networks, and this reduced the cost of electricity as demand sored through the turn of the century to 1973.

Secondly, Slayton (2013) argues that information infrastructure aided the creation of electricity markets, which would yield "more efficient" transactions (Rozek 1989; Forth and Tobin 2002). After the oil crisis of 1973, utilities' economies of scale and scope were threatened. Costs of electricity rose as did environmental concerns, and energy security became increasingly salient. This led to the decline of the natural monopoly paradigm solidified in the PURPA 1978. In response, utilities began to create smaller and less centralized forms of electricity generation, which was only made possible by advances in IT such as microprocessors and computer networks (Slayton 2013).

Third, a new regulatory order was implemented alongside IT advances. New computer networking and microprocessor developments "could enable a more competitive market structure, reducing of eliminating the need for regulators to establish market prices" (Slayton 2013: 458). MITs Energy Lab, and more prominently EPRI (part of Edison Electric Institute), began to advocate for the role of computing and information technology to enhance productivity and competitiveness with "smarter and more efficient microtechnology." Economic efficiency was assumed for market competition. In many ways, technical improvements and efficiencies in the smart grid shaped and were shaped 
by the push for market competition (Slayton 2013; Mitchell 2008). PUCs also played a major role suggesting that microelectronics could help provide consumer choice, a trope that still rings true more than twenty years later. ICTs also enabled new forms of spot pricing systems to help cut demand in a more "consumer-oriented" way. ICTs enabled a complex power market feasible, and this fueled the boosterism from economists and some regulators who believed that the market would allow the most efficient allocation of resources (i.e. the cheapest generating units would run so prices could be competitive). Computer networks allowed trading between ever more utilities and non-utility generators.

The vision of a future smart grid was pronounced in the pages of technical journals, industry magazines, and in public media as well. A realization that the smart grid was a necessity of the energy future was stated almost universally. For example, representatives of EPRI and CEIDS (Consortium of Electric Infrastructure to Support a Digital Society) wrote in the pages of IEEE's Power and Energy Magazine about the coming necessity of two-way communications network for electric power systems: "The future of the power industry will require the continued development and integration of two infrastructures, not just one: both power delivery and communications" (Gellings, Samotyj, and Howe 2004). Likewise, the Department of Energy, in collaboration with Pacific Northwest National Labs, developed the GridWise ${ }^{\mathrm{TM}}$ Testbed Demonstration in 2004, suggesting that "smart grid-management technologies based on real-time, electronic communication and intelligent devices" would mature within several years eliminating the need for expanding construction of traditional power-grid infrastructure (Hammerstrom 2007, v). The end-use energy experiments with dynamic pricing and au- 
tomation and control of smart appliances would set the pace for industry growth in this area. Peter Fox-Penner describes the Sequim, Washington based GridWise experiments in his influential text, Smart Power, as precursors to the smart grid of today, with demand responding to "sometimes sever price spikes" to successfully prevent overloading on the small town's grid infrastructure. The GridWise Alliance and the GridWise Architecture Council were offshoots of this initial project, with the Alliance serving as a member organization for a broad range of energy supply chain actors, from utilities and large technology companies to academia, venture capitalists and emerge companies.

As the smart grid paradigm has emerged in the last fifteen years, political coalitions, such as GridWise, have been built around smart technologies and advocated for industry and regulatory changes. As they explain in their informational brochure: "The technology exists to enable a radical overhaul of the way in which energy is generated, distributed and consumed - an overhaul whose impact on the energy industry could match the Internet's impact on communications. But unless regulators restore the economic incentives for investment, the future looks bleak." 5 Organizations such as these pronounce the technical and economic benefits and efficiencies of the smart grid, and attempt to create further public and government support for smart grid technologies.

At the center of these appeals to policymakers is a central notion that smart grid technologies benefit consumers. The Smart Grid Interoperability Panel's, mission statement, for example, explains: "SGIP is an industry consortium representing a cross-

\footnotetext{
${ }^{5}$ See http://www.gridwise.org/smartgrid_whatis.asp
} 
section of the energy ecosystem focusing on accelerating grid modernization and the energy Internet of Things through policy, education, and promotion of interoperability and standards to empower customers and enable a sustainable energy future." ${ }^{6}$ While the notion that efficiencies will not only benefit utilities and technology companies, but also the public has been around since the early provisions of the EISA 2007, a renewed interest in making appeals to cost and convenience benefits to consumers. Discourse in IEEE publications, in EPRI's Publications, and in industry journals, has turned to embrace these notions of consumer empowerment (see discourses of economy below).

Environmental benefits of efficiency have also been discussed by groups such as the Environmental Defense Fund and the National Resources Defense Council. But the primary benefits of smart grid improvements for carbon dioxide emissions, climate change, and environmental pollution are discussed in the smart grid's potential to help consumer save energy and increase energy efficiency: "The smart grid can reduce $\mathrm{CO} 2$ emissions primarily by helping customers use less electricity, and in some cases by shifting demand away from peak periods, reducing the need for utilities to bring extra power plants on line that emit CO2 and other pollutants" (Succar and Cavanagh 2012, 4). Similarly, EDF focused on how many of the environmental benefits of the smart grid are realized through consumption changes via dynamic pricing programs, more efficient smart technologies, and opening electricity markets to competition and entrepreneurs (EDF 2016b; EDF 2016a)

\footnotetext{
${ }^{6}$ See http://www.sgip.org/about-us/organization-purpose/
} 
And certainly these environmental benefits are welcome! Strategies to reduce consumption are necessary components of a sustainability transition. Smart grids enable greater integration of renewables, but dominant discourse strands from environmental groups tend to focus on efficient use of energy. This places responsibility for environmental change on consumers, and suggests utilities are too staid, rigid, and not responsive enough to achieve the goals of environmental protection and climate change mitigation and adaptation.

While industry groups, utilities, and non-profits highlighted efficiency benefits of the smart grid, the White House, Congress, and National Labs all touted these benefits louder and with more force. On October 26, 2009, President Obama traveled to Arcadia, Florida to celebrate the largest solar power plant in the nation. Florida Power and Light's plant was celebrated by President for its contribution to growing the economy and reducing the carbon impacts of electricity production. But, he also remarked that the electric grid was old, inefficient, and susceptible to blackouts and outages. He compared the rebuilding of the electric grid to the building of the US system of interstate highways, a massive investment that reinvented the way people travelled the country. It would support economic growth through jobs and industry and at the same time save customers money on their utility bills. It was on this day that President Obama also announced, as a part of the Recovery Act, the largest ever investment in a "stronger, smarter, and more secure electric grid," totaling 3.4 billion dollars. Investment in "recovery" also meant "strengthening, smartening, and securing" the nation. The smart grid, thus, was a national project for reinvigorating the US economy through the stimulation of a clean energy economy. 
What is surprising, however, is how President Obama didn't focus so much on the technical specifics of how the grid was getting safer, more reliable, or more secure, but rather the benefits this posed to customers of utilities. He didn't focus on smart transformers, sensors or grid operations, but rather he focused on smart meters and consumer benefits.

[Smart meters] will help you greatly improve the energy efficiency in your own home. ... Smart meters will allow you to actually monitor how much your family is using by the month, by the week, by the day, or even by the hour. Coupled with other technologies, this is going to help you manage your electricity use and your budget at the same time. Allowing you to conserve electricity during times when prices are highest, like hot summer days.

President Obama described the transition to a clean energy economy as a desirable future, but also a contested and uncertain one, a future that would require substantial change by individuals and the incumbent energy regimes. Promises of the modernization of the electric grid and the demonstration projects he championed meant a "continuation of that long march of progress in this country, and we refuse to believe our politics are too broken to meet this challenge" (infomisa 2016). Efficiency coincided with a discourse of technological modernization and progress that "determined" social progress as well.

The smart grid needed to prove its efficiency as hype and speculation grew in the broader discourse. Many of the claims for efficiency were met with new social expectations for the smart grid: that it could be more responsive to customer needs, more reliable, more efficient, cleaner, integrate more renewable energy, and be more resilient against severe weather. To meet some of these growing expectations, a considerable focus on demonstration projects was established with the Recovery Act funds. Prioritization of delivery on various promises created tensions between various actors in the smart grid, 
as some wanted more focus on renewable energy integration while others wanted more focus on market liberalization, for example.

Although there was considerable discussion and tension, in the 2011 "A Policy Framework for the $21^{\text {st }}$ Century Grid," plan was laid out that put priorities into place, with a focus on boosting a clean energy economy and creating of new jobs while "empowering consumers" and reducing carbon dioxide emissions (seemingly in this order). The policy framework "promotes cost-effective investment, fosters innovation to spur the development of new products and services, empowers consumers to make informed decisions with better energy information, and secures the grid against cyber attacks" (Chopra, Kundra, and Weiser 2011, 1). As technical and economic efficiencies were touted from Capitol Hill, the growing concern of security also began to take hold in smart grid discourse revealing another tension in smart grid implementation.

\subsubsection{Security: Smart grid as a mechanism to secure critical infrastructure for human well-being}

Growing concerns of cybersecurity had started as early as 1988 , recognizing the increasing role of computers in grid operation. In the wake of terrorist attacks at the World Trade Center in 1993 and the Oklahoma City bombings in 1995, President Clinton ordered a study of critical infrastructure(Slayton 2013). This spurred numerous studies by industry groups such as EPRI and the National Research Council. After Sept 11, the work exploded significantly, claiming smart and intelligent solutions were to be the most important changes in combating cyberattacks. The Department of Homeland Security had 
been given responsibility over critical infrastructure protection, not FERC, and it had no authority over private-sector changes.

Cybersecurity is seen both as a strength of the smart grid, and a possible weakness. As the smart grid is implemented, new sensors and networks are designed to be more secure, yet at the same time, provide more access to the network through various internet enabled devices (Kurada, Dhanhal, and Venkatesh 2014). In 2012, Televent, a large smart grid company owned by Schneider Electric released a notice that their networks had been breached by hackers who installed malicious software and accessed project files for SCADA systems used to control the power grid (Zetter 2012). Coupled with attacks on the Department of Energy and the Department of Defense, President Obama issued an executive order (EO13636) for increasing critical infrastructure cybersecurity. This led to the NIST Cybersecurity Framework that was "created through collaboration between government and the private sector, uses a common language to address and manage cybersecurity risk in a cost-effective way based on business needs without placing additional regulatory requirements on businesses" (NIST 2014, 3). Critical infrastructure Protection is part of the work of DHS and NERC. NERC established CIP standards for electric power systems and FERC mandates NERC Compliance (as established in the EPA of 2005).

Experts on the smart grid highlight the security tradeoffs with goals for economic growth (Amin 2008; Amin 2002; Amin 2004). As Amin (2004, 31) notes, "[the electricity] network has evolved without formal analysis of the system-wide implications of this evolution, including its diminished transmission and generation shock-absorber capacity under the forces of deregulation, the digital economy, and interaction with other infra- 
structures." Security issues already were of concern with smart grid applications in 2004, when terrorist activities were of great concern, and multiple vulnerabilities were being explored for repair and reconfiguration. These also reflected public concerns over "cyberterrorism" and more general terrorist attacks on vital infrastructures.

But the security of the grid also relates to its reliability and protection from extreme weather events and other external pressures. In the wake of Superstorm Sandy which create extended blackouts in Manhattan and billions of dollars in "lost output and wages, spoiled inventory, delayed production, inconvenience and damage to grid infrastructure" cast the light on an "aging" grid with the oft-cited statistic that it has been built over the last one hundred years (Council of Economic Advisers and US Department of Energy 2013). In addition, the DOE highlighted multiple vulnerabilities resulting in decreases in plant efficiency, reduction in available generation, and increased risk to inland and coastal facilities, while demands for heating and cooling would increase (Zamuda et al. 2013). Likewise, the Union of Concerned Scientists cautioned that "unless we reduce global warming emissions and mitigate the worst effects of climate change, the need for costly adaptation measures will only grow"(Davis and Clemmer 2014, 9). One common effort to make grids more resilient is to bury power lines, but this is a costly endeavor that would likely require rate increases for customers (Short 2016). This again positions security concerns against economic efficiency.

In addition to the concerns over securing networked infrastructures from climate change and weather, there is a parallel concern on geopolitical security through energy independence. While this discourse was stronger during President George W. Bush's term, there is still considerable effort at securing the US supply of energy through a tran- 
sition to an electrified transportation system made possible by smart grid technologies. The EISA of 2007 made this a goal and policy of the nation, and political discourse has continued to support "independence" variably from "foreign oil" and for individuals willing to be isolated from the electric grid (Hertzog 2013; Murray 2014; Lacey 2015).

\subsubsection{Economy: Helping customers save money}

President Obama's charge for a clean energy economy under the Recovery Act of 2009 championed the economic benefits of an American energy transition, one that like ecological modernization discourses, promised both economic and environmental improvements (Hajer 1995). President Obama remarked about the ARRA funds earmarked for smart grid development in 2009:

We'll fund a better, smarter electricity grid and train workers to build it a grid that will help us ship wind and solar power from one end of this country to another. Think about it. The grid that powers the tools of modern life - computers, appliances, even blackberries - looks largely the same as it did half a century ago. Just these first steps toward modernizing the way we distribute electricity could reduce consumption by 2 to 4 percent. $^{7}$

Two issues about President Obama's remark are poignant. What caught my eye was the way his phrasing makes it seem that smart grid development inevitably leads to reduced consumption. This suggests that smart technologies enable and indeed guarantee some sort of reduction in demand. The experience of energy efficiency industry suggests that technological change does not automatically lead to reduced consumption

\footnotetext{
${ }^{7}$ President Barack Obama, "Remarks of President Barack Obama: Promoting the Recovery Plan with Secretary Chu", February 5, 2009, https://www.whitehouse.gov/blog/2009/02/05/serious-about-energyindependence
} 
(Lutzenhiser 2014). Certainly technologies enable new forms of energy consumption, control, management, etc., but they do not guarantee people will use them as intended, nor does it prevent the dreaded "rebound effect." This phrasing obfuscates the centrality of consumption behavior, and the larger issues of cultural and societal expectations, conventions, and norms, which create the context for energy demand. The second issue relates to the way President Obama's vision, although quite broad, highlighted how he envisioned the smart grid as a "modernization" project, freeing the US electric industry from its technological stasis in the late $20^{\text {th }}$ century (Hirsh 2003). The discourse mirrored the language of post-war electrification associated with grand visions of progress. Obama was hoping to create economic growth and innovation, a "new new deal." ${ }^{\prime}$ As Grunwald (2012) explains, "the smart grid seemed perfect, a modern moon mission, a $21^{\text {st }}$ century version of the interstates."

It is worth considering the central role of economic collapse in the heightened attention to smart grid development. After the mortgage crisis, economic stagnation and recession created a deafening and disheartening decline. Marked by responses of massive layoffs, austerity measures from local governments, and sharp decreases in housing values, the national government and politicians across the partisan aisle sought solutions. One area that promised to boost the economy was the ecological modernization agenda of clean-tech solutions. Alternative energy and smart grid solutions became the saving grace

\footnotetext{
${ }^{8}$ Greenwald's 2012 book, A New New Deal: The Hidden Story of Change in the Obama Era shows how the smart grid project for Obama was about getting the US out of a heap of economic trouble following the Great Recession of 2007-8 and its legacy years on. A short glimpse of the smart grid aspects of this book are available in a Time article by Greenwald at http://business.time.com/2012/07/26/obamas-smartelectrical-grid-plan/.
} 
for venture capitalists. As venture capitalists funded startups and established companies from Solyndra and Solar City, to Tesla and Opower, the distributed technologies of the smart grid were subject to financial speculation as new financial products were created to aid development and investment in these firms.

From solar panels and associated hardware, to electric vehicles and energy storage, and energy efficiency programs, a large part of smart grid innovation was subject to the variability and risk of venture capital. In many sectors, this led some of the "thoughtleaders" to look towards the microcomputer and digital tech worlds for precedence. The term "disruption" often leads discussions of innovation and market opportunity. The story goes something like this: utilities are encountering a threat to their existing business models as distributed generation technologies electric vehicles, LED lights, and energy storage technologies "disrupt" the $\$ 300$ billion electricity market in the US. This presents an opportunity for investors to ride the wave of technological change, making great sums of money while helping the environment.

Even as investors position the old and failing grid as an investment opportunity, a way to make returns and profit, a blank slate for rebuilding our relationship to energy, we are encountering a hurdle. And it's not just technical. The move towards the smart grid has positioned the "social" front and center. Consumer/customer engagement, consumer behavior, and consumer empowerment have overtaken parts of the smart grid agenda. New utility departments focused on customer relations, outreach, and engagement have 
been appended to billing departments, often offering customer additional services. ${ }^{9}$ As the "social" is positioned as a key to smart grid development and success, new ways of managing the so-called "social element" has failed to take a more nuanced understanding beyond individual behavior change. Studies of behavior change fail to understand the broader social, political, and cultural context that shapes energy demand (Moezzi and Janda 2014; Lutzenhiser 1993; Shove 2010). Instead, they take only economic or environmental concerns as factors that influence individual decision-making.

For example, the smart grid research lead by the Department of Energy and national labs conducted a series of "consumer behavior studies" in numerous demonstration project locations: from Detroit to Sacramento. In Vermont, for example, the Transco eEnergy Project was a collaboration between 11 publicly and investor-owned utilities that implemented smart grid technologies on the transmission, distribution, and end-use areas of the grid. The consumer behavior study investigated the impacts of time-of-use and peak-time rebate programs utilizing customer web portals and in-home displays (Bleything et al. 2015). The study saw as its major question, "What influence do changing electricity prices have on residential utility consumers?” (Bleything et al. 2015, 5).

In their variable peak pricing events, customers were notified of upcoming changes in price, and findings suggest customers were responsive in the summer and spring (and less so in the winter) but they also noted uncertainty of perceived benefits. Customers reported saving money was their primary reason for participating in the program

\footnotetext{
9 Two important elements here: (1) organizational change to address growing importance of customer engagement, and (2) transition to energy services rather than purely commodity or a singular service.
} 
(Bleything et al. 2015, 48). Similarly, a study in FirstEnergy's Ohio Territory (conducted by EPRI) described their study focus was "to quantify how residential customers respond to a monetary inducement (Peak Time Rebate (PTR)) to reduce load during pre-specified hours (events) with a day's advance notice" (Neenan 2013, iii).

Referencing the successes of industrial and commercial demand response programs using similar "treatments" (or technological interventions or pricing events), this study highlighted that residential applications of demand response programs utilizing programmable communication thermostats (such as Nest) and in-home displays coupled with PTRs produced statistically significant responses (reductions) but with many caveats. These include rebound-effects of increases usage after event pricing, "event fatigue" which indicated less response over time as the summer progressed, and small or no reduction in total daily energy usage on days with pricing events (Neenan 2013, 6-3).

In general, the DOE's approach to consumer behavior studies focuses on economic or rate-based treatments for demand response including time-of-use pricing, variable peak pricing, and peak time rebates (Table 3). These are made possible by the rollout of advanced metering infrastructure (AMI), which enables data collection, storage, transmission, and communication to consumers and utilities at intervals ranging from one to sixty minutes. As the DOE explains, "By introducing more dynamic rates and providing customers with more detailed information about their usage patterns, AMI provides customers with an incentive to invest in control technologies that can make it easier for them to change their consumption patterns with real and predictable impacts on their overall electricity bills" (US Department of Energy 2011,2). 
Table 3: Rate schedules for demand response ${ }^{10}$

\begin{tabular}{|c|c|c|}
\hline Programs & Description & Participation \\
\hline $\begin{array}{l}\text { Time of Use Pric- } \\
\text { ing }\end{array}$ & $\begin{array}{l}\text { Broad blocks of hours are given specif- } \\
\text { ic rates which are predetermined and } \\
\text { constant (e.g. } 6 \text { hour peak vs. non } \\
\text { peak). }\end{array}$ & $\begin{array}{l}\text { Voluntary response to } \\
\text { price signals }\end{array}$ \\
\hline $\begin{array}{l}\text { Critical Peak Pric- } \\
\text { ing }\end{array}$ & $\begin{array}{l}\text { Prices vary when utilities are stressed } \\
\text { and they trigger a response event (e.g. } \\
\text { summer between } 3 \mathrm{pm} \text { and } 6 \mathrm{pm} \text { on a hot } \\
\text { day). Prices and duration may be prede- } \\
\text { termined or not. }\end{array}$ & $\begin{array}{l}\text { Voluntary response to } \\
\text { event pricing (substan- } \\
\text { tial increase) }\end{array}$ \\
\hline Real-Time Pricing & $\begin{array}{l}\text { Prices are updated on an hourly basis } \\
\text { based on market costs. }\end{array}$ & $\begin{array}{l}\text { Voluntary response or } \\
\text { automated response to } \\
\text { price signals through } \\
\text { opt-in programs and } \\
\text { smart appliances }\end{array}$ \\
\hline $\begin{array}{l}\text { Variable Peak Pric- } \\
\text { ing }\end{array}$ & $\begin{array}{l}\text { Similar to TOU, blocks of hours are } \\
\text { predetermined, however, prices fluctu- } \\
\text { ate based on market and utility condi- } \\
\text { tions }\end{array}$ & $\begin{array}{l}\text { Voluntary response or } \\
\text { automated response to } \\
\text { price signals through } \\
\text { opt-in programs and } \\
\text { smart appliances }\end{array}$ \\
\hline $\begin{array}{l}\text { Critical Peak Re- } \\
\text { bates }\end{array}$ & $\begin{array}{l}\text { Critical events are predicted and denot- } \\
\text { ed and price remains the same, but cus- } \\
\text { tomers are given a rebate at a predeter- } \\
\text { mined outcome for energy conserved } \\
\text { compared to historical or utility ex- } \\
\text { pected consumption }\end{array}$ & $\begin{array}{l}\text { Voluntary response or } \\
\text { automated response to } \\
\text { price signals through } \\
\text { opt-in programs and } \\
\text { smart appliances }\end{array}$ \\
\hline
\end{tabular}

Smart meter and user control technologies enable a new regulatory regime of dynamic pricing, which has been discussed in utility commissions and regulatory agencies across the country over the last decade (and longer) (Hausman and Neufeld 1984; Faruqui and Malko 1983; Faruqui and Sergici 2010). A key issue is economic recovery of investment in AMI for utilities which claim operational benefits are not enough, and in-

\footnotetext{
${ }^{10}$ See https://www.smartgrid.gov/recovery_act/time_based_rate_programs.html for more definitions.
} 
stead need benefits from peak demand reductions which can drastically reduce the cost of power at those times (from "peaker plants"). As such, demand response from the residential sector is a key component of making an economic argument for utilities to implement smart grid technologies (such as AMI).

Consumer behavior studies thus presented a key area of research for smart grid implementation. In the smart grid ARRA funding (of more than 3.4 billion dollars), the DOE "encouraged applicants to propose [consumer behavior] studies and collect hourly load and customer demographic data for investigating AMI and its ability to integrate pricing and customer systems to accomplish changes in the electricity usage and behavior of consumers"(US Department of Energy 2011, 3). Differences amongst "market segments" would need to be investigated: "Advanced metering infrastructure provides the opportunity to expand a utility's offering of time-based rate programs for electricity, potentially changing customer behavior through the interaction of pricing mechanisms, technology, and information systems in the home"(US Department of Energy 2011, 5). These ideas were also carried out in a number of other campaigns aimed towards education of the general public on the smart grid, and through different technological competitions (Green Button, Apps for Energy, etc.).

In the former, the US DOE "brought knowledge to power" (the Foucauldian metaphor here is too strong to pass) with the Smart Grid Book with aims to "acquaint nontechnical yet interested readers about: the existence of, and benefits accruing from, a smarter electrical grid; what the application of such intelligence means for our country; how DOE is involved in helping to accelerate its implementation"(US Department of Energy 2016b, i). With allusions to "killer apps," the way email changed our lives, and 
the colossal project of the interstate highway system, this introduction implies technological progress determines social change that will result in better social outcomes. The report communicates risks of rising demand, power reliability requirements, and the struggles of infrastructure to "keep up" with the digital economy. And it positions the smart grid as "an enabling machine" for EVs, renewable energy, energy storage, green buildings, and importantly, a "new era of consumer choice" (US Department of Energy 2016b, 15). The report also details the way the smart grid transforms consumers' relation to energy and introduces a new form of economic management and responsibility on the part of consumer for the electric grid and their "home":

For most consumers, energy has long been considered a passive purchase. After all, what choice have they been given? The typical electric bill is largely unintelligible to consumers and delivered days after the consumption actually occurs - giving consumers no visibility into decisions they could be making regarding their energy consumption. However, it pays to look at electric bills closely if for no other reason than this; they also typically include a hefty "mortgage payment" to pay for the infrastructure needed to generate and deliver power to consumers. A surprisingly substantial portion of your electric bill - between $33 \%-50 \%$ - is currently assigned to funding our "infrastructure mortgage," our current electric infrastructure. This item is non-negotiable because that infrastructure power plants, transmission lines, and everything else that connects them must be maintained to keep the grid running as reliably as it does. In fact, the transmission and distribution charge on the electric bill is specifically for infrastructure. With demand estimated to double by 2050 - and more power plants, transmission lines, transformers and substations to be built the costs of this "big iron" will also show up on your bill in one way or another. (The only difference this time is that global demand for the iron, steel, and concrete required to build this infrastructure will make these commodities far costlier; in fact, the cost of many raw materials and grid components has more than tripled since 2006.) (18)

In addition to this threat of rising utility bills, the DOE explains that consumers are going to benefit from smart grid implementation, and they are going to help the grid in a collective sense. Paradoxically, this "collective" sense of maintaining the grid is real- 
ized through changes in individual consumption habits and choice. President Obama remarked in his Policy Framework that "[E]very institution and every household has to start thinking about how are we reducing the amount of energy that we're using and doing it in more efficient ways" (Chopra, Kundra, and Weiser 2011).

The role of consumers is to be connected

by means of the right price signals and smart appliances, for example $-\mathrm{a}$ smarter grid can reduce the need for some of that infrastructure while keeping electricity reliable and affordable. [...] By enabling consumers to automatically reduce demand for brief periods through new technologies and motivating mechanisms like real-time pricing, the grid remains reliable - and consumers are compensated for their help. [...] Ultimately, tapping the collaborative power of millions of consumers to shed load will put significant brakes on the need for new infrastructure at any cost. [...] Consumers are advocating for choice in market after market, from telecom to entertainment. Already comfortable with the concept of timedifferentiated service thanks to time-dependent cell phone rates and airline fares, it follows that they just might want insight and visibility into the energy choices they are making, too. Enabled by Smart Grid technology and dynamic pricing, consumers will have the opportunity to see what price they are paying for energy before they buy - a powerful motivator toward managing their energy costs by reducing electric use during peak periods. Currently, recognition of the time-dependent cost of energy varies by region. In areas where costs are low and specialized rates to this point nonexistent, there is little interest or economic incentive on the part of the consumer to modify usage or even think about energy having an hourly cost. In California, on a hot afternoon, consumers are well aware of the possibility of a blackout driven by peak demand and familiar with adjusting their energy usage accordingly. [...]At the residential level, Smart Grid must be simple, "set-it-and-forget-it" technology, enabling consumers to easily adjust their own energy use. Equipped with rich, useful information, consumers can help manage load on-peak to save money and energy for themselves and, ultimately, all of us. (US Department of Energy 2016, 1920)

This characterization of the consumer role in the smart grid captures several issues. The first, which stems from the prior quote suggests a logic of dependence paradoxically positioned against control and responsibility. While there is a growing cost of the 
"infrastructure mortgage," consumers are supposed to contribute to solutions by reducing peak period consumption. Another key tension is pronounced here in the provision of information and consumer awareness and incentive to change behaviors against a logic of "set-it-and-forget-it" technological automation. While the desire for an informed and active consumer is detailed and made "real" through dynamic pricing, there is concern that consumers will not care enough to change with rhythms of the market. Thus, a logic of automation and control away from consumers is desirable.

Underlying these notions of consumer change is an economic understanding of energy consumption habits. In the findings of these studies, the DOE reported that smart meters "require customers to 'climb learning curves' that require extensive communication and education" (US Department of Energy 2014, iv). This implies normalization of smart technologies is needed for their success in reducing peak demand and enabling further innovations. But this process of normalization also carries specific logics, economic and managerial. Similarly, in programs such as the popular Green Button - an initiative of the Obama Administration facilitated through the Smart Grid Interoperability Panel to work with utilities, technology companies, and entrepreneurs to develop privatesector online tools for providing customers information on energy use.

Armed with that information, consumers can use a growing array of new web and smartphone tools to make more informed energy decisions, optimize the size and cost-effectiveness of solar panels for their home, or verify that energy-efficiency retrofit investments are performing as promised. Consumers can even use fun innovative apps that allow individuals to compete against Facebook friends to save energy and lower their carbon emissions. (US Department of Energy 2016a)

Green Button provides open data for app developers and utilities alike. The focus is on data provision and catering to influence and shape the behavior of consumers. 
Green Button has brought together federal agencies (e.g. NIST, DOE), industry groups (e.g. Association for Demand Response and Smart Grid (ADS)), utilities (e.g. Austin Energy, SDG\&E, PG\&E, etc.), and technology companies (e.g. Itron, Tendril, Comverge, etc.) to "empower residential consumers to better manage their electricity consumption by allowing them and authorized third parties access to their electricity usage information on demand through a standardized data access architecture" (US Department of Energy 2016a). Similarly, Itron, a giant in the smart metering industry, released a press statement on the Green Button in which the President and CEO, Leroy Nosbaum was quoted: "Itron is deeply committed to changing the way energy is managed by providing tools to empower consumers who want to control their energy usage and costs. [...] With a modernized grid and engaged consumers, we aim to achieve broad societal, environmental and financial benefits and help build a sustainable future" (S. Moore 2012).

Other companies, smaller startups like Tendril, for example, offer energy management apps and services that help utilities "succeed in the Age of the Customer, [where] what matters most is user experience. Look no further than the taxi industry, which Uber has completely upended with its mobile app and its focus on simplicity for the consumer" (Tendril 2016, 3). The proliferation of digital technologies, on-demand services, and smartphone ease of access is forecast to alter social expectations about energy utilities as well. The customer no longer is passive, but active, informed, and engaged. The discourse of empowerment captures this trend, but does so in the context of energy management. Empowerment here refers to the ability to control consumption, to manage the household activities that consume energy, and to renegotiate social practices around price signals and other utility cues. 
The Environmental Defense Fund utilizes a similar discourse to describe the smart grid and demand response possibilities of consumer engagement. By quoting former FERC Chairman, Jon Wellinghoff, saying "Demand response is clearly the 'killer application' for the smart grid," and emphasizing the way demand response enables consumer to "take control over their energy use and lower their electricity bills," EDF highlighted the role of consumer empowerment and technologies for engaging consumers in protecting the environment (EDF 2014). The US EPA, likewise, explained that the smart grid can also be a "green grid," but this depends largely on consumer behavior:

Many of the benefits of a smart grid come from expected changes in consumer behavior. However, it is difficult to accurately predict how customers will react to price signals. It is possible that customers may not change their electricity demands much, even when faced with different prices at different times of the day. [...] If customer demand is not notably affected, then the costs of smart grid implementation may outweigh the benefits. Putting into place proper, complementary policies (such as funding broader programmatic efforts to educate and encourage customers to save energy and adopting fair rates and interconnection standards for distributed generation) are therefore critical for successful implementation of a smart grid. (US EPA 2011,6)

The utility industry had similar concerns with the notion that "consumers don't understand that it costs more to produce electricity at peak times," suggesting their lack of education and understanding are barriers to smart grid implementation (Spencer and Vadari 2009, 49). Digital technologies, information, and education - "knowledge" dissemination - is seen as a key component of smart grid success (Vadari 2009; Durand 2013; Ockwell 2016; Casey and Jones 2013; Chassin 2010; Hledik 2014). Consumer empowerment is the vehicle to communicate and spread this knowledge. Programs have been designed to be more passive, or more active (Table 4), playing on different types of consumer "segments": "innovators" who are tech savvy, "early adopters" who are opin- 
ion leaders for their social networks, "early majority", a "late majority", and laggards (Spencer and Vadari 2009; Pedersen, Hydro, and Authority 2008). Rate designs accompany these different approaches, which poses issues for equity and fairness.

Table 4: General types of user participation in industry discourse

\begin{tabular}{|c|c|c|c|}
\hline Programs & Activities & Technologies & Outcomes \\
\hline Passive/Motivational & Opt-in program & $\begin{array}{l}\text { Programmable con- } \\
\text { trollable thermo- } \\
\text { stats }\end{array}$ & $\begin{array}{l}\text { Consumers con- } \\
\text { trols temperature } \\
\text { and other systems } \\
\text { (innovators) }\end{array}$ \\
\hline Active/Motivational & $\begin{array}{l}\text { Response to mes- } \\
\text { saging and dynam- } \\
\text { ic pricing }\end{array}$ & $\begin{array}{l}\text { Normative messag- } \\
\text { ing on utility bills } \\
\text { or through apps or } \\
\text { texts }\end{array}$ & $\begin{array}{l}\text { Consumer behav- } \\
\text { ior change possible } \\
\text { (early adopters) }\end{array}$ \\
\hline Passive/Enabling & $\begin{array}{l}\text { Incentives to } \\
\text { change behavior or } \\
\text { technology }\end{array}$ & $\begin{array}{l}\text { HEMS, GreenBut- } \\
\text { ton, Web Portals, } \\
\text { etc. }\end{array}$ & $\begin{array}{l}\text { Suggestions on } \\
\text { how to reduce con- } \\
\text { sumption (early } \\
\text { majority) }\end{array}$ \\
\hline Active/Enabling & $\begin{array}{l}\text { Incentives to opt- } \\
\text { in }\end{array}$ & $\begin{array}{l}\text { Smart appliances } \\
\text { and thermostats }\end{array}$ & $\begin{array}{l}\text { "Set and forget" } \\
\text { approach where } \\
\text { utilities control } \\
\text { tech (late majority) }\end{array}$ \\
\hline
\end{tabular}

New interest groups with industry partners have been formed specifically around consumers in the smart grid (i.e. the Smart Grid Consumer Collaborative), while staid consumer advocacy and privacy groups have made a presence in smart grid discussions (e.g. Electric Privacy Information Center). The Smart Grid Consumer Collaborative was formed through a group of companies and organizations including GE, IBM, Silver Spring Networks, the GridWise Alliance, NREL, and others in March 2010. The purpose and mission of the organization was to boost consumer acceptance for the smart grid (Price and Thomson 2009; Price 2010). The organization continues to do advocacy, plan- 
ning and policy work, addressing consumer needs that correlate with smart grid implementation. ${ }^{11}$

There is an inherent tension here between consumer protection, for privacy and other data security concerns, and consumer education and awareness. This is represented in the different discourses and issues as discussed by different consumer advocacy groups. For example, the SGCC focuses on "consumer empowerment" and "value propositions" to the consumer, while EPIC focuses on the collection and use of data for information provision (i.e. "empowerment") programs and concerns over privacy and security. While facilitated by the same technological intervention, the technical bits of how data management and who manages data, for example, are still to be worked out in a contested sociotechnical domain.

\subsubsection{Summary of discourse analysis}

This discourse analysis revealed three rationalities and associated techniques and imagined subjects that form a specific form of governmentality in the smart grid. This governmentality attempts to render electricity system issues technical, in a "will to improve," as Li $(2007 \mathrm{~b}, 7)$ suggests, that directs knowledge and action to address particular problematizations.

First, the electricity system is problematized as inefficient, or at least not as efficient as it could be. The discussion of efficiency above highlighted the way new smart technologies enable more efficient production, transfer, and consumption of electricity,

\footnotetext{
${ }^{11}$ See http://smartgridcc.org/
} 
and at the same time, more efficient means of transacting electricity markets. This is backed by a techno-economic episteme, understanding electricity as a strictly technological system. New technologies enable the envisioning, monitoring, and identification of deficiencies in the system making them open and ready for change (creating the field of visibility). The notion of efficiency is also tied to the idea that governing electricity markets and technologies will result in better outcomes, less waste, lower cost, greater benefits (telos).

Efficiency is both the means and ends in this case. Techniques that enable greater efficiency include the implementation of ICTs for the smart grid, the regulatory space and coordination to allow for electricity markets, and the everyday practices of engineers and economists who utilize their expertise towards maximizing efficiency. The imagined subjects and identities concerned with efficiency are not only engineers that privilege efficiency over competing concerns (cybersecurity for example), but also particular publics who value market-led decision making over public regulation.

Second, while most literature on energy security refers to geopolitics or cybersecurity (M. Amin 2008; Clastres 2011), here I mean security in the sense Foucault discussed related to security "apparatuses" in his lectures on governmentality. Security here refers to the rationalities of government, providing "security" for a particular population of governed subjects. Security as related to electricity system, then, considers electricity as a vital infrastructure for human well-being. Management of this critical infrastructure is dominated by the techno-economic episteme enacted as technological solutionism fueled by concerns over economic losses resulting from failures or blackouts. Similar to 
efficiency, then, the both the approach to governing and its telos are dominated by engineering and economics that shape political discussion and governmental approaches.

Here, however, the techniques differ because they refer to securitization. Whereas efficiency saw the technological benefits of ICTs and smart grid technologies as ways to improve processes for reduction of costs, the rationalities of security utilize techniques to maintain normal conditions, ensure reliable supply, and smooth demand. This implies, however, an imagined subject who participates in demand side schemes, either in voluntary programs, or in opt-out type forms of automation.

Lastly, I highlighted the theme of economy. Here, again, a techno-economic episteme shapes the field of visibility and the telos of government, but as a political rationality it is much aligned with Foucault's discussion of neoliberal governmentality (Foucault 2010). Here, the techniques are related with the economization of all aspects of life (W. Brown 2015), policies and technologies that enable price mechanisms to guide decisions of "active" consumers. As Brown $(2015,61)$ explains, "the distinctiveness of neoliberalism, for Foucault, is that it 'generalizes the economic form of the market' or 'generalizes the 'enterprise' form within the social body,' producing an 'economization of the entire social field."

Techniques highlighted above include various forms of pricing, behavioral experiments, consumer engagement, and public education. The notion of economy relates to self-regulation and enterprise, two concepts that Foucault explained were central to a neoliberal form of governmentality that places the imagined economic subject, homo oeconomicus, at its center. As such, homo oeconomicus, is created through the "idea and practice of responsibilization - forcing the subject to become a responsible self-investor 
and self-provider-reconfigures the correct comportment of the subject from one naturally driven by satisfying interests to one forced to engage in a particular form of selfsustenance that meshes with the morality of the state and the health of the economy" (Brown 2015, 84). The rationality of economy, thus, places the conduct of populations towards using energy differently, in lines with the health of the grid system, as the proper or correct mode of conduct.

Each of the governmental rationalities discussed above solidifies the smart grid not only as a sociotechnical system that is under transition or change, but a governmental program that seeks to "conduct the conduct" of energy consumers in lines with efficiency, security, and economy.

\subsubsection{Review of findings}

This section has focused on the discourse of powerful smart grid actors at the national scale. These actors influence state and local level smart grid projects and implementation as funders, experts, and producers of discourse from positions of power. Through analysis of documents, texts, policies, speeches, websites, scholarly and industry journals, and media, I identified major discourse strands and grouped them around three primary analytical categories: efficiency, security, and economy.

I found that the dominant discourse highlights technical and economic efficiencies in relation to security and economy benefits, while positioning consumer adoption, education, and awareness as the major barrier to smart grid implementation. The result of this is a growing effort to educate and inform consumers, a discourse of "empowerment," that focuses on energy savings through behavior change and technology adoption motivated 
primarily by monetary gains (or cost savings). This discourse, and the smart technologies which make these programs possible, are utilized by an emergent governance regime that has moved beyond the utility-regulator model to involve a broader array of stakeholders in a utility- regulator- interest group model.

While this shift signals greater consideration of the consumer, the dominant discourse explains a knowledge-power relationship that privileges economic, social psychological approaches to understanding consumer energy use behavior. These models have been critiqued for their lack of attention to larger structures of power. However, using a Foucauldian governmentality perspective, it is also clear that power operates in more diffuse and subtle ways, through knowledge and techniques and rationales of smart grid programs, compromising a form of governing the smart grid through economic, consumer subjects.

\subsection{Conclusion: The Smart Grid and Smart Consumer}

In this chapter, I presented a discourse analysis of major policy, regulatory, technical, media, and interest group texts. I highlighted several different promises of the smart grid, accompanying visions, and the discursive storylines that weave together various actors, practices, technologies, and rules in a sociotechnical regime. The main argument of the chapter is that the discourse of the smart grid shapes the conceptions of domestic energy consumption as a purely (or mostly) economic and individual activity, enacting governmental power to enable a governance regime that shapes the conduct of energy consumers. 
I interpreted the discourse using an analytics of governmentality, describing the ways in which relations of power/knowledge are manifest through "technologies of government" to manage and control populations of economic subjects (homo oeconomicus). In this regard, I focused not only the control and governance of populations through the exercise of various forms of state power (biopower and biopolitical technologies) through information provision, behavioral nudging, metrics, labels, and standards - and also on the central role of energy in the shaping of social action and political power.

This analysis of governmentality aids in our study of sociotechnical transitions because it adds an important dimension of power, understanding how the transition towards the smart grid is also part of a governmental program. This places emphasis on the rationalities, techniques and subjectivities, highlighted above, which enable and enact the governing of the conduct of energy consumers. As Li (2007a, 279) explains:

a program is the goal to be accomplished, together with the rationale that makes it thinkable, and the associated strategies and techniques. In order to formulate a governmental program, the domain to be governed must be rendered technical, that is, represented "as an intelligible field with specifiable limits and particular characteristics...whose component parts are linked together in some more or less systematic manner by forces, attractions and coexistences." The relevant ensemble of population must be bounded, linked to a defined problem, and that problem linked again to an account of the mechanisms through which the problem can be addressed, the design for measures for evaluation and so on.

Therefore, what I outlined above positions the smart grid as a governmental program, one that has real impacts on the sociotechnical system of the smart grid. Yet, "real" impacts do not mean that the envisioned program is fully realized. Power operates and produces actual effects, but with limitations. As Li (2007a, 279) explains, programs are not determinant, they have "instabilities, fragilities, and fractures" that often create 
grounds for "new programming." This is particularly important in the context of sociotechnical transitions. Transitions depend on instabilities in regimes for niche innovations to be realized. These niche-regime dynamics, however, are influenced strongly by governmental programs that attempt to shape the conduct of a population in line with particular rationalities of governance. This highlights a need for attention to the practices of everyday life in studies of sociotechnical transitions and further ethnographic study (Shove and Walker 2010). 


\section{Chapter 4: "A Living Lab for the Smart Grid": Experimentation, Governmen- tality, and Urban Energy Transitions}

\subsection{Urban Living Labs and Smart Grids}

Cities are increasingly experimenting with smart grid technologies to simultaneously address climate change, environmental, economic, and sustainability concerns. Reconfiguring urban electricity systems to allow for more renewable energy integration, increased reliability, and new forms of consumer engagement have been seen as a vital ingredient for a smart, and low-carbon, energy transition. In attempts to govern energy transitions, sociotechnical interventions are being tested out in experimental venues where new knowledge can be gained on how cities are best to react to pertinent energy sustainability issues. On the one hand, experimentation offers opportunities for radical alternatives and innovations, and on the other, it opens pathways for existing regimes to be further entrenched.

In Austin, Texas, an urban smart grid experiment known locally as the Pecan Street Project, was developed as an urban living lab to demonstrate and learn from various sociotechnical interventions. Fueled by local political leaders, a private-public part-

nership, and a national smart grid demonstration program (funding support), the Pecan Street Project created "the most innovative neighborhood" and the "world's largest database on customer energy use" (Frangoul 2015). By engaging environmentally concerned and/or technologically savvy residents of the Mueller neighborhood (and beyond) with incentives to adopt electric vehicles, solar panels, home energy management systems (HEMS) and numerous other smart technologies, Pecan Street was able to get considera- 
ble participation and access to collect fine-grained data on energy usage of consumers. This urban smart grid experiment has garnered attention from numerous city officials, technology companies, and researchers interested in the smart energy transition and all of its possible benefits, including "jolting up the green economy."

Urban smart grid projects, like this one, are being pursued as experiments that take place outside the normal processes of long-term planning and investment aimed at improving both physical and social infrastructures. In the face of stalled state and national action on climate change, cities have become key sites for the governance of energy transitions (Rutherford \& Coutard, 2014; Rutherford \& Jaglin, 2015). Urban energy governance, as Rutherford and Jaglin (2015, p. 174) note, refers to the "multitude of ways in which urban actors engage with energy systems, flows, and infrastructures in order to meet particular collective goals and needs, framed or expressed in policymaking processes, but also in debates, contestations, and conflicts over policy orientations, resources, and outcomes." This definition suggests that urban energy governance does not only rest in official policy making procedures or contestations, but also in the various ways that urban actors interact with energy infrastructures.

Urban living labs (ULLs) are one mode of experimentation. They are simultaneously modes of technological implementation in the "real-world," forms of experimentation that facilitate learning and experiential knowledge production, and social arrangements that interlink various actors from research and development to government and industry. ULLs are one particular mode of urban experimentation that facilitates action in a particular (often closed-off) place. The burgeoning literature and emergent policy attention to living labs suggests that they can serve not only as one-off projects for demonstra- 
tion, but sustained sociotechnical niches that help cities achieve goals for sustainability and low-carbon transition more broadly. At the same time, however, ULLs are often oneoff projects, mapping particular pathways and materializing visions, but not generative of systemic change.

ULLs have been implemented to address a variety of challenges, especially relating to climate adaptation, urban sustainability, and more recently, "smart" technology. At the intersection of these challenges is the urban smart grid. The growth of smart city and smart grid projects has made integration of digital information and communication technologies (ICTs) a prominent part of the urban electricity system (Marvin, Luque-Ayala, and McFarlane 2015; McLean, Bulkeley, and Crang 2015). Smart grids are being implemented as a "necessary" part of a larger transition to "smart" urban infrastructures. The "smart city" has become a dominant trope for the future city arising in discrete places all over the globe. Although the definition of smart is broad and discordant, there is considerable purchase in the idea that smart urbanism is a necessary socio-technological progression for the cities we inhabit (Marvin, Luque-Ayala, and McFarlane 2015). The growth in smart city plans and projects, corporate models and businesses emerging around smart technologies and services, and the staggering figures on the projected value of smart cities markets point towards an established trend. For example, ARUP, a consulting and engineering firm, estimated the value of "smart city solutions and additional services required for deploying them to be $\$ 408$ billion by 2020" (ARUP 2013). With such tremendous investment potential, smart city advocates and companies are promoting transformative visions of urban futures riddled with techno-utopian fantasies and a whole array of smart city technologies and products for cities to test-out (Luque-Ayala and 
Marvin 2015; Wiig 2015). These promises and fantasies are infiltrating the minds of powerful decision-makers in cities around the globe - from India's 100 Smart Cities project to the Smart London Plan.

A dominant area of concern across comprehensive smart city projects is energy: the more efficient use of energy, integration of renewable energy, and a more robust and resilient energy system. The smart grid integrates ICTs with the electricity system to provide data on the use, distribution, supply, and demand of electricity on the electrical grid. Equipped with sensors, monitors, and internet-enabled digital communication devices, data circulates alongside electrons to provide information on outages, time-of-use, variations in loads, and energy consumption in fine-grained detail. But the smart grid is much more than an array of networked technologies. As Luque (2014, p. 160) explains, "the smart grid is an assemblage of networks, technologies, and users interacting through telecommunications platforms. It is a socio-technical intervention that relies on utility networks, technological equipment and digital software as well as knowledge networks and an emerging set of user practices." As a socio-technical intervention, smart grids offer a jumping off point for new relations of production and consumption, but also further investment and public buy-in for larger smart city projects including implementation of smart, networked technologies for transportation, environmental conditions monitoring, water, waste, government operations, etc.

The urban smart grid project discussed in this chapter configures governance through experimentation (Bulkeley \& Castán Broto, 2013b; Castán Broto \& Bulkeley, 2013a), utilizing the city as a place to experiment with different ways of implementing and governing smart grid technologies and infrastructures. But it also is an experiment in 
changing the way energy users interact with energy infrastructures and consume energy. This chapter thus fills an empirical need to explicate how experimentation aims to reconfigure everyday energy use through smart technologies utilizing theories of governmentality.

I start by discussing how ULLs are created materially and discursively as particular places - living laboratories, demonstrations, and test-beds. ULLs tend to focus heavily on demonstration and market-testing rather than radical changes or transitions towards low-carbon or socially just urban futures. I then discuss the development of the smart grid experiment in Austin and how this experimentation facilitated demonstration and test-bedding approaches. This 'governing by experiment' relates to the broader political economy of urban development in the knowledge-based and high-tech economy of Austin. I then explicate how smart grid experiments attempt to reconfigure the relationship that consumers have with energy systems. Using insights from governmentality studies, I argue that smart grid experiments rely on governing through "smart" subjects who reshape their energy consumption patterns in line with individual economic or environmental concerns. The discursive formation of smart subjects used to characterize and govern energy consumption limits our ability for innovative energy system changes that are sensitive to the social context of consumption - meeting the demands of everyday urban life. Tying smartness to neoliberal forms of rationality paints the smart grid end-user as an entrepreneurial subject, wherein the practice of governance focuses on individual environmental commitment motivated by reductions in energy costs, environmental egoism, or the acquisition of more sustainable technologies and products. This influences the design of ULLs, their practice, and the knowledge produced from their implementation. 


\subsection{Laboratorizing the City: A Smart Grid Experiment in Austin, Texas}

Claims that are true everywhere should come from nowhere in particular... Experiments conducted in physical surrounds just like anyone else's lab become "everybody's" beliefs (Gieryn, 2008, p.798)

For the world to become knowable, it must become a laboratory (Latour, 1999, p. 43)

\subsubsection{Labs in, of, or for the city?}

Cities are increasingly made the node for experimentation with sociotechnical interventions for sustainability and low-carbon transitions through living laboratories (König and Evans 2012), urban laboratories (Evans \& Karvonen, 2013; Karvonen \& van Heur, 2014), and urban living labs (Reimer et al. 2012; Voytenko et al. 2016). The concept of the laboratory invokes the idea of a sterile, enclosed, and exclusive space for knowledge production wherein scientific experiments are run separate from society (Strebel and Jacobs 2014; Evans and Karvonen 2013; Gopakumar 2014; Heathcott 2005; T. F. Gieryn 2006; B. L. Allen 2011). But classic work in science and technology studies (STS) - especially laboratory studies in the late 1970s - examined and unpacked the "hard core" of scientific work: its technical content and the production of knowledge (Knorr-Cetina 1995). ${ }^{12}$ These early studies showed how cultural and social process impacted and shaped the work of scientists and "contaminated" the otherwise sanitized and purified scientific process.

\footnotetext{
${ }^{12}$ See Latour, B. and S. Woolgar (1979) Laboratory life: the social construction of scientific facts. Princeton University Press, Princeton, NJ; Lynch, M. (1985) Art and artifact in laboratory science: a study of shop work and shop talk in a research laboratory. Routledge, London.
} 
The laboratory itself, as Knorr-Cetina (1995) posits, is an important theoretical notion in the social studies of science because it reveals "the power of locales in modern institutions and raise[s] questions about the status of 'the local' in modern society in general." At the same time, Livingstone (2003, p. 3) suggests that the laboratory is a privileged place of knowledge production, where a concerted effort was made to create it as a "placeless place" to do scientific activities and where local contingency has no impact on those activities. A laboratory here is the same as a laboratory anywhere. This "placelessness" was also key to securing the credibility and objectivity. The concept of placelessness poses difficulties for ULLs, however, because they are situated in urban contexts which often have porous boundaries presenting a complex mix of endogenous and exogenous or environmental factors contributing to observed changes. At the same time, the place of an urban living lab tends to influence the legitimacy and credibility of knowledge claims within and about the city (Gieryn, 2006). For example, early Chicago School urban sociology used the city both as a field site - an uncorrupted reality — and a laboratory - a controlled environment providing the ability for generalizations true for other cities. Living labs tend to draw on the virtues of both lab and field, wherein the city becomes both the object (what) and venue (where) of study, allowing multiple modes of inquiry to make "valid" claims while "creating a discursive situation in which location, geography and situated materialities get foregrounded as ratifiers of believability" (Gieryn, 2006, p. 28). Sites where knowledge claims are made about the efficacy of urban sustainability or low-carbon transitions have a bearing on how urban sustainability or low-carbon transitions are defined and legitimated. 


\subsubsection{Urban living labs and governance}

As a mode of governing urban sociotechnical systems, such as the smart grid, living labs facilitate forms of experimentation that utilize place-based claims and claims to placelessness simultaneously. This central tension filters through the two modes of urban energy governance examined in this chapter: governing by experiment and governing through consumer-subjects. First, governing by experiment relies on place-based claims to demonstrate the efficacy of urban experiments, to provide material manifestations of possible futures, and to show how novel sociotechnical configurations work in the realworld. At the same time, knowledge generated from these experiments is supposed to be useful in other places, providing a real-world "truth-spot" that attests legitimacy of claims. The design and siting of the living lab are important political resources for giving authority to experiments and building momentum for transitions. As Gieryn (2006, p.28) notes, "political pronouncements have different consequences when uttered from the street corner - or from the floor of an official parliamentary space." So, while experimentation may harness the radical contingency and messiness of cities, living labs provide a structured and politically powerful space for protecting and nurturing sociotechnical interventions.

Secondly, governing through smart subjects expresses a mode of governance tied to relations of power tied to the provision of information and proper conduct, building on Foucault's concept of governmentality. Instead of using place or placelessness to support claims, ULLs use the discursive space of the "laboratory" to attempt to shape actions and behaviors through power relations, practiced primarily through discourse but also embodied in technologies, or forms of political knowledge and rationality undergirded by ne- 
oliberal conceptions of homo oeconomicus, or economic man. Similar to Strengers (2013, p. 51) "resource man" - "a data-driven, information-hungry, technology-savvy home energy manager" - homo oeconomicus captures the subjectivity of energy users implied in many urban living lab strategies. The critical perspective of Foucauldian governmentality helps us to locate and potentially confront this political rationality in urban smart grid experiments.

At the same time, STS scholars show us how science and technology co-produce social orders and arrangements (Jasanoff, 2004a). In particular, technological systems generate certain forms of "user scripts" - sets of "normal" and acceptable use for various technologies - which govern the way people use technologies (Oudshoorn and Pinch 2005). These technological inscriptions are of course contestable and open to change. Technologies have "interpretive flexibility" but often are locked-in over time (Bijker, Hughes, and Pinch 1987), becoming part of larger sociotechnical systems, sets of practices, and political economic rationalities that make them resistant to change. As smart technologies are implemented in the context of ULLs, they configure particular sets of user practices normal and acceptable. In the smart grid, this is primarily concerned with energy conservation and the temporality of energy use. Modifications in use behavior are supposed to be achieved by persuading, nudging, or convincing through appeals to environmental or economic rationalities. The epistemological approaches of social psychology and economics influence these strategies of governing energy consumption - information provision and enhanced control made possible by the use of smart grid technologies. Governmental logics and forms of expertise are solidified in smart grid technologies. 


\subsubsection{A living lab for the smart grid in Austin, Texas}

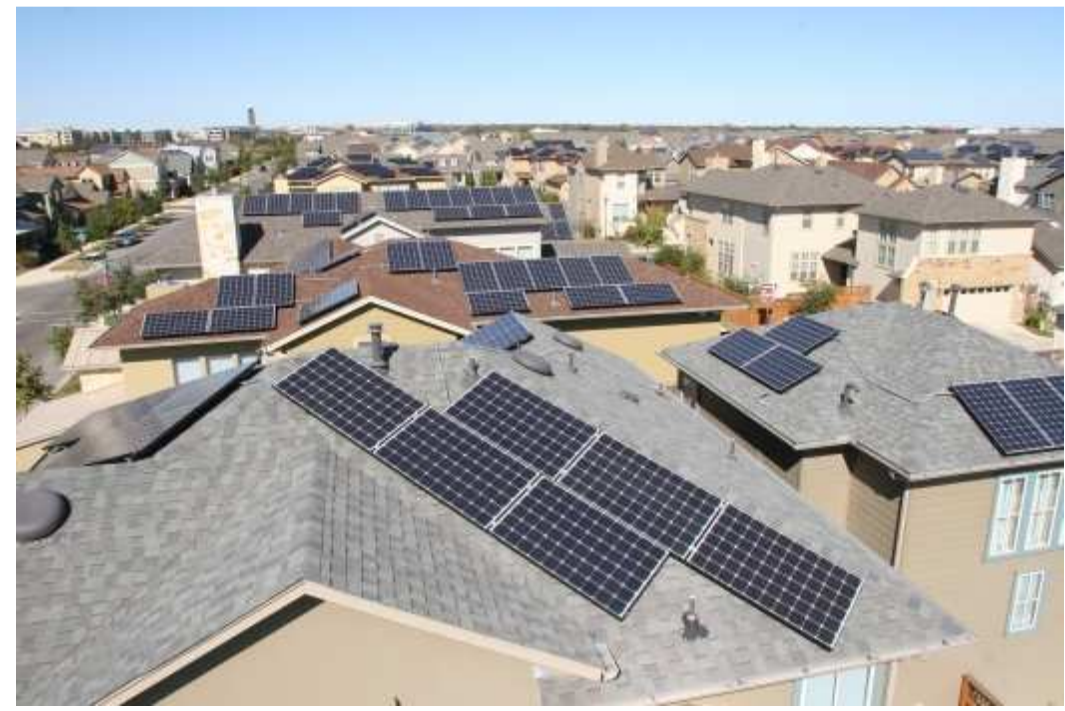

Figure 8: Aerial view of solar installations in Mueller neighborhood. Photo: Energy.gov. Accessed at: http://energy.gov/sites/prod/files/styles/borealis_article_hero_respondmedium/public/Aus tin\%20Energy\%20-\%20Mueller\%20development.JPG? itok=EQBFEVOq

The City of Austin has been recognized as a leader in sustainability. Austin is known for an environmentalist ethos that emerged most prominently in the actions to preserve Barton Springs and the Edwards Aquifer during the 1970s and 80s, an issue that aligned various actors on two sides of a long-term environmental and political struggle (S. A. Moore, 2007). Since the early 1990s, the city has worked to tackle energy and climate issues through green building programs, energy efficiency strategies, and implementation of clean energy production. With the growth in Austin's economy - focused on creative and tech industries - the city is positioned as a leader for innovation in clean tech and clean energy solutions. The large research university - the University of Texas (UTAustin) - has also positioned Austin as an important hub for knowledge-based industries, often leveraging university partnerships for research and development. Austin's organizational structure of energy provision also helps to foster an engaged citizenry: Austin 
has one of the largest municipal utilities in the nation, Austin Energy, responsible to Austin's City Council. These characteristics of Texas's most liberal and progressive city created a favorable environment for the smart grid demonstration project implemented by Pecan Street, a 503 (c) non-profit research and development organization.

The smart grid project, originally known as the Pecan Street Project, aimed to research and learn from the implementation of various smart grid and smart home technologies - including solar panels, electric vehicles, various home energy management systems, smart meters, control and visualization technologies, and energy storage technologies - implemented in an urban neighborhood. The project started at the Mueller Development - a private-public redevelopment project that commenced in 2004 on a nearly 700-acre defunct airport base just three miles northeast of downtown Austin and the University of Texas. The redevelopment project was a source of political contestation during development and more recently during disputes over affordability and density (ClarkMadison 2002; King 2015; Reeves 2008). As the LEED certified neighborhood was celebrated for its sustainability, it was able to gain the political momentum needed for implementation of the development plan. The "clean slate" of the new development project also served as an ideal location for the Pecan Street urban living lab project. As one interviewee mentioned:

Our research started here because it's really easy for us to get involved with people when they are building homes. It started here because it was easy to get people, the equipment. We had our laboratory here... it's easier when they are doing new construction to get some of these things put in. We knew they had good electrical service if we wanted to do any electrical testing, you know things like batteries, EV level 2 chargers, its harder when you get into old homes, it costs a lot more. (Pecan Street representative, Interview, October 2015). 
The demands of the smart grid experiment, thus, required a physical infrastructure that was already "modernized," or in this case, built from scratch. This included the development of Austin Energy's smart grid platform (Carvallo and Cooper 2015), new green-built homes, and Pecan Street's own information and communications or smart grid network. In addition, to test various smart grid technologies, the research participants needed to acquire various smart grid technologies - everything from solar panels and electric vehicles to smart appliances and home energy management systems (HEMS) equipped with visualization and control technologies. The new development project in central Austin was the ideal location for this ULL also because it served as a way to recruit participants for the research Pecan Street would conduct. As one of the studies based on the demonstration project describes it: "Mueller was selected as the test-bed for this research project because of its location, the relative uniformity of new homes, and the developer's requirement to build energy efficient homes and buildings" (Rhodes et al., 2014: 463).

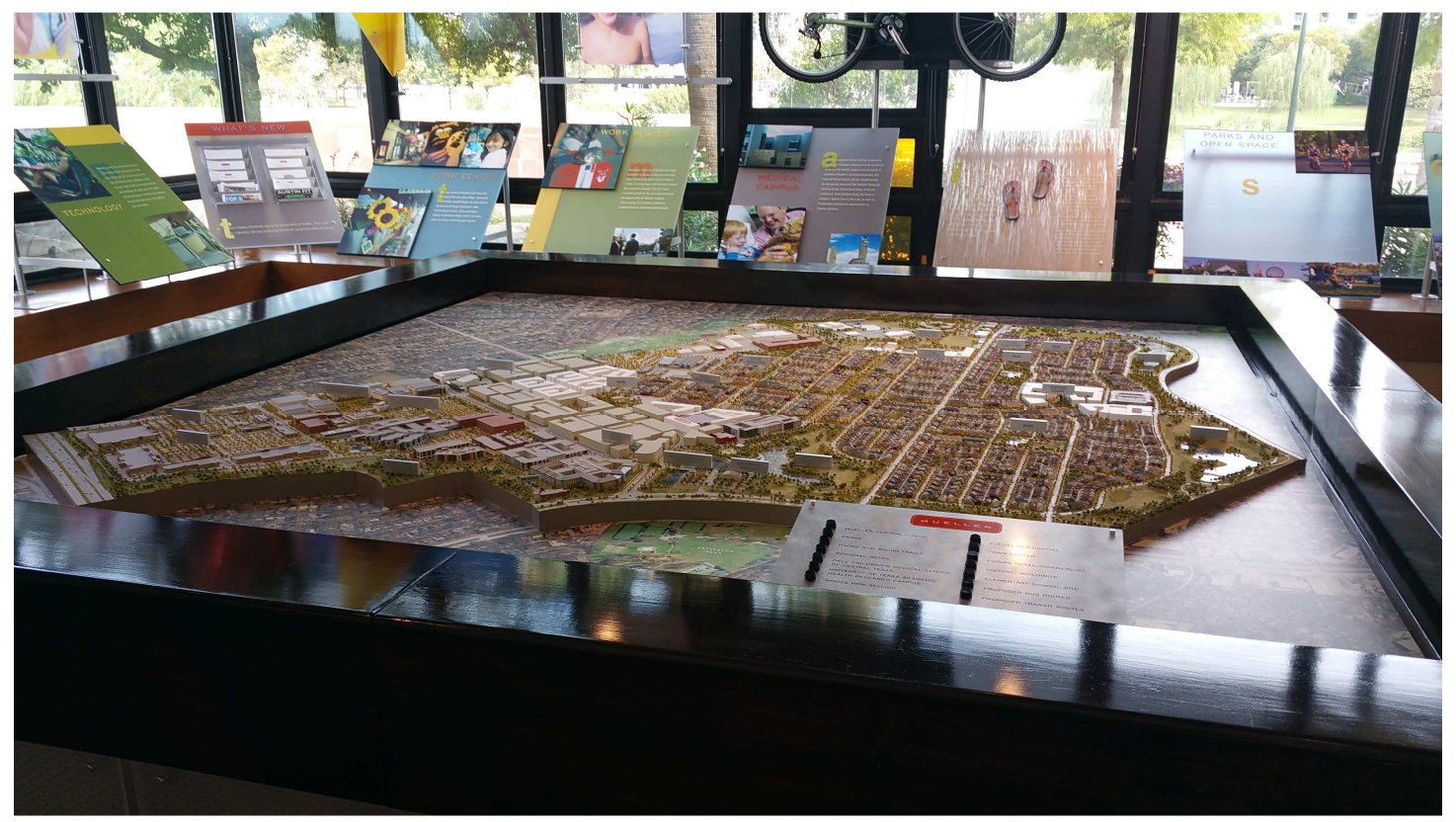


Figure 9: Three dimensional model of Mueller PUD in the development offices on site. The right side of the model shows the planned residential area and are of future housing growth. Photo: Anthony M. Levenda.

The living laboratory project started as a partnership with the University of Texas, the Mueller Development, the City of Austin, Austin Energy (the municipal utility), the Austin Technology Incubator and industry partners, led by the non-profit umbrella organization, Pecan Street Inc. Now known simply as Pecan Street, the organization has been leading research and implementation of smart grid technologies on "the consumer-side of the grid" (Pecan Street representative, Interview, October 2015). The smart grid experiment started as an "energy internet demonstration" project, spurred and supported by a Department of Energy Smart Grid Demonstration grant part of the larger American Recovery and Reinvestment Act (ARRA) of 2009. One of the key actors in the project described the genesis of the project and explained its initial purpose and goals:

That group came together and then, I acted as chairman of the group, and we applied for DOE grant that kicked us off with major funding. So we started working and focusing on the data acquisition and manipulation side of energy, energy efficiency, renewable energy, electric vehicles and so forth. And through the DOE grant we were able to take a new development at the Mueller Airport site and focus on it. [...] Through that grant we were able to focus on a mass deployment of both electric vehicles and solar, so we had the highest concentration of electric vehicles and solar in any neighborhood in the country. We were able to analyze the impact of that on the electric grid. And of course it's a new grid out there the city put in, but we were able to show such things as how the electric vehicles, well we did electric vehicles initially and I was part of the group that got the automakers to build plug-in hybrids and such. One of the arguments we made for them was that there was plenty of capacity for the electric vehicles because people would be charging at night. Well, we actually didn't know that... [laughter] and if everyone was plugging in their vehicles and charging them in the afternoon, then that adds to the problem rather than relieving it. Fortunately, the research has shown the charging is spread out pretty evenly throughout and we were able to document that and show it. And we were also able to show that orientation of solar on the roof between south and west, and the benefit to the electric utility with a different 
orientation and carry that forward, and we expanded from there. We have a very sophisticated data collection now, making it available to universities around the world, and curated data sets, and a lot of different resources going on now. Because we are able to, we are about the only place able to get 15 second granularity of the data by circuit on this built infrastructure, the home and such. (Former Austin Energy Executive, Interview, May 2016)

As the interview quotation above suggests, the project was aimed at proving that smart grid technologies would allow integration of electric vehicles and distributed solar generation reliably. The data collected through the smart grid project also helped show the efficacy of interventions, with granularity providing greater insights. By focusing on energy monitoring and data collection, Pecan Street's database, analysis and sharing wiki, Dataport, the group has built a fundamental resource for energy research in smart grids. The dissemination of information via Dataport on energy consumption and production has influenced numerous lessons and possible research trajectories on energy management both by consumers and utilities (inter alia Alahakoon \& Yu, 2013; Ranganathan \& Nygard, 2011). This ever-growing dataset is informing research on a variety of issues positioned as solutions for numerous energy and environmental problems (such as climate change) and technical problems for utilities (such as demand side management and peak load shaving). This focus has positioned this smart grid experiment as a place for learning about how to create a viable and profitable smart energy transition.

\subsection{Governing through Experimentation: Demonstration and Test-bedding}

Pressures to mitigate and adapt to climate change are necessitating and shaping urban transitions to sustainability. As actors and sites for transitions, cities have developed key strategic responses in the form of urban experiments with new policies and 
technologies. Experiments are "purposive and strategic but explicitly seek to capture new forms of learning or experience... they are interventions to try out new ideas and methods in the context of future uncertainties serving to understand how interventions work in practice, in new contexts where they are thought of as innovative" (Castán Broto \& Bulkeley, 2013: 93). They offer the "means through which discourses and visions concerning the future of cities are rendered practical, and governable" (Bulkeley and Castan Broto, 2013b: 367). The way localities respond to and govern energy challenges such as climate change and sustainability are, in part, choreographed and mediated through the experimental landscapes and infrastructures of ULLs. Thus, ULLs not only require consideration as spaces of knowledge production and innovation, but also as places where (the future of) cities are governed.

ULLs entail different forms of experimentation that characterize and define the ULL itself. Although many scholars suggest that ULLs move beyond policy experiments or "protected" niche innovations, they also seem malleable enough to include protected sociotechnical niches, private sector-led test-beds, and technological demonstrations. Thus, ULLs may be thought of as experiments to carry out sociotechnical interventions and associated policies, demonstrations of particular technological systems carried out in real-world settings, or as test-beds or niches for testing out various technologies in controlled settings. In many ways, the smart grid experiment carried out in Austin fits all of these definitions, suggesting the framing of the ULL and its various interventions is important to its broader impacts on urban (energy) governance.

ULLs are not only aimed at guiding particular "experiments" but are experiments themselves. This disambiguation explains the difference between living labs as mere 
hosts of technological interventions, and living labs as unique sociotechnical configurations that promise learning and radical innovations in both social and technical realms. ULLs can be more formalized experiments, consisting of a "specific type of niche that is often created by university-led partnerships to emphasize the importance of knowledge production" (Evans and Karvonen, 2011: 415). And like many other ULLs they often simply provide a space for "testing existing forms of knowledge and technology" (Evans, 2011: 225) in the context of the city.

While experiments offer opportunities for learning and radical innovation, they also may simply reinforce existing regimes. Experiments are often driven by the motivations of powerful actors - profit, a sense of urgency to act, a desire to expand authority and express ideologies. These are all clearly visible in the ways cities are responding in experiments, and in the visions they express discursively and manifest materially (Hodson and Marvin 2009a; While, Jonas, and Gibbs 2010). At the same time, experiments can be exclusionary, technological "fixes" for issues that are inherently social and political, reflecting particular visions of powerful actors and interests reinforcing or creating new injustices (Swyngedouw 2011; While, Jonas, and Gibbs 2004). Experimentation offers opportunities to "open-up" the city for private investment and control of urban infrastructures. Fitting with the dominant form of neoliberal urban governance, governing through experiment aligns with the entrepreneurial role of local governments (T. Hall and Hubbard 1996; Davidson and Gleeson 2014; MacLeod 2002). As Harvey (1989: 5) argued, with the turn from managerialism to entrepreneurialism in urban governance, "investment increasingly takes the form of a negotiation between international finance capital and local powers doing the best they can to maximise the attractiveness of the local 
site as a lure for capitalist development." Opening up the city as a test-bed or a demonstration site for new smart technologies provides an opportunity to attract highly mobile capital. However, this may have "splintering" impacts in the city (Graham and Marvin 2001) that create spaces of high-value while simultaneously excluding and marginalizing other spaces and communities.

Numerous case studies and a plethora of literature supports this idea, understanding local processes of globalization and urban development wherein the state becomes a facilitator rather than regulator of market processes leading to, for example, gentrification and displacement, privatization and financialization of infrastructures (Swyngedouw 2004; Torrance 2008; Hackworth 2008; Peck, Theodore, and Brenner 2009; Brenner 2004). Similarly, entrepreneurial urban strategies and policies focused on creating spaces that can reproduce a system of accumulation have taken on sustainability and the urban environment as a central focus in order to clear new spaces for development and to neutralize political opposition (While, Jonas, and Gibbs 2004; Davidson and Gleeson 2014). Under these "new environmental politics of urban development," carbon reduction strategies, such as implementation of low-carbon infrastructures, have profound implications for interurban competition and the practices of local governance and planning (Jonas, Gibbs, and While 2011; While, Jonas, and Gibbs 2010).

In Austin, for example, the Mueller redevelopment project has been marred with the problematics of meeting and sustaining affordable housing requirements guaranteed in the original partnership and development agreement. This problematic stems from the Travis Central Appraisal District (TCAD) methods for taxation, appraising affordable housing at market rates, sometimes 100 percent over the purchase price (King 2015). 
While the rising attention to the Mueller redevelopment as a model of sustainability has captured the attention of so-called new urbanists and sustainability officers of cities around the world, it has also contributed a growing unaffordable housing market and the correlated issue of greater displacement of communities of color in east Austin (Long 2016).

A representative of the development group involved with the project explained the conundrum of meeting the 25 percent affordable housing commitment referring to some of the technical details with appraisal and homeowners selling the affordable homes at market rates, and the nonprofit Mueller Foundation:

The original buyer, in a lot of affordable housing programs, they are only required to stay in the home a year before they sell it, and they bought it at a controlled price, but they can sell it at market price and then get a windfall which wasn't what the city was trying to achieve. So the idea was how can you prevent that from happening, have people gain from the appreciation of the asset, and the investment and the responsibility they had, but reinvest that and keep the program going. Not lose that house into just a market value housing. So the foundation has, essentially, the first option to keep the house in the program and sell it to another affordable buyer so that way we imagine affordability will be here in the much longer term. (Catellus Development Representative, Interview, November 2015)

While the affordability issue of "losing properties to the market" was battled with a nonprofit organization, the Mueller Foundation, considerable taxation increases based on market-rate appraisals were creating un-affordable conditions for many homeowners. The program's commitment to a sustained affordable homes program is laudable, but the struggle to keep housing "off the market" will likely continue as the redevelopment project continues to add new housing units into the future. And while many of the initial homeowners benefitted from the subsidies and tax breaks organized by the Pecan Street project, state government, and federal government, the access to smart grid technologies 
(including EVs, PV systems, HEM systems, smart appliances, etc) may not reach the broad growing community of affordable homes buyers. The affordability issues are not only tied to the improved infrastructure of the redevelopment and the technological innovation spurred by the ULL project, but it also signals a larger trend in the political economy of Austin's urban development with the creation of "ecological enclaves" for welloff sustainability-minded citizens and urban "technological zones" for the testing and establishing network and connection standards for new ICT infrastructures (Barry 2006; Hodson and Marvin 2010c).

A popular media story portrayed the Mueller development as a "masterwork of smart urban design," a model for sustainable new-urbanism concepts in practice, and home to the smart grid demonstration project, but also highlighted several incidents at Mueller that illustrates the community's struggles with racial segregation (Burnett 2015a; Burnett 2015b). The problematic of inequality does not escape the settings of ULLs or urban experiments, and instead, the Mueller community highlights how the context of ULLs must be considered when conducting different sociotechnical interventions so that inequalities are not further reinforced.

Mueller's sustainability features also made the development particularly desirable for conducting research on smart grids and renewable energy. As a representative of the development group explained:

On the sustainability front, the Pecan Street consortium, the community leaders, the City of Austin, the electric utility, the university, the significant leaders in the commercial community were trying to look ahead at Austin's future and talk about how do we manage the grid how do we as a utility better supply, but where do we find better energy options, they were trying to grapple with the future of electric and water utilities. So that group for at least two years before the DOE grant opportunities came up 
were at work in the conceptual, lets have a vision about this, lets figure out something long-range because our community is going to need that and so the DOE was doing smart clean energy demonstration grants so that became it was viewed as an opportunity to take this thinking about what the future could be and apply for a grant to really pursue what those alternatives might be and to do what DOE was looking for which was demonstration projects. So they were evolving that thinking about what that would look like, and this development with a sustainability platform and a green building approach was being rolled out, it was a logical marriage that that demonstration project could be housed here, and its expanded well beyond Mueller for the types of study they are doing. But to have a place to begin, and the advances that were being made in how the infrastructure was being delivered here and what they could do with all this new housing that was all at least a 3 star building requirement and they could do all the smart meters and they knew that there were controls already in the infrastructure to support the project, that this would be a logical place to do it. The application went through that way. And being a public-private partnership and the city of Austin being the utility all of that made a whole lot of sense. (Catellus Development Representative, Interview, November 2015)

As a sustainability-focused development with a "clean-slate" of green-built homes, and a newly modernized electrical grid, the smart grid experiment and demonstration was thought to "logically" fit at Mueller. This highlighted the necessities of new infrastructure for integration of smart grid technologies, and the difficulties of retrofitting older homes.

\subsubsection{Urban living labs as demonstrations}

Providing vision and leadership is essential to governing in a democracy (Ezrahi 1990). Living labs test out competing visions of urban energy futures that align various actors around extensive reconfigurations of urban infrastructures (Bulkeley, Castan Broto, \& Maassen, 2013). These visions reflect broadly shared values and beliefs about technologies and their social impacts (Jasanoff 2004b; Jasanoff and Kim 2009). Living labs offer ways to produce, reinforce, and strengthen particular visions of technologically mediated urban futures (Bulkeley \& Castán Broto, 2013b; Hodson \& Marvin, 2009a; 
Reimer et al., 2012). At the same time, they provide opportunities to address global climate and energy concerns with particular "testable" or demonstrated solutions in localized places (Bulkeley \& Castán Broto, 2012; Castán Broto \& Bulkeley, 2013a). Alternative conceptions of urban experimentation offer different and often competing modes of knowledge production about urban sustainability that provide a different set of norms and rules by which communities can respond to climate change.

Serving as a model for other urban sustainability projects, the Mueller neighborhood the takes this as a central goal. The Mueller development itself - not just the Pecan Street project - is characterized as an urban living lab and a model for sustainable urban development. A representative of the development company explained:

A model of urban development, that's part of our vision. We actually learned from Stapleton, and other folks are learning from us.The other thing that this has done for the City of Austin is that it sort of has become a living lab. A lot of the zoning for this site was done as a PUD, a planned unit development, where you can have a lot of different regulations to the standard zoning or building ordinances. So for us it was narrower streets than you can build anywhere else in the city, the houses are closer together, the houses are closer to the curb, that whole new urbanist development style where you develop on a small footprint so you preserve open spaces, and so there were 100 differences to build what we are building at Mueller to what is normal for the ordinances in Austin. And they had to actually go department by department to say OK fire department, if a street is this wide, if the houses are alley served, are you going to be able to provide service. (Catellus Development Representative, Interview, November 2015)

Mueller had to push the threshold of what was prescribed for Austin development projects, and by doing so offered a controlled area wherein new ordinances could be tested for evaluation and possible future use and adoption in the great Austin area. The publicprivate partnership documentation - the Master Development Agreement between the City and developer - made many provisions for the PUD, and the design guidelines high- 
lighted how the community would focus on green buildings and green infrastructure to mitigate urban heat island impacts and protect the night sky, for example. The development project was cast both as a demonstration and a place of learning and experimentation.

In the case of the Pecan Street smart grid demonstration project, a similar trend of demonstration and learning is evident. Given the context of the project - the Mueller development - the Environmental Defense Fund (2014) ardently promoted it:

The Mueller neighborhood, the locus of Pecan Street, is a laboratory of ideas and technologies that will move the nation's $\$ 1.3$ trillion electricity market toward a future in which energy is cheap, abundant and clean. If Pecan Street is successful, every neighborhood in America will look like it in 20 years.

Creating knowledge in living labs has an intensive focus on learning and demonstration. Thus, the way people view the living labs and the knowledge they generate or demonstrate is integral to the activities conducted within. This has informed the Pecan Street projects movement towards the production of datasets and an accessible database on home energy consumption. By focusing on energy monitoring and data collection, Pecan Street Inc.'s database, analysis and sharing wiki, Dataport, is a fundamental resource for energy research on smart grids:

We have built the world's preeminent research network of energy and water customers. The anonymized data from these volunteer participants' home electricity use, solar panel performance, electric vehicle charging, and response to utility programs has become the world's largest research database of customer water and disaggregated electricity insight. Our unique research network data is at the core of Dataport, which makes the terabytes of customer data accessible, manageable, visible and usable for university researchers around the world. In the year our data has been made available, researchers from more than 50 universities in 12 countries have joined. (PecanStreet.org, February 2015) 
This database serves several purposes. First, it offers researchers data on energy usage where smart technologies have been implemented. This influences research findings and possibly, future policies regarding smart grid systems. Second, it offers companies opportunities to see how effective their technologies are, both in terms of energy efficiency or reliability, and in terms of customer acceptance. As one Pecan Street representative explained:

We're always happy to exchange information with people. It really helps that we are a non-profit. [...] I talk to cities, I talk to for-profit companies. We meet with them and they say, what have you learned, and I'll be happy to tell the for-profit company that is trying to build a product that this is what we've learned, this is what's failed, and this is what's succeeded. [...] We're happy to show off our work, even though our work is in beta, and you would think that like oh we shouldn't show off our secrets before, but I'm happy to say like look, this is the cool stuff we are making right now. My job is to make sure we can get as much data as possible to give to people so they can utilize it and learn from it. (Pecan Street representative, Interview, October 2015)

Living labs, thus, can be viewed as a "theatre of proof" (W. Smith 2009; E. Simakova 2010) for ways of configuring smart technologies in urban space to achieve sustainable, low-carbon outcomes. Stemming from work in STS around the role of demonstrations and public engagement with technology (Rosental 2014; Marres 2011; Marres and Lezaun 2011; Laurent 2011), especially in contemporary practices of the product "launch" in high-tech industries, this notion of the theatre of proof typically is framed by the situation where an organization "offers a 'novel' product to 'the market" (Simakova 2010: 549). Living labs, I suggest, are not only places of knowledge production, but venues for linking technological artifacts and publics. In this sense, livings serve as mediators between possible sociotechnical futures and a wider public who might adopt the knowledge or technological systems emanating from the living lab. 


\subsubsection{Urban living labs as test-beds and protected niches}

Connecting local, place-based "experiments" to broader urban transitions has been the subject of much research utilizing the multi-level perspective on transitions. The MLP is primarily concerned with how sociotechnical regimes interact with niches and innovations that result in shifts or replacement of current regimes. Sociotechnical regimes are understood mainly as "rules" (Geels and Kemp 2007; Geels 2007) that guide and orient activities of social groups who maintain and refine sociotechnical systems.

As such, regimes shape and influence, and are hard to change. In the MLP, sociotechnical regimes include scientists, users, policy makers and societal groups outside technical fields. These regimes are the meso level of the MLP, niches are the micro level, and the sociotechnical landscape is the macro level. The sociotechnical landscape is exogenous, outside the direct influence of actors (Geels 2007). It is heterogeneous and includes issues such as economic growth, cultural and normative values, environmental problems such as climate change, and resource scarcities. It is also the large scale "material context of society, e.g. the material and spatial arrangement of cities, pervasive technologies, etc." (Geels 2007: 443). Niches may be thought of as the loci of innovation. They are the micro-level phenomenon, and often are "protected" spaces, or "incubators" for new technologies that protect them from market or societal pressures.

As protected niches, ULLs might serve as mediators in urban energy transitions but they are also geographical configurations that leverage local and regional assets to address more than local concerns and influence broader global audiences. Transitions research, however, is insufficiently prepared to account for the "the advantages, conflicts and tensions that are constituted by the economical, institutional, social and cultural terri- 
tories in which transitions dynamics and pathways by default are embedded, except as passive contexts" (Coenen \& Truffer, 2012: 367). Although some urban scholars and geographers have addressed the role of the city in transition processes (i.e. Bulkeley \& Castan Broto, 2013; Hodson \& Marvin, 2010a; 2010b; Karvonen \& Evans, 2013), there are still gaps in understanding that may be bridged by more actively engaging economic geographers and regional studies scholars in these issues (Coenen \& Truffer, 2012; Truffer \& Coenen, 2013). For example, links between transitions processes and uneven urban development and urban political economy still have yet to be made explicitly.

But the conception of a test-bedding approach helps bridge this gap in many ways by considering the development of "platforms" for development and testing. The rise of so-called "platform capitalism" (Morozov 2015) makes information infrastructure central to the provision of urban services, from transportation to energy, marked by the growth of the knowledge-based and sharing economies. The platform metaphor is popular in the electricity industry as well, and Pecan Street's original idea was to create a so-called "energy Internet" - an open-platform for testing a variety of smart grid technologies. The group developed their own open-platform that fits with the broader movement towards creating an "information technology platform that makes possible a wide range of new products and services that provide customer value" where "mobile phone app stores and the Internet provide powerful examples of how a grid operator can earn more revenue and catalyze significant private sector opportunity by structuring its grid as a platform for a broad range of private sector activity" (Pecan Street, 2011:7). The obvious allusions to the platform services such as Facebook, Amazon, and Uber are discussed here as models for the electric grid. This allusion to the cell phone apps provides a vision of a radically 
decentralized electricity system where grid operators supply a platform and utilities and new energy companies offer energy services to customers in a highly competitive electric marketplace. This vision has captivated a whole array of private sector actors operating on speculative future scenarios to capture the growing smart grid and internet of things markets. Cities operating in financially restricted positions with limited budgets and pressures to develop and meet a variety of public needs find this opportunity to attract capital enticing, thus creating entrepreneurial strategies to retain large smart grid and internet of things (IoT) companies.

In Austin, the Chamber of Commerce has a specific strategy to attract startups with potential to receive venture capital for growing their companies. Startups working on clean energy and power technology, creative and digital media technology, or data management are able to add to the key industries in Austin, all of which relate to smart grid technology and development. The Austin Chamber of Commerce boasts the municipal utilities commitment to renewable power, the Pecan Street's research potential, and ERCOT's willingness to integrate clean energy companies into their electric grid as drawing points for energy companies. ${ }^{13}$ Supportive of these efforts is the University of Texas Clean Energy Incubator, the Clean TX cluster development organization, and the already large clean tech industry located in Austin. But the city more largely is thought of as an experimental space for these companies, nurtured by the various resources the city offers. As one Chamber of Commerce representative explained:

${ }^{13}$ Please see: https://www.austinchamber.com/economic-development/key-industries/clean-energy-power. 
The Chamber cares about business. So we were tasked with bringing the industry, bringing the clean industry. We like what Pecan Street was doing, we do have a board seat because they are a pretty iconic clean tech group, and they are headquartered here. [...] From a more strategic standpoint this year is that, alright look, there is a lot of wind in this state, no one is going to come here and build a wind farm. There are a lot of solar panel manufacturers and there is a lot of, there are a lot of companies who support residential solar installations, and yada yada yada. So those companies, let's assume, these companies are going to continue to grow. What's the future of clean energy, clean tech? Its that efficiency piece, right. So, clean energy has grown into from renewables, natural gas, whatever into this 'how can we do things better, cheaper, faster?' Pecan Street is a great example. Any technology now, is what, my targets are less solar panel manufacturers and more people creating efficiency. So, like, anyone who is doing battery, software, hardware integration to support communications between utilities and residents, etcetera... there is a lot of software engineers here, there is a lot of people who know how to analyze data. Austin is a good fit for those companies. This is a natural place for them to be. [Clean tech] is going towards devices that communicate to create efficiencies. Austin is very good at, we have a lot of software engineers, and there is an incredible quality of life. You've got the Pecan Street Project where companies can test their sensors. You've got a very progressive utility, who is more or less open to adopting new things and trying new things, and they're changing their generation mix to look very green. (Chamber of Commerce Representative, Interview, November 2015)

The political-economic position of a sociotechnical regime has implications for how these "niches" infiltrate the urban fabric as socio-technological experiments in living labs. In Austin, for example, having a large public-private redevelopment project provided the opportunity for the smart grid demonstration project to flourish in a community of so-called "early adopters": largely upper-middle class residents that are motivated to save energy or participate in new technology testing.

We have a unique opportunity that if someone approaches us, and this happens all the time, someone will come up to us and say I have this product right. Like, these incubator companies will come up to us, I have this product, I need to get it field tested. We have three hundred volunteers in this neighborhood who will let us install it in their house. And, I would say, more than half of them want it in there, and the other half you usually have to convince a little bit with a financial incentive, and say hey if you 
let us install this we will give you a five dollar gift card to Home Depot, and most of them will say yes, but more than half will jump at the fact to become a test-bed you know what I mean. So I would wholeheartedly agree with that synopsis of Mueller [as a living laboratory]. It's a really great test-bed of people that are early-adopters. Now having said that, its also self selecting, right. Because everyone here is an early-adopter, so its really funny because we do work in Austin because we have to beat people off with a stick when we tell them have a new product and everyone wants it, I mean like I only got like twenty. But then its funny because we get paid by utilities to do work in other jurisdictions. We went to California of all places, and recruitment out there was so difficult because, A, no one knew who we were, and the utility wanted us to recruit a very specific location, and it was just hard to convince people to let us install our equipment in their house. And its funny because we have never, like, that kind of difficulty. It's really nice to work here because we have such a close relationship with the participants. (Pecan Street representative, Interview, October 2015)

Certainly, particular kinds of people are more likely to participate in field trials for new technologies, but what is less well understood is the role of citizens (users, consumers, or prosumers) in urban energy transitions and broader sustainability transitions. While there are more grassroots approaches that promise greater democratic engagement (Blanchet 2015; Seyfang and Haxeltine 2012; A. Smith et al. 2016), the approach taken in the Mueller neighborhood utilizes a more top-down approach where residents are encouraged to install technologies, receive incentives or benefits for doing so, and in return they participate in the research that monitors energy consumption and performance. This approach relies on "early-adopters" who are willing to participate in already designed programs, unlike a grassroots approach that focuses on collective visioning processes and ownership to govern energy system change. The focus of approaches taken in Pecan Street research, instead, is on individual energy consumption behaviors and technological efficiency, fitting with the existing sociotechnical regime of energy provision. While this is certainly a worthwhile project for understanding technical limits of the smart grid, this 
approach contributes to the lock-in of particular pathways for smart grid development without broader consideration of the various concerns of citizens or with structural limitations to managing energy consumption and production. This problematic is reinforced by the rhetoric of collaboration and innovation that much of the Mueller development officials use.

You had to have, I think again the spirit of collaboration that has always been around this supports doing innovative things, trying new things, testing new things, so it was the perfect setting for this. The DOE grant was applied for and they got the grant, the idea that the lab would be built so they could literally test things in the lab, the idea that there were people, residents moving into Mueller, into these homes, and that by virtue of the fact that this was rolling out, and we had connections with the homebuilders, that the introductions could be made between the research project and the residents, so we facilitated those introductions, finding people to introducing them to the demonstration project, and saying they were looking for volunteers, and having them meetings where pecan street could educate and inform and inspire and rally folks to participate. So they, that's the way we supported the research, or the opportunity for them to do research, and then how they have taken that and expanded that to the dimension of solar panels, and the dimension of electric cars, and the dimensions of both combined, and water savings. Because as the grant evolved, it wasn't just the supply but also the consumption part of it, so how do you manage both. And also understanding how its used. I'm sure you've heard about all the statistics about how much data they have, in such tiny increments, and what they're learning from that, and then also what they are learning as far as the end-user, and when you supply them with that kind of knowledge, does that change their behavior, and what does change their behavior, and how do you encourage that, how do you as a utility get people to do the right thing in their house. So its apparently the largest amount of data in the tiniest increments ever available. (Catellus Development Representative, Interview, November 2015)

In addition, governing by experiment in demonstrations and test-beds suggests that a particular, governable subject already exists. However, in ULLs and other urban experiments, urban citizens are often made to be the object of engagement - the engaged customer, active participant, technology adopter. The literature on urban experiments has 
treated these urban sociotechnical interventions mainly as governmental programs and projects applied to existing urban landscapes and populations. Empirically, however, as suggested in urban smart grid experiments, the governing of energy use is enacted through particular subjectivities. More than simply technological interventions aimed at increasing renewable integration or grid reliability, smart grid experiments attempt to orchestrate and govern energy demand according to particular political-economic rationalities.

\subsection{Making Smart Consumers, Governing Demand}

Urban living lab projects offer new opportunities for various actors to participate in urban energy and sustainability transitions. If ULLs take on test-bed or demonstration approaches, what are the roles of participants and other actors? Do test-bed approaches suggest citizens are just consumers awaiting more sustainable technologies, or are they passive observers of demonstration projects, waiting to lend their approval for new technological solutions? As smart grid experiments proliferate, customer-utility relations are being reconfigured. The consumer, or household, is positioned as an engaged and active consumer, making decisions about energy consumption throughout the day. The smart grid enacts a set of relations and practices, both materially and discursively, wherein the conduct of end-users is governed through "technologies of government" guided by particular political-economic rationalities. Smart grid experiments reconfigure familiar domains and categories - the household, the consumer - to govern how everyday practices are performed. 
For example, smart grid demonstration projects have increasingly used the vocabulary of customer engagement and empowerment (Gangale, Mengolini, and Onyeji 2013). The customer moves beyond the role as a passive consumer and becomes an active participant in the electricity grid with new responsibilities, choices, and opportunities (Naus, van Vliet, and Hendriksen 2015). Yet, as this discourse becomes pervasive, there is still little evidence that households are afforded autonomy or agency for engaging in smart energy transitions, with the existing sociotechnical regimes playing the dominant role in shaping the implementation and standardization of smart grid systems (Goulden et al. 2014).

The growth in attention to demand response, time-of-use pricing, and other "customer side" interventions have been celebrated by utilities and electricity providers as potential opportunities to shave or shift peak demand while increasing customer awareness and engagement. Yet, these practices rely on significant changes in energy consumption that have not been realized (Hargreaves, Nye, and Burgess 2013). Underlying much of these programs is a conceptualization of the end-user as a rational economic actor, or what Strengers (2013: 51) calls "resource man" - "a data-driven, information-hungry, technology-savvy home energy manager." These depicted smart end-users are made to be subjects, conscribed by social norms, expected to perform the scripted uses for smart technologies, with the encouragement to act rationally both economically and environmentally. 


\subsection{Rationalities of Governance Experimentation}

As discussed in Chapter 3, Foucault's lectures from 1977-1978 at the College de

France focused on the "genealogy of the modern state" wherein he built the concept of governmentality as a guideline for analyzing technologies of power with an analysis of political rationality (Lemke 2002). Governmentality helps us analyze how power operates beyond consensus or violence, linking technologies of the self (self-regulation) with technologies of domination (discipline), while also providing a linkage between the state apparatus and the constitution of the subject. Foucault posited that power was about "governing the forms of self-government, structuring and shaping the field of possible action of subjects" (Lemke, 2002: 50), or in other words, the "conduct of conduct."

Foucault also suggested that political rationality creates a discursive field wherein the exercise of power is made rational: “One isn't assessing things in terms of an absolute against which they could be evaluated as constituting more or less perfect forms of rationality, but rather examining how forms of rationality inscribe themselves in practices or systems of practices, and what role they play within them, because it's true that 'practices' don't exist without a certain regime of rationality" (Foucault, Burchell, Gordon, \& Miller, 1991: 79, italics added). Thus, if we take governmentality as a way to understand the governance of urban energy systems, we must understand the way it operates through the practices of those being governed (i.e. subjects), and the political rationalities informing these technologies of governance. Foucault's later lectures from 1979-1980 (Foucault, 2008) suggest that a specific neoliberal political rationality was coming to predominate the practice of government. 
The proliferation of "enterprises" was a central tenet within Foucault's understanding of neoliberalism. He suggested that that the role of homo oeconomicus - the consumer subject - is not so much a consumer as a person of "enterprise and production" (Foucault, 2008). Foucault (2008: 147-8) argued that the "generalization of forms of 'enterprise' by diffusing and multiplying them as much as possible ... within the social body is what is at stake in neoliberal policy. It is a matter of making the market, competition, and so the enterprise, into what could be called the formative power of society." Lois McNay (2009: 56) explains how neoliberal governmentality is expressed through the concept of "self as enterprise" where individuals are encouraged to view their lives and identities as an enterprise, "understood as a relation to the self based ultimately on a notion of incontestable economic interest." Foucault's investigation into American neoliberalism explains the proliferation of enterprise, entrepreneurship, and policies empowering individuals into the social fabric, and reveals its central importance as a reinforcement of neoliberal subjectivity.

The concept neoliberal governmentality can be extended to analyze the informational (self-) governance of home energy management through the shaping of discourse and standards of practice (Levenda, Mahmoudi, and Sussman 2015). Likewise, Bulkeley, Powells, \& Bell (2016: 20) argue that governing energy use in the smart grid "works through the disposition of sociomaterial configurations through which conducts unfold and accompanying processes of normalized what constitute both acceptable and optimal forms of conduct," and that smart grids entail a specific governmental program that works through "recomposing the ways in which everyday practices are conducted." It is 
in this sense that the reworking of relations of consumption and production in smart grid experiments can be understood through the notion of governmentality.

\subsubsection{Making smart subjects or a smart techno-fix?}

Smart grid experiments, as a governmental program and specific locale (i.e. in a ULL), suggest a proper and optimal form of social conduct for their participants. The idea of "self as enterprise" is central to the implementation, political legitimacy, and "success" of smart grid experiments. The promise of smart grids relies, in one part, on behavioral changes of users, expecting "smart users" to become active participants in the smart grid, performing their part as solar pioneers, eco-energy misers, or flexible energy users adjusting consumption to the dynamics of a time-of-use rate structure. In this sense, smart grid experiments "success" presupposes (rational and individual) market actors who manage their everyday practices in a careful, calculative, and reflexive way. But as the experience in some of the households in Austin's smart grid experiment show, people do not necessarily act "rationally." A Pecan Street representative explained this point directly with a story of a multi-family tenant and research participant:

We found crazy stuff occurring. We showed up to one unit, and, the guy knocks on the door, our technician, and he's like 'Oh I'm here to diagnose, there is a problem with our monitoring device,' and the guy goes, 'Oh yeah what's going on?' And he's like, 'well it always shows your oven's on', and the guy goes, 'yeah, my oven is on,' and our technician was like, 'no no no no, we show that your oven is on' and the guy's like, 'yeah yeah yeah, my oven's on.' And it turns out this guy just like left his oven on all the time. Cause like, he always wanted a hot oven because he didn't have a microwave and he'd throw his food in there when he wanted it hot, and he'd heat up his food and take it out and eat it. We have actually heard of other cases, by the way, since this where this has occurred which is just crazy to me, but nonetheless. So going to this person, we were like, it costs 
a lot of money to you right. And the guy had like no clue. (Pecan Street Representative, Interview, October 2015).

Similarly, a representative from the Environmental Defense Fund, a part of the founding of Pecan Street and a continuing member of the board, explained that from his research in the smart grid experiment in Austin, and on energy more generally, people just don't think or care about energy enough to change their behavior or their practices.

It's a very wonky subject, its not necessarily the most interesting conversation material for a lot of people so one barrier is just peoples interest levels. There is a statistic that is widely quoted that people think about their energy bills and electricity six minutes a year. For most people its not something that you choose to focus on. One barrier for scaling up demand response and smart technology and that sort of thing is just generating interest. I've talked to representatives of utilities. I feel like demand response is pretty well received, but I guess there is a barrier in the way its designed. Getting the design of these programs right so that customers have a positive experience, that's one of the current barriers for it to catch. Even if they don't think about it that much, they think about ways to save money, if something is a no-brainer, then you make that choice. (EDF Representative, Interview, October 2015)

As energy researchers engage with smart grid users, they often seem to get dismayed by the irrationality of human energy decisions. As the quote above illustrates, the researchers involved with smart grid experiments understand that end-users don't necessarily think about energy very often, but they still feel they can be persuaded economically. However, this logic is changing the nature of smart grid implementation. Lessons learned from early studies on energy efficiency impacts of smart meters and in-home displays suggest little evidence of sustained behavior change (Hargreaves, Nye, and Burgess 2010; Hargreaves, Nye, and Burgess 2013). Studies on voluntary demand response and time of use pricing have indicated that these options may work (Dyson et al. 2014; Muratori, Schuelke-Leech, and Rizzoni 2014), but the trend towards automating decision-making to 
maximize energy and economic efficiency seem to be the dominant trend. As one EDF representative explained:

In terms of energy efficiency and smart grid and how they are related, its just sort of the next evolution, its using machines and technology that doesn't have the human error element, or the human interest level, you have these items programmed to be more efficient and at scale that will take a lot of the human element of being more efficient with energy out of the equation. So its just the next evolution of it. It just makes it easier for humans to act with the environment in mind. I mean, humans might want to act with the environment in mind, but they have their priorities and they have a lot of other things to do that day, and some things slip through the cracks, and if you want to be a good environmentalist but that's a low priority for you that can slip through the cracks and the technology can make it a lot easier. (EDF Representative, Interview, October 2015)

While automation may provide energy and cost savings for end-users, it also rationalizes and normalizes the deep integration of smart technologies in everyday life most probably without deliberation over end-users concerns or values (Strengers 2013). Putting in place of a technological fix for the seeming inflexibility of energy demand and the irrationality of human behavior frames these problems as purely technical ones. But, these problems are more than technical. Energy demand is structured by the rhythms and patterns of everyday life (Walker 2014). Consumption is not for the sake of consumption, but rather for aiding in everyday practices shaped by social norms, habits, economic demands, and other conventions (Shove, Pantzar, and Watson 2012; Shove and Walker 2014). The limitations of the techno-economic approach exemplified by the forms of experimentation discussed in this chapter explains, however, is that the design and implementation of urban living labs -whether for smart grid experiments or other purposes - needs to be questioned along axes of social and political concern. Who shapes the agenda and vision of a 
living lab, what are the planned outcomes and impacts, and who benefits? All of these questions require further consideration in the study of ULLs.

\subsection{Conclusion: Urban Smart Grids for Whom?}

In this chapter I have highlighted how a specific urban living lab was constructed materially and discursively as a place of demonstration for public approval and a test-bed for smart technologies. Although there are certainly positive benefits from smart grid implementation and demonstration, the role of citizens in determining or influencing the pathways to a smart energy future seem to be limited to very narrow realms of participation through consumption. I suggested that the approach of neoliberal governmentality helps explain how the actions of users of ULLs are governed - proper forms of conduct that adhere to particular governmental rationalities described by techno-economic concerns. However, a contradictory trend towards automation and algorithmic, market-minded decision-making - a technological fix - is progressing such that the "empowered" consumer no longer needs to act on information provision, they simply adopt technologies and enroll in programs, reinstituting a passive consumer role.

Therefore, while the current approaches to smart grid experiments rely on reshaping the "conduct of conduct," there is a trend towards automation and a technoeconomic fix which vastly diminishes the potential for democratic engagement with planning or shaping energy systems. Just as smart city strategies that promise safer, healthier, more democratic, and sustainable cities, urban smart grid projects promise greater roles for consumers and place responsibility on citizens to facilitate change under a constrained environment and set of conditions. Yet, the agency of users is limited to 
consumption habits, preferences, and technology adoption. As ULLs for smart grid projects serve as demonstrations for particular pathways, there is risk that lock-in will occur without engagement of a broader public sphere (Verbong, Beemsterboer, and Sengers 2013). Experimentation must account for alternative visions to avoid furthering the notion that users and citizens are just barriers to smart grid implementation.

With the ever greater entrenchment of smart technologies, greater amounts of data are also being collected and analyzed. With the smart grid, this offers opportunities for the deepening of surveillance in everyday life (F. R. Klauser and Albrechtslund 2014), while at the same time strengthening the opportunities for "corporate storytelling" to further normalize unequal social relations in the smart grid and the smart city by placing the private corporation - with profit motives - at the center of the construction and implementation smart urban technologies (Söderström, Paasche, and Klauser 2014). The governmental rationalities of these projects must also take into account these private interests and the prescribed roles for urban citizens - now as smart-users, Resource Men, or neoliberal consumers.

By highlighting how particular governmental rationalities enable particular technologies to arise as solutions to urban problems, the problematics of "smart" user subjectivities in smart grid experiments, and the limitations of demonstration and test-bed approaches to ULLs, this chapter has raised several critical issues for future scholarship on ULLs. First, although ULLs promise ways to test-out and experiment with solutions to climate change and urban sustainability, they are in large part shaped by existing sociotechnical regimes with political economic interests and goals of developing technologi- 
cal fixes to urban problems. This also contributes to creating pockets of sustainability in the city where only small portions of the population benefit.

Second, as demonstrations, ULLs are significant opportunities to enroll public support for addressing key issues in transitions to urban sustainability or renewable energy. Yet, these approaches seem to have a limited conception of how users can interact with and participate in energy transitions. The Austin case study demonstrates that techno-economic approaches seek to regulate the conduct of individuals through economic incentives, but this limited approach fails when people act irrationally. Thus, a less democratic option of centralized automation and control is being pursued in smart grid implementation as a technological fix for the barriers of active human and user participation. These trends point towards the necessity of reinvigorating experimentation in ULLs with a radically democratic agenda. We should take seriously the role that seemingly oneoff experiments have for possible co-production of more sustainable and just urban futures. 


\section{Chapter 5: Mobile Experiments: Models, Visions, and Politics}

\subsection{Introduction}

The smart grid is largely discussed as a national project. The electric grid stretches across the entire continental US, linking together parts of generation, transmission, distribution and end-use in what some call the "largest machine ever built." But the grid is also regional in nature. Different regions of the country are linked to different electrical grids, managed and coordinated by different grid operators (ISOs or RTOs), individual utilities (such as Portland General Electric), or utility holding companies (such as PacifiCorp). These grid operators coordinate the supply and demand of electricity on a minute by minute basis, almost perfectly matching supply and demand to maintain the health and reliability of the grid (its frequency, $60 \mathrm{~Hz}$, and voltage, variable). In some regions, such as ERCOT in Texas, PJM in the east, or CAISO in California, the grid operators also operate a regional electricity market regulated by FERC. With deregulation, as discussed earlier, many generators were able to sell power to the wholesale markets being created in single or multi-state transmission networks. The development of ISOs and RTOs were central to the development of a competitive wholesale market. RTOs and ISOs are operators not owners of transmission networks. The mandatory 'unbundling' of utility services allowed transmission networks to be opened to many independent producers. Power producers sell power to the wholesale market where utilities and distributors sell it to the retail market, where eventually customers in residential, commercial, and (sometimes) industrial sectors purchase electricity at predetermined (usually) rates. This highly complex, multi-actor, multi-level system was traditionally much more simple: state regulators 
set rates (retail sales), utilities get guaranteed returns, and investors get promised, lowrisk dividends. This simple model, however, has been reworked in the name of competition and market-first policy, enabled by decades or deregulation, restructuring, and regulatory reforms.

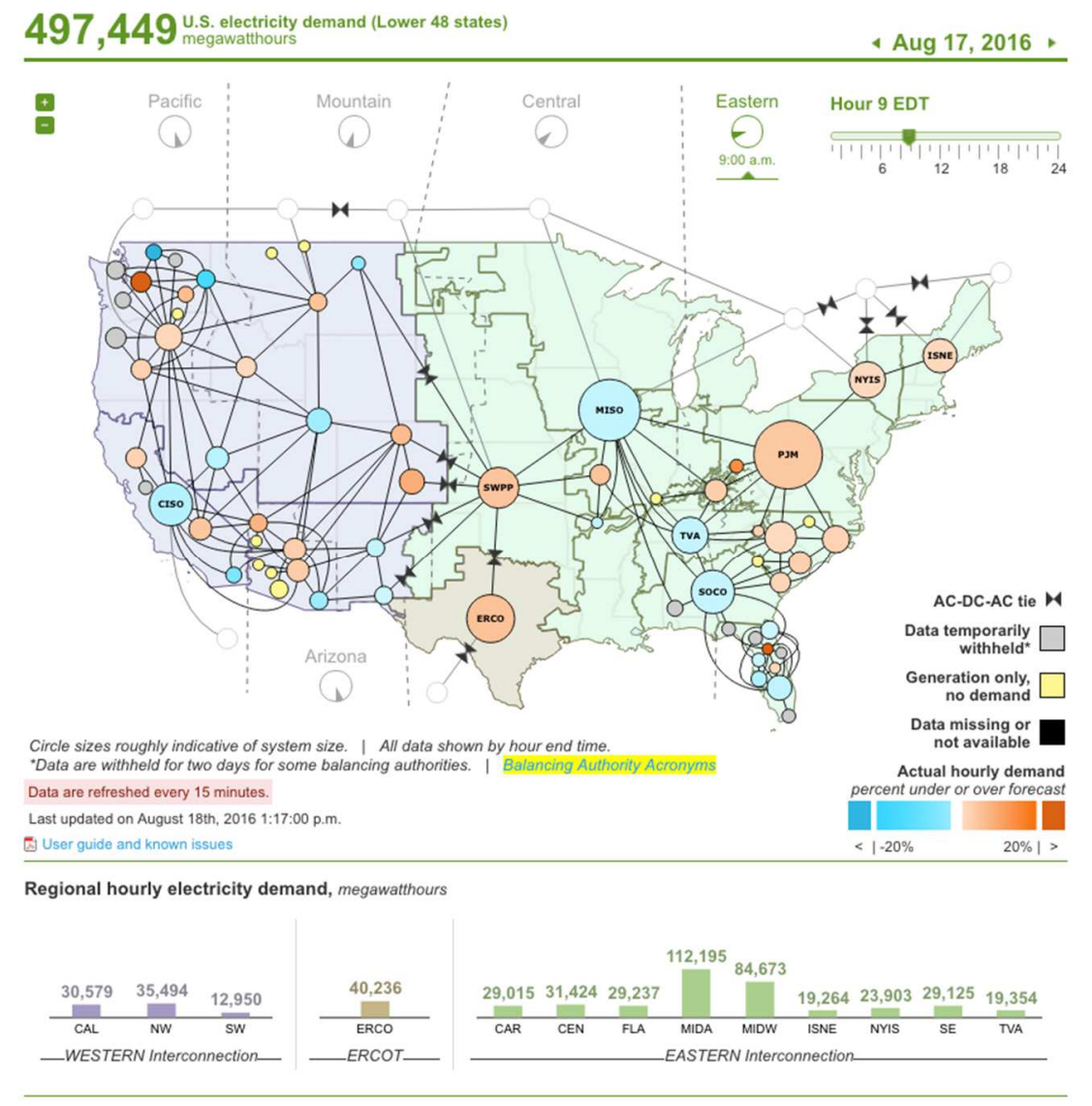

Figure 10: Balancing Authority, RTO, and ISO Regions. Source: eia.gov

The development of smart grid technologies, growing interest in microgrids, the increasing adoption of distributed generation such as solar PV, and the growing need to address climate change has cut into the revenue streams of utilities. Even as US electricity demand is increasing, and projected to continue to increase, the threat of a so-called "utility death spiral" has introduced anxiety and incited political conflict between utilities 
of incumbent regimes and citizens and government actors looking for solutions to climate problems. The utilities trade group, Edison Electric Institute (EEI), released a report in January 2013 explaining the financial implications of the changing utility business model making analogies to the telephone industry and citing the decline in credit ratings for the electric utility industry (Kind 2013). In particular, smart grid enabled technologies and programs such as distributed energy resources and demand side management are considered threats to utility revenues. As the report explains $(2013,1)$ :

While the various disruptive challenges facing the electric utility industry may have different implications, they all create adverse impacts on revenues, as well as on investor returns, and require individual solutions as part of a comprehensive program to address these disruptive trends. Left unaddressed, these financial pressures could have a major impact on realized equity returns, required investor returns, and credit quality. As a result, the future cost and availability of capital for the electric utility industry would be adversely impacted. This would lead to increasing customer rate pressures.

Adding to this pressure on existing utility regimes is the efforts by cities and states to meet greenhouse gas emission reductions and (in some states) renewable portfolio standards. In Austin, Texas, the municipal utility and its city council leadership has pressures from a conservative state legislature to pull back on progressive, local energy action and policy, such as the recent procurement of a $300 \mathrm{MW}$ solar power purchase agreement (Rockwell 2015; Trabish 2015). In Boulder, Colorado, for example, the contestation between the City and the utility, Xcel Energy operating locally as PSCO, has incited a near decade long, conflictual process of municipalization of the electric utility. In Fort Collins, Colorado, the municipal utility has struggled with power purchase agreements for renewables with the Platte River Power Authority who has less than five percent of its portfolio from non-hydro renewables and renewable energy credits. In Oak Park, Illinois, the sub- 
urb of Chicago has attempted to work with ComEd, its local utility, on demand management and solar PV programs to meet the community's environmental goals, but has landed short of the partnership desired and support needed. In each of these cases, smart grid experiments and demonstrations have captured the attention of city leaders and concerned citizen groups, but each has struggled with implementation and realization of broader visions due to conflicts with incumbent sociotechnical (or technopolitical) regimes. While the smart grid promises made on the national scale have ignited support and visions for a more efficient and secure energy future, experiences in cities attempting to implement these programs have had mixed results.

Learning from these cities experiences with smart grid implementation and demonstration projects - or broadly smart grid experiments - city officials, non-profits, and activists have tried to emulate or re-work bits and pieces of the experiments to see how they work in their own urban settings. In particular, Austin's Pecan Street smart grid experiment in the Mueller neighborhood has captured the attention of "vanguard" cities like Boulder and Boston. The impacts of smart grid experiments and demonstrations on urban energy transitions has remained understudied. And this is likely for good reason its difficult to trace these connections and influences outside formal policy channels. Recent work in urban studies and geography on "policy mobility," however, offers methods for studying these dynamics and insights into how influential projects might spur action in other urban domains.

In this chapter, I discuss the intersections of urban energy transitions, experimentation, and policy mobility which has received little attention in the scholarly literature, but has significant potential for building an understanding of innovation and knowledge 
transfer through processes of learning and adaptation in a relational perspective (McCann 2011b; Peck 2011; McCann and Ward 2011). The next section details some of the theoretical framework advanced in this chapter, and positions it in the existing literature. Section 3 presents three case studies of urban smart grid experiments that are interrelated, to varying extents, with the networks of actors, technologies, and knowledge of Austin's own smart grid experiment discussed in Chapter 4. The last section discusses some of the conclusions from the case studies and how they contribute to building a better understanding of urban energy transitions and embedded governmental logics in smart grid experiments.

\subsection{Urban Energy Transitions and Policy Mobilities}

The work in the developing field of "transition studies" has influenced a wide variety of scholars from urban studies, technology studies, political science, sociology and geography. At the center of this field is an understanding of sociotechnical change and innovation, typically explained with a historical and evolutionary model (Elzen, Geels, and Green 2004; Geels 2002; Geels and Raven 2006). The dominant multi-level perspective (MLP) (Figure 10) is primarily concerned with how sociotechnical regimes interact with niches and innovations that result in shifts or replacement of incumbent regimes. Sociotechnical regimes are understood as group of actors, institutions, norms, and technologies. The regime acts as a "rule set" for innovation (Geels and Kemp 2007; Geels 2007) that guides and orients activities of social groups who maintain and refine sociotechnical systems. Rip and Kemp $(1998,340)$ explain that these technological regimes are: 
... the rule-set or grammar embedded in a complex of engineering practices, production process technologies, product characteristics, skills and procedures, ways of handling relevant artifacts and persons, ways of defining problems; all of them embedded in institutions and infrastructures.

While there are numerous iterations of the definitions of sociotechnical regimes, and of course the similarly to Hecht's notion of technopolitical regimes cannot go unstated, there is a general consensus that regimes are powerful meso-level networks that influence transition processes and have stakes in the outcomes of sociotechnical change. Regime dynamics are power-laden. Regimes make, shape, and influence, but are hard to change. In the MLP, socio-technical regimes include scientists, users, policy makers and societal groups outside technical fields. These social groups interact and form networks with mutual dependencies (Geels 2007). These regimes are the meso level of the MLP, while niches are the micro level, and the sociotechnical landscape is the macro level (as depicted in Figure 11). The sociotechnical landscape is exogenous, outside the direct influence of actors (Geels 2007). It is heterogeneous and includes issues such as economic growth, cultural and normative values, environmental problems such as climate change, and resource scarcities. It is also the large scale "material context of society, e.g. the material and spatial arrangement of cities, pervasive technologies, etc." (Geels 2007: 443). Niches may be thought of as the loci of innovation. They are the micro-level phenomenon, and often are "protected" spaces, or "incubators" for new technologies that protect them from market or societal pressures. In contexts such as urban smart grid experiments, niches infiltrate the urban fabric and become important sites in urban political economies and urban transitions at the same time. 


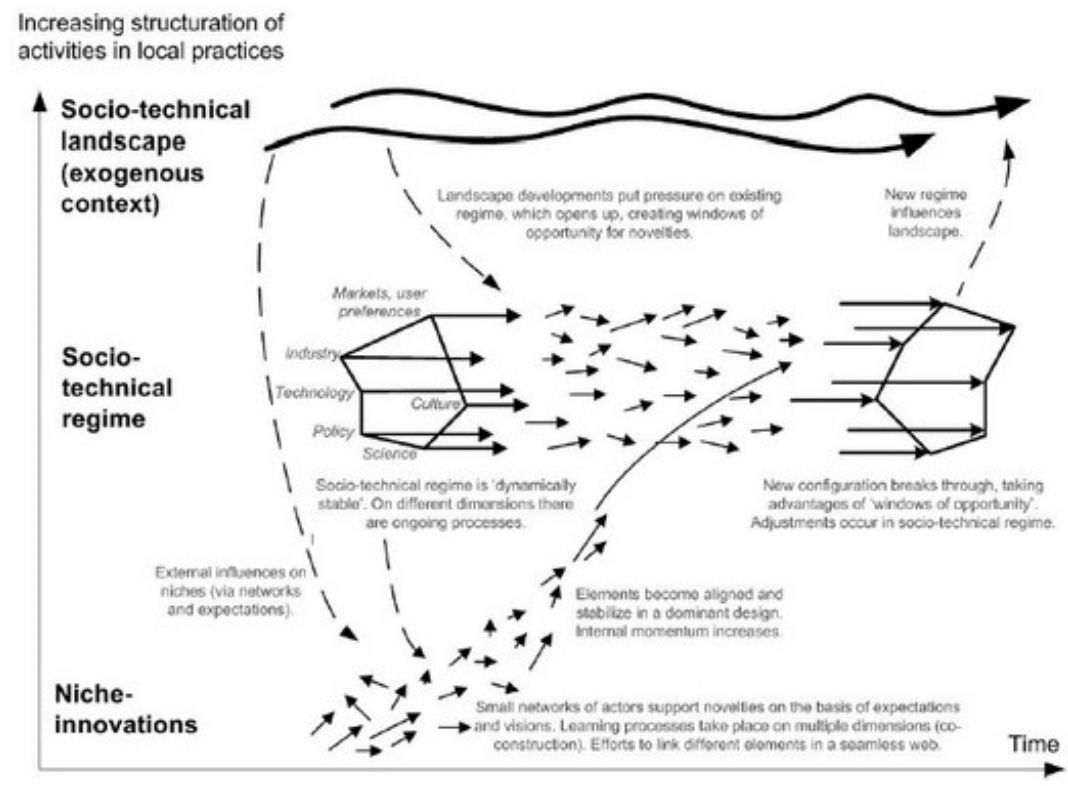

Figure 11: Geels (2007) Diagram of Niche-Regime-Landscape Interactions

Connecting local, place-based "experiments" to broader issues within urban development and governance, and even to global concerns of climate change, necessitates careful examination and analysis of scale, space, and place and the impacts of these analytical categories on analysis of transitions. The literature on sustainability transitions has recently started to acknowledge the importance of spatial considerations and new work has emerged on the geographies of transition. These geographical considerations address the limitations of transitions scholarship, which has insufficiently accounted for the "the advantages, conflicts and tensions that are constituted by the economical, institutional, social and cultural territories in which transitions dynamics and pathways by default are embedded, except as passive contexts" (Coenen and Truffer 2012, 367).

Although many scholars and geographers have addressed the role of the city in transition processes (e.g. Bulkeley and Castán Broto 2013; Hodson and Marvin 2010; Hodson and Marvin 2012a; Hodson and Marvin 2009b) there are still gaps in understanding that may be bridged by more actively engaging geographers and urban studies schol- 
ars in these issues (Truffer and Coenen 2012; Hansen and Coenen 2015; Truffer, Murphy, and Raven 2015). For example, links between transitions processes and uneven urban development have seen little explicit attention, although numerous studies tangentially provide connections. Likewise, the connection between "experiments" and particular pathways has been the subject of recent debates in research on innovations in sociotechnical systems, but lacks consideration of the way the materiality of the city might prevent particular smart grid configurations from emerging (Rydin et al. 2013; Foxon 2013; Bai, Roberts, and Chen 2010; Geels and Schot 2007). Experimental projects can (re)present alternative pathways towards urban sustainability, but also may further entrench existing regimes. Pathways intersect with multiple scales of governance, aligning actors and institutions of various interests along particular networked trajectories. In short, pathways and their projected visions are mechanisms to govern cities and energy systems (Späth and Rohracher 2010).

Urban energy and sustainability transitions, in particular, have been of considerable attention as cities attempt to address climate change through various policy and technology interventions. Energy infrastructures are critical for the functioning of nearly all production, services, and infrastructure sectors in cities, and are vitally important for social practices such as heating, cooking, and transport (Marvin, Graham, and Guy 1999; Graham and Marvin 2001). Energy utilities also are important regional economic actors, with significant employment, land ownership, and capital investments. Energy systems also structure the environment-society relationship and the "metabolism" of cities, often as the largest source of greenhouse gases (Gandy 2004; Newell and Cousins 2014; Swyngedouw 2006). In addition to the vital importance of energy systems to urban and 
regional development and economies, institutional changes - outlined in Chapter 3 - have explained how governance of energy systems has become more complicated as new actors have participated in energy networks in the era of deregulation, restructuring, and proliferation of renewable and distributed generation.

An energy transition, more generally, has been deemed a necessity for addressing global sustainability by industry, environmental groups, and governments (e.g. Shell 2016; Canete 2016; US Department of Energy 2016). The models of regulated monopolies are no longer as prevalent, and large utilities in general are receiving competition from various entities. The failures of large utilities to produce efficiencies, innovate, and meet consumer demands (Hirsh 2004), coupled with growing environmental policies for energy efficiency and renewable energy, and the development of innovative technologies for power generation, distribution, and control of end-use has led to a situation wherein cities have become key sites for energy system change (Monstadt 2007). Cities are depicted simultaneously as the largest consumers of energy and emitters of greenhouse gases, while also being the source for potential solutions, innovations, and action on energy system change, as well as being made up of the infrastructural systems and material environment which makes sustainable change possible. But as the growing literature on urban energy and sustainability transitions explains, its far from this simple.

Energy is bound up with the various social, political and economic aspects of our communities and livelihoods in various ways. Beyond the primary discourse on energy transitions at the national or international scale through lens of technical experts and sectoral interests (such as transportation or housing), energy transitions have implications for a broad array of social and political issues intersecting in multiple processes of urban life 
and located in particular places. Urban energy transitions, then, bring together the work on urbanism and energy to examine how cities and energy systems are "not just, or even mainly, the product of narrow (predominantly technical/technocratic) processes of energy production, distribution and consumption, but they are primarily concerned with the 'urban' - i.e. with how infrastructures, buildings, industries, institutions, as well as individuals and social groups, their practices and values both shape and are shaped by contextspecific, conflicting energy needs, uses, forms of management, etc. ... the energy question is inherently an urban question, and vice versa" (Rutherford and Coutard 2014, 1371). Scholarship on urban energy transitions has worked to distinguish itself from disparate literatures working on energy transitions, low-carbon transitions, energy and social practice, resource geographies, or urban studies of large technological transitions towards a synthesis of these literatures and concepts. Instead, urban energy transitions, according to Rutherford and Coutard $(2014,1362)$, brings together several elements with "a focus a focus on energy materialities through a transversal view of energy systems as articulating contexts, infrastructures, flows and practices of production and consumption; a relational view of 'the urban' which is cognizant of the links between near and far places through which urban energy systems work; and a concern for socio-technical change as always contested and thoroughly political."

Building on urban energy transitions as defined here, the move away from a rather apolitical and straightforward view of technological transitions as laid out in the MLP (Meadowcroft 2009; Shove and Walker 2007; Scrase and Smith 2009) is matched with a particular concern for politics of shaping the 'urban.' The focus on cities and the urban level, "recognises that policies, processes and practices at work in cities are inherently 
intertwined with broader pat- terns in the spatial, economic and socio-political organisation of societies. Yet they also collectively go beyond this and foreground energy transitions as spatially constituted processes, by opening up notions of urban space to include the 'distant' sites and 'external' relational processes through which, in this case, urban energy transitions are shaped" (Rutherford and Coutard 2014, 1365). Urban energy transitions thus take the work of geographers on relational comparison and relational space to understand the contingent processes and practices by which energy systems shape and are shaped by cities. While this work has seen recent scholarship with implications for understanding urban energy governance (Rutherford and Jaglin 2015; Jaglin 2013; Emelianoff 2014), and relationships between space and low-carbon economies (Bridge et al. 2013), there has been surprisingly little consideration of the socio-spatial processes of policy, learning, and knowledge production related to energy transitions and inter-urban referencing so characteristic of transnational/global urban climate governance literature (Aylett 2013; McGuirk, Dowling, and Bulkeley 2014; Hoffmann 2011; Bulkeley 2010).

Here, work of geography scholars on policy mobilities is particularly important and insightful for understanding the connection between energy transitions and cities, especially in the case of innovative technological changes and experimentation with smart grid technologies. The policy mobilities approach brings together work on policy transfer with geographical political economy and global-relational concepts of place (McCann 2011b). Urban policy mobilities, McCann (2011b, 109) explains, are the "socially produced and circulated forms of knowledge addressing how to design and govern cities that develop in, and are conditioned by, travel through, connect, and shape various spatial scales, networks, policy communities, and institutional contexts." Urban policy 
mobilities, then, can and should be considered in work on the diffusion/mobility and adoption/mutation of smart grid experiments and associated policies, models, visions, and knowledge.

Some of the work on policy transfer from political science has tried to explain diffusion of policy innovations through an approach akin the the MLP's approach to explaining technological diffusion. Policy experiments, carried out in different "policy laboratories" are evaluated and if appropriate, alter policy prescriptions more broadly (Karch 2007; Shipan and Volden 2008). This literature provides insights into key actors and institutions that shape policies and policy models often focusing on policy mediators, or the "supply-side" and not so much on adopters on the "demand-side" (McCann 2011b). This includes think-tanks, policy entrepreneurs and "transfer agents" who may bring not only off the shelf policies or best practices, but norms, ideologies, and attitudes that accompany transfer as a form of learning (Stone 2001; Stone 2004; Stone 2000). Policy transfer itself is a learning experience that involves different epistemic communities who provide the substantive knowledge utilized to inform policy objectives shaped by policy elites and decision-makers (Dunlop 2009). The vast array of forms of policy transfer has led some political science scholars to argue for better models and frameworks that capture this complexity and the general dynamics of policy transfer and its concomitant learning processes (Dolowitz and Marsh 2000).

The policy mobility approach builds on these approaches to policy transfer scholarship, but adds various dimensions. Adding a socio-spatial dimension to traditional models of policy transfer brings structural considerations to flows of knowledge, ideas, and models, and characterizes this as a power-laden process (Peck and Theodore 2015). 
The policy mobilities approach takes into account the processes of learning, emulation, and making (Peck 2011), while also considering various scales at which policies are adapted, implemented, and ultimately shaped by, which includes the local and regional (not only the state and federal levels as smart grid policy is currently discussed) (Peck and Theodore 2001). While the smart grid has in large part been pushed forward by federal legislation with states altering some regulations to accompany the changing electricity industry, smart grid implementation, especially on the demand/consumer-side is a regional, local, and even bodily process. At the same time, as the case studies below illustrate, smart grid experiments pull ideas and models and consultation from places all over the globe. Some places become privileged sites, or vanguards for a particular way of conducting urban smart grid experiments, while others scan the landscape of projects, policies, and best practices to incorporate or emulate in their own cities.

Integrating the analysis of smart grid experiments (see chapter 4) from the perspectives of urban energy transitions and urban policy mobilities literatures allows three key insights and benefits. Firstly, policy mobilities brings an explicit attention to the socio-spatial aspects of learning, inter-referencing, mutation, and emulation for the rather aspatial (and usually national level) transitions perspective. This allows consideration of the way models, ideas, and knowledge travel from city to city, nation to city, region to region, state to state, etc. in a global context, the way this travel takes place, who is involved, their practices, the spaces this work is done, and the implications of all of this for policymaking and learning. In general, it adds the dimension of knowledge transfer, not just knowledge generation, through processes of learning, adaptation, and mutation (Affolderbach and Schulz 2016). 
Secondly, it brings a critical relational perspective on the inter-urban referencing and learning of smart grid experiments and innovations in the context of urban energy transitions. Policy mobilities literature builds on economic geography scholars to understand how circuits of policy knowledge are composed of epistemic communities who transfer, emplace, and utilize certain forms of knowledge as part of their practice (McCann 2011b; McCann 2008). The economic geography approach here also bring consideration of the institutional legacies, ideologies, and frames of reference, and issues such as political-economic restructuring so dominant over the past three decades in electricity networks, which often means that the "easiest, fastest, and most politically feasible transfers" are sought (McCann 2011b, 109; Peck and Theodore 2010a; Peck and Theodore 2015). Policy mobilities also considers the connections between knowledge, expertise, and governmental rationalities, and the ways in which certain ideas become hegemonic or orthodoxy. This builds heavily on the perspectives of governmentality in geographical scholarship to various rationalities and technologies of government to study the (banal) practices of bureaucrats, consultants, engineers, and others and the way they construct narratives of commensurability to make their place (city) comparable to another so the policy might take. The practice of making comparable itself is a way to mobilize particular knowledges and in the process, normalize or stabilize through particular rationalities, logics and discourses, a way of seeing and acting in the world that legitimizes action and practice (Larner and Heron 2002; Larner and Heron 2005; McCann 2011b).

Thirdly, the synergies between mobilities, transitions, and experimentation highlights the materiality and technical efficiency of particular policy assemblages. One element that transitions approaches adds to mobilities perspective is a focus on the role of 
technology, its technical efficiency, performativity, social construction, and agency in (techno)politics. While policy mobilities uses the concept of assemblage, which "indicates a perspective focused on the detailed qualitative and ethnographic study of the practice of assembling some form of coherence, such as a policy... [or] a scale like the 'local"' (McCann and Ward 2013, 8; McCann and Ward 2012b), it also considers the materiality of policy including the objects and things that are part of policymaking and implementation (Lovell 2016). The sociotechnical systems approach of transitions meshes with the assemblage approach of mobilities to provide some conceptual overlap, at least at a general level of considering the various actors, institutions, capacities, forms of expertise, models, technologies, techniques that are not only local to a particular place, but also emerge from elsewhere (McCann and Ward 2012a; McCann and Ward 2011; McCann 2011a).

In the following section I explicate three intertwined case studies of smart grid experiments, each of which highlight the contribution that policy mobilities has for our understanding of urban energy transitions and the various forms of smart grid experimentation that are cast as opportunities to ignite broader sociotechnical changes and innovation in electricity systems.

\subsection{Mobile Experiments, Failed Experiments, Spectacular Experiments?}

Case studies are useful for drawing out intricacies of particular phenomena. Relational comparative approaches (Ward 2008; Ward 2010; Mcfarlane 2010; Robinson 2014) in case study methodology provides opportunities for greater external validity (generalization) and clearer illustration of differences and similarities, and importantly, 
contingencies in local processes. Explanatory models used to draw these relationships between cases reflect theorizations about space, place, and scale, and about the process of knowledge production and its relationships with urban development and governance.

The relational comparative approach advocated by Ward (2010) has three key components relevant to this study. The first suggests that the city should be theorized as "open, embedded and relational," and as important elements of global systems, processes and flows that serve as, for example, "the 'laboratories' for policy formation and as arenas for the practising of state power" (Ward 2010: 482). The second concerns the dynamic and socially constructed nature of the 'city' scale. The third relates to the political aspect that the relational comparative approach takes in "speaking back" to established theories, and in asserting the context-specificity of theories to question their universalizing tendencies.

With these considerations, I attempt to use comparison not to measure the cases developed in this dissertation against a universal 'yardstick' that shows difference and similarity. Instead, I start with tracing how smart grid experiments are constructed through policy and knowledge networks, how they are conceived, and how different actors interact and shape objectives and outcomes. This allows particularities and specificities to come through that relate to urban energy transitions, their politics, and the efficacy of smart grid experiments in different cities. This helps explicate the complicated relationships between knowledge production, urban governance, and sociotechnical change. 


\subsubsection{Seductive visions: Oak Park's SmartCityUSA project}

When I first went to the Village of Oak Park, an inner ring suburb of Chicago, I was only eleven years old. On that school field trip, we went to visit several of the turn of the century homes that Frank Lloyd Wright designed in the area. It was in Oak Park that Wright's "prairie style" architecture came to be known as a pathbreaking set of artistic works. The Frank Lloyd Wright Trust, operating out of The Rookery, a building constructed under the direction of Daniel Burnham and John Root, features one of Wright's own interior designs. In Chicago's Downtown Loop, the Trust serves as the "International Gateway to Wright's Chicago," offering tours, guided visits, and outreach programs for various audiences from students to tourists ("Frank Lloyd Wright Trust" 2016). Wright's architectural works live today through preservation and the work of the Trust and others in highlighting his architectural style. Oak Park's architectural history and location has in many ways shaped the environmental commitments of the city today. Oak Park, in connection with River Forest, developed a sustainability plan called PlanItGreen, which had a tremendous focus on energy and carbon. The Village also approved a community choice aggregation program in April of 2011, which allows the municipality to seek alternate suppliers of electricity as a way to get lower rates and lower-carbon sources, which is made possible by state statues that mandate the incumbent utility still offer services as a distributor.

Oak Park emerged in my research on the Pecan Street project in Austin, Texas. I first noticed a few stories in 2014 in industry media and in press releases, the Village of Oak Park explained how they were working with Pecan Street on a "project to demonstrate the potential cost savings of electric smart grid technologies" and made progress on 
the project through "hiring an organization credited with creating the national model for smart grid project planning, implementation, and management" (Village of Oak Park 2014b). The Village Manager noted that:

Smart grid technology is new territory for communities such as ours, but its promise for energy savings and efficiency is real. Oak Park already has made great strides toward setting up a demonstration project. With Pecan Street's help, we can begin the journey from an idea to a working model. This is an exciting time for our community." (Village of Oak Park 2014b)

In the face of the fast moving smart city, smart grid and internet of things markets, this new arena for cities and economic development, the Village of Oak Park was looking for models to implement smart grid solutions. The notion of "fast policy" here captures this movement by Oak Park's city officials, where working with Pecan Street would enable the quick implementation of a perceived "off-the-shelf" smart grid community model (Peck and Theodore 2015). The expertise of an organization like Pecan Street, as the Village Manager explained to me, is "to really give us sort of the playlist of how we can do smart city. ... they have done and exceptional job and delivered to the Village really the kind of project ready to go" (Interview, October 2015).

Oak Park's desire to implement a "ready to go" project shows how the financially constrained city was not only working within the confines of time, but also how policy is increasingly influenced by a variety of non-state actors operating outside established, "slow" channels of policy. Pecan Street's work, however, is more about creating the technical and social conditions needed to make a smart grid experiment possible. Of course, this fits with the broader state and federal smart grid policy landscape, wherein "test-beds" and "demonstrations" are written into legislation. Years of discussion and debate led to the 2014 Illinois Energy Infrastructure Modernization Act, which had pre- 
viously been vetoed in 2011 by then Governor Pat Quinn calling the Act a "dream come true of Commonwealth Edison, but a nightmare for Illinois consumers" and overridden by the Illinois legislature (Wernau 2011; Guerrero and Wernau 2013). The Act provides a mandate for utilities to create neutral "test-beds" where companies can test-out their solutions in a real-world utility environment. The promise, of course, was for the smart grid to be an ecological modernization strategy that would help create jobs, spur growth in the tech industry, and at the same time, help lower carbon emissions and meet environmental goals.

The smart grid experiment in Oak Park was in the works for several years before the 2014 press release. The Village had actively participated in ComEd's smart meter pilot program in 2010 , where over 20,000 meters were installed by the incumbent utility. The pilot program led by the utility was implemented in nine different Illinois communities with the expressed goal of enabling time-of-use pricing and information gathering. City officials saw this as a way to bring the smart grid to their citizens, but at first didn't see any customer-side benefits (Village Manager, Interview, October 2015). But Oak Park wanted to get involved to bring the possible benefits of the smart grid to their community. As Oak Park's sustainability director described it at the 2013 summer meeting of the Mayors Innovation Project, ${ }^{14}$

\footnotetext{
14 The Mayors Innovation Project is a learning network among American mayors committed to "high road" policy and governance: shared prosperity, environmental sustainability, and efficient democratic government. [...] The Mayors Innovation Project exists to help its member participants lead by example, share their experiences with peers, and make this argument for cities nationally. See http://www.mayorsinnovation.org/
} 
The Village of Oak Park kept putting itself out there as a test-bed, we wanted to bring some of these new technologies to Oak Park and we kept inviting new companies and utilities to try their projects here in Oak Park, and someone finally took us up on it.

This outward looking strategy that Oak Park took on represents an entrepreneurial strategy for attracting new capital for infrastructure improvements, but aimed specifically at a green and high-tech solution for environmental problems (Harvey 1989; While, Jonas, and Gibbs 2004). While the incumbent utility aimed to upgrade infrastructure for its own benefits (reducing operational costs through decreasing meter-reading staff, improving reliability, etc.), Oak Park did not see any immediate benefits for its citizens in terms of hands-on smart technology or other visible or tactile technological change. This highlights two key issues: (1) the invisibility debate of modern infrastructures (Star 1999; Larkin 2013; Carse 2012), and (2) the necessity of visibility for legitimacy of technological demonstrations (Elena Simakova 2010; Späth and Rohracher 2012; Ezrahi 1990).

While Oak Park city officials were arguably looking for a local "sustainability fix" in smart grid programs, which always involves an 'extralocal' element for construction and legitimation (Temenos and McCann 2012, 1391), they struggled with these two issues. To circumvent these issues, or at least to address them, Oak Park attempted to make electricity infrastructure visible through the development of a customer facing program which would not only serve to make the smart grid visible, but would also enroll selected participants in a smart grid experiment and a form of low-carbon energy governance as subjects of learning and education (N. Rose 1999; N. Rose 1993; Temenos and McCann 2012). 
As the project progressed, the Village began to seek international support and collaboration. The Illinois Citizen's Utility Board and other groups had facilitated contact of Oak Park City Officials with the Korean Smart Grid Institute who had developed an internationally recognized smart grid test-bed on Jeju Island. The Jeju Island project was implemented by the South Korean state-run transmission operator, Korea Electric Power Corporation (KEPCO), and has positioned South Korea as a leader in smart grid technology development (Kanellos 2010; Tweed 2011; Kaye 2011; Woods 2014). The State of Illinois and South Korea established a partnership in 2010 to facilitate the development and testing of smart grid models, with South Korea wanting to take the "island model to the city" (Woods 2014). And they also needed to find a place that could work for advanced testing which involved both a willing municipality and an infrastructure that needed minimal updating. As the sustainability director of Oak Park explained,

I think one of the attractions was not only the progressive mentality of our officials and senior staff, but also because we are in an urban area. Jeju island is kind of like a resort area, their Hawaii, so it was a bit more rural, and they really wanted to test their model in a compact urban scenario. (Presentation at Summer 2013 meeting of the Mayor's Innovation Project)

After several meetings with delegations from the Korean Smart Grid Institute, Oak Park was eventually chosen, out of 288 surveyed communities, as the place to implement the project. This fit with the ongoing smart grid collaboration, which positioned the resources around Oak Park and Chicago in their competitive bid. The resources of the Illinois Institute of Technology and the University of Chicago were involved in smart grid activities through testing technologies on campus micro-grids (IIT) or through data collection and analysis (UC). ComEd had selected Oak Park as the location for a smart substation as apart of the larger ComEd smart grid innovation corridor in northern Illi- 
nois. Together with favorable state funding and state legislation, Oak Park's project was being set up as a community demonstration project that didn't need to wait for the smart grid to come to them, but instead could "showcase the technological, financial, and policy investments communities can make right now"(Hamilton et al. 2011, 37). The economic push from the State of Illinois and political pressure to implement the smart grid coupled with the utopian smart grid project implemented in Jeju Island provided a model and guiding vision for the City of Oak Park's own smart grid program which came to be called the SmartCityUSA project.

In 2013, Oak Park hosted the Mayors Innovation Project's summer meeting, which brought together city officials from around the Midwest, consultants, and nonprofit organizations to discuss early childhood education, promoting walkable urbanisms, promoting diverse communities, and benefiting from smart meters and grids. Oak Park's Sustainability Director discussed the SmartCityUSA project alongside executives of Pecan Street, and the Mayor of Tallahassee, Florida. The plan the city had laid out had still lacked specificity in terms of technical project implementation, the Korean Smart Grid Institute had stopped actively participating in Oak Park's plans and did not continue to fund the project, and in August 2014, the Village Board had determined they needed outside support for successful planning and implementation. As a result of a request for proposals, Pecan Street was brought on board to work with Oak Park to develop and implement the project, taking their experience in Austin and elsewhere as an example for emulation, applying lessons learned. In March of 2015, Pecan Street came and presented a plan to Oak Park's board and staff which explained the various parts of the SmartCityUSA project collaboration with the Korean Smart Grid Institute. Pecan Street 
explained SmartCityUSA as a project is the "creation of a nationally known research testbed [...] basically setting up a framework for doing all the smart grid research programs you want" (Village of Oak Park 2015). The SmartCityUSA project was positioned, again, as a way to bring ground-breaking research to Oak Park, which provide opportunities for broader learning related to the Village's own attempt to transition towards lowcarbon energy generation and reduce consumption. The Village officials identified the benefits of the project in the ability to meet the community's environmental goals. The Village President in 2014 explained:

Having the demonstrated knowledge, experience and expertise in getting smart grid projects up and running is a major step toward achieving our goal of keeping Oak Park a leader in environmental initiatives. [...] With Pecan Street's assistance, we can move closer to implementing a project that will underscore the Village's commitment to environmental sustainability. (Village of Oak Park 2014a)

However, the impacts of the project beyond the benefits to local goals for sustainability and citizen empowerment to become "prosumers" as the Village Manager explained,

Oak Park would like to create a program for homeowners and renters to participate so we can analyze the utilization of home energy management systems, solar panels, and battery backup systems so we can determine, the viability of that type of program within an urban community and how that technologies can integrate into the grid, and how we can really make homeowners I guess, our new favorite word is prosumers, like producers and consumers of electricity. (Interview, October 2015)

While the logic of providing the ability of citizens to be more active consumers, not passive, Oak Park found distributed energy, storage, and smart technologies to be essentially technological components for enabling a "smarter" energy consumer and an environmentally-minded citizen. In this respect, the governance of energy seemed to be 
enacted through the practices of Oak Park's citizens, and the local government was only a facilitator of this more environmentally friendly energy conduct. As the Village Manager explained:

I think Oak Park continues to play an important role by having the community awareness of the issue and being part of the conversation. Its everything from building codes, and how those work, to battery backup and solar is not the normal thing to do, so I think we are playing an important part of the conversation making sure we have codes that facilitate and allow those types of opportunities and we have a lot of residents who are doing it on their own and they just need community support to make it a little bit easier, instead of those handful of people who have shear determination to kind of go off the grid to some degree. (Interview, October 2015)

The Village Manager also saw the role of Oak Park as a facilitator, and intermediary in a broader energy transition, where local government could be the "community outreach" and "community awareness" of the need to bring smart grid solutions to Oak Park's environmental problems. Two key issues relating both to energy transitions and policy mobilities are central here. Firstly, the city serves as an intermediary in a broader energy transition, itself acting as a laboratory for policy and sociotechnical interventions and a facilitator of partnerships, or to "shape technological transitions through strategic intermediaries that mediate relations systemically between technological potentials and local context" (Hodson and Marvin 2009d, 516; Hodson and Marvin 2010a; Hodson and Marvin 2012; Moss 2009; Guy, Marvin, and Medd 2011). But the city is also shaped by pressures to compete locally and globally for innovations, and limited in ability to shape transitions by exogenous conditions or social, political and economic positions and institutional pathdependencies. Therefore, the city can act to both develop "place-based" visions of technological change and work to govern that change, as in the case of SmartCityUSA, but they do so in the context of a global flow of knowledge (McFarlane 2011). 
Secondly, this illustrates a point which McCann (2013) describes as policy boosterism and extrospection. Policy boosterism plays an important role in the mobilization of polices, models, visions, and knowledge from place to place, city to city around the world. Similarly, extrospection refers to "the various ways in which policy actors in the city are tied to a range of national and global policymaking communities and institutions as well as to various cities elsewhere as they teach and/or learn about innovative policies" (McCann 2013, 7). In Oak Park, the Village Manager explained that the SmartCityUSA project was explicitly about vision the city projected and opportunities for intercity learning:

I think it might be more about helping other cities understand that there is municipal role, possibly, in facilitating this. So I have worked in Iowa, Nebraska, and Illinois, and every state has different, both Nebraska and Iowa were both public power systems, and each municipality has a different perspective on what roles and responsibilities they play in their relationship to the electrical supplier, and so I think a demonstration project, if we can help municipalities understand what the benefits are of being a facilitator between the resident as an individual and the public power supplier or the private power supplier to facilitate more community based goals, its an important role for a municipality to play. (Interview, October 2015)

Oak Park saw the benefits of the SmartCityUSA project not just for their own citizens, but for a wider policy audience of municipalities across the country and globe. The case of Oak Park shows how cities - although only a small municipality of only 52,000 people, and overshadowed in many ways by the adjacent City of Chicago - engage in these practices of policy boosterism and extrospection as a part of urban energy transition processes. This indicates that these practices play an important role in the governance of urban energy transition. 
As of 2016, the SmartCityUSA project has still not been implemented. While the project has yet to be completed, funding streams are still being considered for the demonstration project, and new partnerships are being sought.

\subsubsection{Take the power back? Boulder's SmartGridCity and municipalization}

The City of Boulder has a long history of environmental activism and energy action. From the early green building ordinances and requirements to the groundbreaking carbon tax, Boulder has often been at the "vanguard" of municipal climate action. The city has a tremendous amount of experience with new programs and policy, and when their electric utility, Xcel Energy, proposed a pilot project for the smart grid, the city accepted with particular requests from the utility in return: increased renewables, customeroriented technology, and no extra costs to ratepayers.

An ABC News segment from 2008 described Xcel Energy’s SmartGridCity project in Boulder as a program that "could change the way we live entirely." The segment included and an interview with Xcel Energy Executive, Ray Gogel, where he explained the desire to integrate the worlds of Thomas Edison and Bill Gates while the news reporter narrated a video segment showing electric poles and linesman calling the city a "living laboratory" for the smart grid. The segment featured the University of Colorado's Chancellor's house which served as a demonstration project for Xcel Energy's project outfitted with smart meters, energy management systems, solar systems, electric vehicles, and battery energy storage systems. Then, they interviewed a local citizen who claimed hanging clothes outside to dry was the biggest energy saving activity the smart grid offered him, a chance to change his behavior to reduce energy consumption. 
This news segment highlighted numerous issues that the SmartGridCity project would face as the project progressed. The first was the one-off demonstration project's success not followed up by broader implementation. While the Chancellor's house was fully outfitted with smart grid technologies, the rest of the community did not have access to these benefits. The second key issue was the lack of insightful or helpful information the smart grid technologies provided to the City. While the smart grid project helped Xcel fund infrastructure upgrades, which was funded by a rate increase that was approved and later overturned, it did little to help Boulder's citizens. Smart grid technologies were enrolled in a broader strategy of low-carbon governance enacted through information provision, training, and learning activities, but without implementation of technologies, this strategy seemed to fail. While the success of changing one citizen's behavior was highlighted in the news segment, it seems difficult to say hang drying clothes was part of the city and utility's smart grid strategy.

The SmartGridCity project captured attention from numerous policymakers and city officials who had their eyes on smart city and smart grid technologies. The project was pitched as a test-bed and a living laboratory to jumpstart an energy transition using smart technologies. Xcel described the project as a technology pilot "that allows us to explore smart-grid tools in a real-world setting" (XcelEnergy 2016). Boulder's city officials were at first quite enthusiastic about the project as it promised benefits locally and regionally. The existing local economy in Boulder has on research and innovation, with a diverse set of industries tied to aerospace, bioscience, cleantech, IT, and outdoor recreation. Significant IT and smart grid related company presences include Siemens, Navigant Consulting, Tendril Networks, Cisco, Oracle, Nest, Google Boulder, Qualcomm, Twitter, 
and IBM (Boulder Economic Council 2016). IBM included Boulder in its Smarter Cities Challenge and worked with city officials on a report to launch its smart grid sector from the Xcel project. The report detailed how Boulder could capitalize on the SmartGridCity project to help meet goals laid out in the City's Climate Action Plan (CAP), but upon consultation with various groups, IBM's team noted disagreement about what benefits the smart grid could offer, and friction between the utility, the City, and its citizens (IBM 2011). IBM's recommendations included both increasing local renewables and developing pilot projects utilizing the resources of nearby National Renewable Energy Laboratory (NREL) and the National Institute of Standards and Technology (NIST). In a reference to the possibilities for these pilots, the report explained examples of a smart city project in Manheim, Germany, or the GridSmartCity in Burlington, Ontario, Canada could be references for renewable integration, while a host of other pilots offered other programs such as automated energy management for different customers, remote control, and grid operations.

Despite the capabilities of the SmartGridCity, Boulder's efforts with carbon reduction were slowed in 2010 when Xcel brought online a new coal power generating facility in Pueblo, Colorado. This occurred around the same time that the City's 20-year franchise agreement with Xcel was about to expire, and when issues with the SmartGridCity project had surfaced. As the sustainability manager for the city explained:

Why does that matter, it matters because in our greenhouse gas inventory we get the same soup of electrons that everybody else gets. So as we looked at our effectiveness on our climate action plan we had turned the trajectory and started to go down, just on demand side [interventions] and then when they bring the new coal plant online brings the carbon intensity of our grid power all the sudden shot our trajectory back up like this. So smart grid falling apart, having to go to the commission to fight them on 
that, and fight on behalf of other customers in the state who are now saying, 'oh Boulder gets this fancy toy and we have to pay for it,' and were saying 'No.' That accompanied with the franchise agreements not going anywhere and then realizing that unless we dealt with our supply, we'll never have an impact on our emissions, kind of those three things happened all at once, and that's when we went to our council and said, we really ought to strongly consider municipalization at this point. (Interview, November 2015)

As the City's long-time commitment to reduce climate change related emissions had been compromised with Xcel's new coal-fired power plant, city officials, and citizens had started to consider municipalization as a real strategy to guide their urban energy transition towards a pathway they desired. Three key issues in the movement towards municipalization are important here and related to smart grid experiments, urban energy transitions, and policy mobilities. Firstly, the political economic context of Boulder's energy system had presented issues for the City's strategies to reduce carbon and tackle climate change goals. While the city had been successful in implementing many demandside programs, such as extensive green building codes and solar rebates, they encountered the troubles of not having agency over the source of electricity which was solely with Xcel and its board and investors. While the smart grid promises more active consumer participation, it was apparent that the active element did not include influence of decision-making over the resource portfolios for the utility. In terms of the energy transitions approach, this reflects the spatially explicit, territorial dimensions of energy systems wherein the approach of an incumbent sociotechnical regime is structured regionally by cheapest resources and by legal frameworks and rules at the state and federal level which allow further construction of coal fired power plants, well outside the agency of cities to change. It also helps explain the resistance of incumbent sociotechnical regimes to 
change, indicating a need to understand issues of geographical political economy, sociotechnical obduracy, and accompanying and interrelated relations of power in urban energy transitions (Chandrashekeran 2016; Geels 2014; Hommels 2005).

Secondly, the Xcel's SmartGridCity fell short of the societal expectations for the project. While the promise of the smart grid resounded with the national attention it had received - outlined in Chapter 3, including promises of greater reliability, cleaner electricity, more efficiency, more customer choice and control, and economic benefits many of these benefits were not visible to Boulder's residents or city officials. The smart grid experiment implemented here lacked the outward, customer-oriented approach needed to gain public trust and legitimation in political processes (Späth and Rohracher 2012; Ezrahi 1990). While a critical approach may show the democratic deficit and spectacle/speculation-orientation of projects that this view may encourage, it also helps to explain why Boulder's smart grid experiment under private utility direction had fallen short of public expectations. This coupled with the lack of the City's ability to serve an intermediary role, seemed to forestall any significant smart grid policy or project innovation (Moss 2009). Instead, what emerged was a point of extrospection as the City look to municipalities elsewhere who had direct control over their electric utility and in this way had a better ability to manage energy system transitions.

This leads to the third point that the case of Boulder highlights. In the face of a lack of agency to control their energy system and their smart grid project, the City of Boulder looked to models and policies elsewhere for the development of a municipal utility that could operate in concert with the goals and values of the City. This points towards an understudied element of urban energy transitions, a deficit which policy mobili- 
ty approaches can help to overcome. While some scholars in transition studies have pointed to the role of places and demonstrations in governing and guiding transitions through visions, little has been done to explain how the context of globalized economic competition, urban entrepreneurialism, or the "extrospective" gaze might impact how transitions occur and are shaped (Späth and Rohracher 2010; Hodson and Marvin 2009d; Coenen and Truffer 2012). Policy mobilities approaches help attend to this problematic by focusing on flows of policy models and knowledge and practices of actors who mobilize models and knowledge.

Boulder's efforts at municipalization are made possible firstly by Colorado state law, which also includes processes for purchasing or condemning the systems at fair market value (Briggerman, Costinescu, and Bond 2012). The city initially started to work with Xcel on developing a partnership to help meet the city's climate goals. But after disagreement in negotiations and a lack of common ground, the City chose to forgo franchise renewal with Xcel. This caused a problem because the city gains revenue from a franchise fee, but to circumvent this, Boulder opted to use a utility occupation tax that would make up for lost franchise revenue. This ballot measure was passed by Boulder voters in 2010 .

The sustainability manager of the City explained that this was a position that they had to take up because of the different goals and values between Boulder and Xcel. He explained the short history leading up to the decision to forgo the franchise,

We found ourselves in a really unique place saying do we really want to sign another 20-year agreement given the priority of climate and the priority of energy, things are changing so rapidly, should we sign another 20year agreement. If so, this is our one chance to negotiate. In terms of energy policy in states like Colorado, you are really limited on what you can 
and can't do. It's a homogenized system. So even if we want to do something different in terms of portfolio, we can't, even if we want to do things on the grid in terms of grid modernization, in terms of large scale DG, you can't without the approval of the incumbent utility. And for them, like it or not, we know that DG is a threat. It's just a reality that every utility is facing now, that are vertically integrated. So we begin negotiating in earnest around 2007 and 2008 and we tried to work on site agreements and ways to really develop a new type of partnership with the utility to say, 'let's go to the commission and see if we can do something different, instead of being the standard white bread franchise, how can we be the test-model for the new utility structure'. We weren't really able to get where we wanted to go, but I should say, dropped right in the middle of this was knowing that we were moving in that direction. They, and when I say they I mean PSCO, operating as Xcel, Xcel operates in 8 states and its PSCO here in Colorado, So they came to us and said 'well you know, we are thinking about this new idea of smart grid and we'd love to see if you guys are interested, but quid pro quo, you need to give up on municipalization for the time being'. We said well we can't tell the future council that they can't go back to it, but we are willing. The direction from our council was work with PSCO on franchise negotiations and implementing smart grid. (Interview, November, 2015)

The SmartGridCity project emerged at a time in 2007-2008 when these negotia-

tions were initially taking place. Used as a sort of 'bargaining chip' the utility promised several key benefits for the project that would help meet the city's CAP goals. But the project missed, the mark as Boulder's sustainability manager explained:

Xcel effectively went dark for over a year, there was a lot of publicity around the SmartGridCity project, international publicity, and we had a lot of people coming to Boulder, saying 'we'd like to see the smart grid,' and we would say 'you need to contact Xcel because we don't really know what you want to see.' They had a mobile unit that really showed automation systems and what you could do with it and they kind of toured this little thing around to say here, 'the vision of smart grid.' It was like a little mobile home and you could go in and there were posters, and it was like, it was a mobile experience of smart grid. They installed a couple test sites, one at the chancellor's house, one at CU, so there was a lot of positive discussion around what smart grid was capable of. They spent a bunch of time doing a lot of installations at some of the transformers, they tore up a lot of streets to lay fiber, and essentially installed a lot infrastructure, installed 23,000 new meters, residential meters, and a handful of commercial meters (we have 50,000 meters). [...] All of that, okay we said 'do 
that, and then we can talk about smart grids', and we were finally able to sit down and talk with Xcel and say 'Okay, when do we start,' and they said, 'Start? We're done.' (Interview, November 2016)

SmartGridCity created massive public expectations for the smart grid in Boulder, but few customer-facing programs or technologies were implemented. Instead, Boulder brought the request to create a municipal utility in 2011 (Ballot Measures 2B and 2C), winning by a narrow margin at approximately 51 percent. This was the result of tremendous local activism in the face of a million-dollar campaign from Xcel (Local Activist, Interview, April 2016). Another ballot measure (2E) passed in 2013 refined acquisition costs, and in 2014 another ballot measure (2B) passed to allow the city council to hold private executive sessions to discuss legal advice for creation of the local utility.

Although legal precedent was in place, Boulder focused heavily on finding examples and models from other cities who operate municipal utilities. Local smart grid initiatives and systems planning for microgrids have taken place in island settings, on military bases, university campuses, and industrial parks. Boulder's case highlights the smart grid tensions that were discussed in Chapter 3 over control and governance of smart grids and energy transitions. Tensions over control involve contests over values and goals, and technical decisions regarding how to meet energy demand, with what technologies and with what sources of electricity. Here, a local technopolitics of energy system design and operation, with different business models, planning mechanisms, and roles for citizens, industry actors, and the municipality are tied up with questions of technical specificity. In this regard, technologies are performative in that they help to enact political goals (Çalışkan and Callon 2009; D. MacKenzie 2009; Hecht 2000). Here, an important issue arises that brings questions of urban energy transitions into the structured, power-laden 
world of policy mobility scholars interested in the way assemblage-thinking allows consideration of technical, material elements of policy in line with the efficacy, mobility, and mutability of policy. Several sociotechnical issues are identified in the actions by Boulder and Xcel to engage in technopolitics, and at the same time pull from examples and histories elsewhere to support their positions.

Table 5: Issues in Boulder's smart grid

\begin{tabular}{|c|c|c|}
\hline $\begin{array}{l}\text { Sociotechnical } \\
\text { Issue }\end{array}$ & Boulder (Challenger) & Xcel (Incumbent) \\
\hline Ownership & Municipal & Investor-Owned Utility \\
\hline Portfolio & $\begin{array}{l}\text { A transition from } 50 \% \text { on } \\
\text { day } 1 \text { to } 100 \% \text { renewables } \\
\text { by } 2030\end{array}$ & $\begin{array}{l}24 \% \text { renewables by } 2037 \text {, with } \\
\text { some transition of reduction in } \\
\text { coal by } 35 \% \text { and increase in gas } \\
\text { by } 29 \%\end{array}$ \\
\hline $\begin{array}{l}\text { Smart } \quad \text { Grid } \\
\text { Technologies De- } \\
\text { sired }\end{array}$ & $\begin{array}{l}\text { Decentralized renewable } \\
\text { generation, smart home } \\
\text { technologies, EVs, market- } \\
\text { place/testbed for local en- } \\
\text { trepreneurs }\end{array}$ & $\begin{array}{l}\text { Installed private high-speed fiber } \\
\text { optic communication system or } \\
\text { backhaul network, distribution } \\
\text { transformers, smart meters, volt- } \\
\text { age, current, and temperature sen- } \\
\text { sors, actuators and automation, } \\
\text { software upgrades }\end{array}$ \\
\hline Carbon Metrics & $\begin{array}{l}\text { Kyoto Protocol goal met } \\
\text { on day } 1 \text { and } 80 \% \text { carbon } \\
\text { reduction by } 2050\end{array}$ & $\begin{array}{l}\text { Leadership in Carbon Disclosure } \\
\text { Project, American Carbon Regis- } \\
\text { try Excellence, public commit- } \\
\text { ment to reduce CO } 2 \text { levels by } \\
20 \% \text { below } 2005 \text { levels by } 2020\end{array}$ \\
\hline
\end{tabular}

While the smart grid offers up new possibilities for more local and distributed generation, the question of control and agency creates an area for contestation, and in many ways plays an important part in the shaping of the smart grid. Conversely, the smart grid actives and experiments in places like Boulder are also shaping the context and possibilities of local energy initiatives and electricity systems planning at the municipal 
level. One major point of contention in Boulder was the issue of the creation of Xcel's fiber optic backhaul network, which due to the cost of digging and burying cables, was a large cost in the SmartGridCity project. The City and local activists contended that other solutions, such as wireless connections would have been much cheaper, but Xcel claimed this would not be secure or reliable for communications. This highlighted one of many issues that resulted in public disapproval of the project. While Xcel made significant upgrades to the electrical grid in Boulder, they focused on grid- and utility-facing improvements, while the citizens and City desired more demand-side and customer-facing technologies (see Table 5).

One part of the City's attempts to create a smart grid for customers, was to build the Community Power Partnership, which is program in partnership with Pecan Street that installed eGauge meters in 48 homes and 14 businesses in Boulder. The eGague meters, produced by a local company of the same name, allows data collection and real-time energy use information to be accessed by customers so they can track their energy usage. The City described the project as a way to harness the power of data:

We all know that information is power. And that power in the hands of community members and businesses can speed up the arrival of a better, cleaner future and a vibrant local economy. To this end, the City of Boulder, in partnership with the Pecan Street Research Institute of Austin, Texas, is collaborating with residents in the Newlands and Kings Ridge/Noble Park neighborhoods as well as local businesses on a research pilot project called the Community Power Partnership. The purpose of this project is twofold: to understand how electricity is being used in Boulder residences and businesses; and to understand what tools and information homeowners, renters and businesses need to better manage their resource use and contribute to innovative community solutions.

Boulder's program worked to transfer Pecan Street's Austin-based project to their city through the use of the same technology, the eGauge, with the hope that homeowners 
and businesses would better manage their electricity consumption. The CPP started to fulfill this need of customer-facing smart grid and data access, and due to the connections of the new Director of Energy Strategy and Electricity Utility Development with Pecan Street, the program chose to utilize their expertise from Austin's smart grid experiment. As Boulder's Sustainability Director explained:

We had been in contact with them, to try to understand how Pecan Street functions as an actual smart grid project and [ask] could we apply some of those learnings as we were negotiating with Xcel early on. We started communicating with them early on, and then, our director, came form Austin. [Boulder's Director of Energy Strategy and Electricity Utility Development] came from Austin because of her work with Austin Energy. And so she is good colleagues with those guys. So as we were talking about where we needed to go next, she I think saw, or I think [Pecan Street's President and CEO] reached out to us and said 'Hey maybe we should talk about trying to do something and maybe we can help.' (Interview, November 2015)

The experimentation from Austin was thought to convey a type of "mobile model" for engaging citizens in the smart grid. Given the context of Austin's municipal utility, and the strategic intermediary role that Pecan Street has played in community involvement and technological testing, the knowledge generated in the Austin context was thought to be transferable to Boulder. It also helped that political processes and connections were able to facilitate this movement of policy models and knowledge. As Temenos and McCann $(2012,1391)$ describe the shift towards municipal sustainability programs, of which the CPP is exemplar, as "a political process of knowledge translation, discursive framing - including the powerful framing of certain problems and policy responses as largely technical rather than political - and the 'education of attention' through the practical training of a wide range of residents." The project was seen as strategic for the City's municipalization efforts, as Boulder's Environmental Action Manager noted, 
What kind of services do people want? Unless we start now trying to figure out what people want, on day one of the utility, we won't know. [...] We want to find out what's useful and what isn't before we end up investing \$50 million or whatever Xcel invested in SmartGridCity. If it doesn’t help people, then it's not a good investment (Meltzer 2014a).

The program was also aimed at "empowering" consumers to reduce their electricity consumption through access to information. But at the same time, the contradictions of the behavioral change - discussed in Chapter 3 and 4 - trouble the actual benefits of the program to consumers. As Boulder's Environmental Action Manager explained,

The primary goal is to provide some tangible benefit to the project participants. What is the most useful format for customers to receive this usage data? We don't know that. We don't really know how resource usage information helps customers. We want to provide a service that is helpful. (Meltzer 2014b)

While the Community Power Partnership did not conclusively help consumers in a direct way, the availability of real-time information, aided by the model and consultancy of Pecan Street, helped address some of Boulder's smart grid concerns over the lack of customer-facing technologies. It seemed that even if the program did little to actually enable savings, it included participants in the smart grid more actively than during the SmartGridCity project which has proved to produce more favorable public attention. This program and partnership with Pecan Street, thus, also helps solidify public approval of municipalization. While the CPP included elements of all of knowledge translation, similar discourse, and learning process through civic engagement, including looking for community 'ambassadors' to advocate for participation in smart grid experiments, it also seemed to lack the efficacy needed for Boulder's local energy action. The CPP and working with Pecan Street, didn't really get what the city needed in terms of data access or 
insights for helping implement their own programs as a municipal utility, the Sustainabil-

ity Manager explained,

Part of that is really understanding how limited we are and how far we could actually go with it. So we said can we actually do some of this stuff internally versus what they can provide for us, and it all really came down to data access. So I think, it was pretty effective with the residents that were in the pilot. But we didn't really set up a mechanism to say here is what we are trying to test, and here is what comes next. So in other words, we had neighborhoods selected, which were great, and they did the work were we were able to develop strategies for the residential customers and really move forward on kind of a collective approach. But ok, it was, they have their data, but what is it really telling us? And that's what we were looking for those guys to kind of dissect for use, but it without the ability to contrast that to some other neighborhoods, and get that information, it wasn't really helpful. Because it was before and after, so how much of that was "hey you are in this pilot now and we are going to be monitoring your energy consumption," how much of it is behavior, how much of it is technology, it was really hard to draw any good conclusions, so that's where I think we could have benefited from Xcel being part of that from the get go. And say Ok, can you, can we identify some similar neighborhoods as a control group or something like that. Now, they probably wouldn't have agreed to it. Or at least can we use some of the facilities and customers that are on eGauge.

The efforts to gather data, access it, analyze it, and do something useful with it, a key strategy for realizing smart grid benefits, did not emerge from the more limited smart grid experiment. Xcel's incumbent sociotechnical regime, and the politics over local control, limited the City's ability to extract the necessary lessons for the broader community. The small-scale experiment was successful for the few households that participated, but it was too limited by the lack of cooperation with the incumbent utility to produce any insights for the planning of the municipal utility.

Boulder's case here is presented to illustrate three interweaving tensions pointed to before. The first is challenge of cities and municipalities to tackle climate change imperatives while operating with limited agency over their electricity systems. For urban 
energy transitions, this case presents a reminder that the political economic context, various forms of power - discursive, instrumental, institutional - impact the ability and pathway of an energy transition process and its outcomes (Geels 2014). The case of SmartGridCity and the CPP, highlights that even through inter-city learning and referencing of policies, the local context and power relations shape the efficacy of the mobile policy, especially under pressures of time and financing (Peck and Theodore 2010b). Secondly, the case highlights issues of public expectations for smart grids and associated visions, which presents opportunities for a technopolitics to emerge between incumbent regimes and its challengers. The alternative visions offered by Boulder positioned certain technologies and benefits of the smart grid (such as increased renewables which align with environmental goals) against the incumbent regimes use of particular smart grid technologies they saw beneficial for more efficient and reliable operations, which was not a key issue for the public. The taken-for-granted nature of infrastructures, where the steady flow electricity is assumed, plays an important role in these smart grid technopolitics. The utility saw, for example, the smart grid helping maintain this "taken-for-grantedness" while the public expectations envisioned something much more engaging and innovative. Lastly, these technopolitical pressures and issues created an opportunity for the city to become "extrospective," searching for smart grid experiments and utility models to implement locally. These models and knowledges filtered through the political actors of the city, privileging the experiences of Austin as a model for Boulder's own smart grid experiment to boost their municipalization efforts. By demonstrating the capabilities of the consumer-side of the smart grid, Boulder's work with Pecan Street, although not ul- 
timately very effective, was a strategic act of technopolitics to enable greater support for the local control of the electricity system.

\subsubsection{A platform for sociotechnical experimentation: Fort Collins' FortZED}

Approximately 45 miles north of Boulder is Fort Collins, a city of approximately 152,000 people in Northern Colorado. The City has received attention for its commitments to sustainability and livable communities. Easy access green spaces and natural landscapes coupled with "urban amenities" led Money magazine, for example, to call give it the first place ranking. ${ }^{15}$ Making the ranks of the "greatest places to live," it has also fostered new growth around research and development in energy and sustainability. Colorado State University (CSU) bolsters the City's research and development industry with a focus on clean and renewable energy.

The FortZED project, Fort Collins leading smart grid project, grows out of this context to concentrate activity on energy production and efficiency in the downtown core and CSU campus. FortZED was originally formulated as a zero energy district (ZED) concept linking the city's downtown, the CSU campus, and buildings along the city's riverfront in a smart micro-grid. The project, like Austin's Pecan Street project, benefitted from federal funding for research and development on smart grid technologies. The first phase of FortZED was initiated in 2008 with the DOE Renewable and Distributed Systems Integration (RDSI) Demonstration Project - Fort Collins was one among a group

15 Much more information about this 2006 ranking and others at Colorado State University's website: http://www.colostate.edu/features/americas-best-place-to-live.aspx. 
of nine communities selected by DOE with a funding pool of $\$ 55$ million for the project. The aims of the RDSI were primarily to use renewables and distributed generation to decrease peak loads by 15 percent or more.

FortZED as primarily an outcome of three entities: Fort Collins Utilities, Colorado Clean Energy Cluster, and UniverCity Connections (and after 2012, only CSU). These institutions are working collaboratively through the FortZED project to shape, construct, and experiment with smart grid technologies. The city-owned and operated Fort Collins Utilities primary interest in FortZED focuses on "transformation" for sustainability and protecting the environment and community in their $21^{\text {st }}$ Century Utilities Initiative. As they note (FCU, 2014) ${ }^{16}$ :

Transformation. It's a pretty big word to imagine for an individual life, let alone a large, multi-service organization. That's what Fort Collins Utilities imagined, though, when we designed our 21st Century Utilities Initiative, which closely aligns with a broader community vision of protecting and preserving our quality of life in Northern Colorado.

Similarly future-oriented and visionary statements envelope the discussion from UniverCity Connections, a partnership between the City, CSU, and the Poudre River (UniverCity Connections, 2014):

Fort Collins' UniverCity Connections focus area, encompassing the CSU campus, Old Town, and the downtown river corridor, is uniquely positioned to be at the forefront of our nation's new energy economy. We will be known as leaders - with many of the nation's experts on renewable energy theory and practice living and working in the UniverCity District. We're calling this FortZED for Zero Energy District.

16 The $21^{\text {st }}$ Century Utilities Initiative is linked to the FortZED project through grid modernization. More information available here: http://www.fcgov.com/utilities/sustainability-leadership 
The Colorado Clean Energy Cluster is a group of local cleantech companies dedicated to growing the cleantech industry in Colorado. The organization sees FortZED as an initiative that "is deployable and replicable nationally and internationally," and provides "a strong competitive advantage for the many clean technology companies in Colorado participating in its signature 'jump-start' project”' (CEC, 2014).

After the first phase of the RDSI project, which was highly successful, Fort Collins was able to secure a second round of funding from DOE to conduct a second phase of research on microgrids and islanding capacity. As a representative of the City's electric utility explained,

The first part of the project was primarily focused on demonstrating both the technical and pragmatic capabilities required to use both distributed energy resources like solar and other sorts of generation at the edge of the grid instead of internally and also behavior changes to reduce peak demand for electricity on a feeder part of the distribution system. [...] there are technical challenges with that, actual control software and systems, switching and stuff, necessary to integrate power coming from multiple places instead of just one. And the other thing is behavioral change, about changing peoples' attitudes, choosing not to demand power at that peak time, its like do it a different time. So both technical issues about communicating with them saying, its time to save, and then are they ready to sign up and do their part and actually save. The phase 1 was focused on that, piloting and setting up the control software. [...] In phase 2 we addressed microgrid, sort of a continuation of the issue of managing demand on the overall grid. The concept of microgrids, about part of the grid, part of the community, the campus, and organization being able to be separate from the grid and have their own energy source. (Interview, November 2015)

Another highly successful project, Fort Collins participation in the RDSI helped position the city at the center of attention in the developing area of smart grid technologies. Not only did the project spur local success with local companies participating and piloting their smart grid technologies such as energy management software, and encourage active 
participation from the local community, it also attracted attention extralocally, with communities from around the country, and internationally, interested in the technical capabilities of the FortZED project. As one city planning office representative explained:

They (local companies) were able to modify their technologies, they work on control systems, platforms for software, they were able to develop their next generation platform based on some of the outcomes of RDSI phase one study. [...] The city had a tremendous amount of PR out of it. So that part was very successful, however it was very hard to convey to the public. It was very engineering-focused, very technical. (Interview, November 2015)

While much of the work on FortZED benefitted local companies and demonstrated various smart grid technologies and models, it didn't actively engage with the local community who had gained interest in the project. However, these technical demonstrations helped the city attract further funding from the Department of Energy with their Smart Grid Implementation Grants program which Fort Collins received. As a representative of the city planning office explained:

The RDSI study was the first of the nine DOE projects to be completed and in my opinion established a very strong reputation for the City of Fort Collins and our municipal utility. [...] It established us with the Department of Energy, allowed us to get the second study, and in my opinion probably allowed us to get a Smart Grid Investment Grant which allowed us to upgrade the entire Fort Collins grid to smart, advanced metering. So we got that Smart Grid Investment Grant back in 2011, SGIG was the name of it. We got half of or maybe seventeen, of the $\$ 36$ million, and we got I think a little more than half, and bonds, so we paid for it, the utility ratepayers paid for it. So it had to go to council, etc. and there was some small incremental rate increase for it, and those were all the mechanisms for it. So basically everything wrapped up by 2012 -2013 for RDSI, and we characterized it as post-project depression, and there was really questions about what do you do next, there really wont be any more of these grants coming out. (Fort Collins City Planning representative, Interview, November 2015) 
The City was able to capitalize on the benefits of the initial RDSI, DOE funded studies to leverage the matching funds from the SGIG, which as Chapter 3 discusses, invested approximately $\$ 8$ billion in smart grid infrastructure and programs throughout the country.

${ }^{17}$ While the funding required matching funds and rate increases, Fort Collins did not experience significant customer dissent. The experimentation with initial FortZED programs gained support as they "proved" different smart concepts early on. For example, they highlight how different parts of the grid system could be "island-ed" or essentially operated as an independent microgrid. This demonstration captured the attention from many resilience minded city officials, including many east coast communities after Superstorm Sandy and officials from Japan after the Fukushima disaster, many of whom visited Fort Collins and attended presentations by utility and city officials. As a planning office representative explained to me:

That one (the microgrid study) generated a lot of interest, particularly from Japan after the nuclear meltdown [...] they were really interested in trying to advance renewables quickly and were interested in microgrids after that. We also got a lot of interest in that study after SuperStorm Sandy, got a lot of communities in the northeast, a lot of communities interested in how it works. But those aren't really sexy to the average person in Fort Collins. (Interview, November 2015)

While much attention was gathered extralocally, the FortZED project had lost the attention of local citizens who initially supported the zero energy district concept. The decrease in local support and excitement for the project translated into difficulties with

17 More information about SGIG and exact funding distribution is available at: https://www.smartgrid.gov/recovery_act/overview/smart_grid_investment_grant_program.html. 
further implementation and political support. This led to a reinvigoration and reinterpretation of the City's project. As the City's lead on FortZED explained:

Its just, people are very busy and, I think where FortZED kind of lies now is, back in March when we adopted the more aggressive greenhouse gas mitigation goals for our climate action plan, we tied not only the vision of expanding the focus of advancing the energy sector. We modified the vision of FortZED to really help the city achieve its environmental and economic goals. And tied that specifically to the energy sector. (Interview, November 2015)

The malleability of the smart grid experiment in Fort Collins allowed the city to alter the discourse and direction of the project to align with community values for climate change mitigation and adaptation. The project received a boost from the Rocky Mountain Institute (RMI) who also gained interest in the project for its ability to test not only new technologies, but new business models. RMI conducted a community charrette to rethink the FortZED model, which resulted in three major things. First, RMI supported the movement towards reinventing FortZED to support climate and environmental goals of the City (Chan et al. 2014; Maurer and Newcomb 2013). Second, this resulted in a reinterpretation of the FortZED project to move beyond the "exclusivity" of the district concept (Fort Collins representative, Interview 2015) towards more city-wide strategies that would enable more explicit connection with more citizens. This helped avoid the "political issue' of the districting concept (ibid.). Third, the RMI charrette helped shift the focus away from zero energy, the other part of the name of FortZED, to focus on broader energy sector issues such as business models. Under the influence of RMI's "own agenda" (ibid.), the City shifted towards attempting to develop integrated utility services (IUS). Under this model, the City created a pilot program (which had only five participants in November 2015) where the utility facilitated demand management, energy effi- 
ciency, and distributed generation packages that consumers could choose from and finance with on-bill financing offered through the City. As RMI's whitepaper on the issue explains (Campbell et al. 2014, 6), "the pilot will provide a model for other utilities and cities around the nation interested in providing clean, reliable electricity to their customers while stabilizing their own utility business models." So while the smart grid experiment, or pilot with on-bill financing, customer engagement using smart technologies, and better integration of sales-to-installation was interested in reinventing the concept of FortZED, it also had a direct focus on influencing other cities and the electricity sector more generally. RMI played a key role in this broader network.

Another key network that the City engaged in was the Urban Sustainability Director's Network (USDN) which enables City staff to engage with a broad network of City officials across the country. Many of the cities in the USDN were also participating in the Georgetown Energy Prize Competition, a competition put on by Georgetown University to encourage energy consumption reduction in cities across the country. As a City Planning representative explained:

I think that's what Georgetown is trying to get at, how can some of this stuff be translated to the rest of the country and rolled out in a way where somebody can learn and just retool it for what works in their community. [...] So we do have a lot of communication with cities through PRPA, CCEC, and then we have a huge network within our own staff that communicates with different cities, Austin has kind of been our BMP city for years, we've gone out there a number of times to talk to them, some of the other cities, Portland, Seattle, we all look too, some of the cities, Sacramento, San Diego, SMUD [Sacramento Municipal Utility District] we all have had some different interactions with them. There is a network called the Urban Sustainability Directors Network which is a non-profit that a number of progressive people working on sustainability issues use, and that's really helpful, but conferences and all that, people come and talk to us a lot, like I said with FortZED, I think 30 different countries have come, and those involve presentations, and those aren't fun to do, having 
to have everything translated, $[\ldots]$ but they are still interested in coming to learn. Our CAP goals alone, I mean everybody who cares about this stuff are watching. (Interview, November 2015)

The outward focus of much of Fort Collins work in their FortZED project had come at the cost of local interest. A confluence of factors ranging from the technical nature of the smart grid interventions to the lack of organizational structure for facilitating volunteers and participants had resulted in a project less about local energy and climate action (at least at first) and more about proving technical smart grid concepts such as islanding and peak demand reduction.

The case of Fort Collins highlights two major issues at the intersection of urban energy transitions and policy mobility. The first relates to the politics of local smart grid experiments and extralocal audiences who include not only other municipalities, but also energy technology companies and federal funders. This led much of the initial FortZED project to focus on technological demonstration and proof of concept, and less on communicating how these technical benefits would impact or resonate community goals and values. Fort Collins volunteers and participants in programs lost interest in FortZED once these primary phases were completed, which caused the city to have difficulty in organizing further smart grid programs with community support. These technical considerations and demonstration also have their flaws and shortcomings. In particular, both engineers and planners cited the issue of data overload and the problem of finding value in smart grid technologies that provided data and information. For example, a city planning representative explained:

The other thing that we are getting a lot of interest in from businesses is a potential FortZED project with [software companies] based on the Internet of Things, which is basically micro metering on our smart grid system. 
But there is a laboratory, at CS interested in this and a couple other buildings on campus that use a lot of energy. Part of the problem we are having with the AMI technology is basically that it's just a flood of data. And there is not a lot of advanced management systems to determine what you are supposed to be doing, energy managers don't know what to do with it, and that's a huge problem. CSU has a huge problem with it. It's really a floodgate of all this data, and they don't know what - they don't have a way of, I guess, aggregating and disseminating the information to get the energy profile of the building, and they can't optimize. [...] But we have had a number of business trying to talk to us because they don't know what to do either. And that's really one of the biggest challenges related to smart grid right now, is this - basically we have this huge investment and we don't have any return on it right now. Because we don't have any way of managing the amount of data we are getting. (Interview, November 2015)

This technical issue resulted in more attention to the FortZED project as companies wanting to test-out their software approached the City and the University. Although FortZED offers a new "platform" for advanced smart grid technologies and applications, the City officials I spoke said that they have the ethical responsibility to not privilege certain technology companies. They explained that the request for proposals process the City uses is mandatory for ensuring fair competition:

I get approached all the time by individual vendors, but I have no procurement process that I can give individual advantage to. [...] it means if you're Verizon and you come talk to me, I can tell you what our challenges are, but we have an RFP going out, which is a request for proposal for services or products, - I don't want to give you advantage because this is a public entity, and those procurement processes are in place to avoid corruption, and earmarking, and contractor advantage, because that's just how it works and should work frankly, but its challenging when you work with businesses for year [...] which [served] on our steering committee and helps us do studies, but an RFP goes out and they have no guarantee of getting it. So it's an investment of time. [...] But can they apply what they learned from Fort Collins utilities to other customers? Of course, but its not a tangible outcome for them always. So that's part of the challenge of having those type[s] of partnerships. (Interview, November 2015) 
This quote raises a second point related to urban energy transitions and experimentation that this case highlights: the smart grid offers a platform for testing varieties of sociotechnical interventions, but these are often shaped by the interests of incumbent regimes. While the case of Austin highlighted a similar dilemma, in terms of "opening-up" the city

to private investors and encouraging entrepreneurial forms of urban governance, Fort Collins shows that the commitment of private companies comes with hopeful expectations for special treatment in public procurement processes.

\subsubsection{Austin as exemplar? Traveling logics, rationalities, techniques}

Chapter 4 highlighted the Pecan Street project in Austin as an "exemplar" for urban smart grid implementation and testing. Two key elements of the project had inspired and traveled, in various ways, to Oak Park, Fort Collins, and Boulder: the test-bed approach and the related logic of customer engagement through particular energy monitoring and feedback programs. This section reflects on the concepts and rationalities that travelled, and the practices and processes which facilitated that travel. Pulling from the cases above, this highlights how inter-city referencing "traveling technocrats" and best practices shape and are shaped by the context of the city and infrastructure project.

As discussed in Chapter 4, I highlighted how Austin's smart grid experiment was conceived and developed as a "test-bed" for new smart grid interventions. These interventions are sociotechnical and attempt to configure energy governance through the materiality of the city and the shaping of energy conduct while also positioning the city as an entrepreneurial hotspot for startups and venture capitalists. The test-bedding approach 
was produced as a model in Austin, but this played a significant role in shaping the urban smart grid projects in both Oak Park and Fort Collins.

Oak Park city officials directly engaged the concept of a "test-bed" in their SmartCityUSA project suggesting that it would stimulate their sustainability efforts. They referenced the Austin and Korean examples, suggesting that "best practices" related to smart grid implementation must be included in a test-bed approach; it's experimental and focused on testing and development, aligning the interests of the incumbent utility, a few interested and motivated research participants, and technology companies. The test-bed approach also is favorable for producing valuable data on energy consumption serving a research purpose needed to get state and private funding.

Similarly, in Fort Collins, the test-bed approach was categorized as an essential feature of the project. Influencing their approach was not only Austin as a "peer" city, but as a way to attract the matching funds of the DOE. The SGIG funding streams had specific requirements for testing which influenced the types of smart grid projects a city or utility would implement. Importantly, this suggests that the test-bed approach is not only related to urban entrepreneurialism and inter-city referencing, but contingent on the national level interests in promoting the smart grid as a governmental program.

This leads to consideration of embedded governmental rationalities that may be carried in urban smart grid experiments, but shaped by particular modes of implementation. This is most apparent in the approach to engaging customers in smart grid projects, enabling participation in research field trials, and in the process, shaping relationships between consumers and the smart grid. Most notable was the interconnection between Austin and Boulder's smart grid experiments, which used the same home energy moni- 
toring technology and software as a way to engage consumers in field trials. As discussed in Chapters 3 and 4, the logics of this approach entail shaping of consumer identities and conduct through feedback, pricing mechanisms, and normative messaging. While these

are certainly general approaches, the positive experiences and new knowledge generated in Austin served as a "proving ground" for these approaches, allowing city officials in Boulder and Oak Park to cite them as a basis for authority and support of their own projects.

\subsubsection{Experiments, Mobilities, Transitions}

These three case studies elucidate key issues in urban energy transitions, building on Rutherford and Coutard's (2014) overview, and help to show why the perspective of policy mobilities is useful for further inquiry and explanation.

(1) The infrastructures, technologies, and material artifacts of the smart grid are fundamentally part of the urban. They constitute the material fabric of the city, facilitating the flows of electricity into, across, and between cities, enabling the everyday activities of lighting, cooling, heating, computing, etc. As such, reconfiguration of these urban infrastructures, as in smart grid experiments described above, can be a major part of testing and implementing pathways for low-carbon transition. At the same time, however, transitions are sociotechnical and include the co-production, shaping, or contestation of both technologies and social practices, norms, and values. This is especially important in consideration of smart grid experiments which may re-orient the relationship between producers and consumers through technologies of demand-side management, demand response, 
or distributed generation. However, the existing sociotechnical regimes have considerable power over the ways in which these infrastructures are utilized and controlled, constricting possible pathways emerging from smart grid experiments.

In Oak Park, the installation of smart meters and smart substations allowed for the incumbent utility to create an "innovation corridor" placing Oak Park at its center. While these infrastructural changes did not represent a part of the SmartCityUSA project, they created the conditions under which a smart grid experiment could be facilitated by providing the necessary background infrastructure. This however, presented the issue of working in partnership with the incumbent utility, which has its own sets of interests and responsibilities to shareholders and regional electricity markets. Points of intersection between the possible integration of distributed renewables and voluntary demand response fit with Oak Park's goals for environmental action, but could create friction with ComEd's desire to manage and dispatch those sources of generation or stored energy. The partnership seemed favorable but also necessary from Oak Park's standpoint. The infrastructural changes that occurred had impacts on the regional economy, and made it possible for smart grid experimentation to take-hold in Oak Park locally.

In Fort Collins, for example, the smart grid experiments already showed some insights and opportunities for alterations in social practice. As a city planning official explained regarding their "Monitor My Use" web portal:

... so what do people do on the weekends? [...] They do laundry, wash clothes. [...] We actually found that highest energy use in our town is on Sunday and lowest on Tuesday. So it tells us how people are using energy. (Interview, November 2015) 
The smart grid enables the tracking and monitoring of not only the quantities of electricity demand, but also the temporality and rhythms of consumption. This proposes "opportunities," as many utilities, regulators, and cities consider them, to alter the "when" of energy use, not necessarily the "how" or "why." Smart grid infrastructures make possible the voluntary or automatic reconfiguration of practices in line with the necessities of a reliable grid and least-cost energy supply.

The case of Boulder, similarly, shows how the reconfiguration of the electric grid to make it "smart" was catered towards the incumbent utilities needs and desires. While the infrastructure created the opportunities for smart grid technologies to benefit citizens and customers, the incumbent utility stopped short of any meaningful implementation on the consumer side. While, like in each case examined here, the infrastructure provided a platform for possible smart grid applications to help the cities meet their goals (for carbon reduction or reducing peak demand), the actual implementation of the projects was shaped largely by existing power relations, institutional and regulatory models, and norms and values of the dominant sociotechnical regime. In Fort Collins, too, the smart grid implemented to facilitate a zero energy district faltered, and instead created a platform for technology companies to test and offer services that, in the eyes of the city council, are too risky to fund with public monies. The possible sociotechnical changes offered by smart grid experiments in these cities are shaped by the infrastructures in place and, critically, by who has control and access to those infrastructures.

(2) In relation to the first point, urban energy transitions, despite a national vision, dominant discourse, similar policies and models, and central funding streams, are shaped differently by contingencies and context-specificity of urban processes in 
each of the cities. This helps elucidate how each city creates the context for sociotechnical change and experimentation, and how these spaces are "constructed and maintained relationally across space by the flows and circulations of energy, of knowledge and expertise, of models and notions of best practice, of norms and conventions of energy supply and consumption" (Rutherford and Coutard 2014, 1364, emphasis added)

This point connects the "work" of creating smart grid experiments for sociotechnical change with the "work" of constructing and maintaining these spaces through networks of policy knowledge, models, and expertise. In a similar manner to which flow of energy create the conditions for urban life, making the material environment "come to life" (Bennett 2010; Nye 1992), flows of knowledge and policy models for smart grid experimentation help create and maintain these experiments through relational understandings of their possibilities to contribute to an energy transition that helps meet the cities goals.

All three cases expressed relationships with the City of Austin, Austin Energy, or Pecan Street. In the case of Oak Park, Pecan Street served as a direct consultant and project manager for the smart grid experiment offering "four years of lessons of failures from Austin" (paraphrased from Pecan Street's presentation to the Village of Oak Park in March 2015) that would not be repeated in Oak Park. In Boulder, Pecan Street became an important part of their Community Power Partnership to reconfigure the urban smart grid to make it more palatable for Boulder's citizens after the relative failure of Xcel's SmartGridCity project. In Fort Collins, Austin was often referenced as a peer city, providing insights on how to manage a progressive municipal utility in line with environmental goals, knowledge that was gained through direct communication and networks 
of local sustainability officials (City of Fort Collins representative, Interview, November 2015).

These flows of knowledge and policy also contain embedded governmental logics that provide a basis and rationale for particular smart grid technology and program implementation. As Chapter 3 and 4 highlighted, the perspective of governmentality captures the particular logics of regulating the conduct of individual users through various "behavior change" programs that are attached and embedded in smart grid projects. This is already a power-laden and conscribed view of energy consumption. While social science approaches of social practices understand energy use as a social and cultural practice, the dominant policy models and knowledge try to intervene through the governing of individual energy use based on epistemic communities of economists and social psychologists. While these epistemic communities do offer a range of variables to consider, they often do not engage with broader structural power relations. The analysis of governance through governmentality highlights in particular how the alternative understandings of electricity consumption, such as that of social practice, are relegated to the minority while dominant modes of explanation support and legitimate existing relations of power, such as economist and engineering dominated policy prescriptions and models for sociotechnical systems change.

(3) Urban energy transitions entail a diversity of processes, and although they have shared and relational networks of knowledge, they touch down differently in different places, often with different outcomes. This perspective can be useful in highlighting the variety of social practices in homes, at work, etc. that may influence processes of sociotechnical change in urban energy transitions. Dominant 
discourse becomes powerful by privileging some forms of knowledge and suppressing others. One key area in smart grid experiments here, refuted by the systemic view of social practice (Shove, Pantzar, and Watson 2012; Shove and Walker 2014), are the "misleading ideas that the social dimension of energy transitions resides in homogeneously inciting consumers to use less energy and expecting them to (simply) 'change behaviours'”(Rutherford and Coutard 2014, 1365). While Chapter 3 and 4 highlighted these issues, they are important here as we analyze the way policies move, mutate, or get appropriated and with what embedded governmental logics and interests.

Each of the cases presented here represent a diversity of contexts and processes. The outcomes of smart grid experiments in each of these places are different. For example, in Fort Collins, the municipal utility directed the FortZED project from the beginning under direction from their city council, but quickly lost control to the engineers and technical experts who guided the project resulting in a disconnection between public excitement and understanding and project implementation. Serving as a "vanguard" similar to Austin, they were evaluating the smart grid in its ability to help meet public goals, but often found difficulties in making these connections. The concerted efforts of city staff were required to connect environmental goals and values to the technical projects, which had gained the attention of numerous urban audiences globally, and this resulted in a new round of project promotion. Ultimately, however, these more "social" elements of the smart grid experiment simply created frustrations with getting citizens to "change behavior." As the FortZED project manager explained: 
It's really hard to get people's attention, I never understood it until I did this project. There's just so much noise. People don't understand, there is so many misunderstandings around energy use, it just boggles my mind. $[\ldots]$ Leaving things plugged in. Does your coffee pot draw electricity? Depends. Probably. Do you have to unplug it? Not necessarily. What are you supposed to tell somebody? What about your TV? Turning down your thermostat, your water heater. Most water heaters have high or low settings, A through C, is there anything that will tell you where you 120degree mark is? No. What do you tell people to do? Turn it down 5 degrees? But how do they do that? [...] How do you convey that to people who don't care about saving energy. Maybe don't believe in climate change. They don't care about saving money even. I mean I have friends who have 7500 square foot houses. Do they care about saving money? No. What are you telling me I can't turn my hot tub on? No. I'm gonna get in my Audi and drive away. [...] So there is just huge divergence in what people care about, what resonates with them, and how you do it in a way that somebody can understand and can hit on those strings.

Similarly, in Boulder's program, the sustainability manager found similar limitations to smart grid programs and policies, ultimately finding that the main benefit wasn't behavior change, but renewable integration to offset "unsustainable practices." But, even then, the excitement around the possibility of entrepreneurial activity for customer-facing apps and smart grid technologies enticed a similar governmental logic of behavior change, just better suited to the " $21^{\text {st }}$ century, active consumer." Similarly, in Oak Park, the Village Manager explained that the SmartCityUSA project was so interested in data acquisition because they wanted to understand how to change behavior:

The project is as equally balanced on the data side, and that's why Pecan Street and University of Chicago are really key partners, because I mean us in Oak park want to say yes let's do this project, but we want to determine and learn things from the project. I think our perception is that the world is going to move this place to having more microgrids and um, but it's a question about of how you do you communicate it and implement it between private utility that has to maintain an infrastructure to a community that wants to have reliability, wants to have, environmental sustainability goals achieved. There is a lot of reasons for doing it, and we think the data is going to be an important part of understanding does this change behavior, does it not change behavior, what does it do? And how do you 
make it a program that everyone wants to be apart of? [...] the more information you have the more they can learn if you can influence behavior. I think it's the connection between what's energy utilization look like when people don't have information about it, in terms of pricing, and if you give people information about pricing, will people change their behavior, or will electrical consumption continue to always, peak and spike, and does that data help influence manufacturers of refrigerators and washing machines and clothes dryers to maybe do something different. (Interview, October 2015)

Highlighting the context of different smart grid experiments and the ultimate outcomes of urban policy mobilities - how they mutate, if they "take" in certain places or not, and what they reference or don't from other places - may contribute to teasing apart the ways governmental logics in smart grids also travel. The variability of context and processes also exposes how smart grid programs are designed to be carried out over a smooth urban space - a clean slate - that encounters issues with complexity and variability. This includes both social issues, such as behavioral change and rationalities, and material issues, such as the actual implementation of infrastructure networks. In Boulder, the Xcel SmartGridCity project required the tearing up of streets to lay fiberoptic cables, but material changes such as these are always intertwined as sociomaterial or sociotechnical issues. In Boulder, the material changes resulted in rate increases and distaste for the SmartGridCity project. In many ways, the city itself becomes an object of impovement as it becomes measured, known, and calculated through smart grid infrastructures (Bulkeley, McGuirk, and Dowling 2016). Each of these case studies has begun to make this notion apparent, that smart grid experiments are not just about shaping the conduct of electricity consumers, but also about reshaping the city as a platform, test-bed, etc. for experimenting with new sociotechnical configurations often to cater towards the interests of incumbent regimes. 


\subsection{Conclusion: Mobile Experiments and the Politics of Urban Energy Transitions}

Urban energy futures are shaped through multiple processes and power relations. They are structured by the material environment's obduracy, the dynamics and needs of everyday experiences, and the cultural values and beliefs that support particular sociotechnical visions. Through examination of urban smart grid experiments in three US cities, this chapter has explicated the role of these projects in the governance of urban electricity networks and urban energy transitions. But it also highlighted the relational nature of these projects, and how even though they share policy knowledge, models, and technologies, each of the experiments actually get configured differently in particular places.

Each case highlighted struggles over urban energy transitions, competing values, and even battles of technopolitics, often putting forth the problematic of dislodging or remaking sociotechnical regimes. The question of control and governance, for example, in these contexts points to the need for further research on the intersection between urban energy transitions and policy mobilities. These case studies help chart some of that territory and offer some insights into the diversity and dynamics of urban energy transitions. 


\section{Chapter 6: Discussion and Conclusions}

This chapter synthesizes the findings and arguments made in the previous chapters. This synthesis explains how the analysis of the material and discursive construction of the smart grid, the implementation and testing of urban smart grid experiments, and the mobilities of smart grid policies, models and knowledge fit with the overall conceptual framework. I then describe the practical, policy, and intellectual contributions that this dissertation makes. I end with a discussion of future research agendas that expand upon this dissertation.

\subsection{Review of findings}

The analysis of discourse and cases of smart grid experiments discussed in this dissertation tells us several new things about the smart grid and energy governance. First, despite the attention and speculation about the technological possibilities of digitizing the grid and enabling an "Internet of things" for all our energy consuming devices, the smart grid has been rolled out, although unevenly, largely as a governmental program that touches down and is shaped by local context, materiality, history, and political economy. Second, although an assumption of a blank slate approach is embedded in policy models and knowledge, the smart grid confronts the city as a smart grid experiment that must be maneuvered and mutated to fit with existing conditions, while also trying to shape the city, both materially and discursively. Third, power operates in many ways in sociotechnical systems, and if we seek to govern and change these systems towards more sustainable configurations, we need to confront these forms of power. 
These broad findings suggest that scholarship on smart grids and transitions in urban infrastructure should account for wider social and political issues to address how energy transitions might not result in changes yield more just or sustainable outcomes, and may only serve to reproduce or reconfigure existing regimes. Addressing governance of transitions is of central importance to questions about urban sustainability and lowcarbon transitions. Governance regimes - as discussed in this dissertation - combine elements of sociotechnical regimes with conceptions of governmental power utilizing theories of governmentality to better understand how energy system transitions are governed.

In Chapter 3, I argued that the smart grid should be understood as governmental "program," as theories of governmentality discuss, and as such, sociotechnical change in the electricity systems needs to be understood not only through the concept of a sociotechnical regime, but instead through a governance regime that expands on the rationalities, techniques, and subjectivities involved in governing sociotechnical change. I conducted a critical discourse analysis of over 400 documents on smart grid policy, research labs, regulators, whitepapers, academic journals, industry journals, professional associations, advocacy groups, non-profits, and technology companies. The analysis revealed three key rationalities for governance: efficiency, security, economy. These rationalities are a series of problematizations of the existing infrastructures and its economic, safety/reliability, and environmental impacts. These rationalities are interlinked with a series of techniques that produce subjects and govern them through the operation of norms, encouragements, and discouragements. Power here is enabling, not disabling (i.e., it is a form of biopower). The purpose is both to govern the conduct of a population of "smart consumers," so as to normalize their energy consumption enabling the sociotechnical 
system to work according to governmental rationales. Smart grid techniques are primarily discussed in terms of techno-economic understandings, and this translates into narrow views of energy users, limiting their ability to influence or participate in sustainability transitions.

In Chapter 4, I argued that urban smart grid experiments, although cast as opportunities for radical innovations to breakthrough and disrupt sociotechnical regimes, are implemented in the context of both dominant governance regimes and urban political economies which shape their purpose, goals, type of experimentation, and impacts. Analyzing the case of Austin, Texas, I found that the smart grid is implemented utilizing a "living lab" approach that serves as a demonstration of Austin's sustainability efforts and high-tech exceptionalism, and at the same time, it serves as a "test-bed" for different smart grid technologies and programs. While both of these models, demonstration and test-beds, have profound socio-spatial implications for urban sustainability and lowcarbon transition, they also have impacts on the imagined role of the energy user. Within the governmental program of the smart grid, the imagined subject is a smart consumer, who contributes to the sustainability and well-being of a population through "active" participation in smart grid programs. Yet, this is a highly limited, apolitical role that tends to reinforce existing sociotechnical regimes, even if change is desirable.

Austin's urban living lab for the smart grid (what I call an urban smart grid experiment), while promising to be the site of a solar revolution, a niche that will alter regimes, is situated within a broader governance regime that limits its ability to create significant change. The smart grid in Austin's neighborhood focuses on consumer pricing trials and technological integration in a test-bed and demonstration approach, furthering dominant 
techno-economic perspectives on the smart grid's abilities and "proving" existing dominant techno-economic perspectives, strengthening governmental rationales, for the most part. However, there is a contradiction, which I point to in Chapter 3, that suggests dominant models need to be reworked to account for the lack of customer engagement with smart technologies. One answer from the dominant techno-economic approach (regime) is to use automation to meet existing goals and designs for smart grid. The economic logics would be programmed into devices and consumer would only need to opt-in. The primary issues this chapter then highlights are important to the following chapter: the test-bed and demonstration approach to experimentation, the possibility of high penetration of EVs and PVs, and the "consumer empowerment" approach to managing demand. These ideas travel in the Austin model of the smart grid experiments, furthering a specific form of governmentality in the logics and rationalities, techniques, and (imagined) subjects of the smart grid.

In Chapter 5, I argued that best practice lessons and models for urban smart grid projects are carried on the experimental models of Austin, yet these ideas, experiences, and models mutate as they "travel" to different cities, Oak Park, Boulder, Fort Collins, with differing impacts as they are implemented or influence projects in each of these cities. This has implications for the governance of urban infrastructure, energy, and cities approaches to climate change. I utilized a relational comparative case study approach to analyze policy mobilities, following different actors, models, and ideas from Austin's smart grid experiment to others. Data collection included depth interviews with key informants, document reviews, observation of meetings, and review of conference transcripts. 
The analysis reveals that urban smart grid experiments are created relationally. This means there are practices of inter-city referencing, consultation, meetings, and other exchanges. These practices enable the movement, through political channels, and uptake of particular approaches to the development of urban smart grid experiments. This is not purely between cities, but also between the work of a variety of federal government organizations (DOE especially) and industry groups. Three concepts travel as "models" or policy knowledge: (1) the "test-bed" concept for the smart grid and economic development suggests a way to frame the experiments as opportunities for economic investment and technological testing; (2) ideas for particular technologies, such as particular smart meter, software packages, and different PV technologies, and techno-utopian visions of what these technologies allow (vast renewable integration, carbon offsetting, etc.); (3) processes for engaging customers/citizens in smart grid technologies.

Yet, different local implementations of these ideas, models, and knowledge depend on their contexts. This also shapes, as Chapter 4 suggests, how experiments may influence sociotechnical regimes. The implications of this include limitations of energy transition for realizing possible benefits of smart grid technologies, and the furtherance of existing sociotechnical regimes that approach the smart grid with a narrow view of participation as consumption, or a desire for a slow pace of transitioning towards renewable energy.

\subsubsection{Synthesis and connections to conceptual framework}

Together, construction, experimentation, and mobilities/diffusion all add to a better understanding of the way urban sociotechnical change may occur. Each of these elements 
shape and are shaped by governance regimes. Governance regimes are broader than, but inclusive of sociotechnical regimes, and explain how more diffuse forms of power shape the way sociotechnical systems develop and change. While existing studies of transition dynamics account for social and political dimensions in various ways, this dissertation suggests these dynamics are shaped by broader cultural forces and governmental programs. Thus, the smart grid is both a sociotechnical system with various actors, institutions, and technologies, and a governmental program that solidifies particular configurations of the urban smart grid.

The conceptual framework provides a valuable way for understanding the role of sociotechnical systems, transitions, and governance in assembling urban energy futures, whether that be a reproduction or reconfiguration of existing regimes, or a transition towards something different. Here, the analysis of power, in the Foucauldian sense, helps us understand how sociotechnical systems are created through and in turn shape power relations. This Foucauldian analysis of power relations explains how "power/knowledge technologies" mediate practice and enable forms of government and subjectivity serving systemic functions. Governing through forms of calculation, measurement, and statistical norms, enables governance regimes to emerge that can best respond to a series of problematics of energy systems (aging infrastructure, energy security, carbon) reducing risks through "rational," self-management techniques. Utilizing this approach, there is normative ambiguity, meaning that, as Tyfield $(2014,590)$ explains:

On the one hand, the flexibility and 'rationality' of this system is what affords its undeniable productivity and the power underpinning its emergence and subsequent stability - i.e. the very potential for (low-carbon, sustainable) 'system transition'. But, on the other, this is necessarily at the cost of systematic and 'rationally irrational' definitions of social exclu- 
sion, their (possibly brutal) enforcement (the more 'rational' the exclusions, the more violence is both 'legitimate' and rationally organised and so 'effective') and thus a schizophrenic zeitgeist of a society that fears the shadow it itself casts or conjures.

This places concern on the "shadowy side" of innovation (Shove 2012) and an impetus for researchers to identify and confront the possible (and realized) inequalities that inevitably will occur in system transition.

Moreover, the Foucauldian concepts of governmentality and "positive" power discussed throughout this dissertation highlight how sociotechnical transitions are as much about transitions in power as they are in reassembling or reconstituting networks of actors, institutions, and technologies with enabling and constraining effects. This helps to reveal a deeper problem with the MLP and its lack of explanation for the "actually existing" forms of technological lock-in and momentum so frustrating to sustainability transition advocates, especially related to energy systems. Governmentality brings an analysis to the ordering of sociotechnical systems, forms of common-sense elaborated in discourse and practice, which in turn produce ordering and lock-in effects. These understandings of power are different than the forms of juridical and disciplinary power discussed by MLP scholars (Geels 2014; Geels 2011), and thus bring a useful analytics for examining not just an array of factors, but the multiple power relations, rationalities, techniques, and subjectivities that reinforce dominant regimes.

\subsubsection{Contributions to scholarship}

In the first instance, this dissertation has provided a much-needed qualitative and empirical analysis of the US smart grid system, albeit only a part of the system (geographically limited study). Social science research on smart grids has primarily focused on soci- 
otechnical imaginaries and visions of policy makers and technology companies without a critical analysis of how these are tied to transitions or power relations. Certainly, this research is valuable, but is limited in terms of both explanation of power of existing regimes and governance of sociotechnical systems. This dissertation directly addresses these empirical and theoretical limitations.

Second, and relatedly, this dissertation makes a theoretical contribution to understanding power and politics in sociotechnical transitions by utilizing Foucauldian insights on governmentality and neoliberalism. The key benefit of this approach is that is more thoroughly accounts for the ways in which power/knowledge configures and strengthens particular sociotechnical regimes. Therefore, analyzing the smart grid as a governmental program places consideration of taken-for-granted dimensions of subjectivity and power/knowledge (in MLP perspectives) at the center of our understanding of sociotechnical transitions. The discourse analysis and cases highlight how these rationalities, techniques, and subjectivities are thus key drivers of system transition or lack thereof.

Another theoretical and empirical contribution relates to understanding the smart grid as not a singular, top-down policy mandate and technological transfer program, but instead a multiplicity of experiments that take place in the context of political economy of electricity systems and the power relations discussed above. Crucially, learning and policy "transfer" related to sociotechnical transitions relies on inter-city referencing, travelling consultants, and ephemeral spaces of knowledge production (such as urban experiments) that shape the political and material programs of urban smart grid projects in particular places. The synergy between transitions and policy mobilities frameworks allows 
a more nuanced understanding of how urban projects are shaped outside the traditional and official institutions of government.

In summary, this dissertation presents a conceptual framework that advances our understanding of sociotechnical transitions and addresses several of the limitations of existing frameworks. Expanding on existing sociotechnical transitions theory applied to urban infrastructures, this dissertation argues that sociotechnical systems are enacted, maintained, and reconfigured in a much broader system of power relations than articulated by the concept of sociotechnical regimes in the dominant MLP framework. The conceptual framework helps explain how sociotechnical systems are reproduced, reconfigured, or transitioned by attending to power relations and "technologies of power" that are enabling rather than disabling, relating to Foucault's understandings of neoliberalism. The notion of a governance regime was proposed as way to understand the role of power relations in the governing of sociotechnical systems, to help explain their apparent (and sometimes frustrating) stability or reconfiguration. Electricity networks both shape and are shaped by governance regimes, which in turn shapes and governs sociotechnical change, materially and discursively. This framework also complicates the MLP because it brings "landscape" factors into play [i.e. neoliberal political economy, urban governance, broad geographies (inter-city/across sociotechnical regimes' territories) of learning and inter-referencing].

\subsection{Implications for policy and practice}

The findings and conceptual framework above are novel contributions to scholarship, however, they also have implications for policy and practice. The first is consideration of 
transitions as highly political processes involving a variety of actors with differing expectations, values, goals, and positions of power. These forms of "power over" are only one form of power, and limit our understanding of how transitions are governed by other forms of power, such as cultural norms, and broader political rationalities. For policy and practice audiences, this suggests a need to consider the varied possible outcomes of transition processes and their inevitable forms of exclusion and inequality which can be resisted, or at very least, reduced by prospective engagement with "transitions thinking."

Similarly, and to the second point, if the normative goal is to destabilize unsustainable regimes, radical reconfigurations are necessary, and this means understanding power and governance beyond the sociotechnical regime. Practitioners need to be sensitive to how cultural norms come to be, how they contribute to stability and lock-in, and how discourse and rhetoric are powerful in this regard.

Third, attention to cultural models of energy use and social practice approaches bring together understandings of political economy with the politics of everyday practice, and thus, are perhaps better models for policy. Social practice approaches suggest that the dominant techno-economic approaches to smart grid policy, engagement, and practice are limited. For example, there is considerable evidence that the practices that contribute to energy consumption and peak demand (washing, cooking, heating, cleaning, etc.) will not change with more information or time-of-use pricing schemes. Cultural models suggest that changes occur, but that these are not always in line with goals of the smart grid (peak demand reduction, peak shifting, etc.), and instead result from interactions between social and cultural practices and technologies that enable or constrain these practices. This sug- 
gests that dominant technological interventions may not have the intended impacts on energy consumption.

Fourth, for urban planning practice, the case studies and lessons suggest that entrepreneurial extrospection and policy scanning are not always the most appropriate approaches to developing policy. Local citizens have their own interests and values that may be overcome by desires to attract technology companies or other sources of mobile capital. One city's approach to sustainability transitions may be markedly different from another's, and simply adopting best practices may serve to repeat and exacerbate longstanding urban problems such as gentrification and displacement. Projects, policies, and models, while certainly benefitting from lessons elsewhere, should utilize democratic processes to see how local communities could benefit, if they see it as acceptable and worthwhile in the context of their community's needs, values, and goals. Projects shouldn't just be a part of an entrepreneurial race to global/sustainable city status. In addition, experimentation may produce unintended impacts of exclusion and political problems, with one-off projects providing benefits to already well-off communities. In this way, urban experiments can exacerbate existing inequalities while trying to catalyze sustainability transitions.

Finally, while the smart grid seems to be a simply technical matter, usually orchestrated through a top-down approach by governments, utilities, and major corporate actors, it is also a profoundly social program that is attempting to reconfigure relationships between utilities and consumers, aligning social practices with new governmental rationales. Acknowledgement of how the "social parts" of a sociotechnical system are expected 
to change may help facilitate (with planning) technological changes that promote both low-carbon and social justice agendas.

\subsection{Limitations and areas for future research}

A number of limitations to this study are important to note. First, the ability to adequately capture the breadth of practices, places, and ephemeral spaces influencing the mobilities of urban smart grid experiments and associated policy, models, and knowledge was limited by geography, accessibility, and funding. While this limitation is practically difficult to overcome, noted by many scholars working on policy mobilities or "fast policy" research, it presents an opportunity for longer-term, collaborative engagements across multiple cities. Tracing and following the policy and knowledge could be a project engaging multiple researchers across space. This leads to a need for further study, for example, to study the ways in which different practices shape local urban energy and sustainability policies and a variety of infrastructures (electricity, transport, waste, etc.) more broadly.

Second, the Foucauldian approach taken in this dissertation entails a reading of discourse, power/knowledge, and governmentality, which critics argue privileges discourse over materiality. However, the approach taken in this consideration attempts to overcome this limitation by explicitly engaging with urban materiality and a sociotechnical approach with its emphasis on technologies and artifacts. Instead of limiting, then, I think this approach is fruitful for study of other sociotechnical systems. The Foucauldian approach, and some version of my framework, could be applied to study a number of sociotechnical systems undergoing transition. 
In sum, energy transitions entail considerable sociotechnical change and shifts in power and politics. This study highlights several issues related to these concerns, but there is still more work to be done both in terms of activism and research. Energy is an existential issue, and, thus, energy transitions will have more than a technological imprint on our world; they will involve remaking our world. In my opinion, that requires our attention, thought, and action. 


\section{References}

Abi Ghanem, Dana, and Sarah Mander. 2014. "Designing Consumer Engagement with the Smart Grids of the Future: Bringing Active Demand Technology to Everyday Life." Technology Analysis \& Strategic Management 26 (10): 1163-75. doi:10.1080/09537325.2014.974531.

Affolderbach, Julia, and Christian Schulz. 2016. "Mobile Transitions: Exploring Synergies for Urban Sustainability Research." Urban Studies 53 (9): 1942-57. doi:10.1177/0042098015583784.

Agamben, Giorgio. 2009. What Is an Apparatus?: And Other Essays. Stanford University Press.

Alahakoon, Damminda, and Xinghuo Yu. 2013. "Advanced Analytics for Harnessing the Power of Smart Meter Big Data." 2013 IEEE International Workshop on Inteligent Energy Systems (IWIES), November. Iee, 40-45. doi:10.1109/IWIES.2013.6698559.

Alford, Robert R. 1998. The Craft of Inquiry: Theories, Methods, Evidence. Oxford University Press.

Allen, Barbara L. 2011. "Laboratorization and the 'Green' Rebuilding of New Orleans's Lower Ninth Ward." In The Neoliberal Deluge:Hurricane Katrina, Late Capitalism, and the Remaking of New Orleans, edited by Cedric Johnson. Minneapolis: University of Minnesota Press.

Allen, John. 2011. "Powerful Assemblages?" Area 43 (2): 154-57. doi:10.1111/j.14754762.2011.01005.x.

Allen, John, and Allan Cochrane. 2010. "Assemblages of State Power: Topological Shifts in the Organization of Government and Politics." Antipode 42 (5): 1071-89. doi:10.1111/j.1467-8330.2010.00794.x.

Amin, Massoud. 2001. "Toward Self-Healing Energy Infrastructure Systems." IEEE Computer Applications in Power 14 (1): 20-28. doi:10.1109/67.893351.

. 2002. "Toward Secure and Resilient Interdependent Infrastructures." Journal of Infrastructure Systems 8 (3): 67-75. doi:10.1061/(ASCE)10760342(2002)8:3(67).

. 2004. "Balancing Market Priorities with Security Issues." IEEE Power and Energy Magazine 2 (4): 30-38. doi:10.1109/MPAE.2004.1310871.

. 2008. "For the Good of the Grid." IEEE Power and Energy Magazine 6 (6): 4859. doi:10.1109/MPE.2008.929745.

. 2008. "Challenges in Reliability, Security, Efficiency, and Resilience of Energy Infrastructure: Toward Smart Self-Healing Electric Power Grid." In 2008 IEEE Power and Energy Society General Meeting - Conversion and Delivery of Electrical Energy in the 21st Century, 1-5. doi:10.1109/PES.2008.4596791.

Araújo, Kathleen. 2014. "The Emerging Field of Energy Transitions: Progress, Challenges, and Opportunities." Energy Research \& Social Science 1 (March): 112-21. doi:10.1016/j.erss.2014.03.002.

Ardoin, Phillip J., and Dennis Grady. 2006. "The Politics of Electricity Restructuring across the American States: Power Failure and Policy Failure." State and Local Government Review 38 (3): 165-75. doi:10.1177/0160323X0603800304. 
ARUP. 2013. "Smart City Market: UK Opportunities - Publications - GOV.UK." BIS Research Paper No. 136. Department of Business Innovation \& Skills,. https://www.gov.uk/government/publications/smart-city-market-uk-opportunities.

Avelino, Flor, and Julia M. Wittmayer. 2015. "Shifting Power Relations in Sustainability Transitions: A Multi-Actor Perspective." Journal of Environmental Policy \& Planning, November, 1-22. doi:10.1080/1523908X.2015.1112259.

Aylett, Alex. 2013. "Networked Urban Climate Governance: Neighborhood-Scale Residential Solar Energy Systems and the Example of Solarize Portland." Environment and Planning C: Government and Policy 31 (5): 858-75. doi:10.1068/c11304.

Bacchi, Carol. 2000. "Policy as Discourse: What Does It Mean? Where Does It Get Us?" Discourse: Studies in the Cultural Politics of Education 21 (1): 45-57. doi:10.1080/01596300050005493.

Bai, Xuemei, Brian Roberts, and Jing Chen. 2010. "Urban Sustainability Experiments in Asia: Patterns and Pathways." Environmental Science \& Policy, Socio-technical experiments in Asia - a driver for sustainability transition?, 13 (4): 312-25. doi:10.1016/j.envsci.2010.03.011.

Ballo, Ingrid Foss. 2015. "Imagining Energy Futures: Sociotechnical Imaginaries of the Future Smart Grid in Norway." Energy Research \& Social Science, Special Issue on Smart Grids and the Social Sciences, 9 (September): 9-20. doi:10.1016/j.erss.2015.08.015.

Barry, Andrew. 2006. “Technological Zones.” European Journal of Social Theory 9 (2): 239-53. doi:10.1177/1368431006063343.

Barry, Andrew, and Thomas Osborne. 1996. Foucault and Political Reason: Liberalism, Neo-Liberalism, and Rationalities of Government. University of Chicago Press.

Bennett, Jane. 2010. Vibrant Matter: A Political Ecology of Things. Durham: Duke University Press.

Benson, David, and Andrew Jordan. 2011. "What Have We Learned from Policy Transfer Research? Dolowitz and Marsh Revisited." Political Studies Review 9 (3): 366-78. doi:10.1111/j.1478-9302.2011.00240.x.

Berkhout, Peter H. G., Jos C. Muskens, and Jan W. Velthuijsen. 2000. "Defining the Rebound Effect." Energy Policy 28 (6-7): 425-32. doi:10.1016/S03014215(00)00022-7.

Biegel, Benjamin, Lars Henrik Hansen, Jakob Stoustrup, Palle Andersen, and Silas Harbo. 2014. "Value of Flexible Consumption in the Electricity Markets." Energy 66 (March): 354-62. doi:10.1016/j.energy.2013.12.041.

Bijker, Wiebe E., Thomas P. Hughes, Trevor Pinch, and Deborah G. Douglas. 2012 [1987]. The Social Construction of Technological Systems: New Directions in the Sociology and History of Technology. MIT Press.

Blanchet, Thomas. 2015. "Struggle over Energy Transition in Berlin: How Do Grassroots Initiatives Affect Local Energy Policy-Making?" Energy Policy 78 (March): 24654. doi:10.1016/j.enpol.2014.11.001.

Blanco, Ismael. 2013. "Analysing Urban Governance Networks: Bringing Regime Theory Back in." Environment and Planning C: Government and Policy 31 (2): 27691. doi:10.1068/c11174. 
Bleything, Sean, Seth Blumsack, Paul Hines, and Lisa Morris. 2015. "Vermont Electric Cooperative Consumer Behavior Study Year 2 Final Report." DOE Consumer Behavior Studies. Vermont Energy Investment Corporation. https://www.smartgrid.gov/files/Vermont-Electric-Cooperative-ConsumerBehavior-Study-Year-2-Final-Report.pdf.

Blumsack, Seth A., Jay Apt, and Lester B. Lave. 2006. "Lessons from the Failure of US Electricity Restructuring." The Electricity Journal 19 (2): 15-32.

Bolton, Ronan, and Timothy J. Foxon. 2015. "Infrastructure Transformation as a SocioTechnical Process - Implications for the Governance of Energy Distribution Networks in the UK." Technological Forecasting and Social Change 90, Part B (January): 538-50. doi:10.1016/j.techfore.2014.02.017.

Borenstein, Severin. 2002. "The Trouble with Electricity Markets: Understanding California's Restructuring Disaster." The Journal of Economic Perspectives 16 (1): 191-211.

Boulder Economic Council. 2016. "Boulder Market Profile: April 2016." Boulder, CO: Boulder Econome Council. http://bouldereconomiccouncil.org/bec publications/market-profile-april-2016/.

Boyer, Dominic. 2011. "Energopolitics and the Anthropology of Energy." Anthropology News 52 (5): 5-7. doi:10.1111/j.1556-3502.2011.52505.x.

Brady, Michelle. 2014. "Ethnographies of Neoliberal Governmentalities: From the Neoliberal Apparatus to Neoliberalism and Governmental Assemblages." Foucault Studies 0 (18): 11-33.

Brenner, Neil. 2004. "Urban Governance and the Production of New State Spaces in Western Europe, 1960-2000." Review of International Political Economy 11 (3): 447-88. doi:10.1080/0969229042000282864.

Breslau, Daniel. 2013. "Designing a Market-like Entity: Economics in the Politics of Market Formation." Social Studies of Science 43 (6): 829-51. doi: $10.1177 / 0306312713493962$.

Bridge, Gavin, Stefan Bouzarovski, Michael Bradshaw, and Nick Eyre. 2013. "Geographies of Energy Transition: Space, Place and the Low-Carbon Economy." Energy Policy 53 (February): 331-40. doi:10.1016/j.enpol.2012.10.066.

Briggerman, Abby, Radu Costinescu, and Ashley Bond. 2012. "Survey of State Municipalization Laws." Washington, D.C: American Public Power Association. http://www.publicpower.org/files/PDFs/Survey\%20of\%20Municipalization\%20L aws\%20-\%20Duncan\%20and\%20Allen\%20_FINAL_\%20_00027359_.pdf.

Bröckling, Ulrich, Susanne Krasmann, and Thomas Lemke. 2010. Governmentality: Current Issues and Future Challenges. Routledge.

Brown, Marilyn A. 2001. "Market Failures and Barriers as a Basis for Clean Energy Policies." Energy Policy, Scenarios for a clean energy future, 29 (14): 1197-1207. doi:10.1016/S0301-4215(01)00067-2.

Brown, Wendy. 2015. Undoing the Demos: Neoliberalism's Stealth Revolution. MIT Press.

Bues, Andrea, and Ludger Gailing. 2016. "Energy Transitions and Power: Between Governmentality and Depoliticization." In Conceptualizing Germany's Energy Transition, edited by Ludger Gailing and Timothy Moss, 69-91. Palgrave Macmillan 
UK. http://link.springer.com.proxy.lib.pdx.edu/chapter/10.1057/978-1-13750593-4 5 .

Bulkeley, Harriet. 2010. "Cities and the Governing of Climate Change." Annual Review of Environment and Resources 35 (1): 229-53. doi:10.1146/annurev-environ072809-101747.

Bulkeley, Harriet, and Vanesa Castán Broto. 2012. "Urban Experiments and Climate Change: Securing Zero Carbon Development in Bangalore." Contemporary Social Science, no. May 2014 (July): 1-22. doi:10.1080/21582041.2012.692483.

_ 2013a. "A Survey of Urban Climate Change Experiments in 100 Cities" 23: 92 102. doi:10.1016/j.gloenvcha.2012.07.005.

— 2013b. "Government by Experiment? Global Cities and the Governing of Climate Change." Transactions of the Institute of British Geographers 38 (3): 36175. doi:10.1111/j.1475-5661.2012.00535.x.

Bulkeley, Harriet, Vanesa Castán Broto, and Gareth A. S. Edwards. 2014. An Urban Politics of Climate Change: Experimentation and the Governing of SocioTechnical Transitions. Routledge.

Bulkeley, Harriet, Vanesa Castán Broto, and Anne Maassen. 2014. "Low-Carbon Transitions and the Reconfiguration of Urban Infrastructure." Urban Studies 51 (7): 1471-86. doi:10.1177/0042098013500089.

Bulkeley, Harriet, Andrés Luque-Ayala, and Jonathan Silver. 2014. "Housing and the (Re)configuration of Energy Provision in Cape Town and São Paulo: Making Space for a Progressive Urban Climate Politics?” Political Geography 40 (May): 25-34. doi:10.1016/j.polgeo.2014.02.003.

Bulkeley, Harriet, Pauline M. McGuirk, and Robyn Dowling. 2016. "Making a Smart City for the Smart Grid? The Urban Material Politics of Actualising Smart Electricity Networks." Environment and Planning A, May, 0308518X16648152. doi:10.1177/0308518X16648152.

Bulkeley, Harriet, Gareth Powells, and Sandra Bell. 2016. "Smart Grids and the Constitution of Solar Electricity Conduct." Environment and Planning A 48 (1): 7-23. doi:10.1177/0308518X15596748.

Burawoy, Michael. 2009. The Extended Case Method: Four Countries, Four Decades, Four Great Transformations, and One Theoretical Tradition. University of California Press.

Burnett, John. 2015a. "With Porches And Parks, A Texas Community Aims For Urban Utopia." Cities Project: NPR's Series on Urban Life in the 21st Century. National Public Radio. http://www.npr.org/2015/02/12/385474414/with-porches-andparks-a-texas-community-aims-for-urban-utopia. . 2015b. "With Porches And Parks, A Texas Community Aims For Urban Utopia." Cities Project: NPR's Series on Urban Life in the 21st Century. National Public Radio. http://www.npr.org/2015/02/12/385474414/with-porches-andparks-a-texas-community-aims-for-urban-utopia.

Çalışkan, Koray, and Michel Callon. 2009. "Economization, Part 1: Shifting Attention from the Economy towards Processes of Economization." Economy and Society 38 (3): 369-98. doi:10.1080/03085140903020580. 
Calvert, Kirby. 2015. 'From 'energy Geography' to 'energy Geographies' Perspectives on a Fertile Academic Borderland." Progress in Human Geography, January, 309132514566343. doi:10.1177/0309132514566343.

Campbell, Martha, Duncan Lawrence, Jamie Mandel, James Newcomb, Eric Wanless, and Dan Wetzel. 2014. "Integrated Utility Services: A New Business Model for Fort Collins Utilities." Boulder, CO: Rocky Mountain Institute. http://www.rmi.org/Knowledge-Center/Library/2014-

36 eLabFortCollinsIUS+Report-FINAL-20141219.

Canete, Miguel Arias. 2016. "Renewable Energy: Catalyst for a Clean Energy Transition - OECD." OECD.org. http://www.oecd.org/environment/renewable-energycatalyst-clean-energy-transition.htm.

Caprotti, Federico. 2012. "The Cultural Economy of Cleantech: Environmental Discourse and the Emergence of a New Technology Sector." Transactions of the Institute of British Geographers 37 (3): 370-85. doi:10.1111/j.1475-5661.2011.00485.x.

Carse, Ashley. 2012. "Nature as Infrastructure: Making and Managing the Panama Canal Watershed." Social Studies of Science 42 (4): 539-63. doi:10.1177/0306312712440166.

Carvallo, Andres, and John Cooper. 2015. The Advanced Smart Grid: Edge Power Driving Sustainability, Second Edition. Artech House.

Casey, Christopher, and Kevin B. Jones. 2013. "Customer-Centric Leadership in Smart Grid Implementation: Empowering Customers to Make Intelligent Energy Choices." The Electricity Journal 26 (7): 98-110. doi:10.1016/j.tej.2013.07.004.

Castán Broto, Vanesa, and Harriet Bulkeley. 2013a. "A Survey of Urban Climate Change Experiments in 100 Cities." Global Environmental Change 23 (1): 92-102. doi:10.1016/j.gloenvcha.2012.07.005.

. 2013b. "Maintaining Climate Change Experiments: Urban Political Ecology and the Everyday Reconfiguration of Urban Infrastructure." International Journal of Urban and Regional Research 37 (6): 1934-48. doi:10.1111/1468-2427.12050.

Chan, Coreina, Lena Hansen, James Newcomb, Greg Rucks, and Joshua Agenbroad. 2014. 'Stepping Up: Benefits and Cost of Accelerating Fort Collins' Energy and Climate Goals." Boulder, Co: Rocky Mountain Institute. http://www.rmi.org/Knowledge-Center/Library/80FortCollinsReport-WEB_201402 .

Chandrashekeran, Sangeetha. 2016. "Multidimensionality and the Multilevel Perspective: Territory, Scale, and Networks in a Failed Demand-Side Energy Transition in Australia." Environment and Planning A, April, 0308518X16643728. doi:10.1177/0308518X16643728.

Chassin, David P. 2010. "What Can the Smart Grid Do for You? And What Can You Do for the Smart Grid?" The Electricity Journal 23 (5): 57-63. doi:10.1016/j.tej.2010.05.001.

Chopra, Aneesh, Vivek Kundra, and Phil Weiser. 2011. "A Policy Framework for the 21 st Century Grid: Enabling Our Secure Energy Future." Washington, D.C: Executive Office of the President of the United States. https://www.whitehouse.gov/sites/default/files/microsites/ostp/nstc-smart-gridjune2011.pdf. 
Clark-Madison, Mike. 2002. "Who Will Rule Mueller?," January 25. http://www.austinchronicle.com/news/2002-01-25/84459/.

Clastres, Cédric. 2011. "Smart Grids: Another Step towards Competition, Energy Security and Climate Change Objectives." Energy Policy 39 (9): 5399-5408. doi:10.1016/j.enpol.2011.05.024.

Cochrane, Allan, and Kevin Ward. 2012. "Researching the Geographies of Policy Mobility: Confronting the Methodological Challenges." Environment and Planning A 44 (1): 5-12. doi:10.1068/a44176.

Coenen, Lars, Paul Benneworth, and Bernhard Truffer. 2012. "Toward a Spatial Perspective on Sustainability Transitions." Research Policy, Special Section on Sustainability Transitions, 41 (6): 968-79. doi:10.1016/j.respol.2012.02.014.

Coenen, Lars, and Bernhard Truffer. 2012. "Places and Spaces of Sustainability Transitions: Geographical Contributions to an Emerging Research and Policy Field." European Planning Studies 20 (3): 367-74. doi:10.1080/09654313.2012.651802.

Cook, Ian R., and Kevin Ward. 2012. "Relational Comparisons: The Assembling of Cleveland's Waterfront Plan." Urban Geography 33 (6): 774-95. doi:10.2747/0272-3638.33.6.774.

Cotton, Matthew, and Patrick Devine-Wright. 2011. "Discourses of Energy Infrastructure Development: A Q-Method Study of Electricity Transmission Line Siting in the UK." Environment and Planning A 43 (4): 942-60. doi:10.1068/a43401.

Council of Economic Advisers, and US Department of Energy. 2013. "Economic Benefits of Increasing Electric Grid Resilience to Weather Outages." Washington, D.C: Executive Office of the President of the United States. http://energy.gov/sites/prod/files/2013/08/f2/Grid\%20Resiliency\%20Report_FIN AL.pdf.

Coutard, Olivier. 2008. "Placing Splintering Urbanism: Introduction.” Geoforum, Placing Splintering Urbanism, 39 (6): 1815-20. doi:10.1016/j.geoforum.2008.10.008.

Coutard, Olivier, and Jonathan Rutherford. 2015. Beyond the Networked City: Infrastructure Reconfigurations and Urban Change in the North and South. Florence: Taylor and Francis.

Davidson, Kathryn, and Brendan Gleeson. 2014. "The Sustainability of an Entrepreneurial City?" International Planning Studies, no. April 2014 (March): 1-19. doi:10.1080/13563475.2014.880334.

Davis, Michelle, and Steve Clemmer. 2014. "Power Failure: How Climate Change Puts Our Electricity at Risk -- and What We Can Do." Union of Concerned Scientists. https://www.cakex.org/sites/default/files/documents/Power-Failure-How-ClimateChange-Puts-Our-Electricity-at-Risk-and-What-We-Can-Do.pdf.

Dean, Mitchell. 2010. Governmentality: Power and Rule in Modern Society. SAGE Publications.

Denholm, Paul, Matthew O'Connell, Gregory Brinkman, and Jennie Jorgenson. 2015. "Overgeneration from Solar Energy in California: A Field Guide to the Duck Chart." National Renewable Energy Laboratory, Tech. Rep. NREL/TP-6A2065023, Nov. http://www.nrel.gov/docs/fy16osti/65023.pdf.

Denny, F. I. 1988. "Future Computer Applications in Power." IEEE Computer Applications in Power 1 (1): 11-14. doi:10.1109/67.896. 
Denzin, Norman K., and Yvonna S. Lincoln, eds. 2011. The SAGE Handbook of Qualitative Research. SAGE Publications.

Dolowitz, David P., and David Marsh. 2000. "Learning from Abroad: The Role of Policy Transfer in Contemporary Policy-Making." Governance 13 (1): 5-23. doi:10.1111/0952-1895.00121.

Dowling, Robyn. 2010. "Geographies of Identity: Climate Change, Governmentality and Activism." Progress in Human Geography 34 (4): 488-95. doi:10.1177/0309132509348427.

Dunlop, Claire A. 2009. "Policy Transfer as Learning: Capturing Variation in What Decision-Makers Learn from Epistemic Communities." Policy Studies 30 (3): 289311. doi:10.1080/01442870902863869.

Dunn, Bruce, Haresh Kamath, and Jean-Marie Tarascon. 2011. "Electrical Energy Storage for the Grid: A Battery of Choices." Science 334 (6058): 928-35. doi:10.1126/science.1212741.

Durand, Patty. 2013. "Accentuate the Positive." Public Utilities Fortnightly, August.

Dyson, Mark E. H., Samuel D. Borgeson, Michaelangelo D. Tabone, and Duncan S. Callaway. 2014. "Using Smart Meter Data to Estimate Demand Response Potential, with Application to Solar Energy Integration.” Energy Policy 73 (October): 607-19. doi:10.1016/j.enpol.2014.05.053.

EDF. 2014. "What Is Demand Response?" Environmental Defense Fund. https://www.edf.org/sites/default/files/demand_response_-july_2014.pdf. . 2016a. "Accelerating the Clean Energy Revolution." Environmental Defense Fund. Accessed August 9. http://www.edf.org/sites/default/files/EDF-Smart-GridFact-Sheet-051712.pdf.

- 2016b. "What Consumers Need to Know about the Smart Grid and Smart Meters." Environmental Defense Fund. Accessed August 9. https://www.edf.org/sites/default/files/EDF-smart-grid-benefits-fact-sheet_0.pdf.

Elden, Stuart. 2007. "Governmentality, Calculation, Territory." Environment and Planning D: Society and Space 25 (3): 562-80. doi:10.1068/d428t.

Elzen, Boelie, Frank W. Geels, and Kenneth Green. 2004. System Innovation and the Transition to Sustainability: Theory, Evidence and Policy. Edward Elgar Publishing.

Emelianoff, Cyria. 2014. "Local Energy Transition and Multilevel Climate Governance: The Contrasted Experiences of Two Pioneer Cities (Hanover, Germany, and Växjö, Sweden)." Urban Studies $51 \quad$ (7): 1378-93. doi:10.1177/0042098013500087.

Emerson, Robert M., Rachel I. Fretz, and Linda L. Shaw. 2001. "Participant Observation and Fieldnotes." In Handbook of Ethnography, edited by Paul Atkinson, Amanda Coffey, Sara Delamont, John Lofland, and Lyn Lofland, 352-68. London: SAGE Publications.

Engels, Franziska, and Anna Verena Münch. 2015. "The Micro Smart Grid as a Materialised Imaginary within the German Energy Transition." Energy Research \& Social Science, Special Issue on Smart Grids and the Social Sciences, 9 (September): 35-42. doi:10.1016/j.erss.2015.08.024. 
Evans, James. 2011. "Resilience, Ecology and Adaptation in the Experimental City." Transactions of the Institute of British Geographers 36 (2): 223-37. doi:10.1111/j.1475-5661.2010.00420.x.

Evans, James, and Andrew Karvonen. 2013. “'Give Me a Laboratory and I Will Lower Your Carbon Footprint!' - Urban Laboratories and the Governance of LowCarbon Futures." International Journal of Urban and Regional Research, December, n/a-n/a. doi:10.1111/1468-2427.12077.

Ezrahi, Yaron. 1990. The Descent of Icarus : Science and the Transformation of Contemporary Democracy. Cambridge: Harvard University Press.

Fairclough, Norman. 2013. Critical Discourse Analysis: The Critical Study of Language. Routledge.

Farhangi, H. 2010. "The Path of the Smart Grid." IEEE Power and Energy Magazine 8 (1): 18-28. doi:10.1109/MPE.2009.934876.

Faruqui, Ahmad, and J. Robert Malko. 1983. "The Residential Demand for Electricity by Time-of-Use: A Survey of Twelve Experiments with Peak Load Pricing." Energy 8 (10): 781-95. doi:10.1016/0360-5442(83)90052-X.

Faruqui, Ahmad, and Sanem Sergici. 2010. "Household Response to Dynamic Pricing of Electricity: A Survey of 15 Experiments." Journal of Regulatory Economics 38 (2): 193-225. doi:10.1007/s11149-010-9127-y.

Flatow, Ira. 2011. "Adding Smarts To The Electrical Grid." Science Friday. National Public Radio. http://www.npr.org/2011/01/14/132934014/adding-smarts-to-theelectrical-grid.

Flyvbjerg, Bent. 2006. "Five Misunderstandings About Case-Study Research." Qualitative Inquiry 12 (2): 219-45. doi:10.1177/1077800405284363.

Flyvbjerg, Bent, Todd Landman, and Sanford Schram. 2012. Real Social Science: Applied Phronesis. Cambridge University Press.

Forth, B., and T. Tobin. 2002. "Right Power, Right Price [Enterprise Energy Management Systems]." IEEE Computer Applications in Power 15 (2): 22-27. doi: $10.1109 / 67.993756$.

Foucault, Michel. 1977. Discipline and Punish: The Birth of the Prison. Vintage Books.

- 1980. Power/Knowledge: Selected Interviews and Other Writings, 1972-1977. Pantheon Books.

. 1981. "The Order of Discourse." In Untying the Text: A Post-Structuralist Reader, edited by Robert Young, 49-78. Boston, Mass: Routledge. https://www.kit.ntnu.no/sites/www.kit.ntnu.no/files/Foucault_The\%20Order\%20o $\mathrm{f} \% 20$ Discourse.pdf.

- 1990. The History of Sexuality: An Introduction. Knopf Doubleday Publishing Group.

. 2002. The Order of Things: An Archaeology of the Human Sciences. Psychology Press.

. 2009. Security, Territory, Population: Lectures at the Collège de France 1977-1978. Macmillan.

- 2010. The Birth of Biopolitics: Lectures at the Collège de France, 1978--1979. Picador. 
Foucault, Michel, Mauro Bertani, Alessandro Fontana, François Ewald, and David Macey. 2003. "Society Must Be Defended": Lectures at the Collège de France, 1975-1976. Macmillan.

Foucault, Michel, Graham Burchell, Colin Gordon, and Peter Miller. 1991. The Foucault Effect: Studies in Governmentality. University of Chicago Press.

Foxon, Timothy J. 2013. "Transition Pathways for a UK Low Carbon Electricity Future." Energy Policy 52 (January): 10-24. doi:10.1016/j.enpol.2012.04.001.

Fox-Penner, Peter. 2014. Smart Power Anniversary Edition: Climate Change, the Smart Grid, and the Future of Electric Utilities. Island Press.

Frangoul, Anmar. 2015. "Pecan Street Inc. | Is This the World's Most Innovative Neighborhood?" $\quad$ http://www.pecanstreet.org/2015/03/is-this-the-worlds-mostinnovative-neighborhood/.

"Frank Lloyd Wright Trust." 2016. Accessed August 21. http://www.flwright.org/.

Fuchs, Gerhard, and Nele Hinderer. 2016. "One or Many Transitions: Local Electricity Experiments in Germany." Innovation: The European Journal of Social Science Research 0 (0): 1-17. doi:10.1080/13511610.2016.1188683.

Gabrys, Jennifer. 2014. "Programming Environments: Environmentality and Citizen Sensing in the Smart City." Environment and Planning D: Society and Space 32 (1): 30 - 48. doi:10.1068/d16812.

Gandy, Matthew. 2004. "Rethinking Urban Metabolism: Water, Space and the Modern City." City 8 (3): 363-79. doi:10.1080/1360481042000313509.

Gangale, Flavia, Anna Mengolini, and Ijeoma Onyeji. 2013. "Consumer Engagement: An Insight from Smart Grid Projects in Europe.” Energy Policy 60 (September): 62128. doi:10.1016/j.enpol.2013.05.031.

Geels, Frank W. 2002. "Technological Transitions as Evolutionary Reconfiguration Processes: A Multi-Level Perspective and a Case-Study.” Research Policy, NELSON + WINTER + 20, 31 (8-9): 1257-74. doi:10.1016/S0048-7333(02)00062-8. . 2004. "From Sectoral Systems of Innovation to Socio-Technical Systems: Insights about Dynamics and Change from Sociology and Institutional Theory." Research Policy 33 (6-7): 897-920. doi:10.1016/j.respol.2004.01.015.

- 2005. Technological Transitions and System Innovations: A Co-Evolutionary and Socio-Technical Analysis. Edward Elgar Publishing.

- 2007. "Transformations of Large Technical Systems: A Multilevel Analysis of the Dutch Highway System (1950-2000)." Science, Technology \& Human Values 32 (2): 123-49. doi:10.1177/0162243906293883.

. 2011. "The Multi-Level Perspective on Sustainability Transitions: Responses to Seven Criticisms." Environmental Innovation and Societal Transitions 1 (1): 24 40. doi:10.1016/j.eist.2011.02.002.

. 2014. "Regime Resistance against Low-Carbon Transitions: Introducing Politics and Power into the Multi-Level Perspective." Theory, Culture \& Society 31 (5): 21-40. doi:10.1177/0263276414531627.

Geels, Frank W., and René Kemp. 2007. "Dynamics in Socio-Technical Systems: Typology of Change Processes and Contrasting Case Studies." Technology in Society 29 (4): 441-55. doi:10.1016/j.techsoc.2007.08.009. 
Geels, Frank W., and Rob Raven. 2006. "Non-Linearity and Expectations in NicheDevelopment Trajectories: Ups and Downs in Dutch Biogas Development (19732003)." Technology Analysis \& Strategic Management 18 (3-4): 375-92. doi:10.1080/09537320600777143.

Geels, Frank W., and Johan Schot. 2007. "Typology of Sociotechnical Transition Pathways." Research Policy 36 (3): 399-417. doi:10.1016/j.respol.2007.01.003.

Geller, Howard, Philip Harrington, Arthur H. Rosenfeld, Satoshi Tanishima, and Fridtjof Unander. 2006. "Polices for Increasing Energy Efficiency: Thirty Years of Experience in OECD Countries." Energy Policy, Hong Kong Editorial Board meeting presentationsHong Kong Editorial Board meeting presentations, 34 (5): 556-73. doi:10.1016/j.enpol.2005.11.010.

Geller, Howard, and S. Nadel. 1994. "Market Transformation Strategies to Promote EndUse Efficiency." Annual Review of Energy and the Environment 19 (1): 301-46. doi:10.1146/annurev.eg.19.110194.001505.

Gellings, C. W. 1985. "The Concept of Demand-Side Management for Electric Utilities." Proceedings of the IEEE 73 (10): 1468-70. doi:10.1109/PROC.1985.13318.

- 2009. The Smart Grid: Enabling Energy Efficiency and Demand Response. The Fairmont Press, Inc.

Gellings, C. W., M. Samotyj, and B. Howe. 2004. "The Future's Smart Delivery System [Electric Power Supply]." IEEE Power and Energy Magazine 2 (5): 40-48. doi:10.1109/MPAE.2004.1338121.

Genus, Audley, and Anne-Marie Coles. 2008. "Rethinking the Multi-Level Perspective of Technological Transitions." Research Policy 37 (9): 1436-45. doi:10.1016/j.respol.2008.05.006.

Gerring, John. 2007. Case Study Research: Principles and Practices. Cambridge University Press.

Gieryn, Thomas F. 2006. "City as Truth-Spot Laboratories and Field-Sites in Urban Studies." Social Studies of Science 36 (1): 5-38. doi:10.1177/0306312705054526.

Goldman, Michael. 2001. "Constructing an Environmental State: Eco-Governmentality and Other Transnational Practices of a 'Green' World Bank." Social Problems 48 (4): 499-523. doi:10.1525/sp.2001.48.4.499.

Goode, William J. 1997. "Rational Choice Theory." The American Sociologist 28 (2): 22-41. doi:10.1007/s12108-997-1004-5.

Gopakumar, Govind. 2014. "Experiments and Counter-Experiments in the Urban Laboratory of Water- Supply Partnerships in India." International Journal of Urban and Regional Research in press (January). doi:10.1111/1468-2427.12076.

Gordon, Colin. 1991. "Governmental Rationality: An Introduction." In The Foucault Effect: Studies in Governmentality: With Two Lectures by and an Interview with Michel Foucault, edited by Michel Foucault, Graham Burchell, and Peter Miller, 1-51. Chicago: University of Chicago Press.

Goulden, Murray, Ben Bedwell, Stefan Rennick-Egglestone, Tom Rodden, and Alexa Spence. 2014. "Smart Grids, Smart Users? The Role of the User in Demand Side Management." Energy Research \& Social Science 2 (June): 21-29. doi:10.1016/j.erss.2014.04.008. 
Graham, Stephen, and Simon Marvin. 2001. Splintering Urbanism: Networked Infrastructures, Technological Mobilities and the Urban Condition. London; New York: Routledge.

Gram-Hanssen, Kirsten. 2008. "Consuming Technologies - Developing Routines.” Journal of Cleaner Production, The Governance and Practice of Change of Sustainable Consumption and Production, 16 (11): 1181-89. doi:10.1016/j.jclepro.2007.08.006.

. 2010. "Residential Heat Comfort Practices: Understanding Users." Building Research \& Information 38 (2): 175-86. doi:10.1080/09613210903541527.

Greening, Lorna A., David L. Greene, and Carmen Difiglio. 2000. "Energy Efficiency and Consumption - the Rebound Effect - a Survey." Energy Policy 28 (6-7): 389-401. doi:10.1016/S0301-4215(00)00021-5.

Groves, Christopher, Karen Henwood, Fiona Shirani, Catherine Butler, Karen Parkhill, and Nick Pidgeon. 2016. "The Grit in the Oyster: Using Energy Biographies to Question Socio-Technical Imaginaries of "smartness." Journal of Responsible Innovation 0 (0): 1-22. doi:10.1080/23299460.2016.1178897.

Guba, Egon G., and Yvonna S. Lincoln. 1994. "Competing Paradigms in Qualitative Research." Handbook of Qualitative Research 2 (163-194): 105.

Guerrero, Rafael, and Julie Wernau. 2013. "Illinois Senate Overrides Quinn Veto of Smart Grid Rate Hike." Chicago Tribune, May 21. http://articles.chicagotribune.com/2013-05-21/business/chi-comed-smart-gridrevenue-20130521_1_smart-grid-bill-comed-quinn-veto.

Guy, Simon, Simon Marvin, and Will Medd. 2011. Shaping Urban Infrastructures: Intermediaries and the Governance of Socio-Technical Networks. Routledge.

Hackworth, Jason. 2008. The Neoliberal City: Governance, Ideology, and Development in American Urbanism. Ithaca, NY: Cornell University Press.

Hajer, Maarten A. 1995. The Politics of Environmental Discourse: Ecological Modernization and the Policy Process. Clarendon Press.

Hajer, Maarten A., and Wytske Versteeg. 2005. "A Decade of Discourse Analysis of Environmental Politics: Achievements, Challenges, Perspectives." Journal of Environmental Policy \& Planning 7 (3): 175-84.

Hall, Stuart. 1997. Representation: Cultural Representations and Signifying Practices. Vol. 2. Sage.

Hall, T., and P. Hubbard. 1996. "The Entrepreneurial City: New Urban Politics, New Urban Geographies?" Progress in Human Geography 20 (2): 153-74. doi:10.1177/030913259602000201.

Hamilton, B., Y. J. Chae, M. Summy, J. Cutler, and D. Kolata. 2011. "Illinois and South Korea: A Model Partnership for Smart Grid Collaboration.” IEEE Power and Energy Magazine 9 (1): 1-1. doi:10.1109/MPE.2010.939563.

Hammerstrom, D. J. 2007. "Pacific Northwest GridWise Testbed Demonstration Project.” PNNL-17167. Richland, Washington: Pacific Northwest National Laboratory.

http://www2.econ.iastate.edu/tesfatsi/OlympicPeninsulaProject.FinalReport_pnnl 17167.pdf. 
Hansen, Teis, and Lars Coenen. 2015. "The Geography of Sustainability Transitions: Review, Synthesis and Reflections on an Emergent Research Field." Environmental Innovation and Societal Transitions 17 (December): 92-109. doi:10.1016/j.eist.2014.11.001.

Hargreaves, Tom. 2011. "Practice-Ing Behaviour Change: Applying Social Practice Theory to pro-Environmental Behaviour Change." Journal of Consumer Culture 11 (1): 79-99. doi:10.1177/1469540510390500.

Hargreaves, Tom, Michael Nye, and Jacquelin Burgess. 2010. "Making Energy Visible: A Qualitative Field Study of How Householders Interact with Feedback from Smart Energy Monitors." Energy Policy, The socio-economic transition towards a hydrogen economy - findings from European research, with regular papers, 38 (10): 6111-19. doi:10.1016/j.enpol.2010.05.068.

. 2013. "Keeping Energy Visible? Exploring How Householders Interact with Feedback from Smart Energy Monitors in the Longer Term." Energy Policy, Special Section: Transition Pathways to a Low Carbon Economy, 52 (January): 12634. doi:10.1016/j.enpol.2012.03.027.

Harris, Chioke, Jeremy P. Meyers, and Michael E. Webber. 2012. "A Unit Commitment Study of the Application of Energy Storage toward the Integration of Renewable Generation." Journal of Renewable and Sustainable Energy 4 (1): 13120. doi:10.1063/1.3683529.

Harvey, David. 1989. "From Managerialism to Entrepreneurialism: The Transformation in Urban Governance in Late Capitalism." Geografiska Annaler 71 (1): 3-17. 2007. A Brief History of Neoliberalism. OUP Oxford.

Hastings, Annette. 1999. "Discourse and Urban Change: Introduction to the Special Issue." Urban Studies 36 (1): 7.

Hausman, William J., and John L. Neufeld. 1984. "Time-of-Day Pricing in the U.S. Electric Power Industry at the Turn of the Century." The RAND Journal of Economics 15 (1): 116-26. doi: 10.2307/3003674.

Heathcott, J. 2005. “"The Whole City Is Our Laboratory': Harland Bartholomew and the Production of Urban Knowledge." Journal of Planning History 4 (4): 322-55. doi:10.1177/1538513205282131.

Hecht, Gabrielle. 2000. The Radiance of France: Nuclear Power and National Identity After World War II. MIT Press.

Hecht, Gabrielle, and Michael Thad Allen. 2001. "Introduction: Authority, Political Machines, and Technology's History." In Technologies of Power: Essays in Honor of Thomas Parke Hughes and Agatha Chipley Hughes, edited by Michael Thad Allen and Gabrielle Hecht. MIT Press.

Hertzog, Christine. 2013. "Smart Grid: American Energy Independence." The Energy Collective. July $9 . \quad \mathrm{http} / / / \mathrm{www}$.theenergycollective.com/christinehertzog/246916/american-energy-independence.

Hess, David J. 2015. "The Politics of Niche-Regime Conflicts: Distributed Solar Energy in the United States." Environmental Innovation and Societal Transitions, National Academy of Engineering, . doi:10.1016/j.eist.2015.09.002. 
Higginson, Sarah, Murray Thomson, and Tracy Bhamra. 2014. "For the Times They Are a-Changin': The Impact of Shifting Energy-Use Practices in Time and Space." Local Environment 19 (5): 520-38. doi:10.1080/13549839.2013.802459.

Hirsh, Richard F. 1999. "PURPA: The Spur to Competition and Utility Restructuring." The Electricity Journal 12 (7): 60-72. doi:10.1016/S1040-6190(99)00060-3.

- 2002. Power Loss: The Origins of Deregulation and Restructuring in the American Electric Utility System. MIT Press.

. 2003. Technology and Transformation in the American Electric Utility Industry. Cambridge University Press.

. 2004. "Power Struggle: Changing Momentum in the Restructured American Electric Utility System.” Annales Historiques de L'électricité N 2 (1): 107-23.

Hledik, Ryan. 2014. "Rediscovering Residential Demand Charges." The Electricity Journal 27 (7): 82-96. doi:10.1016/j.tej.2014.07.003.

Hodson, Mike, and Simon Marvin. 2009a. “Urban Ecological Security': A New Urban Paradigm?" International Journal of Urban and Regional Research 33 (1): 193215. doi:10.1111/j.1468-2427.2009.00832.x.

. 2009b. "Cities Mediating Technological Transitions: Understanding Visions, Intermediation and Consequences." Technology Analysis \& Strategic Management 21 (4): 515-34. doi:10.1080/09537320902819213.

- 2010a. "Can Cities Shape Socio-Technical Transitions and How Would We Know If They Were?" Research Policy, Special Section on Innovation and Sustainability Transitions, 39 (4): 477-85. doi:10.1016/j.respol.2010.01.020.

. 2010b. "Urbanism in the Anthropocene: Ecological Urbanism or Premium Ecological Enclaves?" City 14 (3): 298-313. doi:10.1080/13604813.2010.482277.

. 2012. "Mediating Low-Carbon Urban Transitions? Forms of Organization, Knowledge and Action." European Planning Studies 20 (3): 421-39. doi:10.1080/09654313.2012.651804.

Hoffmann, Matthew J. 2011. Climate Governance at the Crossroads: Experimenting with a Global Response after Kyoto. Oxford University Press.

Hommels, Anique. 2005. "Studying Obduracy in the City: Toward a Productive Fusion between Technology Studies and Urban Studies." Science, Technology, \& Human Values 30 (3): 323-51.

Hommels, Anique, Peter Peters, and Wiebe E. Bijker. 2007. "Techno Therapy or Nurtured Niches? Technology Studies and the Evaluation of Radical Innovations." Research Policy 36 (7): 1088-99. doi:10.1016/j.respol.2007.04.002.

Huber, Matthew. 2015. "Theorizing Energy Geographies." Geography Compass 9 (6): 327-38. doi:10.1111/gec3.12214.

Huber, Matthew T. 2013. Lifeblood: Oil, Freedom, and the Forces of Capital. University of Minnesota Press.

Hughes, Thomas P. 1983. Networks of Power: Electrification in Western Society, 18801930. JHU Press.

Hughes, Thomas P., and Olivier Coutard. 1996. "Fifteen years of social and historical research on large technical systems. An interview with Thomas Hughes." Flux 12 (25): 44-47. 
IBM. 2011. "IBM's Smarter Cities Challenge Boulder Report." https:/wwwstatic.bouldercolorado.gov/docs/IBM_SmrtCity_SGC_Report-1201306171551.pdf.

infomisa. 2016. President Obama Explains the Smart Grid and Economic Recovery. Accessed August 3. https://www.youtube.com/watch?v=7kOWu5MeRWk.

Isser, Steve. 2015. Electricity Restructuring in the United States: Markets and Policy from the 1978 Energy Act to the Present. Cambridge University Press.

Jacobs, Keith. 2006. "Discourse Analysis and Its Utility for Urban Policy Research." Urban Policy and Research 24 (1): 39-52. doi:10.1080/08111140600590817.

Jager, Siegfried. 2001. "Discourse and Knowledge: Theoretical and Methodological Aspects of a Critical Discourse and Dispositive Analysis." In Methods of Critical Discourse Analysis, edited by Ruth Wodak and Michael Meyer, 32-62. SAGE.

Jaglin, Sylvy. 2013. "Urban Energy Policies and the Governance of Multilevel Issues in Cape Town." Urban Studies, September, 42098013500091. doi:10.1177/0042098013500091.

Jasanoff, Sheila. 2004a. Earthly Politics: Local and Global in Environmental Governance. MIT Press.

- 2004b. States of Knowledge. Edited by Sheila Jasanoff. Abingdon, UK: Taylor \& Francis. doi:10.4324/9780203413845.

Jasanoff, Sheila, and Sang-Hyun Kim. 2009. "Containing the Atom: Sociotechnical Imaginaries and Nuclear Power in the United States and South Korea." Minerva 47 (2): 119-46. doi:10.1007/s11024-009-9124-4.

Jessop, Bob. 2007. "From Micro-Powers to Governmentality: Foucault's Work on Statehood, State Formation, Statecraft and State Power." Political Geography 26 (1): 34-40. doi:10.1016/j.polgeo.2006.08.002.

Jonas, a. E. G., D. Gibbs, and a. While. 2011. "The New Urban Politics as a Politics of Carbon Control." Urban Studies 48 (12): 2537-54. doi:10.1177/0042098011411951.

Jørgensen, Marianne W., and Louise J. Phillips. 2002. Discourse Analysis as Theory and Method. Sage.

Joseph, Jonathan. 2013. "Resilience as Embedded Neoliberalism: A Governmentality Approach.” Resilience 1 (1): 38-52. doi:10.1080/21693293.2013.765741.

Joskow, Paul L. 2001. "California's Electricity Crisis." Oxford Review of Economic Policy 17 (3): 365-88. doi:10.1093/oxrep/17.3.365.

Kahneman, Daniel. 2003. "Maps of Bounded Rationality: Psychology for Behavioral Economics." The American Economic Review 93 (5): 1449-75.

Kanellos, Katherine Tweed, Michael. 2010. "South Korea Guns for Smart Grid Finish Line.” March 16. http://www.greentechmedia.com/articles/read/south-korea-gunsfor-smart-grid-finish-line.

Karch, Andrew. 2007. Democratic Laboratories: Policy Diffusion Among the American States. University of Michigan Press.

Karvonen, Andrew, and Bas van Heur. 2014. "Urban Laboratories: Experiments in Reworking Cities." International Journal of Urban and Regional Research 38 (2): 379-92. doi:10.1111/1468-2427.12075. 
Kaye, Leon. 2011. "Pushing the Low Carbon Boundaries: South Korea's Smart Grid Initiative." The Guardian, September 5, sec. Guardian Sustainable Business. https://www.theguardian.com/sustainable-business/south-korea-smart-grid-lowcarbon.

Kemp, René. 1994. "Technology and the Transition to Environmental Sustainability." Futures 26 (10): 1023-46. doi:10.1016/0016-3287(94)90071-X.

Kemp, René, Derk Loorbach, and Jan Rotmans. 2007. "Transition Management as a Model for Managing Processes of Co-Evolution towards Sustainable Development." International Journal of Sustainable Development \& World Ecology 14 (1): 78-91. doi:10.1080/13504500709469709.

Kemp, René, Johan Schot, and Remco Hoogma. 1998. "Regime Shifts to Sustainability through Processes of Niche Formation: The Approach of Strategic Niche Management." Technology Analysis \& Strategic Management 10 (2): 175-98. doi:10.1080/09537329808524310.

Kind, Peter. 2013. "Disruptive Challenges: Financial Implications and Strategic Responses to a Changing Retail Electric Business." Washington, D.C: Edison Electric Institute.

http://ceem.unsw.edu.au/sites/default/files/event/documents/Passeyeceee2013.pdf.

King, Michael. 2015. "Mueller vs. TCAD: No Room for Affordability?," November 6. http://www.austinchronicle.com/news/2015-11-06/mueller-vs-tcad-no-room-foraffordability/.

Kirschen, D. S. 2003. "Demand-Side View of Electricity Markets." IEEE Transactions on Power Systems 18 (2): 520-27. doi:10.1109/TPWRS.2003.810692.

Klauser, Francisco, Till Paasche, and Ola Söderström. 2014. "Michel Foucault and the Smart City: Power Dynamics Inherent in Contemporary Governing through Code." Environment and Planning D: Society and Space 32 (5): $869-885$. doi:10.1068/d13041p.

Klauser, Francisco R., and Anders Albrechtslund. 2014. "From Self-Tracking to Smart Urban Infrastructures: Towards an Interdisciplinary Research Agenda on Big Data." Surveillance \& Society 12 (2): 273-86.

Knorr-Cetina, Karin. 1995. "Laboratory Studies: The Cultural Approach to the Study of Science.” In Handbook of Science and Technology Studies, edited by Sheila Jasanoff, Gerald E Markle, James C Peterson, and Trevor Pinch, 141-66. Thousand Oaks: Sage Publications, Inc.

König, Ariane, and James Evans. 2012. "Introduction: Experimenting for Sustainable Development? Living Laboratories, Social Learning and the Role of the University," 1-24.

Kurada, Naresh, A. Alex Dhanhal, and Bala Venkatesh. 2014. "Evolving Perimeter Information Security Models in Smart Grids and Utilities." ISACA Journal 4. http://www.isaca.org/Journal/archives/2013/Volume-4/Pages/JOnline-EvolvingPerimeter-Information-Security-Models-in-Smart-Grids-and-Utilities.aspx.

Lacey, Stephen. 2015. "Move Over Mandates: Can a New 'Personal Energy Independence' Bill Entice Congress?" The Energy Collective. May 15. http://www.theenergycollective.com/stephenlacey/2225261/move-over-mandatescan-new-personal-energy-independence-bill-entice-congress. 
Langheim, Ria, Melissa Skubel, Xiao Chen, William Maxwell, Tarla Rai Peterson, Elizabeth Wilson, and Jennie C. Stephens. 2014. "Smart Grid Coverage in U.S. Newspapers: Characterizing Public Conversations." The Electricity Journal 27 (5): 7787. doi:10.1016/j.tej.2014.05.008.

Larkin, Brian. 2013. "The Politics and Poetics of Infrastructure." Annual Review of Anthropology 42 (1): 327-43. doi:10.1146/annurev-anthro-092412-155522.

Larner, Wendy, and Richard Le Heron. 2002. "The Spaces and Subjects of a Globalising Economy: A Situated Exploration of Method." Environment and Planning D: Society and Space 20 (6): 753-74. doi:10.1068/d284t.

. 2005. "Neo-Liberalizing Spaces and Subjectivities: Reinventing New Zealand Universities.” Organization 12 (6): 843-62. doi:10.1177/1350508405057473.

Laurent, Brice. 2011. "Technologies of Democracy: Experiments and Demonstrations." Science and Engineering Ethics 17 (4): 649-66. doi:10.1007/s11948-011-9303-1.

Lawhon, Mary, and James T. Murphy. 2012. "Socio-Technical Regimes and Sustainability Transitions Insights from Political Ecology." Progress in Human Geography 36 (3): 354-78. doi:10.1177/0309132511427960.

Lemke, Thomas. 2001. "The Birth of Bio-Politics": Michel Foucault's Lecture at the Collège de France on Neo-Liberal Governmentality." Economy and Society 30 (2): 190-207. doi:10.1080/03085140120042271.

. 2002. "Foucault, Governmentality, and Critique." Rethinking Marxism 14 (3): 49-64. doi:10.1080/089356902101242288.

Levenda, Anthony, Dillon Mahmoudi, and Gerald Sussman. 2015. "The Neoliberal Politics of 'Smart': Electricity Consumption, Household Monitoring, and the Enterprise Form." Canadian Journal of Communication 40 (4). http://www.cjconline.ca/index.php/journal/article/view/2928.

Li, Tania Murray. 2007a. "Governmentality." Anthropologica 49 (2): 275-81. . 2007b. The Will to Improve: Governmentality, Development, and the Practice of Politics. Duke University Press.

Livingstone, David N. 2010. Putting Science in Its Place: Geographies of Scientific Knowledge. University of Chicago Press.

Long, Joshua. 2016. "Constructing the Narrative of the Sustainability Fix: Sustainability, Social Justice and Representation in Austin, TX." Urban Studies 53 (1): 149-72. doi:10.1177/0042098014560501.

Loorbach, Derk. 2010. "Transition Management for Sustainable Development: A Prescriptive, Complexity-Based Governance Framework." Governance 23 (1): 16183. doi:10.1111/j.1468-0491.2009.01471.x.

López, M. A., S. de la Torre, S. Martín, and J. A. Aguado. 2015. "Demand-Side Management in Smart Grid Operation Considering Electric Vehicles Load Shifting and Vehicle-to-Grid Support." International Journal of Electrical Power \& Energy Systems 64 (January): 689-98. doi:10.1016/j.ijepes.2014.07.065.

Loughran, David S., and Jonathan Kulick. 2004. "Demand-Side Management and Energy Efficiency in the United States." The Energy Journal 25 (1): 19-43.

Lovell, Heather. 2007. "The Governance of Innovation in Socio-Technical Systems: The Difficulties of Strategic Niche Management in Practice." Science and Public Policy 34 (1): 35-44. doi:10.3152/030234207X190540. 
2016. "The Role of International Policy Transfer Within the Multiple Streams Approach: The Case of Smart Electricity Metering in Australia." Public Administration, April, n/a-n/a. doi:10.1111/padm.12259.

Luque, Andrés. 2014. "The Smart Grid and the Interface between Energy, ICT, and the City." In Urban Retrofitting for Sustainability: Mapping the Transition to 2050, edited by Tim Dixon, Malcolm Eames, Miriam Hunt, and Simon Lannon. New York: Routledge.

Luque-Ayala, Andrés, and Simon Marvin. 2015. "Developing a Critical Understanding of Smart Urbanism?" Urban Studies 52 (12): 2105-16. doi:10.1177/0042098015577319.

Lutzenhiser, Loren. 1992. "A Cultural Model of Household Energy Consumption.” Energy 17 (1): 47-60. doi:10.1016/0360-5442(92)90032-U.

. 1993. "Social and Behavioral Aspects of Energy Use." Annual Review of Energy and the Environment 18 (1): 247-89. doi:10.1146/annurev.eg.18.110193.001335. . 2014. "Through the Energy Efficiency Looking Glass." Energy Research \& Social Science 1 (March): 141-51. doi:10.1016/j.erss.2014.03.011.

M D Levine, J G Koomey, J E McMahon, A H Sanstad, and and E. Hirst. 1995. "Energy Efficiency Policy and Market Failures." Annual Review of Energy and the Environment 20 (1): 535-55. doi:10.1146/annurev.eg.20.110195.002535.

MacKenzie, Donald. 2009. "Making Things the Same: Gases, Emission Rights and the Politics of Carbon Markets." Accounting, Organizations and Society 34 (3-4): 440-55. doi:10.1016/j.aos.2008.02.004.

MacKenzie, Donald A. 1993. Inventing Accuracy: A Historical Sociology of Nuclear Missile Guidance. MIT Press.

MacLeod, Gordon. 2002. "From Urban Entrepreneurialism to a 'Revanchist City'? On the Spatial Injustices of Glasgow's Renaissance." Antipode 34 (3): 602-24. doi:10.1111/1467-8330.00256.

Markard, Jochen, Rob Raven, and Bernhard Truffer. 2012. "Sustainability Transitions: An Emerging Field of Research and Its Prospects." Research Policy, Special Section on Sustainability Transitions, 41 (6): 955-67. doi:10.1016/j.respol.2012.02.013.

Marres, Noortje. 2011. "The Costs of Public Involvement: Everyday Devices of Carbon Accounting and the Materialization of Participation." Economy and Society 40 (4): 510-33. doi:10.1080/03085147.2011.602294.

Marres, Noortje, and Javier Lezaun. 2011. "Materials and Devices of the Public: An Introduction." Economy and Society 40 (4): 489-509. doi: 10.1080/03085147.2011.602293.

Marvin, Simon, Stephen Graham, and Simon Guy. 1999. "Cities, Regions and Privatised Utilities." Progress in Planning 51 (2): 91-165. doi:10.1016/S03059006(98)00028-2.

Marvin, Simon, Andrés Luque-Ayala, and Colin McFarlane. 2015. Smart Urbanism: Utopian Vision or False Dawn? Routledge.

Maurer, Eric, and James Newcomb. 2013. "Building the Electricity System of the Future: Fort Collins and FortZED." Boulder, CO: Rocky Mountain Institute. 
http://www.rmi.org/Knowledge-Center\%2FLibrary\%2F2013-

07 FCFZFinalReport.

McCann, Eugene. 2008. "Expertise, Truth, and Urban Policy Mobilities: Global Circuits of Knowledge in the Development of Vancouver, Canada's 'four Pillar' Drug Strategy." Environment and Planning A 40 (4): 885-904. doi:10.1068/a38456.

. 2011a. "Veritable Inventions: Cities, Policies and Assemblage." Area 43 (2): $143-147$.

. 2011b. "Urban Policy Mobilities and Global Circuits of Knowledge: Toward a Research Agenda." Annals of the Association of American Geographers 101 (1): 107-30. doi:10.1080/00045608.2010.520219.

- 2013. "Policy Boosterism, Policy Mobilities, and the Extrospective City." Urban Geography 34 (1): 5-29. doi:10.1080/02723638.2013.778627.

McCann, Eugene, Ananya Roy, and Kevin Ward. 2013. "Assembling/Worlding Cities." Urban Geography 34 (5): 581-89. doi:10.1080/02723638.2013.793905.

McCann, Eugene, and Kevin Ward. 2011. Mobile Urbanism: Cities and Policymaking in the Global Age. U of Minnesota Press.

. 2012a. "Assembling Urbanism: Following Policies and 'studying Through' the Sites and Situations of Policy Making." Environment and Planning A 44 (1): $42-$ 51. doi:10.1068/a44178.

. 2012b. "Policy Assemblages, Mobilities and Mutations: Toward a Multidisciplinary Conversation.” Political Studies Review 10 (3): 325-32. doi:10.1111/j.14789302.2012.00276.x.

2013. "A Multi-Disciplinary Approach to Policy Transfer Research: Geographies, Assemblages, Mobilities and Mutations." Policy Studies 34 (1): 2-18. doi:10.1080/01442872.2012.748563.

McFarlane, Colin. 2010. "The Comparative City: Knowledge, Learning, Urbanism.” International Journal of Urban and Regional Research 34 (4): 725-42. doi:10.1111/j.1468-2427.2010.00917.x.

. 2011. Learning the City: Knowledge and Translocal Assemblage. John Wiley \& Sons.

McGuirk, Pauline, Robyn Dowling, and Harriet Bulkeley. 2014. "Repositioning Urban Governments? Energy Efficiency and Australia's Changing Climate and Energy Governance Regimes." Urban Studies 51 (13): 2717-34. doi:10.1177/0042098014533732.

McLean, Anthony, Harriet Bulkeley, and Mike Crang. 2015. "Negotiating the Urban Smart Grid: Socio-Technical Experimentation in the City of Austin." Urban Studies, November, 42098015612984. doi:10.1177/0042098015612984.

McNay, Lois. 2009. "Self as Enterprise Dilemmas of Control and Resistance in Foucault's The Birth of Biopolitics." Theory, Culture \& Society 26 (6): 55-77. doi: $10.1177 / 0263276409347697$.

Meadowcroft, James. 2009. "What about the Politics? Sustainable Development, Transition Management, and Long Term Energy Transitions." Policy Sciences 42 (4): 323-40. doi:10.1007/s11077-009-9097-z.

. 2011. "Engaging with the Politics of Sustainability Transitions." Environmental Innovation and Societal Transitions 1 (1): 70-75. doi:10.1016/j.eist.2011.02.003. 
Meltzer, Erica. 2014a. "Boulder to Track Energy Use in 50 Homes, 25 Businesses over next 2 Years." Daily Camera, January 25. http://www.dailycamera.com/news/boulder/ci_24992390/boulder-seeks-energymonitor-volunteers.

- 2014b. "Boulder Rolls out Real-Time Home Energy Monitoring Pilot Program." Daily Camera, March 21. http://www.dailycamera.com/news/boulder/ci_25393378/boulder-energymonitoring-pilot-program.

Merriam, Sharan B. 2009. Qualitative Research: A Guide to Design and Implementation. John Wiley \& Sons.

Mirowski, Philip. 1991. More Heat Than Light: Economics as Social Physics, Physics as Nature's Economics. Cambridge University Press.

Mitchell, Timothy. 1998. "Fixing the Economy." Cultural Studies 12 (1): 82-101. doi:10.1080/095023898335627.

—. 2008. "Rethinking Economy." Geoforum, Rethinking EconomyAgro-food activism in California and the politics of the possibleCulture, nature and landscape in the Australian region, 39 (3): 1116-21. doi:10.1016/j.geoforum.2006.11.022.

Moezzi, Mithra, and Kathryn B. Janda. 2014. "From 'if Only' to 'social Potential' in Schemes to Reduce Building Energy Use.” Energy Research \& Social Science 1 (March): 30-40. doi:10.1016/j.erss.2014.03.014.

Monstadt, Jochen. 2007. "Urban Governance and the Transition of Energy Systems: Institutional Change and Shifting Energy and Climate Policies in Berlin." International Journal of Urban and Regional Research 31 (2): 326-43. doi:10.1111/j.1468-2427.2007.00725.x.

Moore, Sharelynn. 2012. "Itron Technology Energizes Energy Efficiency with White House Green Button Functionality (NASDAQ:ITRI)." Itron.com. March 22. http://investors.itron.com/releasedetail.cfm?ReleaseID=658870.

Moore, Steven A. 2007. Alternative Routes to the Sustainable City: Austin, Curitiba, and Frankfurt. Lexington Books.

Morozov, Evgeny. 2015. "Where Uber and Amazon Rule: Welcome to the World of the Platform." The Guardian, June 6, sec. Technology. https://www.theguardian.com/technology/2015/jun/07/facebook-uber-amazonplatform-economy.

Moss, Timothy. 2009. "Intermediaries and the Governance of Sociotechnical Networks in Transition." Environment and Planning A 41 (6): 1480-95. doi:10.1068/a4116.

- 2014. "Socio-Technical Change and the Politics of Urban Infrastructure: Managing Energy in Berlin between Dictatorship and Democracy." Urban Studies 51 (7): 1432-48. doi:10.1177/0042098013500086.

Muratori, Matteo, Beth-Anne Schuelke-Leech, and Giorgio Rizzoni. 2014. "Role of Residential Demand Response in Modern Electricity Markets." Renewable and Sustainable Energy Reviews 33 (May): 546-53. doi:10.1016/j.rser.2014.02.027.

Murphy, James T. 2015. "Human Geography and Socio-Technical Transition Studies: Promising Intersections." Environmental Innovation and Societal Transitions 17 (December): 73-91. doi:10.1016/j.eist.2015.03.002. 
Murray, David. 2014. "Protecting Us Abroad, Ensuring Energy Independence at Home." The Energy Collective. 27. http://www.theenergycollective.com/nrdcswitchboard/545401/protecting-usabroad-ensuring-energy-independence-home.

Nadesan, Majia Holmer. 2010. Governmentality, Biopower, and Everyday Life. Routledge.

Nasiri, A. 2008. "Integrating Energy Storage with Renewable Energy Systems." In 34th Annual Conference of IEEE Industrial Electronics, 2008. IECON 2008, 17-18. doi:10.1109/IECON.2008.4757918.

Naus, Joeri, Gert Spaargaren, Bas J.M. van Vliet, and Hilje M. van der Horst. 2014. "Smart Grids, Information Flows and Emerging Domestic Energy Practices." Energy Policy 68 (May). Elsevier: 436-46. doi:10.1016/j.enpol.2014.01.038.

Naus, Joeri, Bas J. M. van Vliet, and Astrid Hendriksen. 2015. "Households as Change Agents in a Dutch Smart Energy Transition: On Power, Privacy and Participation." Energy Research \& Social Science, Special Issue on Smart Grids and the Social Sciences, 9 (September): 125-36. doi:10.1016/j.erss.2015.08.025.

Neenan, Bernard. 2013. "FirstEnergy's Consumer Behavior Study Preliminary Evaluation of the Summer 2012." DOE Consumer Behavior Studies. https://www.smartgrid.gov/files/FirstEnergy_Consumer_Behavior_Study_Prelimi nary_Evaluation_of_the_Summer_2012_Final_PDF_R_May_13_copy.pdf.

Newell, J. P., and J. J. Cousins. 2014. "The Boundaries of Urban Metabolism: Towards a Political-Industrial Ecology." Progress in Human Geography, December. doi: $10.1177 / 0309132514558442$.

NIST. 2014. "Framework for Improving Critical Infrastructure Cybersecurity." National Insititute of Standards and Technology. http://www.cslawreport.com/files/2015/04/07/nist-combined-file.pdf.

Nyborg, Sophie. 2015. "Pilot Users and Their Families: Inventing Flexible Practices in the Smart Grid." Science \& Technology Studies 28 (3). http://ojs.tsv.fi/index.php/sts/article/view/55342.

Nye, David E. 1992. Electrifying America: Social Meanings of a New Technology, 18801940. MIT Press.

Ockwell, Gary. 2016. “Activating the Human Grid.” Public Utilities Fortnightly, February.

Office of the Press Secretary. 2005. "President Signs Energy Policy Act." August 8. https://georgewbush-whitehouse.archives.gov/news/releases/2005/08/200508086.html.

Oregon Senate Bill 1149. 1999. http://energytrust.org/About/PDF/sb1149.pdf.

Oudshoorn, Nelly, and Trevor J. Pinch. 2005. How Users Matter: The Co-Construction of Users and Technology. MIT Press.

Payne, G. 2005. "Generalization in Qualitative Research." Sociology 39 (2): 295-314. doi: $10.1177 / 0038038505050540$.

Pecan Street. 2011. "Pecan Street Project Energy Internet Demonstration Request for Information." http://www.pecanstreet.org/wordpress/wpcontent/uploads/2011/02/RFI-Pecan_St_Project1.pdf. 
Peck, Jamie. 2011. "Geographies of Policy From Transfer-Diffusion to MobilityMutation." Progress in Human Geography 35 (6): 773-97. doi:10.1177/0309132510394010.

Peck, Jamie, and Nik Theodore. 2001. "Exporting Workfare/Importing Welfare-to-Work: Exploring the Politics of Third Way Policy Transfer." Political Geography 20 (4): 427-60. doi:10.1016/S0962-6298(00)00069-X.

—. 2010a. "Mobilizing Policy: Models, Methods, and Mutations." Geoforum, Themed Issue: Mobilizing Policy, 41 (2): 169-74. doi:10.1016/j.geoforum.2010.01.002. 2010b. "Recombinant Workfare, across the Americas: Transnationalizing 'fast' Social Policy." Geoforum, Themed Issue: Mobilizing Policy, 41 (2): 195-208. doi:10.1016/j.geoforum.2010.01.001.

- 2012. "Follow the Policy: A Distended Case Approach." Environment and Planning A 44 (1): 21-30. doi:10.1068/a44179.

Peck, Jamie, Nik Theodore, and Neil Brenner. 2009. "Neoliberal Urbanism: Models, Moments, Mutations." SAIS Review 29 (1): 49-66. doi:10.1353/sais.0.0028.

Peck, Jamie, and Nikolas Theodore. 2015. Fast Policy: Experimental Statecraft at the Thresholds of Neoliberalism. University of Minnesota Press.

Pedersen, Marc, B. C. Hydro, and Power Authority. 2008. "Segmenting Residential Customers: Energy and Conservation Behaviors." Proceedings of the ACEEE Summer Study on Energy Efficiency in Buildings 7: 229-41.

Powells, Gareth, Harriet Bulkeley, Sandra Bell, and Ellis Judson. 2014. "Peak Electricity Demand and the Flexibility of Everyday Life." Geoforum 55 (August): 43-52. doi:10.1016/j.geoforum.2014.04.014.

Price, Michael. 2010. "Bringing Customers On Board, Part II." Public Utilities Fortnightly, August.

Price, Michael Henry, and Jim Thomson. 2009. "Bringing Customers On Board." Public Utilities Fortnightly, September.

Rahimi, F., and A. Ipakchi. 2010. "Demand Response as a Market Resource Under the Smart Grid Paradigm." IEEE Transactions on Smart Grid 1 (1): 82-88. doi:10.1109/TSG.2010.2045906.

Ranganathan, Prakash, and Kendall Nygard. 2011. "Smart Grid Data Analytics for Decision Support." 2011 IEEE Electrical Power and Energy Conference, October. Ieee, 315-21. doi:10.1109/EPEC.2011.6070218.

Reeves, Kimberly. 2008. "Mueller Revisits Affordability and Density," October 3. http://www.austinchronicle.com/news/2008-10-03/681440/.

Reimer, Maria Hellström, Kes Mccormick, Elisabet Nilsson, and Nicholas Arsenault. 2012. "Advancing Sustainable Urban Transformation through Living Labs: Looking to the Öresund Region," no. August.

Rhodes, Joshua D., Charles R. Upshaw, Chioke B. Harris, Colin M. Meehan, David A. Walling, Paul A. Navrátil, Ariane L. Beck, et al. 2014. "Experimental and Data Collection Methods for a Large-Scale Smart Grid Deployment: Methods and First Results." Energy 65 (February): 462-71. doi:10.1016/j.energy.2013.11.004. 
Rip, Arie, and René Kemp. 1998. "Technological Change." In Human Choice and Climate Change, edited by S. Rayner and E.L. Malone, 327-99. Columbus, OH: Battelle Press. http://doc.utwente.n1/34706/1/K356.pdf.

Robinson, Jennifer. 2014. "Introduction to a Virtual Issue on Comparative Urbanism: Introduction." International Journal of Urban and Regional Research, May, n/an/a. doi:10.1111/1468-2427.12171.

Rockwell, Lilly. 2015. "Austin Energy Poised to Secure Its Biggest Solar Power...” Austin Statesman, October 1. http://www.mystatesman.com/news/news/local/austinenergy-poised-to-secure-biggest-solar-power/nnsJ3/.

Rose, Nikolas. 1993. "Government, Authority and Expertise in Advanced Liberalism." Economy and Society 22 (3): 283-99. doi:10.1080/03085149300000019. 1998. Inventing Our Selves: Psychology, Power, and Personhood. Cambridge University Press.

1999. Powers of Freedom: Reframing Political Thought. Cambridge University Press.

—. 2001. "Biopolitics in the Twenty First Century—Notes For a Research Agenda." Distinktion: Journal of Social Theory 2 (3): 25-44. doi:10.1080/1600910X.2001.9672798.

Rose, Nikolas S. 1999. Powers of Freedom: Reframing Political Thought. Cambridge, United Kingdom ; New York, NY: Cambridge University Press.

Rosental, C. 2014. "Toward a Sociology of Public Demonstrations." Sociological Theory 31 (4): 343-65. doi:10.1177/0735275113513454.

Rozek, Richard P. 1989. "Competitive Bidding In Electricity Markets: A Survey." The Energy Journal 10 (4): 117-38.

Rudolph, Richard, and Scott Ridley. 1986. Power Struggle: The Hundred-Year War Over Electricity. Harper \& Row.

Rutherford, Jonathan, and Olivier Coutard. 2014. "Urban Energy Transitions: Places, Processes and Politics of Socio-Technical Change." Urban Studies 51 (7): 135377. doi:10.1177/0042098013500090.

Rutherford, Jonathan, and Sylvy Jaglin. 2015. "Introduction to the Special Issue - Urban Energy Governance: Local Actions, Capacities and Politics.” Energy Policy 78 (March): 173-78. doi:10.1016/j.enpol.2014.11.033.

Rutherford, Stephanie. 2007. "Green Governmentality: Insights and Opportunities in the Study of Nature's Rule." Progress in Human Geography 31 (3): 291-307. doi:10.1177/0309132507077080.

Rutland, Ted, and Alex Aylett. 2008. "The Work of Policy: Actor Networks, Governmentality, and Local Action on Climate Change in Portland, Oregon." Environment and Planning D: Society and Space 26 (4): 627 - 646. doi:10.1068/d6907.

Rydin, Yvonne, Catalina Turcu, Simon Guy, and Patrick Austin. 2013. "Mapping the Coevolution of Urban Energy Systems: Pathways of Change." Environment and Planning A 45 (3): 634-49. doi:10.1068/a45199.

Saunders, Harry D. 2013. "Historical Evidence for Energy Efficiency Rebound in 30 US Sectors and a Toolkit for Rebound Analysts." Technological Forecasting and Social Change 80 (7): 1317-30. doi:10.1016/j.techfore.2012.12.007. 
Schatzki, Theodore R., Karin Knorr-Cetina, and Eike von Savigny. 2001. The Practice Turn in Contemporary Theory. Psychology Press.

Scrase, Ivan, and Adrian Smith. 2009. "The (Non-)Politics of Managing Low Carbon Socio-Technical Transitions." Environmental Politics 18 (5): 707-26. doi:10.1080/09644010903157008.

Seyfang, Gill, and Alex Haxeltine. 2012. "Growing Grassroots Innovations: Exploring the Role of Community-Based Initiatives in Governing Sustainable Energy Transitions." Environment and Planning C-Government and Policy 30 (3): 381-400. doi:10.1068/c10222.

Sheldrick, Alistair, James Evans, and Gabriele Schliwa. 2016. "Policy Learning and Sustainable Urban Transitions: Mobilising Berlin's Cycling Renaissance." Urban Studies, July, 42098016653889. doi:10.1177/0042098016653889.

Shell. 2016. "Climate Change and Energy Transitions." http://www.shell.com/sustainability/environment/climate-change.html.

Shipan, Charles R., and Craig Volden. 2008. "The Mechanisms of Policy Diffusion." American Journal of Political Science 52 (4): 840-57. doi:10.1111/j.15405907.2008.00346.x.

Shirilau, M. S. 1988. "Computerized Data Collection for End-Use Experiments." IEEE Computer Applications in Power 1 (1): 19-20. doi:10.1109/67.898.

Short, John Rennie. 2016. "A Perfect Storm: Climate Change, the Power Grid, and Regulatory Regime Change after Network Failure." Environment and Planning C: Government and Policy 34 (2): 244-61. doi:10.1177/0263774X15614185.

Shove, Elizabeth. 2004. "Efficiency and Consumption: Technology and Practice." Energy \& Environment 15 (6): 1053-65. doi:10.1260/0958305043026555.

- 2010. "Beyond the ABC: Climate Change Policy and Theories of Social Change." Environment and Planning A 42 (6): 1273-85. doi:10.1068/a42282. . 2012. "The Shadowy Side of Innovation: Unmaking and Sustainability." Technology Analysis \& Strategic Management 24 (4): 363-75. doi:10.1080/09537325.2012.663961.

—. 2014. "Putting Practice into Policy: Reconfiguring Questions of Consumption and Climate Change." Contemporary Social Science 9 (4): 415-29. doi:10.1080/21582041.2012.692484.

Shove, Elizabeth, Mika Pantzar, and Matt Watson. 2012. The Dynamics of Social Practice: Everyday Life and How It Changes. SAGE Publications.

Shove, Elizabeth, and Gordon Walker. 2007. "CAUTION! Transitions Ahead: Politics, Practice, and Sustainable Transition Management." Environment and Planning A 39 (4): 763-770.

. 2008. "Transition Management and the Politics of Shape Shifting." Environment and Planning $A 40$ (4): 1012-14.

- 2010. "Governing Transitions in the Sustainability of Everyday Life." Research Policy, Special Section on Innovation and Sustainability Transitions, 39 (4): 47176. doi:10.1016/j.respol.2010.01.019.

. 2014. "What Is Energy for? Social Practice and Energy Demand." Theory, Culture \& Society 31 (5): 41-58. 
Shove, Elizabeth, Matt Watson, and Nicola Spurling. 2015. "Conceptualizing Connections Energy Demand, Infrastructures and Social Practices." European Journal of Social Theory, April, 1368431015579964. doi:10.1177/1368431015579964.

Siano, Pierluigi. 2014. "Demand Response and Smart grids-A Survey." Renewable and Sustainable Energy Reviews 30 (February): 461-78. doi:10.1016/j.rser.2013.10.022.

Simakova, E. 2010. "RFID 'Theatre of the Proof': Product Launch and Technology Demonstration as Corporate Practices." Social Studies of Science 40 (4): 549-76. doi: $10.1177 / 0306312710365587$.

Simakova, Elena. 2010. "RFID 'Theatre of the Proof': Product Launch and Technology Demonstration as Corporate Practices." Social Studies of Science 40 (4): 549-76. doi: $10.1177 / 0306312710365587$.

Simon, Herbert A. 1986. "Rationality in Psychology and Economics." The Journal of Business 59 (4): S209-24.

Slayton, Rebecca. 2013. "Efficient, Secure Green: Digital Utopianism and the Challenge of Making the Electrical Grid 'Smart."' Information \& Culture 48 (4): 448-78. doi: $10.7560 /$ IC48403.

Slocum, Rachel. 2004a. "Polar Bears and Energy-Efficient Lightbulbs: Strategies to Bring Climate Change Home." Environment and Planning D: Society and Space 22 (3): 413 - 438. doi:10.1068/d378.

- 2004b. "Consumer Citizens and the Cities for Climate Protection Campaign." Environment and Planning A 36 (5): 763-82. doi:10.1068/a36139.

Slocum, Tyson. 2001. "Electric Utility Deregulation and the Myths of the Energy Crisis." Bulletin of Science, Technology \& Society 21 (6): 473-481.

Slovic, Paul, Melissa Finucane, Ellen Peters, and Donald G MacGregor. 2002. "Rational Actors or Rational Fools: Implications of the Affect Heuristic for Behavioral Economics." The Journal of Socio-Economics 31 (4): 329-42. doi:10.1016/S1053-5357(02)00174-9.

Smith, Adrian, Tom Hargreaves, Sabine Hielscher, Mari Martiskainen, and Gill Seyfang. 2016. "Making the Most of Community Energies: Three Perspectives on Grassroots Innovation." Environment and Planning A 48 (2): 407-32. doi:10.1177/0308518X15597908.

Smith, Adrian, Andy Stirling, and Frans Berkhout. 2005. "The Governance of Sustainable Socio-Technical Transitions." Research Policy 34 (10): 1491-1510. doi:10.1016/j.respol.2005.07.005.

Smith, Adrian, Jan-Peter Voß, and John Grin. 2010. "Innovation Studies and Sustainability Transitions: The Allure of the Multi-Level Perspective and Its Challenges." Research Policy 39 (4): 435-48. doi:10.1016/j.respol.2010.01.023.

Smith, Vernon L. 1991. "Rational Choice: The Contrast between Economics and Psychology." Journal of Political Economy 99 (4): 877-97.

Smith, W. 2009. "Theatre of Use: A Frame Analysis of Information Technology Demonstrations." Social Studies of Science 39 (3): 449-80. doi:10.1177/0306312708101978.

Söderström, Ola, Till Paasche, and Francisco Klauser. 2014. "Smart Cities as Corporate Storytelling." City 18 (3): 307-20. doi:10.1080/13604813.2014.906716. 
Sovacool, Benjamin K. 2014. "What Are We Doing Here? Analyzing Fifteen Years of Energy Scholarship and Proposing a Social Science Research Agenda." Energy Research \& Social Science 1 (March): 1-29. doi:10.1016/j.erss.2014.02.003.

Späth, Philipp, and Harald Rohracher. 2010. “"Energy Regions': The Transformative Power of Regional Discourses on Socio-Technical Futures." Research Policy 39 (4): 449-58. doi:10.1016/j.respol.2010.01.017.

— 2012. "Local Demonstrations for Global Transitions - Dynamics across Governance Levels Fostering Socio-Technical Regime Change Towards Sustainability." European Planning Studies 20 (3): 461-79. doi:10.1080/09654313.2012.651800.

Spencer, Robert, and Mani Vadari. 2009. "Smart Grid: A Customer Challenge." Public Utilities Fortnightly, October.

Stake, Robert E. 1995. The Art of Case Study Research. Sage Publications, Inc.

Star, Susan Leigh. 1999. "The Ethnography of Infrastructure." American Behavioral Scientist 43 (3): 377-91. doi:10.1177/00027649921955326.

Stephens, Jennie C., Elizabeth J. Wilson, Tarla R. Peterson, and James Meadowcroft. 2013. "Getting Smart? Climate Change and the Electric Grid." Challenges 4 (2): 201-16. doi:10.3390/challe4020201.

Stephens, Jennie C., Elizabeth J. Wilson, and Tarla Rai Peterson. 2015. Smart Grid (R)Evolution. Cambridge University Press.

Stirling, Andy. 2014. "Transforming Power: Social Science and the Politics of Energy Choices." Energy Research \& Social Science 1 (March): 83-95. doi:10.1016/j.erss.2014.02.001.

Stone, Diane. 2000. "Non-Governmental Policy Transfer: The Strategies of Independent Policy Institutes." Governance 13 (1): 45-70. doi:10.1111/0952-1895.00123. . 2001. "Learning Lessons, Policy Transfer and the International Diffusion of Policy Ideas." Working or Discussion Paper. April. http://www2.warwick.ac.uk/fac/soc/csgr/research/workingpapers/2001/wp6901.p df. 2004. "Transfer Agents and Global Networks in the 'transnationalization' of Policy." Journal of European Public Policy 11 (3): 545-66. doi:10.1080/13501760410001694291.

Strebel, Ignaz, and Jane M. Jacobs. 2014. "Houses of Experiment: Modern Housing and the Will to Laboratorization." International Journal of Urban and Regional Research, January, n/a-n/a. doi:10.1111/1468-2427.12079.

Strengers, Yolande. 2012. "Peak Electricity Demand and Social Practice Theories: Reframing the Role of Change Agents in the Energy Sector." Energy Policy 44 (May): 226-34. doi:10.1016/j.enpol.2012.01.046.

—. 2013. Smart Energy Technologies in Everyday Life: Smart Utopia? Palgrave Macmillan.

Stripple, Johannes, and Harriet Bulkeley. 2013. Governing the Climate: New Approaches to Rationality, Power and Politics. Cambridge University Press.

Succar, Samir, and Ralph Cavanagh. 2012. "The Promise of the Smart Grid: Goals, Policies, and Measurement Must Support Sustainability Benefits." NRDC ISSUE BRIEF. https://www.nrdc.org/sites/default/files/smart-grid-IB.pdf. 
Sweeney, James L. 2002. "The California Electricity Crisis: Lessons for the Future." The Bridge, National Academy of Engineering, 32 (2): 23-31.

Swyngedouw, Erik. 2004. 'Globalisation or 'Glocalisation'? Networks, Territories and Rescaling.” Cambridge Review of International Affairs 17 (1): 25-48. doi:10.1080/0955757042000203632.

. 2006. "Circulations and Metabolisms: (Hybrid) Natures and (Cyborg) Cities." Science as Culture 15 (2): 105-21. doi:10.1080/09505430600707970.

. 2011. "The Non-Political Politics of Climate Change," 1-8.

Temenos, Cristina, and Eugene McCann. 2012. "The Local Politics of Policy Mobility: Learning, Persuasion, and the Production of a Municipal Sustainability Fix." Environment and Planning A 44 (6): 1389-1406. doi:10.1068/a44314.

—. 2013. "Geographies of Policy Mobilities." Geography Compass 7 (5): 344-57. doi:10.1111/gec3.12063.

Tendril. 2016. "Welcome to Tendril My Home: The Mobile-First Application That Wil Revolutionize Your Customer Communications." //www.tendrilinc.com/.

The Economist. 2004. "Building the Energy Internet," March 11. http://www.economist.com/node/2476988.

The White House Office of the Press Secretary. 2016. "FACT SHEET: Obama Administration Announces Federal and Private Sector Actions on Scaling Renewable Energy and Storage with Smart Markets." Whitehouse.gov. June 16. https://www.whitehouse.gov/the-press-office/2016/06/16/fact-sheet-obamaadministration-announces-federal-and-private-sector.

Thomas, Gary. 2010. "Doing Case Study: Abduction Not Induction, Phronesis Not Theory." Qualitative Inquiry 16 (7): 575-82. doi:10.1177/1077800410372601. . 2011. "A Typology for the Case Study in Social Science Following a Review of Definition, Discourse, and Structure." Qualitative Inquiry 17 (6): 511-21. doi:10.1177/1077800411409884.

Torrance, Morag I. 2008. "Forging Glocal Governance? Urban Infrastructures as Networked Financial Products." International Journal of Urban and Regional Research 32 (1): 1-21. doi:10.1111/j.1468-2427.2007.00756.x.

Torriti, Jacopo. 2012. "Price-Based Demand Side Management: Assessing the Impacts of Time-of-Use Tariffs on Residential Electricity Demand and Peak Shifting in Northern Italy." Energy, Integration and Energy System Engineering, European Symposium on Computer-Aided Process Engineering 2011, 44 (1): 576-83. doi:10.1016/j.energy.2012.05.043.

Trabish, Herman K. 2015. "Austin Energy Approved for 300 MW Utility Solar Buy under 4ф/kWh." Utility Dive. October 5. http://www.utilitydive.com/news/austinenergy-approved-for-300-mw-utility-solar-buy-under-4kwh/406752/.

Tricoire, Aurélie. 2015. "Uncertainty, Vision, and the Vitality of the Emerging Smart Grid." Energy Research \& Social Science, Special Issue on Smart Grids and the Social Sciences, 9 (September): 21-34. doi:10.1016/j.erss.2015.08.028.

Truffer, Bernhard, and Lars Coenen. 2012. "Environmental Innovation and Sustainability Transitions in Regional Studies." Regional Studies 46 (1): 1-21. doi:10.1080/00343404.2012.646164. 
Truffer, Bernhard, James T. Murphy, and Rob Raven. 2015. "The Geography of Sustainability Transitions: Contours of an Emerging Theme." Environmental Innovation and Societal Transitions 17 (December): 63-72. doi:10.1016/j.eist.2015.07.004.

Tweed, Katherine. 2011. "IBM Coordinates Smart Grid Data in South Korea." June 29. http://www.greentechmedia.com/articles/read/ibm-coordinates-smart-grid-data-inkorea.

Tyfield, David. 2014. "Putting the Power in 'Socio-Technical Regimes' - E-Mobility Transition in China as Political Process." Mobilities 9 (4): 585-603. doi:10.1080/17450101.2014.961262.

Undrill, J. 1988. "Where We Stand (Power System Computer Applications)." IEEE Computer Applications in Power 1 (1): 9-10. doi:10.1109/67.895.

US Department of Energy. 2011. "U.S. Department of Energys Approach for Conducting Consumer Behavior Studies within the Smart Grid Investment Grant Program." US

DOE.

https://www.smartgrid.gov/document/us_department_energy_approach_conductin g_consumer_behavior_studies_within_smart_grid_inve.html.

. 2014. "Customer Participation in the Smart Grid: Lessons Learned." smartgrid.gov. http://energy.gov/oe/downloads/customer-participation-smart-gridlessons-learned-september-2014.

. 2016a. "Energy Transition Initiative | Department of Energy." Energy.gov. http://energy.gov/eere/technology-to-market/energy-transition-initiative.

- 2016b. "What Is the Smart Grid?" Smartgrid.gov. https://www.smartgrid.gov/the_smart_grid/smart_grid.html.

. 2016a. "Green Button Gives Millions of Consumers Access to Electricity Usage Information." Smartgrid.gov. Accessed August 10. https://www.smartgrid.gov/featured_initiatives/green_button_gives_millions_con sumers_access_electricity.html.

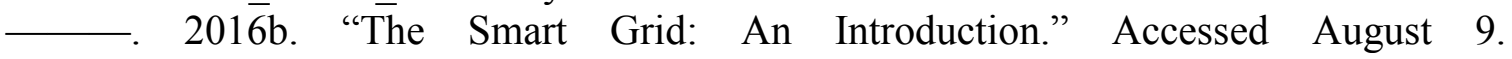
http://energy.gov/sites/prod/files/oeprod/DocumentsandMedia/DOE_SG_Book_S ingle_Pages $\% 281 \% 29$.pdf.

US EPA, OAR. 2011. "Smart Grid and Clean Energy for Local Governments." Background and Resources. Local Government Climate and Energy Strategy Series. US Environmental Protection Agency. https://www.epa.gov/statelocalclimate/local-government-climate-and-energystrategy-series.

Vadari, Mani. 2009. "Active Demand Management." Public Utilities Fortnightly, November.

Vanolo, Alberto. 2013. "Smartmentality: The Smart City as Disciplinary Strategy." Urban Studies, July, 42098013494427. doi:10.1177/0042098013494427.

Verbong, Geert P.J., Sjouke Beemsterboer, and Frans Sengers. 2013. "Smart Grids or Smart Users? Involving Users in Developing a Low Carbon Electricity Economy." Energy Policy 52 (January): 117-25. doi:10.1016/j.enpol.2012.05.003.

Vesnic-Alujevic, Lucia, Melina Breitegger, and Ângela Guimarães Pereira. 2016. "What Smart Grids Tell about Innovation Narratives in the European Union: Hopes, Im- 
aginaries and Policy." Energy Research \& Social Science 12 (February): 16-26. doi:10.1016/j.erss.2015.11.011.

Village of Oak Park. 2014a. "Screenings Begin for Smart City USA Participants." Village of Oak Park. April 25. http://www.oak-park.us/news/screenings-begin-smartcity-usa-participants. . 2014b. "Pecan Street Inc. | Smart Grid Project Moves Closer toward Implementation." September 18. http://www.pecanstreet.org/2014/09/oak-park-il-smartgrid-project-moves-closer-toward-implementation/.

- 2015. "Meeting of Village of Oak Park President and Board of Trustees on 2015-03-09 7:00 PM.” March 9. http://oakpark.granicus.com/MediaPlayer.php?view_id=2\&clip_id=588.

Vliet, Bas Van, Elizabeth Shove, and Heather Chappells. 2012. Infrastructures of Consumption: Environmental Innovation in the Utility Industries. Earthscan.

Voytenko, Yuliya, Kes McCormick, James Evans, and Gabriele Schliwa. 2016. "Urban Living Labs for Sustainability and Low Carbon Cities in Europe: Towards a Research Agenda." Journal of Cleaner Production, Advancing Sustainable Solutions: An Interdisciplinary and Collaborative Research Agenda, 123 (June): 4554. doi:10.1016/j.jclepro.2015.08.053.

Vu, K., M. M. Begouic, and D. Novosel. 1997. "Grids Get Smart Protection and Control." IEEE Computer Applications in Power 10 (4): 40-44. doi:10.1109/67.625373.

Waitt, Gordon. 2005. "Doing Foucauldian Discourse Analysis: Revealing Social Realities." In Qualitative Research Methods in Human Geography, edited by Iain Hay, 217-40. Oxford University Press.

Walker, Gordon. 2014. "The Dynamics of Energy Demand: Change, Rhythm and Synchronicity." Energy Research \& Social Science 1 (March): 49-55. doi:10.1016/j.erss.2014.03.012.

Walker, Gordon, and Elizabeth Shove. 2007. "Ambivalence, Sustainability and the Governance of Socio-Technical Transitions." Journal of Environmental Policy \& Planning 9 (3-4): 213-25. doi:10.1080/15239080701622840.

Ward, Kevin. 2008. "Editorial-Toward a Comparative (Re)turn in Urban Studies? Some Reflections." Urban Geography 29 (5): 405-10. doi:10.2747/0272-3638.29.5.405. - 2010. "Towards a Relational Comparative Approach to the Study of Cities." Progress in Human Geography 34 (4): 471-87. doi:10.1177/0309132509350239.

Warwick, W.M. 2002. "A Primer on Electric Utilities, Deregulation, and Restructuring of US Electricity Markets." PNNL. http://www.pnl.gov/main/publications/external/technical_reports/PNNL13906.pdf.

Wernau, Julie. 2011. "ComEd Bill: Clock Ticking for Smart-Grid Bill after Quinn Veto." Chicago Tribune, September 13. http://articles.chicagotribune.com/2011-0913/business/ct-biz-0913-quinn-legislation-20110913_1_smart-grid-comed-veto.

While, Aidan, Andrew E G Jonas, and David Gibbs. 2004. "The Environment and the Entrepreneurial City: Searching for the Urban $\square$ Sustainability Fix â in Manchester and Leeds *." International Journal of Urban and Regional Research 28 (3): 549-69. 
While, Aidan, Andrew E G Jonas, and David Gibbs. 2010. "From Sustainable Development to Carbon Control: Eco-State Restructuring and the Politics of Urban and Regional Development." Transactions of the Institute of British Geographers 35 (1): 76-93. doi:10.1111/j.1475-5661.2009.00362.x.

Wiig, Alan. 2015. "IBM's Smart City as Techno-Utopian Policy Mobility." City 19 (23): 258-73. doi:10.1080/13604813.2015.1016275.

Wilhite, Harold, and Loren Lutzenhiser. 1999. "Social Loading and Sustainable Consumption." Advances in Consumer Research 26 (1): 281-87.

Wilhite, Harold, Elizabeth Shove, Loren Lutzenhiser, and Willett Kempton. 2000. "The Legacy of Twenty Years of Energy Demand Management: We Know More about Individual Behaviour but next to Nothing about Demand." In Society, Behaviour, and Climate Change Mitigation, edited by Eberhard Jochem, Jayant Sathaye, and Daniel Bouille, 109-26. Advances in Global Change Research 8. Springer Netherlands. http://link.springer.com.proxy.lib.pdx.edu/chapter/10.1007/0-306-48160$\mathrm{X} 4$.

Winner, Langdon. 2010. The Whale and the Reactor: A Search for Limits in an Age of High Technology. University of Chicago Press.

Wodak, Ruth, and Michael Meyer. 2001. Methods of Critical Discourse Analysis. SAGE.

Woo, Chi-Keung, Debra Lloyd, and Asher Tishler. 2003. "Electricity Market Reform Failures: UK, Norway, Alberta and California." Energy Policy, Themes in current Asian energy, 31 (11): 1103-15. doi:10.1016/S0301-4215(02)00211-2.

Woods, Eric. 2014. "South Korea Draws an Ambitious Roadmap for Smart Grids and Smart Cities." Navigant Research. November 12. https://www.navigantresearch.com/blog/south-korea-draws-an-ambitiousroadmap-for-smart-grids-and-smart-cities.

XcelEnergy. 2016.2 "SmartGridCity." SmartGridCity. http://smartgridcity.xcelenergy.com/.

Yin, Robert K. 2003. Case Study Research: Design and Methods. SAGE.

Zamuda, Craig, Bryan Mignone, Dan Bilello, K. C. Hallett, Courtney Lee, Jordan Macknick, Robin Newmark, and Daniel Steinberg. 2013. "US Energy Sector Vulnerabilities to Climate Change and Extreme Weather." DTIC Document. http://oai.dtic.mil/oai/oai?verb=getRecord\&metadataPrefix $=$ html\&identifier $=\mathrm{AD}$ A583709.

Zetter, Kim. 2012. "Maker of Smart-Grid Control Software Hacked." WIRED. September 26. https://www.wired.com/2012/09/scada-vendor-telvent-hacked/. 


\section{Appendices}

\section{Appendix A: Sample Recruitment Letter}

From: Anthony Levenda <anthonylevenda@pdx.edu>

Sent: 27 October 2014 XX:XX

To: [Interviewee]

Subject: Interview request for urban energy research project

Dear Mr/s. [],

I am a researcher at Portland State University, currently undertaking research on the integration and demonstration of smart grid technologies in North American cities.

I will be conducting field research in [your city] from [March $10^{\text {th }}$ until March $\left.28^{\text {th }}, 2015\right]$ where I hope to interview several people in key organizations that are strategic to the deployment and demonstration of urban energy technologies in [city's living lab project] - specifically, [the particular project]. Of particular interest to me is the urban planning and larger visioning process in which [the particular project] demonstrates what cities may need to do to become sustainable in the future.

I was hoping to arrange an approximately 1 hour-long meeting at your convenience to find out more about your work in [city/living lab]. I appreciate that as a busy [organization] you have many competing demands on your time and I am grateful for your time and assistance with this research.

Attached is a brief outline of the project for your information. Also, feel free to circulate the details of this research project to any interested parties. Within this project there is scope for eventually sharing some key research findings with you.

Thanks for your consideration, and I look forward to hearing from you.

Best wishes,

Anthony Levenda 


\section{Appendix B: Sample Interview Protocol}

Introduction

Hi __ as you know, my name is Anthony Levenda. First, thanks for volunteering to talk with me today. Our talk should only take between 30 and 45 minutes. Do you still have time available to talk today?

Great, thanks again. As you know, I'm a doctoral candidate in the Urban Studies and Planning department at Portland State and am working on a project about innovation and governance in smart grid and smart city sectors. As a part of this project, we're interested in understanding your experiences with the Pecan Street Project and the Mueller Development.

That's where you come in. I'm hoping we can start from how you got started in Pecan Street Project.

Do you have any questions for me before we begin?

Interview Questions

1. First, could you please tell me about your role in Pecan Street, and with the PSP?

2. What is the Pecan Street Project?

2.1. Can you briefly describe the history of the project? When was it discussed for the first time? Who were the key stakeholders involved in its development? What were the defining moments in the process of developing it? How did you get participants to enroll in the program? Were there any barriers or concerns to enrollment?

3. What do you think are the most important achievements of this project?

4. Who would you say are the major actors or institutions in the project?

4.1. Why? What is their role?

4.2. What is the role of Mueller Development in this project?

4.3. What is the role of the Austin Energy?

4.4. What are the key aspects of your support?

4.5. Do you feel the City has played a key role in supporting innovation in this project?

4.5.1. How so?

5. How does this project benefit the city/consumers?

5.1. How do you think that the project responds to the specific needs of the city/consumers? How does it connect with the specific goals of Pecan Street? Specific goals of the city?

5.2. What do you think has been the impact of the project so far? What could be its impact in the future?

6. How do you see the project playing a role in changing the way in which the city approaches issues of energy? 
7. What barriers are yet to be overcome to further promote the use of smart technology (as used in Pecan Street Participants homes/neighborhoods)?

8. Do you see opportunities for this project to be replicated in other parts of the city or in other cities? Where and how?

9. What has been learned from this project? What would you tell other cities/utilities/consumers trying to implement similar projects?

9.1. What other places have learned from Austin's experience?

10. How do you define the "smart grid"? Do you hear this concept come up much around the office? If so, could you describe a few examples of how people bring up the idea around here? How do you think the smart grid will shape/change Austin?

11. Do you think smart grid and smart city projects are highly related?

11.1. How so?

12. Data seems to be a really important element of the smart grid and smart city. Can you tell me about the data you collect and how it's used?

12.1. What is the role of data in smart energy?

12.1.1. Is this important to innovation?

12.2. How does data get used?

12.3. Have you ever heard of the term big data?

12.3.1. What is the connection between big data and energy?

12.4. What does data say about consumers' energy use?

12.5. Do consumers use data about their energy consumption?

12.5.1. How?

13. What is the connection between smart energy technologies and energy efficiency, or environmental initiatives in the city?

14. Tell me about how you think the smart grids and energy affects cities...

15. Thanks again for your time.

15.1. Are there any questions you think I should have asked regarding innovation in the smart grid, city, neighborhood, home sector?

15.2. Is there anything else you'd like to mention?

15.3. Who else do you think I should talk to?

15.4. Do you have any questions for me before we conclude? 